\title{
POSITIVE EDUCATION AS A WHOLE SCHOOL APPROACH: BROADENING THE PERSPECTIVE ON LEARNING
}

\author{
Jochem Goldberg
}




\title{
POSITIVE EDUCATION AS A WHOLE SCHOOL APPROACH:
}

\section{BROADENING THE PERSPECTIVE ON LEARNING}

\author{
PROEFSCHRIFT
}

\author{
ter verkrijging van \\ de graad van doctor aan de Universiteit Twente, \\ op gezag van de rector magnificus, \\ prof.dr. T.T.M. Palstra, \\ volgens besluit van het College voor Promoties \\ in het openbaar te verdedigen \\ op 02 april 2020 om 12.45 uur
}

door

\section{Jochem Marcel Goldberg}

geboren op 02 oktober 1990

te Roden, Nederland 
Dit proefschrift is goedgekeurd door:

De promotoren:

Prof.dr. E.T. Bohlmeijer

Prof. dr. K.M.G. Schreurs

De co-promotor:

dr. A.M. Clarke

Cover image: Olav Ahrens Røtne

Printed by: Gildeprint

Lay-out by: Gildeprint

ISBN: 978-90-365-4962-2

DOI: 10.3990/1.9789036549622

Funding: Fonds Kinderpostzegels

(C) 2020 Jochem Goldberg, The Netherlands. All rights reserved. No parts of this thesis may be reproduced, stored in a retrieval system or transmitted in any form or by any means without permission of the author. Alle rechten voorbehouden. Niets uit deze uitgave mag worden vermenigvuldigd, in enige vorm of op enige wijze, zonder voorafgaande schriftelijke toestemming van de auteur. 


\section{PROMOTIE COMMISSIE:}

$\begin{array}{ll}\text { Voorzitter/secretaris } & \begin{array}{l}\text { Prof. dr. T.A.J. Toonen } \\ \text { (Universiteit Twente) }\end{array} \\ \text { Promotor(en) } & \text { Prof. dr. E.T. Bohlmeijer } \\ & \text { (Universiteit Twente) } \\ & \text { Prof. dr. K.M.G. Schreurs } \\ & \text { (Universiteit Twente) } \\ \text { Co-promotor(en) } & \text { dr. A.M. Clarke } \\ & \text { (Early Intervention Foundation, London) } \\ & \text { dr. T.H.S. Eysink } \\ \text { Leden } & \text { (Universiteit Twente) } \\ & \text { Prof. dr. N.E. Jacobs } \\ & \text { (Universiteit Maastricht) } \\ & \text { Prof. dr. F. Laevers } \\ \text { (Katholieke Universiteit Leuven) } & \text { Porf. dr. S.E. McKenney } \\ \text { (Universiteit Twente) } & \\ \text { (Universiteit Twente) } & \\ & \end{array}$




\section{Contents}

Chapter $1 \quad$ General Introduction $\quad 9$

Chapter 2 Effectiveness of interventions adopting a whole school approach to enhancing social and emotional development: a meta-analysis

Chapter 3 Positive Educative Programme, a whole school approach to supporting children's well-being and creating a positive school climate: a pilot study

Chapter $4 \quad$ Positive Education in daily teaching, the promotion of wellbeing and engagement in a whole school approach: A clustered quasiexperimental trial

Intermezzo The Dutch Positive Education Programme in practice: Real life examples of implementing a whole school approach in special needs education

Chapter $5 \quad$ Wellbeing and Social Safeness Questionnaire (WSSQ): Initial psychometric assessment of a short digital screening instrument for primary school children

Chapter 6 Exploring signs of wellbeing and behavioural intentions in youth's future expectations

Chapter $7 \quad$ General Discussion list of publications 
Chapter 1:

General Introduction 


\section{Background}

Pupils spend around 30 to 35 hours per week in school, presenting endless opportunities for teachers and other practitioners to stimulate pupil's strengths, to encourage them to chase their dreams and to help them flourish. In reality however, schools often just focus on the academic achievement of the pupils, instead of engaging them to the curriculum and increasing their wellbeing. This emphasis on academic achievement may not align with the values of the teachers, the values of the parents and the values of the entire school community. Therefore, in this dissertation, the enhancement of the whole school is discussed by looking through a lens of wellbeing, engagement and values.

\section{Wellbeing and engagement}

When experiencing a high level of wellbeing, pupils feel at ease, feel emotionally safe and feel the freedom to be themselves. A high level of wellbeing is expressed through spontaneity, vitality and enjoyment (Laevers, Heylen \& Maes, 2013). The concept of wellbeing consists of hedonic and eudaimonic wellbeing. Hedonic wellbeing aligns with emotional wellbeing and encompasses feelings of happiness, satisfaction and interest in life (Ryan \& Deci, 2001; Keyes et al., 2002; Keys (2007). Eudaimonic wellbeing aligns with psychological and social wellbeing and encompasses an individual's positive functioning at the psychological level (e.g. self-acceptance, purpose in life, autonomy, positive relations, environmental mastery and personally growth; Ryff, 1989) and at the social level (Keyes, 2007). When individuals combine high levels of emotional, psychological and social wellbeing, they can be characterised as flourishing (Keyes, 2002). Research demonstrates that flourishing youth experiences the fewest depressive symptoms and conduct problems as well as the highest levels of selfdetermination, closeness to other people and school integration (Keyes, 2009).

Engagement refers to the intensity of an activity, to concentration, to being focused, to exploring and to lose track of time (Laevers, Heylen \& Maes, 2013). Engagement only occurs in the small area in which the activity matches the capabilities of the person, that is in the 'zone of proximal development'. Engagement therefore means that there is intense mental activity, that a person is functioning at the very limits of his or her capabilities, with an energy flow that comes from intrinsic sources (Laevers, 
$2000,2005 \& 2015)$. In this description engagement is seen as emotional or psychological engagement and not as behavioural engagement (e.g. attendance or homework completion). Psychological engagement is the focus of this dissertation. There is growing evidence on factors that are related with engagement. Research found that a pupil's feelings of belonging with peers, were predictive of later engagement (Furrer \& Skinner, 2003). Also, family involvement in education is positively related to engagement (Gutman \& Midgley, 2000) and pupils with positive supportive connections to school staff show more engagement and are more successful academically and socially (Furlong, Pavelski \& Saxtion, 2002). Additionally, the school-wide positive school climate plays an important role in influencing the development and maintenance of student's engagement (Griffins, Sharkey \& Furlong, 2009). Based on such findings and the self-determination theory (SDT), the Centre of Experience Based Education (CEGO) distinguishes seven engagement increasing factors: 1) A positive class climate, 2) Building on possibilities, 3) Closeness to reality, 4) Student-activity, 5) Expression, 6) Learning together, and 7) Student initiative.

In experiential perspectives on learning, wellbeing and engagement are considered important process indicators of learning. It can be stated that the learning curve of pupils is optimal when they experience wellbeing and engagement (Laevers, Heylen \& Maes, 2013). Research done by the CEGO at primary schools indicates that daily focusing on wellbeing and engagement during one school year leads to higher levels of pupil engagement and wellbeing at the end of the school year (Laevers, Stas, \& van Cleynenbreugel, 2018). Intervention studies conducted in Kent and Milton Keynes (UK) show that levels of wellbeing and engagement can be raised significantly in less than one year even in settings situated in deprived areas (Laevers, 2015). The key lays in helping practitioners to observe levels of wellbeing and engagement and identifying promising interventions to promote them (Laevers, 2015). Recent data (Laevers \& Declerc, 2018) reveal that higher levels of wellbeing and engagement are associated with a better quality of emotional and educational support and better quality of the characteristics of the environment (such as the space for children to take initiatives and the richness of the offered materials and activities).

Additionally, increasing the wellbeing and engagement of pupils has been found to increase academic achievement (e.g. Pietarinen, Soini \& Pyhalto, 2014; Hughes \& Kwok, 2007; Reyes, Brackett, Rivers, White \& Salovey, 2012). Also, wellbeing and engagement are associated with a wide range of other beneficial outcomes, such as social emotional learning (Buhs, Ladd \& Herald, 2006; Hosan \& Hoglund, 2017) and decreasing internalizing symptoms (Fredrickson, 2001). Wellbeing and engagement are highly 
correlated with each other (Gase, Gomez, Kuo, Glenn, Inkelas \& Ponce, 2017; Datu, King \& Valdez, 2017). This research suggests the importance of regularly focussing on wellbeing and engagement of pupils in the whole school and to implement activities to increase wellbeing and engagement, especially when they are suboptimal.

\section{Positive Education}

Optimising the wellbeing and engagement of pupils is a core objective of positive education. Positive psychology in education, or Positive Education, is concerned with the development of pupils' strengths and wellbeing and thereby making the pupils flourish and achieve academic goals. A key tenet within the field of positive education is that wellbeing and engagement can be explicitly promoted through the implementation of positive psychology programmes, activities and practices aimed a cultivating positive feelings, positive behaviour or positive cognitions (Sin \& Lyubomirsky, 2009; Norrish \& Vella-Brodrick, 2009; Seligman et al., 2009). In a recent systematic review of 12 international school-based positive psychology interventions, Waters (2011) found that positive psychology interventions (PPI's) were significantly related to improved student wellbeing, relationships and academic performance. Such PPI's often focus on developing and using strengths, supporting positive relationships and enhancing positive emotions.

A strength-based approach shifts the focus from targeting specific problems or risks of pupils to the focus on developing strengths and potential. Developing one's strengths determines one's success and happiness in one's live (Park \& Peterson, 2009). In a strength-based approach, teachers encourage pupils to get to know their positive attributes and strengths and they teach them to develop and use these strengths. Growing evidence shows that character strengths such as hope, kindness, social intelligence and self-control can protect against the negative effects of stress and trauma (Park \& Peterson, 2009). An example of such a strength-based approach is the Positive Psychology Programme (Seligman et al., 2009). The main goal of this programme is to help pupils identify their signature character strengths and to increase student's use of these strengths in daily life. The programme increases student's enjoyment, engagement and social skills (Seligman et al., 2009).

Additionally, positive education often emphasises the development of positive relationships. Positive relationships are relationships that are non-directive, empathic, warm, and encourage thinking and 
learning (Roffey, 2012). Pupils flourish by strong and profound contact with others. Having positive relationships bring support in difficult times (Wentzel, Baker \& Russel, 2009). Teachers can for example, positively use the diversity of the group in their lessons, they can stimulate pupils to learn together and they can invest in positive relations with parents. In terms of academic success, the relationship between teacher and pupil is most influential (Doll et al., 2009). Pupils feel stronger connections to teachers who are helpful, warm and honest and who help pupils to develop autonomy (Wentzel, 2002). Like teacher-pupil relationships, peer relationships support the psychological wellbeing of pupils and are significantly related to active participation and interest in learning, and subsequent academic success (Malecki \& Elliot, 2002; Wentzel \& Caldwell, 1997). Classmates provide each other with emotional support, companionship, amusement, and assistance (Doll, 1996). Additionally, pupil's academic success is supported when their home and schools are supportive and effective partners (Christenson \& Anderson, 2002). There are three important aspects to these partnerships: parent's involvement in support of schooling, school support for family goals and effective communication between home and school (Doll et al., 2009).

The third focus in positive education is on positive emotions. Positive emotions lead to a high variety of desired effects on pupils: they become more creative, they learn better, they develop and utilise more resources, they broaden their attention, they are more social and they are more resilient (Fredrickson, 1998). At the same time, people suffer from a negativity-bias: they are more focused on negative experiences and they tend to remember these experiences better as well. It is therefore important to pay attention to the experiencing of positive emotions and to put effort in increasing these positive emotions (Fredrickson, 2001). Barbara Fredrickson distinguishes several positive emotions: fun, gratitude, calmness, interest, cheerfulness, inspiration, hope, pride, awe and love. The challenge is to strengthen the awareness of positive emotions in the whole school through positive education interventions.

Taken together, Waters (2011) concludes that the results of PPI's are significant, robust and promising. However, the implementation of positive education has primarily taken place at the level of the classroom, with relatively short curriculum-based interventions being taught in isolation (Chodkiewicz \& Boyle, 2017). The results in the absence of wide reaching and sustained effects on the wellbeing of students (Waters, 2011). Positive education should therefore be seen as positive psychology integrated in education and not solely as the application of positive psychology interventions in education 
(Shankland \& Rosset, 2016). Positive psychology needs to be woven into the DNA of the wider school culture (Waters, 2011).

\section{Whole School Approaches}

Several researchers recommend an integrated approach to strengthen the wellbeing of pupils in education (Weare \& Nind, 2011; Seligman et al., 2009; Bolier, Walburg \& Boerefijn, 2013; Dix, Slee, Lawson \& Keeves, 2012). Whole-school programmes adopt an integrated approach: they integrate interventions into daily practice and school culture, seek to engage all staff, reinforce skills outside of the classroom such as hallways and playgrounds, support parental engagement, and coordinate work with outside agencies (Barry, Clarke \& Dowling, 2017; Jones \& Bouffard, 2012; Weare \& Nind, 2011; Ttofi \& Farrington, 2011; Adi, Killoran, Janmohamed \& Stewart-Brown, 2007a, b; Wilson, Lipsey \& Derzon, 2003). Based on the World Health Organization's definition of a Health Promoting School (WHO, 1998), a whole school approach defines the entire school community as the unit of change and involves coordinated action between three interrelated components: (i) curriculum, teaching, and learning; (ii) school ethos and environment; (iii) family and community partnerships. This approach moves beyond a quick application of a curriculum programme. A whole school approach provides schools with a framework, in which all activities of the schools can be integrated.

Effective curriculum teaching and learning involves teaching skills through the implementation of evidence-based programmes as well as modelling social-emotional competencies, and providing continuous and consistent opportunities to practice these skills during everyday classroom situations (Oberle, Domitrovich, Meyers \& Weissberg, 2016). At the school level, skills are reinforced in noncurriculum-based ways through policies, social relations, whole staff training, organisational structure, and daily activities in the school that are designed to promote a positive school climate which, in turn helps pupils to develop positively across academic, social, emotional and behavioural domains (Jones \& Bouffard, 2012; Meyers, Gil, Cross, Keister \& Domitrovich, 2015). Family and community partnerships involve extending learning to the home and community context.

Norrish and colleagues (2013) developed an applied whole school framework for positive education, the Geelong Grammar School Model for Positive Education. This applied framework works around six domains central to wellbeing (positive emotions, positive engagement, positive accomplishment, 
positive purpose, positive relationships, and positive health) which are comparable to the five aforementioned elements of Seligman (2011), and all underpinned by a focus on character strengths (Norrish, Williams, O'Connor \& Robinson, 2013). Reviewers of the evidence to date conclude that a whole school approach is more likely than classroom-based interventions to result in enduring positive change, because of its multi-component focus (Weare \& Nind, 2011; Adi et al., 2007a, b; Tennant, Goens, Barlow, Day \& Stewart-Brown, 2007; Jane-llopis, Barry, Hosman \& Patel, 2005; Wells, Barlow \& Stewart-Brown, 2003).

\section{Dutch Positive Education Programme}

The Dutch Positive Education Programme (PEP) was developed by the University of Twente as a response to the need for a whole school approach based on positive education with a daily focus on wellbeing and engagement. PEP covers all the aspects of a whole school approach as described by the WHO (1999) and is based on the principles of positive psychology. It starts with the assumption that every child has its talents and competencies. Education should therefore be focused on structuring their study programmes in such a way that every child can express those talents, resulting in flourishing pupils.

PEP is a bottom up programme of which the content largely is determined by the school and its context. A general outline of the programme content is provided in Table 1. Every school is different, and therefore PEP is implemented differently in every school. PEP aims to discover the needs of every individual student in the process of learning and uses the shared values of the team as a context for the learning process. PEP is "self-made" by every team and can therefore not be implemented as a structured programme. This bottom up process should result in a long-lasting vision which is secured in the "DNA" of the schools, whilst other programmes have the tendency to fade. The bottom up process also means that PEP is not solely suitable for a specific education context. PEP can be (and already is) implemented in regular education, special needs education, primary education, secondary education and higher education. Mandatory elements in PEP are the two workshops 'wellbeing and engagement' and 'values and life rules', as well as the monthly PEP-talks in which the entire team gathers to talk about PEP (Table 1). 
During PEP the process of learning is a constant central theme. Teachers are trained to observe wellbeing and engagement of their pupils and to react on these observations. Increased wellbeing and engagement are expected to lead to better learning outcomes (e.g. Pietarinen, Soini \& Pyhalto, 2014) and a decrease in problem behaviour and psychological complaints (e.g. Fredrickson, 2001). This in turn has a positive impact on the school climate, of which all people involved will benefit. A positive school climate focusing on wellbeing and engagement is not possible without clear, shared values of all team members. It is about questions as: 'Why am I a professional in education?' and 'How do we want to represent our school?'. Shared values express shared motivation. The values that a school puts central form the context and provide a direction for the actions of the team members. When looking at values this way, they can be seen as life-rules. Life-rules determine how you want to interact with your pupils, their parents and your team members in daily practice.

Table1: PEP implementation activities

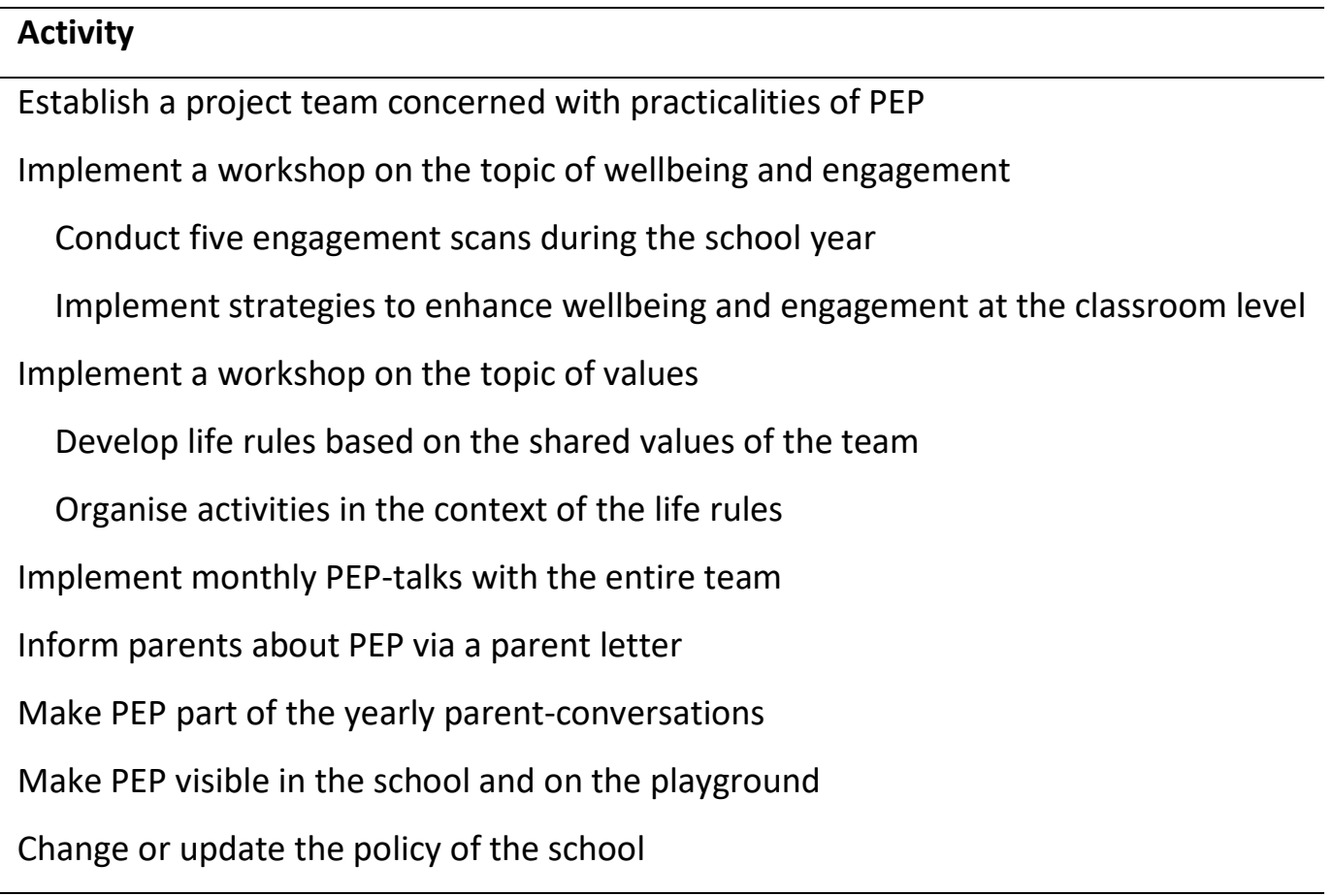




\section{Aims and outline of this dissertation}

The overall aim of this dissertation is to contribute to evidence-based integration of positive education in primary schools in the Netherlands. Central is the proposition that positive education should not just be implemented as yet another specific positive psychology intervention in the classroom but as a whole school approach. This whole school approach should result in a positive school climate inside and outside classrooms, encouraging the enhancement of pupils' wellbeing and engagement.

Chapter two focusses on whole school programs aiming to increase wellbeing of pupils through the development of social and emotional skills. A growing number of studies has investigated the effectiveness of these whole school programmes but the findings of these studies have not yet been synthesised. The aim of the first study presented in chapter two is therefore to assess the effects of whole school programs on social emotional skills across studies. A meta-analysis was conducted with a total of 45 studies (30 interventions) involving nearly 500,000 participants. This study will contribute to our knowledge about the current state of art of whole school approaches in social emotional learning. Chapters three and four focus on the development and evaluation of the Dutch Positive Education Program. Though whole school programs in positive education have been developed, few studies have evaluated the impact in controlled designs. One of the core activities in PEP is learning teachers in primary schools to observe and improve wellbeing and engagement of pupils while teaching. Though this intervention has been amply implemented in primary schools in Belgium and Netherlands, few studies have studied the impact on engagement and wellbeing in a controlled design. Therefore, the studies presented in chapter three and four contribute to our knowledge about the feasibility and impact of training teachers to monitor and improve engagement in the classroom. In chapter three a process and impact evaluation were performed within the context of two schools piloting the programme. Employing questionnaires and interviews, the evaluation sought to examine the implementation of PEP, participants' experiences with key components and the programme impact of PEP. In chapter four PEP was investigated through a clustered quasi-experimental trial. Four primary schools totalling 639 pupils were included of which two were allocated to PEP and two were placed in a control condition. At the beginning and end of the school year, student-report and teacher-report questionnaires were administered and observations were made to examine wellbeing, engagement, emotional problems, prosocial behaviour, student-teacher relationships, bullying and victimization. 
Chapter five focusses on the development and psychometric properties of the Wellbeing and Social Safeness Questionnaire (WSSQ). As of 2015, the Dutch government requires schools to keep track of the wellbeing and social safeness of their pupils and to have an anti-bullying policy in place. Till date however, no validated measures exist that measure this concept. Therefore, the WSSQ was developed. The WSSQ is set up as a screening instrument, allowing teachers to intervene during the school year when pupils experience troubles in the domains of wellbeing and social safeness. Since it is an online instrument, it is easy to use and easy to extract the results. In chapter five the development of the WSSQ is explained, the factor structure is assessed, and the reliability and validity are determined. Chapter six focusses on a frequently used positive psychology intervention: the Best Possible Self exercise. The ability to develop specific and realistic best possible selves has been shown to relate to wellbeing and predicts more positive mental health outcomes. In the research described in chapter six, pupils wrote about their best possible selves at the beginning and the end of the school year, while their teachers had deployed several wellbeing related lessons. It is investigated whether it is possible to identify wellbeing signs in the future perceptions, whether it is possible to identify signs of behavioural intention and whether changes occur in the writings during a school year. Analysing the best possible selves of pupils adds to the knowledge of the wellbeing of pupils and the integration of positive psychology interventions in education. 


\section{References}

Adi, Y., Killoran, A., Janmohamed, K., \& Stewart-Brown, S. (2007a). Systematic review of the effectiveness of interventions to promote mental wellbeing in primary schools: universal approaches which do not focus on violence or bullying. London: National Institute for Health and Clinical Excellence.

Adi, Y., Killoran, A., Janmohamed, K., \& Stewart-Brown, S. (2007b). Systematic review of the effectiveness of interventions to promote mental wellbeing in primary schools: universal approaches with focus on prevention of violence or bullying. London: National Institute for Health and Clinical Excellence.

Barry, M.M., Clarke, A.M., \& Dowling, K. (2017). Promoting social and emotional wellbeing in schools. Health

Education, 117(5), 434-451.

Berger, C., Alcalay, L., Torretti, A., \& Milicic, N. (2011).

Socio-emotional well-being and academic achievement: Evidence from a multilevel approach. Psicologia: Reflexão e Crítica, 24(2), 344-351.

Bolier, L., Walburg, J.A., \& Boerefijn, J. (2013). Positieve psychologie op school. In Bohlmeijer, E.T., Bolier, L., Westerhof, G.J., \& Walburg, J.A. (Eds), Handboek Positieve Psychologie (pp. 325-354). Amsterdam: Uitgeverij Boom.

Buhs, E. S., Ladd, G. W., \& Herald, S. L. (2006). Peer exclusion and victimization: Processes that mediate the relation between peer group rejection and children's classroom engagement and achievement?. Journal of Educational Psychology, 98(1), 1.

Christenson, S. L., \& Anderson, A. R. (2002). The centrality of the learning context for students' academic enabler skills. School Psychology Review, 31, 378-393.

Chodkiewicz, A. R., Boyle, C. (2017). Positive psychology school-based interventions: A reflection on current success and future directions. Review of Education, 5(1), 60-86. doi:10.1002/rev3.3080

Datu, J. A. D., King, R. B., \& Valdez, J. P. M. (2017). The academic rewards of socially-oriented happiness: Interdependent happiness promotes academic engagement. Journal of school psychology, 61, 19-31.

Dix, K. L., Slee, P. T., Lawson, M. J., \& Keeves, J. P. (2012). Implementation quality of whole-school mental health promotion and students' academic performance. Child and Adolescent Mental Health, 17(1), 45-51.

Doll, B. (1996). Children without friends: Implications for practice and policy. School Psychology Review, 25, 165183.

Doll, B., Kurien, S., Leclair, C. Spies, R. Champion, A., \& Osborn, A. (2009). The ClassMaps survey: A Framework for Promoting Positive Classroom Environments. In R.Gilman, E. S. Huebner, \& M. J. Furlong (Eds.), Handbook of positive psychology in schools (pp. 65-76). New York, NY US: Routledge/Taylor \& Francis Group.

Durlak, J. A., Weissberg, R. P., Dymnicki, A. B., Taylor, R. D., \& Schellinger, K. B. (2011). The impact of enhancing students' social and emotional learning: a meta-analysis of school-based universal interventions. Child Development, 82(1), 405-432.

Fredrickson B. L. (1998). What Good Are Positive Emotions? Review of general psychology : journal of Division 1, of the American Psychological Association, 2(3), 300-319. doi:10.1037/1089-2680.2.3.300

Fredrickson B. L. (2001). The role of positive emotions in positive psychology. The broaden-and-build theory of positive emotions. The American psychologist, 56(3), 218226.

Furlong, M. J., Pavelski, R., \& Saxton, J. (2002). The prevention of school violence. In S. Brock, P. Lazarus \& S. 
Jimerson (Eds.), Best practices in school crisis management (pp. 131 -150). Washington, DC: National Association of School Psychologists.

Furrer, C., \& Skinner, E. (2003). Sense of relatedness as a factor in children's academic engagement and performance. Journal of Education Psychology, 95, 148162.

Gase, L. N., Gomez, L. M., Kuo, T., Glenn, B. A., Inkelas, M., \& Ponce, N. A. (2017). Relationships among student, staff, and administrative measures of school climate and student health and academic outcomes. Journal of school health, 87(5), 319-328.

Griffins, A-J., Sharkey, J. D., Furlong, M. J. (2009). Student engagement and Positive School Adaptation. In R.Gilman, E. S. Huebner, \& M. J. Furlong (Eds.), Handbook of positive psychology in schools (pp. 65-76). New York, NY US: Routledge/Taylor \& Francis Group.

Gutman, L. M., \& Midgley, C. (2000). The role of protective factors in supporting academic achievement of poor African American students during the middle school transition. Journal of Youth and Adolescence, 29, 223-248.

Hosan, N. E., \& Hoglund, W. (2017). Do Teacher-Child Relationship and Friendship Quality Matter for Children's School Engagement and Academic Skills?. School Psychology Review, 46(2), 201-218.

Hughes, J., \& Kwok, O. M. (2007). Influence of studentteacher and parent-teacher relationships on lower achieving readers' engagement and achievement in the primary grades. Journal of Educational Psychology, 99(1), 39.

Jane-Llopis, E., Barry, M. M, Hosman, C., \& Patel, V. (2005). Mental health promotion works: a review. Promotion \& Education, (Suppl 2), 9-25.

Jones, S. M., \& Bouffard, S. M. (2012). Social and emotional learning in schools: from programs to strategies: social policy report. Society for Research in Child Development, 26(4), 3-22.

Keyes, C. L. M. (2002). The Mental Health Continuum: From Languishing to Flourishing in Life. Journal of Health and Social Behavior, 43(2), 207-222.

Keyes, C. L. M. (2005). Mental illness and/or mental health? Investigating axioms of the complete state model of health. Journal of Consulting and Clinical Psychology, 73(3), 539-548.

Keyes, C. L. M. (2007). Promoting and protecting mental health as flourishing: A complementary strategy for improving national mental health. American Psychologist, 62(2), 95-108.

Keyes, C. L.M. (2009). The nature and importance of Positive Mental Health in America's Adolescents. In R.Gilman, E. S. Huebner, \& M. J. Furlong (Eds.), Handbook of positive psychology in schools (pp. 65-76). New York, NY US: Routledge/Taylor \& Francis Group.

Laevers, F. (2000). Forward to Basics! Deep-level-learning and the Experiential Approach. Early Years, 20(2), 20-29.

Laevers, F. (2005). The curriculum as means to raise the quality of early childhood education. Implications for policy. European Early Childhood Education Research Journal, 13(1), 17-29.

Laevers, F. (2015). Making care and education more effective through wellbeing and involvement. An introduction to Experiental Education. Leuven: Center for Experiental Education.

Laevers, F., \& Declerq, B. (2018). How well-being and involvement fit into the commitment to children's rights. European Journal of Education, 53(3), 325-335.

Laevers, F., Heylen, L., \& Maes, J. (2013). Een

Procesgerichte Aanpak Voor 6- tot 12-jarigen in Het

Basisonderwijs. Leuven: Averbode. 
Laevers, F. Stas, T., Van Cleynenbreugel, C. (2018). Elk kind goed in zijn vel. Implementatie en effectonderzoek van een interventiepakket voor de preventie van emotionele problemen en zelfdoding. Rapportage van het flankerend onderzoek. Leuven: ExpertiseCentrum ErvaringsGericht Onderwijs, KU Leuven.

Malecki, C. K., \& Elliot, S. N. (2002). Children's social behaviors as predictors of academia achievement: a longitudinal analysis. School Psychology Quarterly, 17, 123.

Martin, A. J., \& Marsh, H. W. (2008). Academic buoyancy: Towards an understanding of students' everyday academic resilience. Journal of School Psychology, 46(1), 53-83. doi:10.1016/j.jsp.2007.01.002

Martin, A. J., \& Marsh, H. W. (2009). Academic resilience and academic buoyancy: Multidimensional and hierarchical conceptual framing of causes, correlates and cognate constructs. Oxford Review of Education, 35(3), 353-370. doi:10.1080/03054980902934639

Meyers, D. C., Gil, L., Cross, R., Keister, S., Domitrovich, C. E., \& Weissberg, R. P. (2015). CASEL guide for schoolwide social and emotional learning. Chicago: CASEL.

Norrish, J.M., \& Vella-Brodrick, D.A. (2009). Positive psychology and adolescents: where are we now? Where to from here?. Australian Psychologist, 44(4), 270-278.

Norrish, J.M., Williams, P., O'Connor, M., \& Robinson, J.

(2013). An applied framework for positive education. International Journal of Wellbeing, 3(2), 147-161.

Oberle, E., Domitrovich, C. E., Meyers, D. C., \& Weissberg, R. P. (2016). Establishing systemic social and emotional learning approaches in schools: a framework for schoolwide implementation. Cambridge Journal of Education, 46(3), 277-297.
OECD. (2015). Skills for social progress: the power of social and emotional skills. Paris: OECD Publishing. https://doi.org/10.1787/9789264226159-en.

Oswald, A. J., Proto, E., \& Sgroi, D. (2015). Happiness and productivity. Journal of Labor Economics, 33(4), 789-822. doi:10.1086/681096

Park, N. \& Peterson, C. (2009). Strengths of character in schools. In R.Gilman, E. S. Huebner, \& M. J. Furlong (Eds.), Handbook of positive psychology in schools (pp. 65-76). New York, NY US: Routledge/Taylor \& Francis Group. Pietarinen, J., Soini, T., \& Pyhältö, K. (2014). Students' emotional and cognitive engagement as the determinants of well-being and achievement in school. International Journal of Educational Research, 67(1), 40-51. doi:10.1016/j.ijer.2014.05.001

Reyes, M. R., Brackett, M. A., Rivers, S. E., White, M., \& Salovey, P. (2012). Classroom emotional climate, student engagement, and academic achievement. Journal of educational psychology, 104(3), 700.

Roffey S. (2012) Developing Positive Relationships in Schools. In: Roffey S. (eds), Positive Relationships (pp. 145162). Dordrecht: Springer.

Rowe, G., Hirsh, J.B., \& Anderson, A.K. (2007). Positive affect increases the breadth of attentional selection. Proceedings of the National Academy of Sciences, 104(1), 383-388.

Ryan, R.M., \& Deci, E.L. (2001). On happiness and human potentials: a review of research on hedonic and eudaimonic well-being. Annual review of psychology, 52, 141-66.

Ryff, C. D. (1989). Happiness is everything, or is it? Explorations on the meaning of psychological wellbeing. Journal of Personality and Social Psychology, 57(6), 1069-1081. 
Seligman, M.E. (2011). Flourish: A Visionary New

Understanding of Happiness and Wellbeing. New York:

Free Press.

Seligman, M.E.P., Ernst, R.M., Gillham, J., Reivich, K. \&

Linkins, M. (2009). Positive education: positive psychology and classroom interventions. Oxford Review of Education, 35(3), 293-311.

Seligman, M.E.P., \& Csikszentmihalyi, M. (2000). Positive psychology: an introduction. American Psychologist, 55(1), 5-14.

Shankland, R. \& Rosset, E. (2017). Review of Brief SchoolBased Positive Psychological Interventions: a Taster for Teachers and Educators. Educational Psychology Review, 29(20), 3630392.

Sin, N.L., \& Lyubomirsky, S. (2009). Enhancing well-being and alleviating depressive symptoms with positive psychology interventions: a practice-friendly metaanalysis. Journal of Clinical Psychology, 65(5), 467-487.

Sklad, M., Diekstra, R., Gravesteijn, C.M., Ben, J., \& Ritter, M. (2012). Effectiveness of school-based universal social, emotional and behavioral programs: do they enhance students' development in the area of skill, behavior, and adjustment? Psychology in the Schools, 49(9), 892-909.

Smeets, E., Neff, K., Alberts, H., \& Peters, M.

(2014). Meeting suffering with kindness: Effects of a brief self-compassion intervention for female college students. Journal of Clinical Psychology, 70(9), 794-

807. https://doi.org/10.1002/jclp.22076

Taylor, R. D., Oberle, E., Durlak, J. A., \& Weissberg, R. P. (2017). Promoting positive youth development through school-based social and emotional learning interventions: a meta-analysis of follow-up effects. Child Development, 88(4), 1156-1171. https://doi.org/10.1111/cdev.12864.

Tennant, R., Goens, C., Barlow, J., Day, C., \& Stewart-

Brown, S. (2007). A systematic review of reviews of interventions to promote mental health and prevent mental health problems in children and young people. Journal of Public Mental Health, 6(1), 25-32.

Ttofi, M. M., \& Farrington, D. P. (2011). Effectiveness of school-based programs to reduce bullying: a systematic and meta-analytic review. Journal of Experimental Criminology, 7(1), 27-56.

https://doi.org/10.1080/1754730X.2008.9715730.

Waters, L. (2011). A review of school-based positive psychology interventions. The Australian Educational and Developmental Psychologist, 28(2), 75-90.

Weare, K., \& Nind, M. (2011). Mental health promotion and problem prevention in schools: what does the evidence say? Health Promotion International, 26(1), 2969.

Wells, J., Barlow, J., \& Stewart-Brown, S. (2003). A systematic review of universal approaches to mental health promotion in schools. Health Education, 103(4), 197-220.

Wentzel, K. R. (2002). Are effective teachers like good parents? Teaching styles and student adjustment in early adolescence. Child development, 73, 287-301.

Wentzel, K., Baker, S., \& Russell, S. (2009). Peer relationships and positive adjustment at school. In R. Gilman, E. S. Huebner, \& M. J. Furlong (Eds.), Handbook of positive psychology in schools (pp. 229-243). New York, NY, US: Routledge/Taylor \& Francis Group.

Wentzel, K. R., \& Caldwell, K. (1997). Friendships, peer acceptance, and group memberships: Relations to academic achievement in middle school. Child development, 68, 1198-1209.

Westerhof, G.J., \& Keyes, C.L.M. (2010). Mental illness and mental health: the two continua model across the lifespan. Journal of Adult Development, 17(2), 110-119. 
Wilson, S. J., Lipsey, M. W., \& Derzon, J. H. (2003). The

effects of school-based intervention programs on

aggressive behavior: a meta-analysis. Journal of Consulting

and Clinical Psychology, 71(1), 136-149.

https://doi.org/10.1037/0022-006X.71.1.136.
World Health Organization (WHO). (1998). Health

Promoting evaluation: recommendations for Policy-

Makers, report of the WHO European Working Group on

Health Promotion Evaluation. Copenhagen: WHO. 


\section{Chapter 2:}

Effectiveness of interventions adopting a whole school approach to enhancing social and emotional development: a meta-analysis

Goldberg, J.M., Sklad, M., Elfrink, T.R., Schreurs, K.M.G., Bohlmeijer, E.T., \& Clarke, A.M.

(2018). Effectiveness of interventions adopting a whole school approach to enhancing social and emotional development: a meta-analysis. European Journal of Psychology of

Education. https://doi.org/10.1007/s10212-018-0406-9 


\begin{abstract}
This article presents findings from a meta-analysis which sought to determine the effectiveness of interventions adopting a whole school approach to enhancing children and young people's social and emotional development. Whole school interventions were included if they involved a coordinated set of activities across curriculum teaching, school ethos and environment, and family and community partnerships. A total of 45 studies (30 interventions) involving 496,299 participants were included in the analysis. Post-intervention outcomes demonstrated significant but small improvements in participants' social and emotional adjustment $(d=0.220)$, behavioural adjustment $(d=0.134)$, and internalising symptoms $(d=0.109)$. Interventions were not shown to impact on academic achievement. Origin of study and the inclusion of a community component as part of a whole school approach were found to be significant moderators for social and emotional outcomes. Further research is required to determine the active ingredients of whole school interventions that we can better understand the components necessary to achieve successful outcomes.
\end{abstract}




\section{Introduction}

Children and adolescents need a balanced set of cognitive, social and emotional skills in order to achieve positive outcomes in school, in work, and in life more generally (OECD, 2015). Social and emotional skills such as understanding and managing emotions, navigating social conflicts effectively, and making responsible decisions have been shown to influence numerous measures of social outcomes, including improved health, life satisfaction, subjective wellbeing, and reduced odds of engagement in anti-social behaviours (Goodman et al., 2015). Social and emotional skills do not play a role in isolation, they interact with cognitive skills which further enhance children's likelihood of achieving positive outcomes in life $(O E C D, 2015)$.

A common approach to supporting the development of children's social and emotional skills has been school-based interventions (Jones \& Bouffard, 2012; Barry et al., 2017). Schools have been identified as a key setting for building social, emotional, and behavioural outcomes because students spend a substantial amount of time there. The school also provides a socialising context in which students are able to learn a range of life skills, many of which are associated with academic success (Taylor et al., 2017; Durlak et al., 2011; Sklad et al., 2012). Many school-based programmes have targeted an interrelated set of skills that fall under the headings of mental health promotion, character education, social and emotional learning (SEL), bullying prevention, life skills, strengths-based approaches, and youth development. Over the last three decades, the concept of social and emotional learning has served as an umbrella framework for a range of approaches and appears to have the largest and most rigorously evaluated evidence base. Social and emotional learning is defined as the process through which students acquire and effectively apply the knowledge, attitudes, and skills necessary to recognise and mange emotions, solve problems effectively, and establish positive relationships with others (CASEL, 2005).

A growing body of research suggests that social and emotional skills are malleable and can be effectively taught using a variety of approaches and formats including classroom-based programming and whole school approaches (Jones \& Bouffard, 2012). Research indicates that interventions yield most successful outcomes when they are integrated into daily practice and school culture, seek to engage all staff, reinforce skills outside of the classroom such as hallways and playgrounds, support parental engagement, and coordinate work with outside agencies (Barry et al., 2017; Jones \& Bouffard, 2012; 
Weare \& Nind, 2011; Ttofi \& Farrington, 2011; Adi et al., 2007a, b; Wilson et al., 2003). Together, these characteristics point to the importance of adopting a whole school approach to enhancing children and young people's social and emotional skill development. Jones and Bouffard (2012) highlighted key principles of social and emotional skill development that supports a move toward that adoption of a whole school approach: (i) continuity and consistency are essential for skill development, thus efforts need to be school wide, span age ranges, and consistent across multiple contexts within the school; (ii) social, emotional, and academic skills are interdependent and, therefore, efforts should be made to promote these skills simultaneously, reducing time pressures for teachers; (iii) social and emotional skills develop in social contexts, hence relationships between students and staff and among students are an important focus in their own right; (iv) classroom and schools operate as systems and both classroomand school-wide efforts can set positive standards and expectations that promote and reinforce social and emotional competencies.

A whole school approach aims to integrate skill development into daily interactions and practices using collaborative efforts that include all staff, teachers, families, and children (Jones \& Bouffard, 2012; Meyers et al., 2015). Based on the World Health Organization's definition of a Health Promoting School (WHO, 1998), a whole school approach defines the entire school community as the unit of change and involves coordinated action between three interrelated components: (i) curriculum, teaching, and learning; (ii) school ethos and environment; (iii) family and community partnerships. Effective curriculum teaching and learning involve teaching skills through the implementation of evidence-based programmes, as well as modelling social emotional competencies, and providing continuous and consistent opportunities to practice these skills during everyday classroom situations (Oberle et al., 2016). At the school level, skills are reinforced in non-curriculum-based ways through policies, social relations, whole staff training, organisational structure, and daily activities in the school that are designed to promote a positive school climate which, in turn, helps children to develop positively across academic, social, emotional, and behavioural domains (Jones and Bouffard, 2012; Meyers et al., 2015). Family and community partnerships involve extending learning to the home and community contexts. Embedding families within a whole school approach reinforces the complementary roles of families and educators and extends opportunities for learning across the two contexts in which children spend most of their time. Community partners provide links with external support and mental health services in the community, thereby ensuring there is access to services for students needing additional social and emotional support. 
Several countries have launched national initiatives that adopt a school-wide approach to social and emotional learning. In Australia, for example, KidsMatter Primary is a mental health and wellbeing whole school framework that supports primary schools in implementing social and emotional learning school-wide (Dix et al., 2012). Through KidsMatter Primary, schools undertake a two-to-three-year cyclical process where they plan and take action to (i) promote social and emotional learning; (ii) work authentically with parents, cariers, and families; and (iii) provide support for students who may be experiencing mental health difficulties. At second level, MindMatters provides professional development, curriculum, and whole school resources aimed at improving the mental health and wellbeing of young people (Wyn et al., 2000). In the UK, the Social and Emotional Aspects of Learning (SEAL) programme was developed as a whole school framework to support the social and emotional skill development of children and young people. This resource includes a curriculum element which is designed to support both universal and targeted work and whole school materials including resources relating to staff development, school organisation, management and leadership, and school ethos (Hallam, 2009; Banerjee et al., 2014).

Despite extensive investment in whole school interventions, their effectiveness remains unclear. Reviewers of the evidence to date conclude that taking a whole school approach is more likely than individual classroom-based interventions to result in enduring positive change, because of its multicomponent focus (Weare \& Nind, 2011; Adi et al., 2007a, b; Tennant et al., 2007; Jane-llopis et al., 2005; Wells et al. 2003). However, some recent reviews suggest that whole school interventions adopting a whole school approach are failing to show impact (e.g. Durlak et al., 2011; Langford et al., 2015). To date, however, no meta-analysis has been carried out specifically on interventions adopting a whole school approach to social and emotional learning. The aim of this review was, therefore, to examine the impact of these interventions on children and young people's outcomes including social and emotional adjustment, behavioural adjustment, academic achievement, and internalising symptoms. A secondary aim was to assess the impact of moderating variables on programme outcomes. 


\section{Methods}

The PRISMA guidelines for conducting a meta-analysis (Moher et al., 2009) were followed for the planning, conducting, and reporting of results.

\section{Selection of studies}

To be eligible for inclusion, studies were required to meet four methodological criteria: (i) utilised an experimental or quasi-experimental design with a control/comparison group; (ii) reported outcomes that could be transformed to Cohen's d effect sizes; (iii) was published after 1998, in line with the World Health Organization's recommendation for schools to focus on the adoption of a whole school approach (WHO, 1998); (iv) was published in English. In addition, the intervention (i) adopted a whole school approach as defined by the WHO (1998), (ii) was aimed at children and young people aged 4-18 years attending primary or secondary school, (iii) adopted a competency enhancement focus or was aimed at reducing problem behaviours through the application of social and emotional skills (e.g. bullying prevention interventions). Whole school interventions and frameworks which focused on behaviour management were not included in the current review, as a separate meta-analysis of this has already been carried out (Solomon et al., 2012).

\section{Search strategy}

Academic databases including Embase, Psyclnfo, Scopus, and ERIC were searched. Eleven education databases were searched: NREPP, Child Trends US, Blueprints for Healthy Youth Development, Office of Justice Programs US, RAND Promising Practice Network on Children Families and Communities, California Evidence-based Clearing House for Child Welfare, Office of Adolescent Health, Crime Solutions US, Washington State Institute Public Policy, CASEL, and Education Endowment Foundation Database, UK. Eight health promotion and public health databases were searched: Evidence for Policy and Practice Information and Coordinating Centre (EPPI-Centre); University of York National Health Service Centre for reviews and dissemination; National Institute of Clinical Excellence (NICE); British Education Index, Databases of Abstracts of Reviews of Effectiveness (DARE); Health Technology Assessment (HTA); Cochrane Database of Systematic Reviews; the Campbell Collaboration; WHO programmes and projects. Additional sources included Google Scholar and reference lists of relevant articles, book chapters, and reviews. Key individuals and organisations identified through the search process were contacted to identify further details on publications. The electronic search strategy used across all databases is 
provided in Table 1. The search for studies was conducted between 15 August and 8 October 2015. A repeated search was conducted between 30 July and 7 August 2017 to include articles published up to July 2017.

Table 1: Original search strategy for electronic databases

\begin{tabular}{|c|c|c|c|c|}
\hline $\begin{array}{l}\text { Social and emotional } \\
\text { adjustment / Positive } \\
\text { Psychology Terms }\end{array}$ & Whole School Terms & $\begin{array}{l}\text { Sample \& } \\
\text { Setting Terms }\end{array}$ & $\begin{array}{l}\text { Programme } \\
\text { Terms }\end{array}$ & Study terms \\
\hline 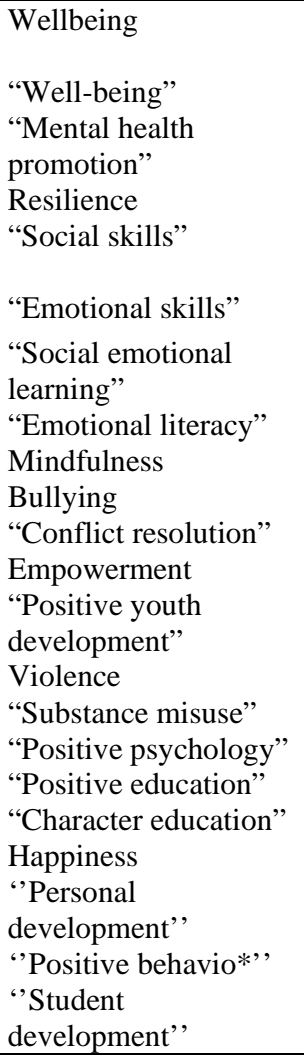 & 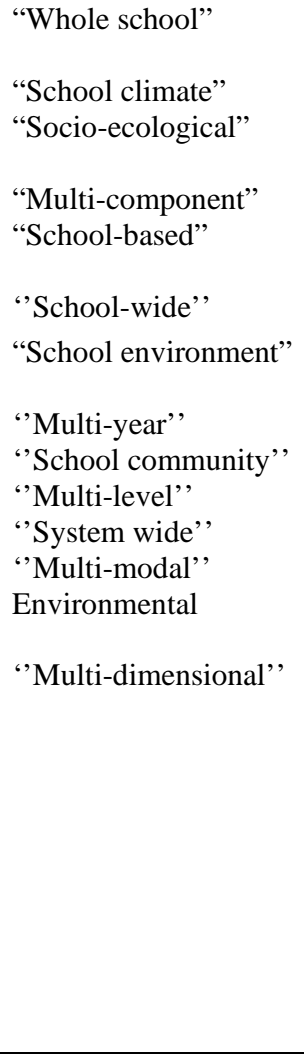 & $\begin{array}{l}\text { Child* } \\
\text { OR } \\
\text { Youth } \\
\text { Adolesce* } \\
\text { "Young people" } \\
\text { School }\end{array}$ & $\begin{array}{l}\text { Education } \\
\text { OR } \\
\text { Intervention } \\
\text { Program* } \\
\text { Training } \\
\text { Prevention }\end{array}$ & $\begin{array}{l}\text { Evaluation } \\
\text { OR } \\
\text { Study } \\
\text { Quantitative } \\
\text { Random control } \\
\text { Quasi experimental } \\
\text { Effect } \\
\text { Outcome }\end{array}$ \\
\hline
\end{tabular}

*denotes multiple word endings including singular and plural

" " denotes only the full term will be searched for

Search string:

(Well-being OR wellbeing "mental health promotion" OR resilience OR "social skills" OR "social emotional learning" OR "emotional literacy" OR mindfulness OR Bullying OR "conflict resolution" OR empowerment OR "positive youth development" OR violence OR "substance misuse" OR "positive psychology" OR "positive education" OR "character education" OR happiness OR "personal development" OR "positive behavio*" OR "student development") AND ("whole-school" OR "school climate" OR "socio-ecological” OR "multi-component" OR "school-based" OR "school-wide" OR "school environment" OR multi-year OR "school community" OR "multi-level" OR "system wide" OR "multi-modal" OR environmental OR "multi-dimensional") AND (child OR youth OR adolesce* OR school) AND (education OR intervention OR program* OR training OR prevention) AND (evaluation OR study OR quantitative OR "random control" OR "quasi experimental” OR effect OR outcome)

\section{$\underline{\text { Results literature search }}$}

The results of the search and study selection are shown in Fig. 1. The original search, in 2015, identified 6626 citations from the academic databases and a further 32 citations from the other sources. After the 
removal of duplicates, 4402 abstracts were screened. A total of 392 full text articles were screened for eligibility. Of these, 348 did not fulfil the inclusion criteria and were excluded. Forty-four studies were selected for inclusion in the meta-analysis. The updated search which was carried out in August 2017 identified a further six studies. The combined searches resulted in a total of 50 articles which fulfilled the inclusion criteria. Six of the included articles reported findings from one evaluation study of the whole school intervention Positive Action. These six articles were therefore perceived as one study, resulting in 45 studies that underwent meta-analysis.

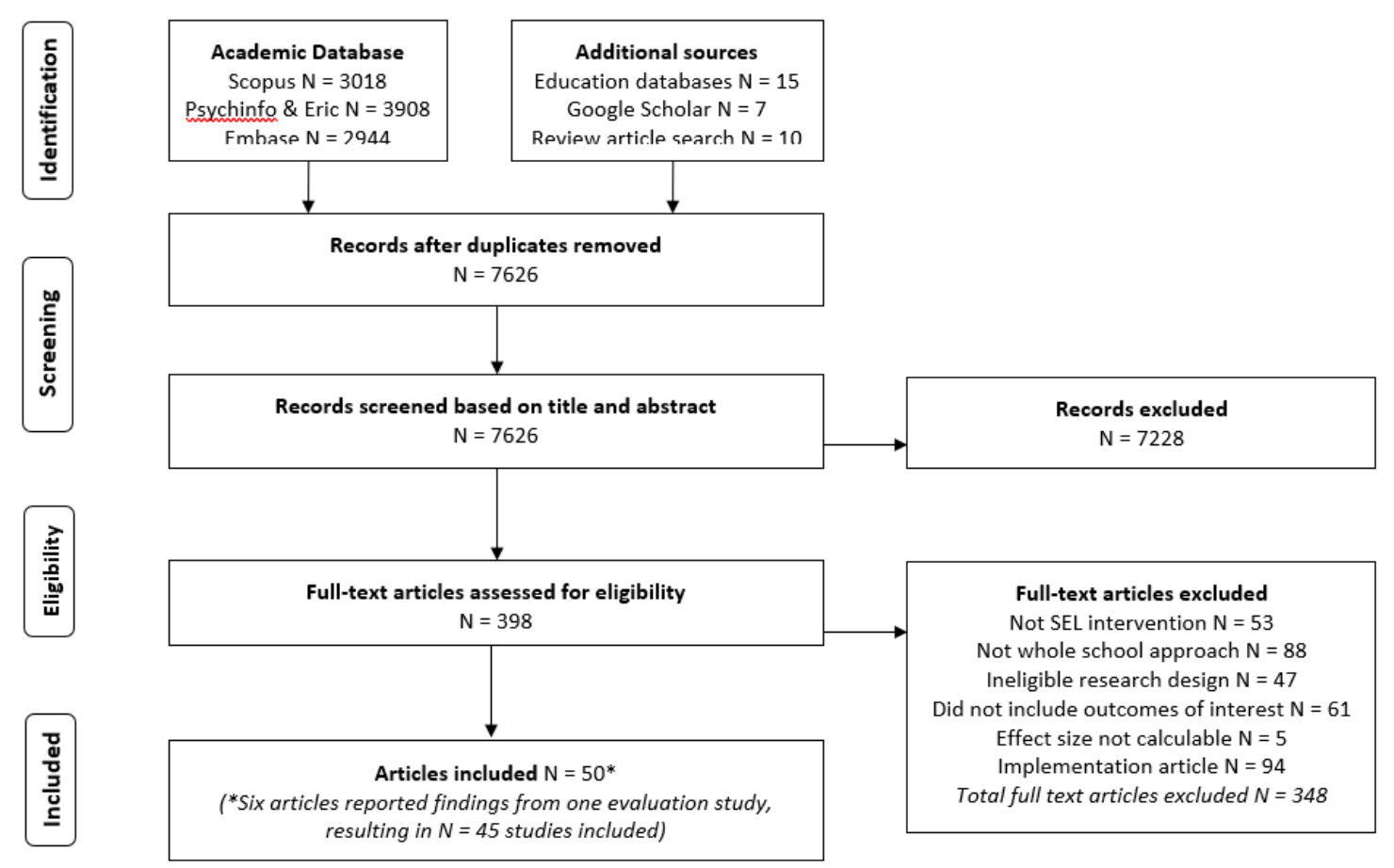

Figure 1: Flowchart study selection, first search (Aug 2015) and update search (Aug 2017) combined

\section{Coding}

A coding sheet was developed by three authors (J.G., A.C., and M.S.). The purpose of the coding sheet was to extract all relevant information from the studies including methodological, intervention, and recipient characteristics. To check for inter-rater reliability, $10 \%$ of all the included articles were independently coded by the first and last authors (J.G. and A.C.). For all the checked articles, the percentage of agreement was above $85 \%$ and was perceived as sufficient. All differences were discussed and resolved.

\section{Assessing quality of evidence}


All studies that fulfilled the criteria for this meta-analysis underwent an assessment of their methodological quality. Following the guidelines of the Cochrane Public Health Group (Jackson and Waters, 2005), the methodological quality of the intervention evaluations was assessed using the Quality Assessment Tool for Quantitative Studies (EPHPP, 1998). Studies were assessed for selection bias, study design, confounders, blinding, data collection method, and dropouts. Each study was rated independently by two reviewers (J.G. and A.C.). The quality assessment results were compared and disagreements were resolved through discussion. Based on the ratings of the six components, each study received an overall rating of strong, moderate, or weak.

\section{Outcomes and moderators}

In line with other meta-analyses in this field (Payton et al., 2008; Sklad et al., 2012, four outcome categories were defined:

I. Social and emotional adjustment: this category included measurements of social or emotional skills, and attitudes toward self and others.

II. Behavioural adjustment: this category included positive social behaviour, conduct problems, victimisation, and risky behaviour (e.g. substance abuse, unprotected sexual intercourse)

III. School performance: this category included all measurements of academic achievement, for example reading achievement scores or academic competence rated by the teacher

IV. Internalising symptoms: this category included outcomes related to reducing psychopathology, such as depression and anxiety, and also feelings of wellbeing.

To assess the impact of moderators on programme outcomes, a number of variables were selected. Methodological variables included the following: research design (randomised controlled trial/quasiexperimental), number of months between pre- and post-intervention (12 or less/13 or more), implementation fidelity (no problems reported/problems reported/not reported), quality assessment (strong/moderate/weak), self-report measure (yes/no), and year of publication (2010 or earlier/2011 or later). Intervention characteristics selected as moderators included the following: intervention focus on behavioural problems (yes/no), school level (primary/secondary), community component included (yes/no), and targeted component included for students at risk of problem behaviour (yes/no). Lastly, a potential moderator regarding the recipient characteristics was the country where the study was carried out (United States/outside United States). 


\section{Analysis plan}

Outcomes reported in the included studies were categorised into one of the four main outcome categories. The intervention and control group's means, standard deviations, and sample size were extracted for each measurement. Standardised difference between two means "Cohen's d" (or Cohen's $\mathrm{g}$ in the case of small sample sizes) was then calculated per measurement based on means and standard deviations or other appropriate data (e.g. odds ratios). When studies failed to report means, standard deviations, or proportions, effect sizes were calculated using a t test, F-statistic, or $p$ value and sample size.

For each effect size, the direction was determined in such a way that positive values indicated a more beneficial outcome favouring the intervention group over the control group. The variance of each effect size was calculated based on the sample sizes. It was also necessary to determine whether the design effect of clustering was taken into account in each study. If a design effect was not in place, the variances of the effect sizes were adjusted based on inter-cluster correlations (ICCs) of the same (or a comparable) article, resulting in true variances.

For each study, mean effect sizes for each outcome category were calculated. If different articles presented data about the same cohort, the data was combined into one mean effect size per outcome. For the mean effect sizes, it was determined whether the direction of the effect size was positive or negative. Effects sizes of 0.20 were considered small, 0.50 moderate, and 0.80 high (Lipsey \& Wilson, 1993). For each mean effect size, a variance was calculated based on an estimated correlation ( $r$ ) and the (true) variance of the individual effect sizes (Morris, 2008).

To analyse the general effectiveness of the interventions on the four main outcome categories, the Comprehensive Meta-Analysis (CMA) programme was used. A random effects model was used with a maximum likelihood estimation procedure to arrive at effect sizes (ES) and 95\% confidence intervals. Outliers were removed from the main analyses. Studies were considered as outliers when their standardised residual exceeded the norm of 3.00. CMA was also used to calculate statistical heterogeneity, publication bias, and the influence of possible moderators. Heterogeneity was determined by calculating $\mathrm{I}^{2}$ values, indicating the degree of inconsistency across studies in a metaanalysis (Higgins et al., 2003). $\mathrm{I}^{2}$ values are derived from $\mathrm{H}^{2}$ values through the following formula: $\left(\mathrm{H}^{2}-\right.$ 1)/ $H^{2}$. Publication bias was estimated by funnel plots, Egger et al.'s (1997) regression tests, and Duval and Tweedie's (2000) trim and fill analyses. The influence of possible moderators was determined by 
calculating $Q$ values (heterogeneity between groups) and their corresponding $p$ values, based on the Zvalues of the different moderator categories (Borenstein et al., 2010). Few studies reported outcomes for subgroups or follow-up data, so it was decided not to do separate analysis for subgroups or followup studies. 
Table 2

Characteristics of included interventions

\begin{tabular}{|c|c|c|c|c|c|c|c|c|c|c|c|c|}
\hline \multirow{2}{*}{$\begin{array}{l}\text { Study } \\
\begin{array}{l}\text { Kärna et al. } \\
\text { (2011) }\end{array}\end{array}$} & \multirow{2}{*}{$\begin{array}{l}\text { Programme } \\
\text { Name } \\
\text { KiVa }\end{array}$} & \multirow{2}{*}{$\begin{array}{l}\text { Country } \\
\text { Finland }\end{array}$} & \multirow{2}{*}{$\begin{array}{l}\text { Design } \\
\text { Quasi }\end{array}$} & \multirow{2}{*}{$\begin{array}{r}\mathbf{N} \\
\\
7737 \\
\end{array}$} & \multirow{2}{*}{$\begin{array}{l}\begin{array}{l}\text { Bullying } \\
\text { focused }\end{array} \\
\text { Yes }\end{array}$} & \multicolumn{3}{|c|}{$\begin{array}{l}\text { Parental/community/ } \\
\text { indicated component }\end{array}$} & \multirow{2}{*}{$\begin{array}{l}\text { Primary } \\
\text { or } \\
\text { secondary } \\
\text { school } \\
\text { Both }\end{array}$} & \multirow{2}{*}{$\begin{array}{l}\text { Implementation } \\
\text { fidelity } \\
\text { Fidelity is fine }\end{array}$} & \multirow{2}{*}{\begin{tabular}{|l|}
$\begin{array}{l}\text { Quality } \\
\text { assessment }\end{array}$ \\
Strong
\end{tabular}} & \multirow{2}{*}{$\begin{array}{l}\text { Outcome } \\
\text { Behavioural adjustment }\end{array}$} \\
\hline & & & & & & Yes & No & Yes & & & & \\
\hline $\begin{array}{l}\text { Kärna et al. } \\
\text { (2013) }\end{array}$ & $\mathrm{KiVa}$ & Finland & RCT & 26930 & Yes & Yes & No & Yes & Both & Fidelity is fine & Strong & Behavioural adjustment \\
\hline $\begin{array}{l}\text { Williford et } \\
\text { al. (2011) }\end{array}$ & $\mathrm{KiVa}$ & Finland & RCT & 7741 & Yes & Yes & No & Yes & Both & Not reported & Moderate & $\begin{array}{l}\text { Behavioural adjustment, } \\
\text { social and emotional } \\
\text { adjustment, } \\
\text { internalizing symptoms }\end{array}$ \\
\hline $\begin{array}{l}\text { Williford et } \\
\text { al. (2013) }\end{array}$ & $\mathrm{KiVa}$ & Finland & RCT & 19905 & Yes & Yes & No & Yes & Both & Not reported & Strong & Behavioural adjustment \\
\hline $\begin{array}{l}\text { Yang \& } \\
\text { Salmivalli } \\
(2015)\end{array}$ & $\mathrm{KiVa}$ & Finland & RCT & 23520 & Yes & Yes & No & Yes & Both & Not reported & Strong & Behavioural adjustment \\
\hline $\begin{array}{l}\text { Salmivalli et } \\
\text { al. (2011) }\end{array}$ & $\mathrm{KiVa}$ & Finland & RCT & 7303 & Yes & Yes & No & Yes & Both & Not reported & Moderate & Behavioural adjustment \\
\hline $\begin{array}{l}\text { Amundsen } \\
\text { \& Ravndal } \\
(2010)\end{array}$ & Olweus & Norway & Quasi & 1527 & Yes & Yes & Yes & Yes & Secondary & Not reported & Weak & Behavioural adjustment \\
\hline $\begin{array}{l}\text { Bauer et al. } \\
\text { (2007) }\end{array}$ & Olweus & USA & Quasi & 6518 & Yes & Yes & Yes & Yes & Secondary & Fidelity is fine & Moderate & $\begin{array}{l}\text { Behavioural adjustment, } \\
\text { social and emotional } \\
\text { adjustment }\end{array}$ \\
\hline $\begin{array}{l}\text { Bavarian et } \\
\text { al. (2013) }\end{array}$ & $\begin{array}{l}\text { Positive } \\
\text { Action }\end{array}$ & USA & RCT & 1170 & Yes & Yes & Yes & Yes & Both & Not reported & Strong & $\begin{array}{l}\text { Behavioural adjustment, } \\
\text { social and emotional } \\
\text { adjustment, school } \\
\text { performance }\end{array}$ \\
\hline $\begin{array}{l}\text { Washburn } \\
\text { et al. (2011) }\end{array}$ & $\begin{array}{l}\text { Positive } \\
\text { Action }\end{array}$ & USA & RCT & 2646 & Yes & Yes & Yes & Yes & Both & Fidelity is fine & Moderate & Behavioural adjustment \\
\hline $\begin{array}{l}\text { Washburn } \\
\text { et al. (2011) }\end{array}$ & $\begin{array}{l}\text { Positive } \\
\text { Action }\end{array}$ & USA & RCT & 936 & Yes & Yes & Yes & Yes & Both & Fidelity is fine & Moderate & Behavioural adjustment \\
\hline $\begin{array}{l}\text { Washburn } \\
\text { et al. (2011) }\end{array}$ & $\begin{array}{l}\text { Positive } \\
\text { Action }\end{array}$ & USA & RCT & 2610 & Yes & Yes & Yes & Yes & Both & $\begin{array}{l}\text { Reported } \\
\text { problems }\end{array}$ & Moderate & Behavioural adjustment \\
\hline $\begin{array}{l}\text { Lewis et al. } \\
\text { (2013) }\end{array}$ & $\begin{array}{l}\text { Positive } \\
\text { Action }\end{array}$ & USA & RCT & 1170 & Yes & Yes & Yes & Yes & Both & Fidelity is fine & Moderate & $\begin{array}{l}\text { Behavioural adjustment, } \\
\text { social and emotional } \\
\text { adjustment }\end{array}$ \\
\hline $\begin{array}{l}\text { Lewis et al. } \\
\text { (2016) }\end{array}$ & $\begin{array}{l}\text { Positive } \\
\text { Action }\end{array}$ & USA & RCT & 1170 & Yes & Yes & Yes & Yes & Both & Fidelity is fine & Moderate & $\begin{array}{l}\text { Behavioural adjustment, } \\
\text { social and emotional } \\
\text { adjustment }\end{array}$ \\
\hline
\end{tabular}




\begin{tabular}{|c|c|c|c|c|c|c|c|c|c|c|c|c|}
\hline $\begin{array}{l}\text { Lewis et al. } \\
\text { (2012) }\end{array}$ & $\begin{array}{l}\text { Positive } \\
\text { Action }\end{array}$ & USA & RCT & 1170 & Yes & Yes & Yes & Yes & Both & Fidelity is fine & Moderate & $\begin{array}{l}\text { Behavioural adjustment, } \\
\text { social and emotional } \\
\text { adjustment }\end{array}$ \\
\hline $\begin{array}{l}\text { Lewis et al. } \\
\text { (2013) }\end{array}$ & $\begin{array}{l}\text { Positive } \\
\text { Action }\end{array}$ & USA & RCT & 1170 & Yes & Yes & Yes & Yes & Both & Fidelity is fine & Moderate & $\begin{array}{l}\text { Behavioural adjustment, } \\
\text { social and emotional } \\
\text { adjustment, } \\
\text { internalizing symptoms }\end{array}$ \\
\hline $\begin{array}{l}\text { Snyder et al. } \\
\text { (2012) }\end{array}$ & $\begin{array}{l}\text { Positive } \\
\text { Action }\end{array}$ & USA & RCT & 10880 & Yes & Yes & Yes & Yes & Both & Fidelity is fine & Moderate & $\begin{array}{l}\text { Social and emotional } \\
\text { adjustment }\end{array}$ \\
\hline $\begin{array}{l}\text { Snyder et al. } \\
\text { (2010) }\end{array}$ & $\begin{array}{l}\text { Positive } \\
\text { Action }\end{array}$ & USA & RCT & 10880 & Yes & Yes & Yes & Yes & Both & Fidelity is fine & Moderate & $\begin{array}{l}\text { Behavioural adjustment, } \\
\text { school performance }\end{array}$ \\
\hline $\begin{array}{l}\text { Flay et al. } \\
\text { (2003) }\end{array}$ & $\begin{array}{l}\text { School } \\
\text { Community } \\
\text { Intervention }\end{array}$ & USA & RCT & 1153 & No & Yes & Yes & No & Primary & Fidelity is fine & Moderate & Behavioural adjustment \\
\hline $\begin{array}{l}\text { Bond et al. } \\
\text { (2004) }\end{array}$ & $\begin{array}{l}\text { Gatehouse } \\
\text { Project }\end{array}$ & Australia & RCT & 2678 & No & Yes & No & Yes & Secondary & Not reported & Strong & $\begin{array}{l}\text { Behavioural adjustment, } \\
\text { social and emotional } \\
\text { adjustment, } \\
\text { internalizing symptoms }\end{array}$ \\
\hline $\begin{array}{l}\text { Patton et al. } \\
\text { (2006) }\end{array}$ & $\begin{array}{l}\text { Gatehouse } \\
\text { Project }\end{array}$ & Australia & RCT & 2678 & No & Yes & No & Yes & Secondary & Not reported & Strong & $\begin{array}{l}\text { Behavioural adjustment, } \\
\text { social and emotional } \\
\text { adjustment, } \\
\text { internalizing symptoms }\end{array}$ \\
\hline $\begin{array}{l}\text { Brown et al. } \\
\text { (2011) }\end{array}$ & $\begin{array}{l}\text { Steps to } \\
\text { Respect }\end{array}$ & USA & RCT & 3119 & Yes & Yes & No & No & Primary & Fidelity is fine & Moderate & $\begin{array}{l}\text { Behavioural adjustment, } \\
\text { social and emotional } \\
\text { adjustment, school } \\
\text { performance }\end{array}$ \\
\hline $\begin{array}{l}\text { Cross et al. } \\
\text { (2010) }\end{array}$ & $\begin{array}{l}\text { Friendly } \\
\text { Schools }\end{array}$ & Australia & RCT & 1968 & Yes & Yes & No & Yes & Primary & $\begin{array}{l}\text { Reported } \\
\text { problems }\end{array}$ & Strong & $\begin{array}{l}\text { Behavioural adjustment, } \\
\text { social and emotional } \\
\text { adjustment }\end{array}$ \\
\hline $\begin{array}{l}\text { Eisen et al. } \\
\text { (2003) }\end{array}$ & Lions Quest & USA & RCT & 7426 & Yes & Yes & Yes & No & Both & Not reported & Strong & $\begin{array}{l}\text { Behavioural adjustment, } \\
\text { social and emotional } \\
\text { adjustment }\end{array}$ \\
\hline $\begin{array}{l}\text { Fonagy et } \\
\text { al. (2009) }\end{array}$ & CAPSLE & USA & RCT & 2534 & Yes & Yes & Yes & Yes & Primary & Fidelity is fine & Strong & $\begin{array}{l}\text { Behavioural adjustment, } \\
\text { social and emotional } \\
\text { adjustment }\end{array}$ \\
\hline $\begin{array}{l}\text { Hoglund et } \\
\text { al. (2012) }\end{array}$ & WITS & Canada & Quasi & 432 & Yes & Yes & Yes & No & Primary & $\begin{array}{l}\text { Reported } \\
\text { problems }\end{array}$ & Moderate & $\begin{array}{l}\text { Behavioural adjustment, } \\
\text { social and emotional } \\
\text { adjustment, } \\
\text { internalizing symptoms }\end{array}$ \\
\hline $\begin{array}{l}\text { Lee \& } \\
\text { Stewart } \\
\text { (2013) }\end{array}$ & $\begin{array}{l}\text { Health } \\
\text { Promoting } \\
\text { Schools }\end{array}$ & Australia & RCT & 2758 & No & Yes & Yes & No & Primary & Not reported & Moderate & $\begin{array}{l}\text { Social and emotional } \\
\text { adjustment }\end{array}$ \\
\hline $\begin{array}{l}\text { Stevens et } \\
\text { al. (2000) }\end{array}$ & $\begin{array}{l}\text { Flemish Anti } \\
\text { Bullying }\end{array}$ & Belgium & RCT & 1104 & Yes & Yes & No & Yes & Both & Not reported & Moderate & Behavioural adjustment \\
\hline
\end{tabular}




\begin{tabular}{|c|c|c|c|c|c|c|c|c|c|c|c|c|}
\hline $\begin{array}{l}\text { Wong et al. } \\
\text { (2011) }\end{array}$ & $\begin{array}{l}\text { Restorative } \\
\text { Whole } \\
\text { School } \\
\text { Approach }\end{array}$ & $\begin{array}{l}\text { Hong } \\
\text { Kong }\end{array}$ & Quasi & 1480 & Yes & Yes & Yes & Yes & Secondary & Not reported & Strong & $\begin{array}{l}\text { Behavioural adjustment, } \\
\text { social and emotional } \\
\text { adjustment, } \\
\text { internalizing symptoms }\end{array}$ \\
\hline $\begin{array}{l}\text { Beran et al. } \\
(2004)\end{array}$ & Dare to Care & Canada & Quasi & 102 & Yes & Yes & No & No & Primary & Not reported & Weak & $\begin{array}{l}\text { Behavioural adjustment, } \\
\text { social and emotional } \\
\text { adjustment }\end{array}$ \\
\hline $\begin{array}{l}\text { Bierman et } \\
\text { al. (2010) }\end{array}$ & $\begin{array}{l}\text { Fast Track } \\
\text { PATHS }\end{array}$ & USA & RCT & 5081 & Yes & Yes & Yes & Yes & Primary & Fidelity is fine & Moderate & $\begin{array}{l}\text { Social and emotional } \\
\text { adjustment, school } \\
\text { performance }\end{array}$ \\
\hline $\begin{array}{l}\text { Gradinger et } \\
\text { al. (2015) }\end{array}$ & ViSC & Austria & RCT & 2042 & Yes & Yes & No & Yes & Both & Not reported & Moderate & Behavioural adjustment \\
\hline $\begin{array}{l}\text { Lynch et al. } \\
\text { (2004) }\end{array}$ & Al's Pals & USA & Quasi & 333 & No & Yes & No & No & Primary & Not reported & Weak & $\begin{array}{l}\text { Social and emotional } \\
\text { adjustment }\end{array}$ \\
\hline $\begin{array}{l}\text { Lynch et al. } \\
\text { (2004) }\end{array}$ & Al's Pals & USA & Quasi & 399 & No & Yes & No & No & Primary & Not reported & Weak & $\begin{array}{l}\text { Behavioural adjustment, } \\
\text { social and emotional } \\
\text { adjustment }\end{array}$ \\
\hline $\begin{array}{l}\text { Menard \& } \\
\text { Grotpeter } \\
(2014)\end{array}$ & BPY School & USA & Quasi & 3497 & Yes & Yes & No & Yes & Primary & $\begin{array}{l}\text { Reported } \\
\text { problems }\end{array}$ & Weak & $\begin{array}{l}\text { Behavioural adjustment, } \\
\text { social and emotional } \\
\text { adjustment }\end{array}$ \\
\hline $\begin{array}{l}\text { Roland et al. } \\
\text { (2010) }\end{array}$ & Zero & Norway & Quasi & 20446 & Yes & Yes & No & Yes & Primary & Not reported & Strong & Behavioural adjustment \\
\hline $\begin{array}{l}\text { Wigelsworth } \\
\text { et al. (2012) }\end{array}$ & SEAL & UK & Quasi & 4351 & No & Yes & Yes & Yes & Secondary & Fidelity is fine & Strong & $\begin{array}{l}\text { Behavioural adjustment, } \\
\text { social and emotional } \\
\text { adjustment, } \\
\text { internalizing symptoms }\end{array}$ \\
\hline $\begin{array}{l}\text { Hennessey } \\
(2007)\end{array}$ & Open Circle & USA & Quasi & 154 & No & Yes & Yes & No & Primary & Not reported & Moderate & $\begin{array}{l}\text { Behavioural adjustment, } \\
\text { social and emotional } \\
\text { adjustment, school } \\
\text { performance }\end{array}$ \\
\hline $\begin{array}{l}\text { Hawkins et } \\
\text { al. (2005) }\end{array}$ & $\begin{array}{l}\text { Seattle } \\
\text { Social } \\
\text { Development } \\
\text { Project }\end{array}$ & USA & Quasi & 643 & No & Yes & Yes & Yes & Primary & Fidelity is fine & Strong & $\begin{array}{l}\text { Behavioural adjustment, } \\
\text { internalizing symptoms, } \\
\text { school performance }\end{array}$ \\
\hline $\begin{array}{l}\text { Battistich et } \\
\text { al. (2000) }\end{array}$ & $\begin{array}{l}\text { Child } \\
\text { Development } \\
\text { Project }\end{array}$ & USA & Quasi & 1334 & No & Yes & No & No & Primary & $\begin{array}{l}\text { Reported } \\
\text { problems }\end{array}$ & Weak & $\begin{array}{l}\text { Behavioural adjustment, } \\
\text { social and emotional } \\
\text { adjustment }\end{array}$ \\
\hline $\begin{array}{l}\text { Solomon et } \\
\text { al. (2000) }\end{array}$ & $\begin{array}{l}\text { Child } \\
\text { Development } \\
\text { Project }\end{array}$ & USA & Quasi & 13464 & No & Yes & No & No & Primary & $\begin{array}{l}\text { Reported } \\
\text { problems }\end{array}$ & Moderate & $\begin{array}{l}\text { Behavioural adjustment, } \\
\text { social and emotional } \\
\text { adjustment, } \\
\text { internalizing symptoms, } \\
\text { school performance }\end{array}$ \\
\hline $\begin{array}{l}\text { Kärnä et al. } \\
\text { (2011) }\end{array}$ & KIVA & Finland & RCT & 8273 & Yes & Yes & No & Yes & Both & Not reported & Strong & $\begin{array}{l}\text { Behavioural adjustment, } \\
\text { social and emotional } \\
\text { adjustment }\end{array}$ \\
\hline
\end{tabular}




\begin{tabular}{|c|c|c|c|c|c|c|c|c|c|c|c|c|}
\hline $\begin{array}{l}\text { Catalano et } \\
\text { al. (2003) }\end{array}$ & $\begin{array}{l}\text { Raising } \\
\text { Healthy } \\
\text { Children }\end{array}$ & USA & RCT & 938 & No & Yes & Yes & Yes & Primary & Fidelity is fine & Moderate & $\begin{array}{l}\text { Behavioural adjustment, } \\
\text { social and emotional } \\
\text { adjustment }\end{array}$ \\
\hline $\begin{array}{l}\text { Brown et al. } \\
\text { (2005) }\end{array}$ & $\begin{array}{l}\text { Raising } \\
\text { Healthy } \\
\text { Children }\end{array}$ & USA & RCT & 1040 & No & Yes & Yes & Yes & Primary & Not reported & Strong & $\begin{array}{l}\text { Behavioural adjustment, } \\
\text { school performance }\end{array}$ \\
\hline $\begin{array}{l}\text { Jones et al. } \\
\text { (2010) }\end{array}$ & 4R's & USA & RCT & 942 & No & Yes & No & No & Primary & Fidelity is fine & Strong & $\begin{array}{l}\text { Behavioural adjustment, } \\
\text { social and emotional } \\
\text { adjustment, } \\
\text { internalizing symptoms, } \\
\text { school performance }\end{array}$ \\
\hline $\begin{array}{l}\text { Frey et al. } \\
\text { (2005) }\end{array}$ & $\begin{array}{l}\text { Steps to } \\
\text { Respect }\end{array}$ & USA & RCT & 1126 & Yes & Yes & No & No & Primary & Fidelity is fine & Strong & $\begin{array}{l}\text { Behavioural adjustment, } \\
\text { social and emotional } \\
\text { adjustment }\end{array}$ \\
\hline $\begin{array}{l}\text { Leadbeater } \\
\text { et al. (2011) }\end{array}$ & WITS & Canada & Quasi & 830 & Yes & Yes & Yes & No & Primary & Not reported & Moderate & Behavioural adjustment \\
\hline $\begin{array}{l}\text { Raskauskas } \\
\text { (2007) }\end{array}$ & Kia Kaha & $\begin{array}{l}\text { New } \\
\text { Zealand }\end{array}$ & Quasi & 3155 & Yes & Yes & No & Yes & Both & Not reported & Weak & $\begin{array}{l}\text { Social and emotional } \\
\text { adjustment }\end{array}$ \\
\hline $\begin{array}{l}\text { Kiviruusu et } \\
\text { al. (2016) }\end{array}$ & $\begin{array}{l}\text { Together at } \\
\text { School }\end{array}$ & Finland & RCT & 3704 & No & Yes & No & & Primary & Not reported & Weak & $\begin{array}{l}\text { Behavioural adjustment, } \\
\text { social and emotional } \\
\text { adjustment }\end{array}$ \\
\hline $\begin{array}{l}\text { Cross et al. } \\
\text { (2016) }\end{array}$ & $\begin{array}{l}\text { Cyber } \\
\text { Friendly } \\
\text { Schools }\end{array}$ & Australia & RCT & 2839 & Yes & Yes & Yes & Yes & Secondary & $\begin{array}{l}\text { Reported } \\
\text { problems }\end{array}$ & Weak & $\begin{array}{l}\text { Behavioural adjustment, } \\
\text { social and emotional } \\
\text { adjustment }\end{array}$ \\
\hline $\begin{array}{l}\text { Bonell et al. } \\
\text { (2015) }\end{array}$ & Inclusive & UK & RCT & 1144 & Yes & Yes & Yes & Yes & Secondary & Not reported & Strong & Behavioural adjustment \\
\hline $\begin{array}{l}\text { Dray et al. } \\
\text { (2017) }\end{array}$ & & Australia & RCT & 3630 & Yes & Yes & Yes & Yes & Secondary & Fidelity is fine & Strong & $\begin{array}{l}\text { Behavioural adjustment, } \\
\text { social and emotional } \\
\text { adjustment, } \\
\text { internalizing symptoms }\end{array}$ \\
\hline $\begin{array}{l}\text { Silverthorn } \\
\text { et al. (2017) }\end{array}$ & $\begin{array}{l}\text { Positive } \\
\text { action }\end{array}$ & USA & RCT & 1170 & Yes & Yes & Yes & Yes & Both & Not reported & Moderate & $\begin{array}{l}\text { Behavioural adjustment, } \\
\text { social and emotional } \\
\text { adjustment, school } \\
\text { performance }\end{array}$ \\
\hline
\end{tabular}




\section{Results}

\section{Characteristics of included interventions}

Table 2 provides the summary characteristics for each study included in the meta-analysis. The 45 studies represented 30 different interventions. The total sample across the 45 studies was 496,299 students aged between 4 and 16 years. The number of students per study varied between 150 (Hennessey, 2007) and 300,000 (Kärnä et al., 2011a, b), with a median of 2242 students. All studies included mixed-sex samples. Twenty-five studies (56\%) were carried out outside of the United States. Twenty-eight studies (62\%) employed randomised controlled designs. Only two studies (4\%) presented a clear distinction between post-intervention and follow-up measurement. In total, 28 studies (62\%) reported on social and emotional adjustment outcomes, 41 studies (91\%) reported on behavioural adjustment outcomes, 10 studies (22\%) reported on internalising symptoms outcomes, and 8 studies (18\%) reported on school performance outcomes. Eighteen studies (40\%) reported a high level of programme fidelity, 6 studies (13\%) reported problems with fidelity, and 21 studies (47\%) did not report fidelity. Of the 45 studies, 44 were published in peer-reviewed journals (98\%). Regarding the quality of the evidence, 22 studies (49\%) received a strong quality assessment rating, 15 studies (33\%) received a moderate rating, and 8 studies (18\%) received a weak quality assessment rating.

Seventeen of the whole school interventions were implemented in primary school (57\%), seven interventions (23\%) were implemented in secondary school, and six interventions were implemented across primary and secondary school (20\%). All interventions provided teacher training and a programme manual. Ten interventions (33\%) were aimed at enhancing social and emotional skills and 20 interventions (67\%) were aimed at reducing bullying behaviour through the application of social and emotional skills. All interventions included a classroom curriculum, strategies addressing the whole school ethos and environment, and a parent component. Seventeen interventions (57\%) included a community component. Fourteen interventions (47\%) contained a targeted component aimed at addressing the needs of children at risk of developing emotional or behavioural problems. 


\section{Intervention effects}

At post-intervention, there were a sufficient number of studies for each outcome category. As shown in Table 3, a small, but statistically significant increased mean effect size in the desired direction, was detected for social and emotional adjustment $(d=0.220)$, behavioural adjustment $(d=$ $0.134)$, and internalising symptoms $(d=0.109)$. Across all outcomes the level of heterogeneity was high with 12 ranging from 87.99 to 99.40 . The mean effect size for school performance was not found to be increased significantly ( $d=0.193,95 \% \mathrm{Cl}-0.105$ to $0.490, p=0.204)$. When analysing the results on school performance more extensively, it is found that one highly positive effect size (Snyder et al., 2010) widened the confidence interval of the mean effect size, thus making it nonsignificant. However, based on the standardised residual of this study (1.44), this study was not perceived as an outlier.

Table 3: Effect size by outcome category (excluding outliers)

\begin{tabular}{|c|c|c|c|c|c|c|c|c|c|c|c|}
\hline \multirow[b]{2}{*}{ Outcome } & \multirow[b]{2}{*}{$\mathrm{N}$} & \multicolumn{2}{|c|}{$\begin{array}{l}\text { Effect Size and } \\
\text { Its Standard } \\
\text { Error }\end{array}$} & \multicolumn{2}{|c|}{$\begin{array}{l}\text { 95\% Confidence } \\
\text { Interval }\end{array}$} & \multicolumn{2}{|c|}{$\begin{array}{c}\text { Test of Null } \\
\text { Hypothesis } \\
\text { (2-Tail) }\end{array}$} & \multicolumn{4}{|c|}{ Heterogeneity } \\
\hline & & $d$ & $\mathrm{SE}(d)$ & $\begin{array}{l}\text { Lower } \\
\text { Limit }\end{array}$ & $\begin{array}{l}\text { Upper } \\
\text { Limit }\end{array}$ & $\begin{array}{l}Z \\
\text { value }\end{array}$ & $\begin{array}{l}p \\
\text { value }\end{array}$ & $Q$ & $\begin{array}{l}d f \\
(Q)\end{array}$ & $\begin{array}{l}p \\
\text { value }\end{array}$ & $I^{2}$ \\
\hline $\begin{array}{l}\text { Social and } \\
\text { emotional } \\
\text { adjustment }\end{array}$ & 27 & 0.220 & 0.070 & 0.083 & 0.356 & 3.156 & 0.002 & 4320.5 & 26 & 0.000 & 99.40 \\
\hline $\begin{array}{l}\text { Behavioural } \\
\text { adjustment }\end{array}$ & 39 & 0.134 & 0.030 & 0.076 & 0.193 & 4.552 & 0.000 & 1980.1 & 38 & 0.000 & 98.08 \\
\hline $\begin{array}{l}\text { Internalizing } \\
\text { symptoms }\end{array}$ & 10 & 0.109 & 0.037 & 0.037 & 0.182 & 2.942 & 0.003 & 74.9 & 9 & 0.000 & 87.99 \\
\hline $\begin{array}{l}\text { School } \\
\text { performance }\end{array}$ & 8 & 0.193 & 0.152 & -0.105 & 0.490 & 1.271 & 0.204 & 1126.3 & 7 & 0.000 & 99.38 \\
\hline
\end{tabular}

Visual inspection of the funnel plots (supplementary materials) showed no evidence of publication bias for the outcomes "social and emotional adjustment" and "behavioural adjustment". The distribution of both these outcomes appears close to symmetrical and Egger's regression tests showed no signs of publication bias (respectively $p$ values of 0.28 and 0.33 ). Also, Duval and Tweedie's trim and fill indicated that for both these outcomes, no studies needed to be filled or trimmed. For "school performance", the funnel plot showed more studies to the left of the mean. Egger's regression test was not significant $(p=0.71)$, but Duval and Tweedie's trim and fill analysis indicated that five studies needed to be trimmed, adjusting the effect size to $d=0.605$. For "internalising symptoms", the funnel plot showed more studies to the right of the mean. Egger's regression test was again not significant $(p=0.40)$, but Duval and Tweedie's trim and fill analysis indicated that three studies needed to be trimmed, adjusting the effect size to $d=0.060$. 


\section{$\underline{\text { Moderators of effect sizes }}$}

Moderator analyses were carried out to determine the effect of methodological, intervention, and recipient characteristics on the two most reported outcomes: social and emotional adjustment and behavioural adjustment (Table 4). Regarding methodological characteristics, the moderator "quality assessment" was of significant influence on students' behavioural adjustment $(\mathrm{Q}=9.141, \mathrm{df}=1, p=$ 0.001), with the highest effect sizes reported for studies that received a moderate or weak quality assessment rating ( $d=0.410$ vs $d=0.090$ ). Regarding the intervention characteristics, the inclusion of a community component as part of a whole school intervention was shown to have a significant impact on participants' social and emotional adjustment $(\mathrm{Q}=5.092, \mathrm{df}=1, p=0.024)$. Results indicated that whole school interventions which contained a community component showed significantly higher effect sizes than interventions without a community component $(d=0.447$ vs $d=$ 0.152). Lastly, regarding recipient characteristics, moderator analysis revealed that interventions evaluated in the United States were found to have significantly higher social and emotional effect sizes than whole school interventions evaluated outside of the United States $(d=0.450$ vs $d=0.120$; $\mathrm{Q}=4.255, \mathrm{df}=1, p=0.039$ ).

Table 4: Moderators of effect sizes (including outliers)

\begin{tabular}{|c|c|c|c|c|c|c|c|c|c|}
\hline \multirow{2}{*}{ Moderator } & & \multicolumn{4}{|c|}{ Social and emotional adjustment } & \multicolumn{4}{|c|}{ Behavioural adjustment } \\
\hline & & $\mathrm{N}$ & Cohen's $d$ & $\mathrm{I}^{2}$ & $\mathrm{Z}$ & $\mathrm{N}$ & Cohen's $d$ & $\mathrm{I}^{2}$ & $\mathrm{Z}$ \\
\hline \multicolumn{10}{|c|}{ Intervention characteristics } \\
\hline \multirow{2}{*}{$\begin{array}{l}\text { Behaviour problem } \\
\text { focused }\end{array}$} & Yes & 17 & 0.391 & 99.67 & $4.09 *$ & 28 & 0.216 & 99.62 & $3.32^{*}$ \\
\hline & No & 11 & 0.151 & 49.42 & 1.24 & 13 & 0.256 & 95.36 & $2.62^{*}$ \\
\hline \multirow[t]{2}{*}{ Community component } & Yes & 14 & 0.447 & 99.56 & $4.80 *$ & 18 & 0.248 & 99.00 & $2.96 *$ \\
\hline & No & 14 & 0.152 & 80.78 & 1.66 & 23 & 0.214 & 99.59 & $2.94^{*}$ \\
\hline \multirow[t]{2}{*}{ Targeted component } & Yes & 13 & 0.395 & 99.66 & $3.55^{*}$ & 25 & 0.232 & 99.66 & $3.30^{*}$ \\
\hline & No & 15 & 0.203 & 97.48 & 1.80 & 16 & 0.223 & 93.40 & $2.38^{*}$ \\
\hline \multirow[t]{2}{*}{ Self-report measure } & Yes & 16 & 0.287 & 98.75 & $2.55^{*}$ & 30 & 0.219 & 99.48 & $3.47^{*}$ \\
\hline & No & 12 & 0.321 & 99.70 & $2.37 *$ & 11 & 0.259 & 99.23 & $2.36^{*}$ \\
\hline \multirow[t]{3}{*}{ School } & Primary & 16 & 0.340 & 97.86 & $3.52 *$ & 19 & 0.214 & 93.57 & $2.41^{*}$ \\
\hline & Secondary & 6 & 0.079 & 63.61 & 0.52 & 9 & 0.073 & 82.61 & 0.60 \\
\hline & Both & 6 & 0.423 & 99.79 & $2.85^{*}$ & 13 & 0.357 & 99.83 & $3.52^{*}$ \\
\hline \multicolumn{10}{|c|}{ Recipient characteristics } \\
\hline \multirow[t]{2}{*}{ Country } & USA & 15 & 0.450 & 99.71 & $4.17 *$ & 17 & 0.265 & 99.11 & $2.98^{*}$ \\
\hline & Non-USA & 13 & 0.120 & 72.98 & 1.02 & 24 & 0.204 & 99.57 & $2.74^{*}$ \\
\hline \multicolumn{10}{|c|}{ Methodological characteristics } \\
\hline \multirow[t]{2}{*}{ Design } & RCT & 16 & 0.347 & 99.69 & $3.68 *$ & 25 & 0.275 & 99.64 & $3.57 *$ \\
\hline & Quasi-experimental & 12 & 0.214 & 77.67 & 1.69 & 16 & 0.149 & 75.18 & 1.45 \\
\hline \multirow[t]{3}{*}{ Months pre - post } & 12 or less & 11 & 0.235 & 98.19 & 1.85 & 18 & 0.245 & 99.68 & $2.85^{*}$ \\
\hline & 13 or more & 17 & 0.335 & 99.54 & $3.52 *$ & 21 & 0.208 & 98.80 & $2.68^{*}$ \\
\hline & Not reported & - & - & - & - & 2 & 0.302 & 96.20 & 1.23 \\
\hline \multirow[t]{3}{*}{ Implementation fidelity } & Good & 12 & 0.352 & 99.75 & $2.83 *$ & 16 & 0.176 & 99.64 & $3.84^{*}$ \\
\hline & Reported problems & 4 & 0.188 & 91.23 & 0.85 & 6 & 0.122 & 79.36 & 0.78 \\
\hline & Not reported & 12 & 0.281 & 97.51 & $2.08 *$ & 19 & 0.315 & 99.24 & 1.86 \\
\hline \multirow{2}{*}{ Year of publication } & 2010 or earlier & 15 & 0.366 & 98.72 & $3.22 *$ & 21 & 0.230 & 98.86 & $2.83^{*}$ \\
\hline & 2011 or later & 13 & 0.230 & 99.68 & $1.97 *$ & 20 & 0.229 & 99.65 & $2.85^{*}$ \\
\hline \multirow[t]{2}{*}{ Quality assessment } & Good & 12 & 0.291 & 99.05 & $2.43^{*}$ & 22 & 0.090 & 88.23 & 1.30 \\
\hline & Moderate or weak & 16 & 0.307 & 99.60 & $2.77 *$ & 19 & 0.410 & 99.69 & $5.15^{*}$ \\
\hline
\end{tabular}

Note: random effects model used; $N=$ amount of studies with this characteristic; bold = significant heterogeneity (Q) between groups; $*=$ effect size significant 


\section{Discussion}

International research highlights the importance of implementing social and emotional skill development within the context of a whole school approach which embraces the wider school, family, and community contexts (Barry et al., 2017; Oberle et al., 2016; Jones \& Bouffard, 2012; Weare \& Nind, 2011). Whole school interventions have received significant investment in the past decade; however, their impact remains unclear. The aim of this meta-analysis was to examine the effectiveness of whole school interventions on a range of social, emotional, behavioural, and academic outcomes. Whilst previous meta-analyses have examined the impact of universal social and emotional learning programmes (e.g. Durlak et al., 2011; Sklad et al., 2012; Taylor et al., 2017), this current meta-analysis is, to our knowledge, the first to examine the effectiveness of interventions that adopt a whole school approach to social and emotional skill development. The main findings indicate that whole school interventions yield small, but significant positive effects on social and emotional adjustment, behavioural adjustment, and internalising symptoms. The highest estimate obtained was for social and emotional adjustment $(d=0.220)$, with estimates for behavioural adjustment and internalising symptoms ranging from $0.109-0.134$. Previous metaanalyses of universal social and emotional learning interventions have reported higher effect sizes across social, emotional, behavioural, and academic domains (e.g. Durlak et al., 2011; Sklad et al., 2012).

It is likely that implementation had a significant role to play in the lower effect sizes reported in this current meta-analysis. Findings from implementation science provide evidence on the importance of quality of implementation in producing programme outcomes (Durlak \& DuPre, 2008; Fixsen et al., 2005). Durlak and colleagues' (Durlak et al., 2011) meta-analysis of universal social and emotional skill-based interventions reported that interventions implemented with high quality produced larger effect sizes across all six social, emotional, behavioural, and academic outcomes, compared with interventions implemented with lower quality which only achieved significant effects in two outcome categories (attitudes and conduct problems). Researchers have found that comprehensive school-wide interventions frequently encounter problems with implementation (Durlak \& Dupre, 2008; Wilson \& Lipsey, 2007; Wilson et al. 2003). These interventions require substantial planning and support as skill development extends beyond the classroom, connecting and extending learning through the school ethos and environment and in partnership with families and communities. There is a need for significant infrastructure and capacity to support system-wide implementation of whole school interventions; however, this is often missing (Spoth et al., 2013). One of the interventions 
included in the current meta-analysis (SEAL) was shown to have no impact on students' social and emotional skills (Wigelsworth et al., 2012). A process evaluation revealed that a lack of buy in from staff, perceived need for the programme, insufficient training, and teachers' self-efficacy were all related to variability in the level of implementation of the programme (Lendrum et al., 2013). Implementation research is critical to understanding the range of factors operating at the level of the intervention, provider, community, delivery, and support system which impact the quality with which a programme is implemented.

Results from this meta-analysis revealed whole school interventions did not have a significant impact on academic performance. This finding is in contrast to results from previous meta-analyses, one of which reported an 11 percentile gain in academic achievement among students who received a social and emotional learning intervention (Durlak et al., 2011). A possible explanation for the nonsignificant finding in this meta-analysis is the small number of studies $(N=8)$ in this outcome category. In addition, one study with a large effect size widened the confidence interval of the mean effect size, thus making the mean effect size non-significant. Furthermore, only one of the eight studies utilised standardised achievement test scores as a measure of academic performance. The remaining studies utilised teacher self-report data of academic competence. The low number of studies combined with the use of teacher self-report data weakens the confidence that can be placed in this finding, and as a result, this finding should be viewed with caution.

Moderator analysis indicated that studies from the United States (US) had a significantly higher effect size that non-US studies. Two possible reasons could explain this finding. Weare and Nind (2011) in their review of social and emotional skill-based interventions suggested that, compared with European and Australian interventions, US interventions are more prescriptive in their training, programme manual, and requirements for programme fidelity. They contend that some non-US interventions fail to show impact as a result of their more flexible, bottom-up approach to skill development which can make it difficult for teacher to know what to implement and how it should be implemented. Another possible reason relates to the level of district and national supports for social and emotional learning across countries. It is argued that whole school interventions are most likely to be successful, effective, and sustainable when the necessary support from educational stakeholders at national level is in place (Mart et al., 2015; Barry et al., 2017). Support from the education system at national level has the power to catalyse systemic change at school level by communicating a culture of "what matters" in school learning (Oberle et al., 2016). This support can include advocating for policies that support whole school integration of social and emotional learning, defining age-specific standards for student outcomes across social and emotional learning domains and allocating the required resources for the adoption of evidence-based interventions. All 
of which can assist in creating the necessary conditions for school-wide social and emotional learning. Over the past number of years, the US has made significant advancements in embedding support for social and emotional learning at district and state levels. Examples of such advancements include the development of learning standards for social and emotional skill development (Dusenbury et al., 2015) and the establishment of CASEL's Collaborative Districts Initiative (CDI) and Collaborative States Initiative (CSI) which are designed to build systemic support for social and emotional learning. Further research is required to advance our understanding of the type of support required by schools from the education system to implement evidence-based programmes with high quality and embed them within the school system.

Additional moderator analysis revealed the impact of implementing a community component as part of a whole school approach. Examples of community components included the following: additional support from community specialists for children considered "at risk" of developing problems; the involvement of community members in school components; the implementation of intervention activities through subgroups of the community including community leaders, the media, and social workers. Results from this meta-analysis indicated that the implementation of a community component was associated with a significant higher effect size on children's social and emotional adjustment. This finding highlights the importance of schools working collaboratively with the wider community in reaching out to and receiving support from parents and local agencies. The development of links with community agencies and services has been argued to be the most essential component of the health-promoting school approach (Goltz et al., 1997; Lister-Sharp et al., 1999; WHO, 1996). Community partners provide links with external support and mental health services in the community, thereby ensuring there is access to services for students needing additional support.

Whilst the interventions varied in their inclusion of a community component and what this consisted of, all of the interventions contained a classroom curriculum, a family component, and strategies aimed at enhancing the school ethos and environment. Furthermore, a number of key practices within these components were common across the majority of interventions. At the school level, practices included the following: the provision of a guide to support schools in developing whole school policies based on the intervention's principles; the establishment of a school committee whose goal is to plan and implement the intervention; staff meetings dedicated to planning the whole school approach, monitoring its progress and arranging professional development. The majority of interventions identified in this meta-analysis established school-wide expectations, defined school-wide rules, displayed posters in school corridors that reflected intervention concepts, and implemented a school-wide system of encouraging the use of skills. Whole staff training was a 
feature of all interventions and included the following: training on the application of teaching strategies throughout the school day; instructional methods in interactive teaching, positive communication, problem solving, and cooperative learning; and strategies to support collaboration with parents. Key strategies used to engage parents included letters sent to parents providing information on the intervention's key principles, teacher-parent meetings, the provision of a parent education programme or workshop targeting risk, and protective factors in the home environment.

\section{$\underline{\text { Limitations }}$}

The findings from this meta-analysis need to be interpreted in the context of their limitations. Firstly, just over half of the studies (54\%) received a strong quality assessment rating, the remaining studies received a moderate $(29 \%)$ or weak $(17 \%)$ rating. Moderator analysis revealed studies with a moderate or weak rating showed significantly larger effect sizes for behavioural adjustment than high-quality studies. Lower quality studies were mostly attributed to a high rate of dropout or failure to report dropout at post-intervention. This is an issue which has been identified as one of the most common pitfalls of efficacy trials (Clarke \& Barry, 2015). Accurate reporting of dropout and analysis on the extent to which dropout may have introduced bias is recommended for future studies in order to strengthen the quality of the evidence base. Secondly, although a total of 48 studies were identified for inclusion in the meta-analysis, the number of studies which examined the impact of whole school interventions on academic achievement and internalising outcomes was low. As a result, the power to detect significant effect sizes was reduced. Thirdly, although significant efforts were made to identify every relevant study for this meta-analysis, we cannot be sure that we identified all possible studies, in particular, unpublished studies which have a tendency to report null effects. A final limitation was the search for English-only studies which limits the representativeness and generalisability of the analysis.

\section{Implications for research}

Eight studies (16\%) provided data on academic achievement. These results highlight the need for future studies to examine the impact of whole school interventions on academic achievement. Furthermore, the use of standardised achievement test scores in determining programme impact should be prioritised. Additional research on the long-term impact of whole school interventions is required in order to determine the durability of programme outcomes. Furthermore, whilst there is emerging evidence on the economic case for investing in school-based SEL (e.g. Belfield et al., 2015), cost-benefit analysis of whole school interventions would provide an important insight into their economic returns as educational investments. 
There is a need for future research to identify the essential ingredients/components of whole school interventions that have been found through research to positively affect proximal outcomes. There is a clear overlap in the core components used across whole school interventions. Identifying the components that are essential for building social and emotional skills at the level of the individual, the classroom, the whole school, the family, and the community could facilitate the use of the most effective strategies with the greatest potential for impact. Research on the identification of "essential ingredients" across evidence-based youth mental health treatment and prevention interventions has shown some promising results in this area (e.g. Chorpita \& Daleiden, 2009; Boustani et al., 2015). Knowing the essential components of whole school interventions could assist schools in implementing whole school programme with high quality and at the same time making the necessary adaptations to suit the local context and specific population needs.

The results from this meta-analysis highlight the current lack of emphasis on programme implementation ( $46 \%$ of studies did not monitor programme implementation). Programme outcomes cannot be interpreted appropriately without information on the quality of programme information or the extent of intervention delivery. A greater focus on implementation research is required in order to understand a programme's true value and to offer guidance in terms of continual improvement to programme delivery (Durlak, 2015). Furthermore, there is a need for specific implementation guidelines and tools to support the effective adoption of whole school interventions in natural contexts. CASEL's School Theory of Action (School ToA) resource is an example of a framework which provides specific tools and resources for setting up and sustaining a whole school approach to social and emotional learning (Oberle et al., 2016). Factors known to promote sustainability and impact are addressed, including the following: ongoing professional development, ongoing assessment and evaluation, infrastructure and school-wide integration, family-school-community partnerships, and ongoing communication. The further development and testing of implementation tools and resources are essential in addressing barriers to effective integration of social and emotional learning within the wider school system.

\section{$\underline{\text { Implications for policy and practice }}$}

The findings from this meta-analysis have a number of implications for policy makers and practitioners, responsible for implementing social and emotional skill-based interventions. The successful implementation of evidence-based whole school practices requires individual motivation, individual and organisational capacity, supportive policies, and attention to the challenges involved in changing practices as well as addressing the challenges posed by the need to adapt programmes once implemented (Oberle et al., 2016). In order for whole school interventions to be used more 
widely, further effort is needed to assist schools in selecting an evidence-based intervention that fits their needs, implementing it with quality and adopting methods to sustain the intervention over the long term (Wandersman \& Florin, 2003).

There is also a need for investment in professional development and learning for building organisational capacity in adopting a whole school approach to social and emotional learning. As part of this, there is a need to promote partnerships between teacher preparation programmes, programme developers, and implementation experts to equip trainee teachers with the competencies necessary to embed social and emotional learning within the curriculum and wider school, family, and community contexts. The provision of leadership support and ongoing professional development is also required to support the integration and sustainability of whole school interventions.

\section{Conclusions}

A growing body of research suggests that for optimal impact, social and emotional skill development needs to be embedded within a whole school, multi-modal approach. This approach typically involves coordinated action between curriculum, teaching, and learning; the school ethos and environment; and family and community partnerships. The results from this meta-analysis indicate a small, but significant positive impact of these interventions on students' social and emotional adjustment, behavioural adjustment, and internalising symptoms. Whole school interventions were not shown to impact on academic achievement. Moderator analysis provides evidence that interventions implemented and evaluated in the US were more effective in enhancing participants' social and emotional adjustment than non-US interventions. In order to advance our understanding of the conditions necessary to achieve successful outcomes, a greater focus on implementation research and the identification of essential components of whole school interventions is required. 


\section{References}

Adi, Y., Killoran, A., Janmohamed, K., \& Stewart-Brown, S. (2007a). Systematic review of the effectiveness of interventions to promote mental wellbeing in primary schools: universal approaches which do not focus on violence or bullying. London: National Institute for Health and Clinical Excellence.

Adi, Y., Killoran, A., Janmohamed, K., \& Stewart-Brown, S. (2007b). Systematic review of the effectiveness of interventions to promote mental wellbeing in primary schools: universal approaches with focus on prevention of violence or bullying. London: National Institute for Health and Clinical Excellence.

Barry, M.M., Clarke, A.M., \& Dowling, K. (2017). Promoting social and emotional wellbeing in schools. Health Education, 117(5), 434-451.

Banerjee, R., Weare, K., \& Farr, W. (2014). Working with 'Social and Emotional Aspects of Learning' (SEAL): associations with school ethos, pupils' social experiences, attendance, and attainment. British Education Research Journal, 40(4), 718-742.

Belfield, C., Bowden, B., Klapp, A., Levin, H., Shand, R., \& Zander, S. (2015). The economic value of social and emotional learning. New York: Center for Benefit-Cost Studies in Education Teachers College, Columbia University.

Borenstein,M., Hedges, L.V.,Higgins, J. P.,\& Rothstein,H.R. (2010). A basic introduction to fixedeffect and random effects models for meta-analysis. Research Synthesis Methods, 1(2), 97-111. https://doi.org/10.1002/jrsm.12.

Boustani, M. M., Frazier, S. L.,Becker,K.D., Bechor, M., Dinizulu, S.M., Hedemann, E. R., Ogle, R. R., \& Pasalich, D. S. (2015). Common elements of adolescent prevention programs: minimizing burden while maximizing reach. Administration and Policy in Mental
Health and Mental Health Services Research, 42(2), 209219.

Chorpita, B. F., \& Daleiden, E. L. (2009). Mapping evidence-based treatments for children and adolescents: application of the distillation and matching model of 615 treatments from 322 randomized trials. Journal of Consulting and Clinical Psychology, 7(3), 566579.

Clarke, A. M., \& Barry, M. M. (2015). Supporting a whole school approach to mental health promotion and wellbeing in post-primary schools in Ireland. In S. Kutcher, Y. Wei, \& M. Weist (Eds.), International school mental health for adolescents- global opportunities and challenges. UK: Cambridge Press.

Collaborative for Academic, Social, and Emotional Learning [CASEL]. (2005). Safe and sound: an educational leader's guide to evidence-based social and emotional learning programs. Chicago: Illinois edition.

Dix, K. L., Slee, P. T., Lawson, M. J., \& Keeves, J. P. (2012). Implementation quality of whole-school mental health promotion and students' academic performance. Child and Adolescent Mental Health, 17(1), 45-51.

Durlak, J. A. (2015). What everyone should know about implementation. In J. A. Durlak, C. E. Domitrovich, R. P.Weissberg, \& T. P. Gullotta (Eds.), Handbook of social and emotional learning: research and practice (pp. 482499). New York: Guilford.

Durlak, J. A., \& DuPre, E. P. (2008). Implementation matters: a review of research on the influence of implementation on program outcomes and the factors affecting implementation. American Journal of Community Psychology, 41(3-4), 327-350.

Durlak, J. A., Weissberg, R. P., Dymnicki, A. B., Taylor, R. D., \& Schellinger, K. B. (2011). The impact of enhancing students' social and emotional learning: a meta-analysis of school-based universal interventions. Child Development, 82(1), 405-432. 
Dusenbury, L. A., Newman, J. Z., Weissberg, R., Goren, P., Domitrovice, C. E., \& Mart, A. K. (2015). The case for preschool through to high school state learning standards for SEL. In J. A. Durlak, C. E. Domitrovich, R. P.Weissberg, \& T. P. Gullotta (Eds.), Handbook of social and emotional learning: research and practice (pp. 482499). New York: Guilford.

Duval, S., \& Tweedie, R. (2000). Trim and Fill: a simple funnel-plot-based method of testing and adjusting for publication bias in meta-analysis. Biometrics, 56(2), 455463. https://doi.org/10.1111/j.0006-341X.2000.00455.x. Effective Public Health Practice Project. (1998). Quality assessment tool for quantitative studies. Hamilton. Available from: http://www.ephpp.ca/index.html. Egger, M., Smith, G. D., Schneider, M., \& Martin, M. C. (1997). Bias in meta-analysis detected by a simple, graphical test. British Medical Journal, 315(7109), 629634.

Fixsen, D. L., Naoom, S. F., Blasé, K. A., Friedman, R. M., \& Wallace, F. (2005). Implementation research: $a$ synthesis of the literature. Tampa: University of South Florida, Louis de la Parte Florida Mental Health Institute, The National Implementation Research Network.

Goltz, K., Colquhoun, D., \& Sheehan, M. (1997). Broadening school health education: towards the health promoting school. In D. Colquhoun, K. Goltz, \& M. Sheehan (Eds.), The health promoting school, policy, programmes and practice in Australia. Marrickville: Harcourt Brace and Company.

Goodman, A., Joshi, H., Nasim, B., \& Tyler, C. (2015). Social and emotional skills in childhood and their longterm effects on adult life. London: Institute of Education.

Hallam, S. (2009). An evaluation of the Social and Emotional Aspects of Learning (SEAL) programme: promoting positive behaviour, effective learning and well-being in primary school children. Oxford Review of Education, 35(3), 313-330.
Hennessey, B. A. (2007). Promoting social competence in school-aged children: the effects of the open circle program. Journal of School Psychology, 45(3), 349-360. https://doi.org/10.1016/j.jsp.2006.11.007.

Higgins, J. P. T., Thompson, S. G., Deeks, J. J., \& Altman, D. G. (2003). Measuring inconsistency in meta-analyses. British Medical Journal, 327(7414), 557-560.

Jackson, N., \& Waters, E. (2005). Criteria for the systematic review of health promotion and public health interventions. Health Promotion International, 20(4), 367-374.

Jane-Llopis, E., Barry, M. M., Hosman, C., \& Patel, V. (2005). Mental health promotion works: a review. Promotion \& Education, 12(Suppl 2), 9-25.

Jones, S. M., \& Bouffard, S. M. (2012). Social and emotional learning in schools: from programs to strategies: social policy report. Society for Research in Child Development, 26(4), 3-22.

Langford, R., Bonell, C., Jones, H., Pouliou, T., Murphy, S., Waters, E., Komro, K., Gibbs, L., Magnus, D., \& Campbell, R. (2015). The World Health Organization's Health Promoting Schools framework: a Cochrane systematic review and meta-analysis. BMC Public Health, 15(1), 130.

Lendrum, A., Humphrey, N., \& Wigelsworth, M. (2013). Social and emotional aspects of learning (SEAL) for secondary schools: implementation difficulties and their implications for school-based mental health promotion. Child and Adolescent Mental Health, 18(3), 158-164.

Lipsey, M. W., \& Wilson, D. B. (1993). The efficacy of psychological, educational, and behavioral treatment: confirmation from meta-analysis. American Psychologist, 48(12), 1181-1209.

Lister-Sharp, D., Chapman, S., Stewart-Brown, S., \& Sowden, A. (1999). Health promoting schools and health promotion in schools: two systematic reviews. Health Technology Assessment, 3(22), 1-207. 
Mart, A. K., Weissberg, R. P., \& Kendziora, K. (2015). Systemic support for social and emotional learning in school districts. In J. A. Durlak, C. E. Domitrovich, R. P. Weissberg, \& T. P. Gullotta (Eds.), Handbook of social and emotional learning: research and practice (pp. 482499). New York: Guilford.

Meyers, D. C., Gil, L., Cross, R., Keister, S., Domitrovich, C. E., \& Weissberg, R. P. (2015). CASEL guide for schoolwide social and emotional learning. Chicago: CASEL.

Moher, D., Liberati, A., Tetzlaff, J., Altman, D. G., \& The PRISMA Group. (2009). Preferred reporting items for systematic reviews and meta-analyses: the PRISMA statement. PLoS Medicine, 6(7), e1000097. https://doi.org/10.1371/journal.pmed.1000097.

Morris, S. B. (2008). Estimating effect sizes from pretestposttest-control group designs. Organizational Research Methods, 11(2), 364-386.

Oberle, E., Domitrovich, C. E., Meyers, D. C., \& Weissberg, R. P. (2016). Establishing systemic social and emotional learning approaches in schools: a framework for schoolwide implementation. Cambridge Journal of Education, 46(3), 277-297.

OECD. (2015). Skills for social progress: the power of social and emotional skills. Paris: OECD Publishing. https://doi.org/10.1787/9789264226159-en.

Payton, J., Weissberg, R. P., Durlak, J. A., Dymnicki, A. B., Taylor, R. D., Schellinger, K. B., \& Pachan, M. (2008). The positive impact of social and emotional learning for kindergarten to eighth-grade students: findings from three scientific reviews. Chicago: Collaborative for Academic, Social, and Emotional Learning.

Sklad, M., Diekstra, R., Gravesteijn, C.M., Ben, J., \& Ritter, M. (2012). Effectiveness of school-based universal social, emotional and behavioral programs: do they enhance students' development in the area of skill, behavior, and adjustment? Psychology in the Schools, 49(9), 892-909.
Solomon, B. G., Klein, S. A., Hintze, J. M., Cressey, J. M., \& Peller, S. L. (2012). A meta-analysis of schoolwide positive behavior support: an exploratory study using single-case synthesis. Psychology in Schools, 49(2), 105121. https://doi.org/10.1002/pits.20625.

Spoth, R., Rohrbach, L. A., Greenberg, M., Leaf, P., Brown, C. H., Fagan, A., Catalano, R. F., Pentz, M. A., Sloboda, Z., Hawkins, J. D., \& Society for Prevention Research Type 2 Translational Task Force Members and Contributing Authors. (2013). Addressing core challenges for the next generation of type 2 translation research and systems: the Translation Science to Population Impact (TSci Impact) framework. Prevention Science, 14(4), 319-351.

https://doi.org/10.1007/s11121-012-0362-6.

Taylor, R. D., Oberle, E., Durlak, J. A., \& Weissberg, R. P. (2017). Promoting positive youth development through school-based social and emotional learning interventions: a meta-analysis of follow-up effects. Child Development, 88(4), 1156-1171.

https://doi.org/10.1111/cdev.12864.

Tennant, R., Goens, C., Barlow, J., Day, C., \& StewartBrown, S. (2007). A systematic review of reviews of interventions to promote mental health and prevent mental health problems in children and young people. Journal of Public Mental Health, 6(1), 25-32.

Ttofi, M. M., \& Farrington, D. P. (2011). Effectiveness of school-based programs to reduce bullying: a systematic and meta-analytic review. Journal of Experimental Criminology, 7(1), 27-56. https://doi.org/10.1080/1754730X.2008.9715730. Wandersman, A., \& Florin, P. (2003). Community interventions and effective prevention. American Psychologist, 58(6-7), 441-448.

Weare, K., \& Nind, M. (2011). Mental health promotion and problem prevention in schools: what does the evidence say? Health Promotion International, 26(1), 29-69. 
Wells, J., Barlow, J., \& Stewart-Brown, S. (2003). A systematic review of universal approaches to mental health promotion in schools. Health Education, 103(4), 197-220.

Wilson, S. J., \& Lipsey, M.W. (2007). School-based interventions for aggressive and disruptive behavior: update of a meta-analysis. American Journal of Preventive Medicine, 33, 130-143.

Wilson, S. J., Lipsey, M. W., \& Derzon, J. H. (2003). The effects of school-based intervention programs on aggressive behavior: a meta-analysis. Journal of Consulting and Clinical Psychology, 71(1), 136-149. https://doi.org/10.1037/0022-006X.71.1.136.

World Health Organization. (1996). The status of school health. Geneva: WHO.

World Health Organization (WHO). (1998). Health Promoting evaluation: recommendations for PolicyMakers, report of the WHO European Working Group on Health Promotion Evaluation. Copenhagen: WHO.

Wyn, J., Cahill, H., \& Holdsworth, R. (2000).

MindMatters, a whole-school approach promoting mental health and wellbeing. Australian \& New Zealand Journal of Psychiatry, 34(4), 594-601.

\section{References: studies included in the meta-analysis}

Amundsen, E. J., \& Ravndal, E. (2010). Does successful school-based prevention of bullying influence substance use among 13- to 16-year-olds? Drugs: Education,

Prevention \& Policy, 17(1), 42-54.

Battistich, V., Schaps, E.,Watson,M., Solomon, D., \& Lewis, C. (2000). Effects of the child development project on students' drug use and other problem behaviors. Journal of Primary Prevention, 21(1), 75-99. https://doi.org/10.1023/A:1007057414994.

Bauer, N. S., Lozano, P., \& Rivara, F. P. (2007). The effectiveness of the Olweus Bullying Prevention Program in public middle schools: a controlled trial. Journal of Adolescent Health, 40(3), 266-274.

https://doi.org/10.1016/j.jadohealth.2006.10.005.
Bavarian, N., Lewis, K.M., DuBois, D. L., Acock, A., Vuchinich, S., Silverthorn, N., Snyder, F. J., Day, J., Ji, P., \& Flay, B. R. (2013). Using social-emotional and character development to improve academic outcomes: a matched-pair, cluster-randomized controlled trial in low-income, urban schools. The Journal of School Health, 83(11), 771-779.

https://doi.org/10.1111/josh.12093.

Beran, T. N., Tutty, L., \& Steinrath, G. (2004). An evaluation of a bullying prevention program for elementary schools. Canadian Journal of School Psychology, 19(1-2), 99-116.

https://doi.org/10.1177/082957350401900105.

Bond, L., Patton, G., Glover, S., Carlin, J., Butler, H., Thomas, L., \& Bowes, G. (2004). The Gatehouse Project: can a multilevel school intervention affect emotional wellbeing and health risk behaviours? Journal of Epidemiology and Community Health, 58(12), 997-1003. https://doi.org/10.1136/jech.2003.009449.

Bonell, C., Fletcher, A., Fitzgerald-Yau, N., Hale, D., Allen, E., Elbourne, D., Jones, R., Bond, L., Wiggins, M., Miners, A., Legood, R., Scott, S., Christie, D., \& Viner, R. (2015). Initiating change locally in bullying and aggression through the school environment (INCLUSIVE): a pilot randomized controlled trial. Health Technology Assessment, 19(53), ISSN 1366-5278), 1-110.

Brown, E. C., Catalano, R. F., Fleming, C. B., Haggerty, K. P., \& Abbott, R. D. (2005). Adolescent substance use outcomes in the Raising Healthy Children project: a twopart latent growth curve analysis. Journal of Consulting and Clinical Psychology, 73(4), 699-710.

Brown, E. C., Low, S., Smith, B. H., \& Haggerty, K. P. (2011). Outcomes from a school-randomized controlled trial of Steps to Respect: a bullying prevention program. School Psychology Review, 40(3), 423-443.

Catalano, R. F., Mazza, J. J., Harachi, T. W., Abbott, R. D., Haggerty, K. P., \& Fleming, C. B. (2003). Raising healthy children through enhancing social development in elementary school: results after 1.5 years. Journal of 
School Psychology, 41(2), 143-164.

https://doi.org/10.1016/S0022-4405(03)00031-1.

Conduct Problems Prevention Research Group. (2010).

The effects of a multiyear universal social-emotional

learning program: the role of student and school

characteristics. Journal of Consulting and Clinical

Psychology, 78(2), 156-168.

https://doi.org/10.1037/a0018607.

Cross, D.,Monks, H., Hall,M., Shaw, T., Pintabona, Y., Erceg, E., Hamilton, G. J., Roberts, C.,Waters, S. K., \& Lester, L. (2011). Three-year results of the Friendly Schools whole-of-school intervention on children's bullying behaviour. British Educational Research Journal, 37(1), 105-129.

https://doi.org/10.1080/01411920903420024.

Cross, D., Shaw, T., Hadwen, K., Cardoso, P., Slee, P., Roberts, C., Thomas, L., \& Barnes, A. (2016). Longitudinal impact of the Cyber Friendly Schools program on adolescents' cyberbullying behavior. Aggressive Behaviour, 42(2), 166-180.

https://doi.org/10.1002/ab.21609.

Dray, J., Bowman, J., Campbell, E., Freund, M., Hodder, R., Wolfenden, L., Richards, J., Leane, C., Green, S., Lecathelinais, C., Oldmeadow, C., Attia, J., Gillham, K., \& Wiggers, J. (2017). Effectiveness of a pragmatic schoolbased universal intervention targeting student resilience protective factors in reducing mental health problems in adolescents. Journal of Adolescence, 57(Supplement C), 74-89.

https://doi.org/10.1016/j.adolescence.2017.03.009.

Eisen, M., Zellman, G. L., \& Murray, D. M. (2003).

Evaluating the Lions-Quest "Skills for Adolescence" drug education program: second-year behavior outcomes.

Addictive Behaviors, 28(5), 883-897.

https://doi.org/10.1016/S0306-4603(01)00292-1.

Flay, B. R., Graumlich, S., Segawa, E., Burns, J. L., Holliday, M. Y., \& for the Aban Aya Investigators. (2004). Effects of 2 prevention programs on high-risk behaviors among African American youth: a randomized trial.
Archives of Pediatrics \& Adolescent Medicine, 158(4), 377-384. https://doi.org/10.1001/archpedi.158.4.377.

Fonagy, P., Twemlow, S. W., Vernberg, E. M., Nelson, J. M., Dill, E. J., Little, T. D., \& Sargent, J. A. (2009). A cluster randomized controlled trial of child-focused psychiatric consultation and a school systems-focused intervention to reduce aggression. Journal of Child Psychology and Psychiatry, 50(5), 607-616. https://doi.org/10.1111/j.1469-7610.2008.02025.x. Frey, K. S., Hirschstein, M. K., Snell, J. L., Edstrom, L. V. S., MacKenzie, E. P., \& Broderick, C. J. (2005). Reducing playground bullying and supporting beliefs: an experimental trial of the steps to respect program. Developmental Psychology, 41(3), 479-490. https://doi.org/10.1037/0012-1649.41.3.479. Gradinger, P., Yanagida, T., Strohmeier, D., \& Spiel, C. (2015). Prevention of cyberbullying and cyber victimization: evaluation of the ViSC social competence program. Journal of School Violence, 14(1), 87-110. https://doi.org/10.1080/15388220.2014.963231. Hawkins, J. D., Kosterman, R., Catalano, R. F., Hill, K. G., \& Abbott, R. D. (2005). Promoting positive adult functioning through social development intervention in childhood: long-term effects from the Seattle Social Development Project. Archives of Pediatrics and Adolescent Medicine, 159(1), 25-31.

Hoglund, W. L. G., Hosan, N. E., \& Leadbeater, B. J. (2012). Using your WITS: A 6-year follow-up of a peer victimization prevention program. School Psychology Review, 41(2), 193-214.

Jones, S. M., Brown, J. L., Hoglund, W. L. G., \& Aber, J. L. (2010). A school-randomized clinical trial of an integrated social-emotional learning and literacy intervention: impacts after 1 school year. Journal of Consulting and Clinical Psychology, 78(6), 829-842. https://doi.org/10.1037/a0021383.

Kärnä, A., Voeten, M., Little, T. D., Poskiparta, E., Alanen, E., \& Salmivalli, C. (2011a). Going to scale: a nonrandomized nationwide trial of the KiVa antibullying 
program for grades 1-9. Journal of Consulting and Clinical Psychology, 79(6), 796-805.

Kärnä, A., Voeten, M., Little, T. D., Poskiparta, E., Kaljonen, A., \& Salmivalli, C. (2011b). A large-scale evaluation of the KiVa antibullying program: grades 4-6. Child Development, 82(1), 311-330. https://doi.org/10.1111/j.1467-8624.2010.01557.x.

Kärnä, A., Voeten,M., Little, T. D., Alanen, E., Poskiparta, E., \& Salmivalli, C. (2013). Effectiveness of the KiVa Antibullying Program: grades 1-3 and 7-9. Journal of Educational Psychology, 105(2), 535-551. https://doi.org/10.1037/a0030417.

Kiviruusu, O., Björklund, K., Koskinen, H. L., Liski, A., Lindblom, J., Kuoppamäki, H., Alasuvanto, P., Ojala, T., Samposalo, H., Harmes, N., Hemminki, E., Punamäki, R., Sund, R., \& Santalahti, P. (2016). Short-term effects of the "Together at School" intervention program on children's socio-emotional skills: a cluster randomized controlled trial. BMC Psychology, 4(1), 27. https://doi.org/10.1186/s40359-016-0133-4.

Leadbeater, B., \& Sukhawathanakul, P. (2011).

Multicomponent programs for reducing peer victimization in early elementary school: a longitudinal evaluation of the WITS Primary Program. Journal of Community Psychology, 39(5), 606-620. https://doi.org/10.1002/jcop.20447.

Lee, P. C., \& Stewart, D. E. (2013). Does a socioecological school model promote resilience in primary schools? Journal of School Health, 83(11), 795-804. https://doi.org/10.1111/josh.12096.

Lewis, K. M., Bavarian, N., Snyder, F. J., Acock, A., Day, J., DuBois, D. L., Ji, P., Schure,M. B., Silverthorn, N., Vuchinich, S., \& Flay, B. R. (2012). Direct and mediated effects of a social-emotional and character development program on adolescent substance use. The International Journal of Emotional Education, 4(1), 56-78.

Lewis, K. M., DuBois, D. L., Bavarian, N., Acock, A., Silverthorn, N., Day, J., Ji, P., Vuchinich, S., \& Flay, B. R. (2013a). Effects of positive action on the emotional health of urban youth: a cluster-randomized trial. Journal of Adolescent Health, 53(6), 706-711. https://doi.org/10.1016/j.jadohealth.2013.06.012. Lewis, K. M., Schure, M. B., Bavarian, N., DuBois, D. L., Day, J., Ji, P., Silverthorn, N., Acock, A., Vuchinich, S., \& Flay, B. R. (2013b). Problem behavior and urban, lowincome youth: a randomized controlled trial of positive action in Chicago. American Journal of Preventive Medicine, 44(6), 622-630. https://doi.org/10.1016/j.amepre.2013.01.030. Lewis, K. M., Vuchinich, S., Ji, P., DuBois, D. L., Acock, A., Bavarian, N., Day, J., Silverthorn, N., \& Flay, B. R. (2015). Effects of the Positive Action program on indicators of positive youth development among urban youth. Applied Developmental Science, 20(1), 16-28. https://doi.org/10.1080/10888691.2015.1039123. Lynch, K. B., Geller, S. R., \& Schmidt, M. G. (2004). Multiyear evaluation of the effectiveness of a resilience based prevention program for young children. Journal of Primary Prevention, 24(3), 335-353. https://doi.org/10.1023/B:JOPP.0000018052.12488.d1. Menard, S., \& Grotpeter, J. K. (2014). Evaluation of BullyProofing Your School as an elementary school antibullying intervention. Journal of School Violence, 13(2), 188-209.

https://doi.org/10.1080/15388220.2013.840641.

Patton, G. C., Bond, L., Carlin, J. B., Thomas, L., Butler, H., Glover, S., Catalano, R., \& Bowes, G. (2006). Promoting social inclusion in schools: a grouprandomized trial of effects on student health risk behavior and well-being. American Journal of Public Health, 96(9), 1582-1587.

https://doi.org/10.2105/AJPH.2004.047399.

Raskauskas, J. (2006). Evaluation of the Kia Kaha Antibullying Programme for students in years 5-8. New Zealand Police, Wellington, New Zealand.

Roland, E., Bru, E., Midthassel, U. V., \& Vaaland, G. S. (2010). The Zero programme against bullying: effects of the programme in the context of the Norwegian 
manifesto against bullying. Social Psychology of

Education, 13(1), 41-55.

https://doi.org/10.1007/s11218-009-9096-0.

Salmivalli, C., Kärnä, A., \& Poskiparta, E. (2011).

Counteracting bullying in Finland: the KiVa program and its effects on different forms of being bullied.

International Journal of Behavioral Development, 35(5), 405-411.

Silverthorn, N., DuBois, D. L., Lewis, K. M., Reed, A., Bavarian, N., Day, J., Ji, P., Acock, A. C., Vuchinich, S., \& Flay, B. R. (2017). Effects of a school-based socialemotional and character development program on selfesteem levels and processes: a cluster-randomized controlled trial. SAGE Open, 7(3), 215824401771323. https://doi.org/10.1177/2158244017713238.

Snyder, F., Flay, B., Vuchinich, S., Acock, A., Washburn, I., Beets, M., \& Li, K.-K. (2010). Impact of a social-emotional and character development program on school-level indicators of academic achievement, absenteeism, and disciplinary outcomes: a matched-pair, cluster randomized, controlled trial. Journal of Research on Educational Effectiveness, 3(1), 26-55.

https://doi.org/10.1080/19345740903353436.

Snyder, F. J., Vuchinich, S., Acock, A., Washburn, I. J., \& Flay, B. R. (2012). Improving elementary school quality through the use of a social-emotional and character development program: a matched-pair, clusterrandomized, controlled trial in Hawai'i. The Journal of School Health, 82(1), 11-20. https://doi.org/10.1111/j.1746-1561.2011.00662.x. Solomon, D., Battistich, V., Watson, M., Schaps, E., \& Lewis, C. (2000). A six-district study of educational change: direct and mediated effects of the child development project. Social Psychology of Education, 4(1), 3-51. https://doi.org/10.1023/A:1009609606692. Stevens, V., De Bourdeaudhuij, I., \& Van Oost, P. (2000). Bullying in Flemish schools: an evaluation of antibullying intervention in primary and secondary schools. British
Journal of Educational Psychology, 70(2), 195-210. https://doi.org/10.1348/000709900158056.

Washburn, I. J., Acock, A., Vuchinich, S., Snyder, F., Li, K.K., Ji, P., Day, J., DuBois, D., \& Flay, B. R. (2011). Effects of a social-emotional and character development program on the trajectory of behaviors associated with social-emotional and character development: findings from three randomized trials. Prevention Science, 12(3), 314-323. https://doi.org/10.1007/s11121-011-0230-9.

Wigelsworth, M., Humphrey, N., \& Lendrum, A. (2012). A national evaluation of the impact of the secondary social and emotional aspects of learning (SEAL) programme. Educational Psychology, 32(2), 213-238. https://doi.org/10.1080/01443410.2011.640308. Williford, A., Boulton, A., Noland, B., Little, T. D., Kärnä, A., \& Salmivalli, C. (2012). Effects of the KiVa antibullying program on adolescents' depression, anxiety, and perception of peers. Journal of Abnormal Child Psychology, 40(2), 289-300. https://doi.org/10.1007/s10802-011-9551-1. Williford, A., Elledge, L. C., Boulton, A. J., DePaolis, K. J., Little, T. D., \& Salmivalli, C. (2013). Effects of the KiVa Antibullying Program on cyberbullying and cybervictimization frequency among Finnish youth. Journal of Clinical Child and Adolescent Psychology, 42(6), 820-833. https://doi.org/10.1080/15374416.2013.787623. Wong, D. S. W., Cheng, C. H. K., Ngan, R. M. H., \& Ma, S. K. (2011). Program effectiveness of a restorative wholeschool approach for tackling school bullying in Hong Kong. International Journal of Offender Therapy and Comparative Criminology, 55(6), 846-862. https://doi.org/10.1177/0306624X10374638.

Yang, A., \& Salmivalli, C. (2015). Effectiveness of the KiVa antibullying programme on bully-victims, bullies and victims. Educational Research, 57(1), 80-90. https://doi.org/10.1080/00131881.2014.983724. 


\section{Chapter 3:}

\section{Positive Educative Programme, a whole school approach to supporting children's well-being and}

\section{creating a positive school climate: a pilot study}

Elfrink, T. R., Goldberg, J. M., Schreurs, K. M. G., Bohlmeijer, E. T., \& Clarke, A. M. (2017). Positive educative programme: A whole school approach to supporting children's well-being and creating a positive school climate: a pilot study. Health Education, 117(2), 215-230. https://doi.org/10.1108/HE09-2016-0039 


\section{Abstract}

Purpose - The purpose of this paper is to report on a process and impact evaluation of the Positief Educatief Programma (Positive Education Programme (PEP)), a whole school approach to supporting children's well-being and creating a positive school climate in primary schools in the Netherlands. PEP adopts a competence skill enhancement approach with a focus on developing children's positive emotions and strengths.

Design/methodology/approach - A process and impact evaluation was performed within the context of two schools piloting the programme. Employing questionnaires and interviews, the evaluation sought to examine the implementation of PEP, participants' experiences with key components and the programme impact of PEP.

Findings - The findings reveal largely positive attitudes towards PEP. Staff and parents were positive about the core components of PEP. Results from standardised questionnaires provide preliminary evidence about the positive impact of PEP on children's self-reported well-being and problem behaviour, teachers' awareness of children's strengths and overall school climate. The provision of practical strategies and activity-based resources was considered essential to the ongoing implementation of PEP.

Research limitations/implications - This study reports on findings from two implementation schools and therefore lacks generalisability. Further research using more robust research methods exploring the effectiveness of PEP when compared with "business as usual" is needed.

Originality/value - School frameworks aimed at creating a positive school climate and promoting well-being at the whole school level have not been carried out in the Netherlands to date. The results from this study provide a unique insight into the implementation and perceived impact of a whole school framework in the context of two primary schools. 


\section{Introduction}

Mental health and mental illness are two related but different dimensions (Keyes, 2005). Decreasing mental illness and increasing positive mental, emotional, psychological and social health and wellbeing are bothcrucial for improving mental health (Westerhof and Keyes, 2010). Positive psychology specifically addresses the promotion of well-being and personal development (Bohlmeijer et al., 2013). Seligman and Csikszentmihalyi (2000) present positive psychology as the science of well-being and optimal functioning, with a focus on promoting positive emotions and positive traits.

In recent years, there has been increasing interest in the application of positive psychology in schools (Gilman et al., 2009; Seligman et al., 2009). Positive psychology in education is concerned with the development of students' strengths and well-being and thereby enabling students to flourish. Keyes (2002) describes flourishing as the presence of positive feelings about oneself and life (emotional well-being), feeling connected to others (social well-being) and functioning well (psychological wellbeing). Seligman (2011) names five specific elements that contribute to this state of optimal wellbeing: positive emotion, engagement, relationships, meaning and accomplishment. A key tenet within the field of positive education is that those elements that promote well-being can be explicitly taught through the implementation of positive psychology programmes, activities and practices aimed a cultivating positive feelings, positive behaviour or positive cognitions (Sin and Lyubomirsky, 2009; Norrish and Vella-Brodrick, 2009; Seligman et al., 2009).

There is accumulating evidence regarding the positive impact of student well-being on student learning. Positive mood has been shown to produce broader attention and more creative and holistic thinking (Fredrickson, 2001; Fredrickson and Branigan, 2005; Rowe et al., 2007; Estrada et al., 1994; Isen et al., 1991; Kuhl, 2000). Research also suggests that learning optimism skills can prevent anxiety and depression in children and adults (Seligman, 2007). In a recent review of 12 international schoolbased positive psychology interventions aimed at cultivating positive emotions, resilience and positive character strengths, Waters (2011) found that positive psychology interventions were significantly related to improved student well-being, relationships and academic performance.

To date, the implementation of positive psychology in schools has primarily taken place at the level of the classroom, with relatively short curriculum-based interventions being taught in isolation. Research, however, recommends an integrated or whole school approach to strengthen the wellbeing of pupils in education (Weare and Nind, 2011; Seligman et al., 2009; Bolier et al., 2013; Dix et al., 2012). This approach moves beyond a focus on the classroom curriculum to consider the broader, more holistic aspect of the school setting (Barry and Jenkins, 2007; Clarke and Barry, 2015a). The 
whole school approach attempts to shape the whole school context, including the school's organisation, management structures, relationships and physical environment as well as the curriculum and pedagogic practices (Weare and Markham, 2005). This approach aims to include all relevant stakeholders including pupils, teachers, school administrators, parents and community members in fostering a positive school environment, ethos and sense of connectedness for pupils and staff (Barry and Jenkins, 2007). Norrish et al. (2013) developed such an applied whole school framework for positive education, the Geelong Grammar School Model for Positive Education. This applied framework works around six domains central to well-being (positive emotions, positive engagement, positive accomplishment, positive purpose, positive relationships, and positive health) which are comparable to the five aforementioned elements of Seligman (2011), and all underpinned by a focus on character strengths.

\section{Background of the current study}

This paper reports on a process and impact evaluation of the Positief Educatief Programma (Positive Education Programme (PEP)), a whole school approach to positive education for primary schools in the Netherlands. The programme was developed by the University of Twente in response to a request from a foundation, working with 33 schools in the region to develop a whole school framework aimed at supporting children's well-being and happiness. Norrish et al. (2013) developed an applied model for positive education derived from positive psychology, on which the philosophy behind PEP is based. PEP adopts a skill enhancement approach with a focus on improving children's well-being and creating a positive school climate. PEP consists of four core components: values, life rules, well-being and engagement and parental engagement (see methods section). Schools are provided with a framework which consists of: an overview of the rationale and goals of the initiative; a series of training workshops that upskills teachers in the enhancement of children's well-being and engagement; and a set of resources to implement a coordinated set of strategies to address the needs of their student population. A core component of PEP is teachers' assessment of the level of children's well-being and engagement using an assessment tool called Looqin. When teachers assess that the level of well-being or engagement of a child falls below a certain threshold, they are encouraged to apply an intervention to enhance the child's skills. This is supported by an online resource with over 100 possible activities. The assessment procedures and online resource have been developed by the University of Leuven (Laevers and Aerden, n.d.).

In the first year of PEP, the programme was implemented in two primary schools in the Netherlands. A process and impact evaluation examining the implementation of the programme in the two schools was carried out over the course of one academic year (September 2014 through June 2015). Fixsen 
et al. (2005) describe implementation as a specified set of activities designed to put into practice an activity or programme of known dimensions. From a research perspective, implementation research enhances our ability to map the critical connections between the local context, intervention activities and the intended outcomes. Implementation information allows for greater understanding of the internal dynamics and operations of interventions, how the intervention components fit together, how the implementers and intervention recipients interact and the obstacles they face and resolve in the process (Clarke and Barry, 2015b; Barry and Jenkins, 2007; Greenberg et al., 2001). The specific aim of this study was to examine how PEP was implemented in the two schools and the impact of the programme on pupils' social and emotional skills from the perspective of the teachers and parents.

\section{Methods}

\section{$\underline{\text { Research design and sample }}$}

An internal process and impact evaluation was employed to investigate the implementation of PEP within two schools in Enschede, the Netherlands. PEP was developed, implemented and evaluated by a group of researchers from the University of Twente. The foundation of the regional schools selected one representative rural and one representative urban school to participate in the study. School A was a primary school based in a village in the region of Twente. At the beginning of PEP, there were 151 pupils attending School A, divided over seven classes. The staff of School A consisted of 11 members, of which nine were classroom teachers. School B was an urban-based school in a town in the region of Twente. School B had 188 pupils at the time of baseline data collection. In school B, there were 22 teaching staff, of which ten were classroom teachers.

Since the intervention used a whole school approach all pupils (age range 4-12) and classes (one to eight) participated in PEP and were given a personal code which they could use to take part in the research anonymously. Before filling out the questionnaires at T0 and T1 the parents/teachers were asked to fill in this unique code. All parents were informed about PEP via a letter. Informed consent was received from the parents of 184 out of a total of 339 children across the two schools (54 per cent). All staff from both schools participated in PEP $(N=33)$.

\section{The intervention}

PEP consists of the following components.

Values workshop 
The implementation of the first component consisted of introducing PEP and identifying values. This one day collective workshop, which took place in September 2014, was led by an external experienced trainer. Following a step-by-step guide, the teachers from both schools first identified their most important values as a teacher and second what they saw as the most important values for their schools. Both the schools discussed the findings amongst their teams and decided on their core values.

\section{Life rules workshop}

At the next joint meeting in November 2014, which was a six hour workshop, the values identified were translated into positive "Life rules", designed to make it clear which behaviour was expected from the pupils and staff. A few weeks later the staff members set goals regarding the "Life rules" based on instructions provided by the trainer. Subsequently, the staff made action plans and thought about possible activities and lessons for the life rule they wanted to start with. Both of the schools focussed on compliments. In the first number of months, the school implemented classroom and whole school activities around the first life rule: "Everybody gets happy from a compliment of mine". Later on, they continued on with a second life rule: "When I do something, I think before I act" (School A) and "Working together counts at our school" (School B).

\section{Well-being and engagement workshop}

In January 2015 the teachers from both schools were jointly trained throughout a day by trainers from CEGO Leuven (Centrum Ervaringsgericht Onderwijs) in the use of Looqin (Laevers and Aerden, n.d.), an evidence-based student tracking system which focusses on well-being and engagement. By observing and ranking the children on a five-point scale, the teachers examined how a pupil is doing in terms of well-being and engagement (see Appendix). Teachers can keep track of the observations and can undertake action when there is a score under 4. By scoring regularly, the teachers can intervene when it is necessary and can adjust their strategies. Looqin also provides multiple ideas for strategies or actions to carry out at the individual child level as well as the grade level. As part of a follow up to the training, teachers were asked to film their class and discuss the scores in team meetings with the support of trainers. This follow up was designed to assist teachers in improving their skills in assessing and scoring children's well-being and engagement.

\section{Parental meeting}

In January 2015 the researchers organised parental meetings of two hours. The purpose of those evenings was to inform and teach parents about PEP, giving and receiving compliments, and supporting children's well-being and engagement. After the meeting, parents were provided with a 
handout with included information and tips for supporting children's well-being at home. PEP was also mentioned as a recurrent theme in other appointments between the school and parents.

Instruments. This process and impact evaluation employed both quantitative and qualitative techniques, including a series of questionnaires and interviews to examine the implementation of PEP, participants' experience with key components, and programme impact.

\section{Workshop questionnaires}

On completion of each training workshop, teachers were asked to complete a questionnaire which was designed to ascertain their opinion about the workshops on a scale of 1-5. Parents also completed a similar questionnaire after the parent workshop. In June, at the end of the academic year, school staff completed a review questionnaire which examined their overall experience of implementing PEP over the course of the academic year.

\section{Interviews}

A total of 19 semi-structured interviews were conducted. Eight teacher interviews (four per school) were carried out in February 2015 and seven teacher interviews were carried out in June 2015 (four teachers from School A and three teachers from School B). Interviews with the two principals were held in February and June. Using Nielsen and Randall's (2013) evidence-based model for process evaluations as a framework, the interviews examined: the quality of the implementation, including the specific activities that were carried out during the pilot; the contextual factors facilitating and hindering implementation; and the perceptions of school staff towards PEP.

\section{Standardised questionnaires}

To gain insight into the possible impact of PEP, five standardised questionnaires were completed by children, teachers and parents at pre-intervention (November/December 2014) and postintervention (May 2015).

Children completed the KINDL-R questionnaire (Ravens-Sieberer and Bullinger, 1998). This questionnaire is designed to measure six dimensions of children's well-being: physical, emotional, self-esteem, family, friends and everyday functioning in schools. Children aged six or younger, together with their teacher, completed the Kiddy KINDL-R, and children aged seven and older completed Kid KINDL-R. In this study, the Cronbach's $\alpha$ for Kiddy KINDL-R was 0.76 at T0 and 0.80 at T1 and for Kid KINDL-R was 0.81 at T0 and 0.87 at T1. Most of the Cronbach's $\alpha$ of the subscale scores were medium to good (0.58-0.77) except for the subscale "everyday functioning" which reliability 
was poor. Ravens-Sieberer and Bullinger (1998) found that the KINDL-R is a reliable, valid and practical instrument to assess the health-related quality of life of children.

Teachers completed the Leerkracht Leerling Relatie Vragenlijst (LLRV)/student-teacher relation questionnaire (Koomen et al., 2007) at pre- and post-intervention. This questionnaire assesses teachers' perception of his/her relationship with an individual. More specifically, the LLRV examines the student-teacher relationship in terms of conflict, closeness and dependency. In this study, the Cronbach's $\alpha$ coefficient was 0.82 at T0 and 0.82 at T1. The reliability of the subscales was good with a range of 0.87-0.93. The criterion validity was assessed to be good (Koomen et al., 2007).

The strengths and difficulties questionnaire (Goodman, 2001) was completed by the children's parents. This 25 -item questionnaire measures children's emotional and behavioural functioning. The questionnaire generated five main subscale scores: emotional symptoms, conduct problems, hyperactivity, peer relationship problems and prosocial behaviour. The Cronbach's $\alpha$ coefficient in this study was 0.77 at T0 and 0.72 at T1. The reliability of the subscales was medium to good ranging from 0.59-0.84 except for the subscale "conduct problems" which was poor. The SDQ scores are found to be predictively valid, attesting to the feasibility of the SDQ as a screening instrument (Goodman, 2001).

To measure school climate, parents were also asked to fill out a professionally translated and shortened version of the psychosocial environment profile (World Health Organization 2003). The questions were concerned with the ethos and environment of the school, cooperative learning, participation in decision making and connection with home life. The Cronbach's $\alpha$ coefficient of the PSE questionnaire in this research was 0.98 , with the subscales ranging from 0.67 to 0.90 .

To examine possible effects on whether and how often children bullied others or were victimised, the children of groups 6-8 (aged 9-12) completed four questions at pre- and post-intervention about the amount and type of bullying behaviour and victimization they experienced.

\section{$\underline{\text { Analyses }}$}

The results of the semi-structured interviews were analysed by using the Atlas.ti software. After transcribing the interviews, a coding scheme based on the four categories of the Nielsen and Randall model (2013) was developed by two of the researchers (T.E. and J.G.). After jointly analysing eight interviews, the coding scheme which consisted of eight sub-codes was finalised. The next four interviews were coded separately which eventually lead to a satisfactory agreement of 85 per cent with a $\mathrm{k}$ of 0.82. After this, one researcher (T.E.) coded the remaining interviews. Sample quotes from the teachers are provided in the results section with " $\mathrm{T}$ " indicating the teacher number. 
The results from the standardised questionnaires were analysed by using the statistical package for social sciences. Prior to statistical analysis, the normality of the data was tested using the ShapiroWilk test. None of the questionnaires were normally distributed. To investigate differences between pre- and post-intervention, Wilcoxon-test was used to analyse the data. Effect sizes (Cohen's d) were calculated and interpreted based on the guidelines of Cohen (1988), with effect sizes of 0.20 considered to be small, 0.50 to be medium and 0.80 to be large. There was a list wise deletion of missing values.

\section{Results}

A total of 184 children ( $N=119$ in School A and $N=65$ in School B) took part in this research study. Table I shows the distribution of pupils across the school grades. There was no significant difference between the two schools in terms of gender, age and distribution across grades.

Table 1: Distribution of student respondents by grades

\begin{tabular}{lllllllll}
\hline Grade (Age) & $1(4-5)$ & $2(5-6)$ & $3(6-7)$ & $4(7-8)$ & $5(8-9)$ & $6(9-10)$ & $7(10-11)$ & $8(11-12)$ \\
\hline Total & 20 & 14 & 23 & 25 & 30 & 25 & 27 & 20 \\
Percentage of total & 10.9 & 7.6 & 12.5 & 13.6 & 16.3 & 13.6 & 14.7 & 10.9 \\
Percentage male & 70 & 43 & 70 & 48 & 63 & 56 & 26 & 80 \\
\hline
\end{tabular}

\section{Workshop evaluation}

After the three training workshops the teachers completed a questionnaire concerning their experience of the workshop. The response rate for the life rules workshop and the well-being and engagement workshop were low as a result of time restrictions at the end of the workshop.

Table II indicates participants' mean rating for each workshop. All three workshops were positively evaluated with a mean scoreW4.1. Teachers reported being inspired by the workshops: "After the workshops, you remain focused on those topics for the next few days. In a way you are 'refreshed' " (T06 January). There was, however, some doubt among teacher about the concepts taught during the workshops and how they can be applied into the classroom "We are teachers and teachers are 'doers' instead of 'thinkers'. So we want to move into action real quick without too much theory" (T07 January).

A total of 98 parents completed the evaluation questionnaire for the parent workshop. This workshop was rated positively by parents. In general parents regarded the evening to be "interesting" and "fun". One of the parents commented: "I'm glad that for once it's not about 
academic achievement but about the well-being of the children". Another parent stated: "This is a must for every parent".

Table 2: Teachers' and parent's mean overall rating per workshop (Scale 1-5)

\begin{tabular}{llllll}
\hline & N & Min & Max & Mean & S.D \\
\hline Values workshop & 31 & 3 & 5 & 4.19 & 0.56 \\
Life rules workshop & 16 & 4 & 5 & 4.51 & 0.42 \\
Well-being \& engagement workshop & 22 & 3.7 & 5 & 4.48 & 0.38 \\
Parental meeting & 98 & 2.6 & 5 & 4.51 & 0.43 \\
\hline
\end{tabular}

At post-intervention, teachers completed a questionnaire concerning their overall view of PEP. The results from this questionnaire are shown in Table III. The highest rated statements included: "PEP is a valuable addition to our school" $(M=4.13, S D=0.61)$ and "I feel comfortable to continue with PEP next academic year" ( $M=4.13, S D=0.61)$. Teachers recognised the need for further work to be done in the coming year to embed and strengthen PEP within their everyday teaching:

We've done a lot the past year, but we definitely need some more work in the upcoming years. The fundamental work must become solid, [...] it (the concepts of PEP) should become automatic (T13 June).

Teachers also reported looking more consciously at the well-being and engagement of students as a result of PEP $(M=4.00, S D=0.730)$. Whilst teachers rated the statement "PEP made me a better teacher" the lowest $(M=3.10, S D=0.98)$, teachers were more positive about the impact of PEP on their relationship with their students $(M=3.44, S D=0.89)$, the atmosphere in the classroom $(M=$ $3.87, S D=0.35)$ and on the school climate as a whole $(M=3.81, S D=0.4)$. PEP received a mean rating of $7.3(S D=0.7)$ on a ten-point scale.

Table 3: Teachers' mean ratings for end of programme questionnaire (Scale 1 - 5)

\begin{tabular}{llllll}
\hline & $\mathrm{N}$ & Min & Max & Mean & S.D \\
\hline PEP is a valuable addition to our school & 16 & 3 & 5 & 4.13 & 0.61 \\
I feel comfortable to continue with PEP next academic year & 16 & 3 & 5 & 4.13 & 0.50 \\
PEP made me look more consciously at the well-being and engagement & 16 & 2 & 5 & 4.00 & 0.73 \\
of the students & & & & & \\
PEP improved the atmosphere in the classroom & 15 & 3 & 4 & 3.87 & 0.35 \\
PEP changed the school climate to a more positive climate & 16 & 3 & 4 & 3.81 & 0.40 \\
PEP improved my relationship with the students & 16 & 1 & 5 & 3.44 & 0.89 \\
I enjoyed working on the different components of PEP & 15 & 3 & 5 & 3.73 & 0.59 \\
The students enjoyed working on the different components of PEP & 15 & 3 & 5 & 3.73 & 0.59 \\
PEP made me become a better teacher & 16 & 1 & 5 & 3.19 & 0.98 \\
I recommend PEP to other colleagues & 16 & 3 & 5 & 3.75 & 0.58 \\
The overall score I would I would give PEP (Scale 1-10): & 15 & 6 & 8 & 7.27 & 0.7 \\
\hline
\end{tabular}




\section{$\underline{\text { Interviews }}$}

As part of the process evaluation of PEP a total of 19 interviews were conducted with teachers and principals in February and June 2015.

\section{Quality of implementation: activities}

Teachers discussed the range of activities that were implemented as part of PEP during the first year. For example, teachers from School A implemented an activity called "Sun of the day/week" where, every day or week, a child was put central and received compliments from the entire class. Teachers in School B implemented "The golden button" where the keeper of the golden button was anonymous and gave compliments to his or her peers. One of the teachers spoke about the use of the "Sun of the week" activity and how enthusiastic the children were during this activity:

Currently I'm working on implementing "Sun of the week". Every week the students are asking for it. On Fridays the little sun is going home with one of the students and then it's always the big question: who is it going to be next week? So the students like it a lot themselves but also by being enthusiastic as a teacher it definitely changes the view of the students (T03 June).

Both of the schools combined the use of these classroom activities about compliments with the introduction of a "life rule":

We now have a very clear life rule: "everybody gets happy from a compliment of mine". In total we came up with five life rules and we want to gradually introduce them at our schools. After the vacation we will continue with the next one (T07 January).

Furthermore, on a whole school level a compliment wall was set up in the hallway of School A. Additionally, Looqin provided a practical resource for the teachers to carry out activities to enhance well-being and engagement: "You can directly extract your aims out of it [Looqin]" (T13 June). Teachers reported that Looqin was easy to use and helped them in observing their students:

"[...] it makes you observe in a more targeted way" (T09 June), "It [Looqin] helps you to find solutions" (T03 June) and "Looqin is accessible [...] it's a beautiful system" (T30 June).

\section{Perception of PEP}

Overall, teachers were positive about the implementation of PEP in their school. There was a notable difference between teachers' comments in February and June 2015. In February, several teachers commented on feeling a little unsure about the application of skills learned in the training workshops into the realities of everyday school life: "In the first half of the year, it is a bit unclear what you have 
to do". In June, however, teachers were more positive about the implementation of PEP and commented on the contribution it was starting to make at their school:

I believe that PEP already is a good contribution at our school. But I think that it has to be worked out more of course. [...] and that it's not visible yet for all of the children. And for the parents, yes, I believe we can make more progress in the aspect of connections with the parents as well (T13 June).

In general teachers considered it important that the implementation of PEP was a bottom up process instead of an obligatory programme. They appreciated the fact that PEP starts from existing values/visions of the schools:

[...] which topics are important for us? What do we need to do as a team? What do you implement in which grade? You can make decisions fit to the school (T15 June).

Some teachers commented on the fact that the training workshops were not practical enough. Teachers stated that the connection between the content of the workshops and their daily practices was not always visible:

"The last workshop was very interesting [...] the first two workshops, however, I felt like 'what can I do with this [content]?" " (T06 January).

Perception of PEP: impact on children

Teachers spoke about the positive impact of PEP on student well-being. One teacher spoke specifically about children in her class that are often restless in the afternoon: "It's great to see how nice the children are working and how relaxed they are during the afternoons" (T11 June). Other teachers noted the impact of compliments on students' awareness of positive behaviour:

In grade 8 we are working with compliments and we notice the children to be more aware of the positive behaviour of the other children (T15 June).

[...] every week one child is put central [...] it's not only about compliments like "he looks nice" or "he is kind", but more like "why is this person kind?" and "can you give an example of this kindness?" (T07 January).

In addition, teachers noted an improvement in student engagement/involvement in learning. One teacher explained: 
Concerning involvement, in my classroom I see that the students now really want to collaborate with each other. During this collaboration their involvement is very high, and yes this increased involvement leads to an increase in wellbeing as well (T07 January).

Perception of PEP: impact on staff

The teachers and principals stated in the interviews that PEP did not just have an impact on student outcomes but its implementation also lead to a more clear vision amongst the staff. Referring specifically to the training they received in well-being and engagement, teachers referred to its positive impact on how staff observe children and support engagement:

"The teachers are very aware of how to observe the children and they are talking with each other about these observations" (T13 June).

In addition, teachers noted a change in their awareness of children's skills and also in their awareness of how they react to children:

I noticed that I'm more aware of the talents of the children. I think I really grew in that aspect (T03 June).

Yes, more awareness on how to react. I'm much more aware of it now (T07 January).

\section{Contextual factors affecting implementation}

The most frequently reported factor that hindered the implementation of PEP was time. Teachers commented on the pressures they experience on a day-to-day basis completing their current workload and the lack of available time to devote to implementing PEP:

There is a lot to be done in the same time [apart from PEP]. Reports, observations [...] You really want to spend time on it [PEP], but you are just not always able to (T15 June).

Teachers did, however, comment on the importance of incorporating PEP into their normal routine as opposed to seeing it as an add on activity. Changes in staff over the course of the academic year were noted by teachers in one school as another hindering factor. The replacement of staff with substitute teachers made it difficult to embed PEP within the curricula and school meetings:

It was a troubled year, especially in grade 4-6. A lot of colleagues were sick and it is hard to instruct substitutes to work on it. Substitutes first need some time to get to know the children (T15 June). 
Future - vision for the future

All the teachers across the two schools were enthusiastic about the future of PEP and they confirmed they would be willing to continue with PEP in the coming years. Teachers noted that their understanding of PEP improved over the course of the academic year and were enthusiastic about the positive impact of PEP on the children and learning environment:

I definitely want to continue with PEP, I think everyone agrees with that. You see that PEP generates a lot of good results: the atmosphere is better, the children are more positive and relaxed, which inevitably leads to better learning results (T15 June).

The teachers did, however, state that they would like to have more practical guidelines for implementing PEP-activities, especially because they saw the positive influence of PEP on their students:

It's very important that it's very clear for the teachers what they can do. In the beginning that was all really uncertain, like: "what are we going to do exactly?" But now when it's clear I definitely see a future for PEP (L2O January).

\section{$\underline{\text { Impact evaluation }}$}

Results from the standardised questionnaires examining the impact of PEP are outlined in Table IV. Well-being and health-related quality of life

Children in grade 1-3 completed the Kiddy KINDL-R questionnaire at pre- and post-intervention $(N=$ 32). Results showed a significant increase in children's total score and indicated a large effect ( $d=$ $3.46, p<0.001)$. These results indicate a significant increase in self-reported well-being and healthrelated quality of life. Both the subscale scores of physical well-being $(d=-3.69, p<0.001)$ and emotional well-being $(d=-3.87, p<0.001)$ increased significantly between pre- and postintervention.

Children in grade 4-8 completed the Kid KINDL-R questionnaire $(N=121)$. Similar results were shown for this group of children. There was a significant increase in children's total score between pre- and post-intervention which indicates a small- to medium-sized effect $(d=0.47, p=0.01)$. Subscale scores on family $(d=-0.51, p=0.007)$, friends $(d=-0.41, p=0.029)$ and everyday functioning $(d=-0.52, p=$ 0.006 ) increased significantly. These results indicate that children felt more pleasant at home, experienced better contacts with friends, and were in general operating better at school at postintervention. 


\section{Student-teacher relationship}

Results from the LLRV which measures teachers' perception of his/her relationship with the students showed no change between pre- and post-intervention. Subscale scores, however, revealed a significant change in "closeness" score $(d=-0.46, p=0.003)$ which indicated that teachers experienced a higher amount of affection, warmth and open communication with their students at post-intervention.

\section{Strengths and difficulties}

A total of 84 parents completed the SDQ at pre- and post-intervention. Results from the total difficulties score indicate a significant decrease between pre- and post-intervention and reveal a medium- to large-sized overall effect $(d=-0.58, p=0.02)$. None of the SDQ subscales were found to change significantly.

\section{School climate}

The PSE questionnaire was completed at pre- and post-intervention by 49 parents. Results indicated a significant increase in the total school climate score which reveals a large effect $(d=1.34, p<$ 0.001). Subscale scores further revealed a significant improvement in "supportive cooperation and active learning" ( $d=-1.75, p<0.001)$; "forbidding physical punishment and violence" $(d=-1.37, p<$ 0.001); "not tolerating bullying, harassment and discrimination" ( $d=-0.94, p=0.18)$; "promoting equal opportunities and participation in decision-making" $(d=-1.15, p=0.001)$.

\section{Bullying}

The percentages of bullying and victimization show a slight change between pre- and postintervention. Pupils reported bullying others less at post-intervention (25.4 per cent at preintervention vs 23.2 per cent at post-intervention) and reported being bullied less at postintervention (29.2 per cent at pre-intervention vs 15.4 per cent at post-intervention).

Table 4: Non adjusted effect sizes per impact evaluation outcome

\begin{tabular}{|c|c|c|c|c|c|c|c|c|}
\hline & \multicolumn{3}{|c|}{ To } & \multicolumn{3}{|c|}{ T1 } & \multicolumn{2}{|c|}{ T1-T0 } \\
\hline & $\mathrm{N}$ & Mean & Std & $\mathrm{N}$ & Mean & Std & $d$ & Sign. \\
\hline SDQ total score difficulties & 84 & 6.226 & 4.796 & 117 & 6.128 & 5.442 & -0.58 & 0.02 \\
\hline Kiddy KINDL-R total score & & & & & & & & \\
\hline health related quality of life & 56 & 2.420 & 0.171 & 32 & 2.730 & 0.271 & 3.46 & 0.00 \\
\hline Kid KINDL-R total score & & & & & & & & \\
\hline $\begin{array}{l}\text { health related quality of life } \\
\text { LLRV total score student- }\end{array}$ & 124 & 3.836 & 0.462 & 121 & 3.911 & 0.480 & 0.47 & 0.01 \\
\hline teacher relationship & 182 & 120.165 & 13.800 & 173 & 119.624 & 16.356 & -0.14 & 0.37 \\
\hline PSE total score school climate & 49 & 3.046 & 0.374 & 72 & 3.107 & 0.432 & 1.34 & 0.00 \\
\hline
\end{tabular}




\section{Discussion}

School frameworks aimed at creating a positive school climate and promoting well-being at the whole school level have not been carried out in the Netherlands to date. The intention of this study was to learn about the implementation process of a whole school framework and potential for change.

The results from this pilot study provide evidence that PEP was well received by the two schools. Both the workshop questionnaires and the interviews indicated that staff and parents were positive about the four components of PEP. All three teacher training workshops were rated positively, with teachers concluding that PEP was a valuable addition to their school and that they would like to continue with PEP the following year. Results from the standardised questionnaires provide preliminary evidence regarding the positive impact of PEP on children's self-reported well-being and on problem behavior including hyperactivity, emotional problems and relationship problems. There is evidence of a reduction in self-reported victimisation between pre- and post-intervention. The results indicate a larger effect for younger children than for older children on health-related quality of life. This difference, however, was not found for the other outcome measures. So, it can be expected that this change is explainable by the tendency of young children to rate their quality of life higher than older children (Ravens-Sieberer and Bullinger, 1998).

The quantitative results were supported by qualitative evidence from teachers about the positive impact of PEP on children's positive behaviour and engagement in classroom activities. In addition, results from the LLRV standardised questionnaire revealed significant improvements in teachers' closeness with students, including enhanced affection, warmth and communication. Teachers themselves spoke about the impact of PEP on their awareness of children's skills, talents and their ability as teachers to observe and support student engagement. Parents also reported an improvement in the school climate including enhanced cooperation and active learning and reduced problem behaviour.

Overall, these results provide preliminary evidence regarding the positive impact of the PEP on children's well-being and engagement and on the positive culture within the school. However, due to the lack of a control group, the observed changes cannot exclusively be attributed to PEP. The positive findings from this pilot study are in line with result from an evaluation of the Geelong Grammar School's Comprehensive Model of Positive Education, which adopts a whole school approach to positive education (Vella-Brodrick et al., 2014). Results from the Geelong Grammar School's quasi-experimental study revealed significant improvements in year nine students' (age 14 
years) well-being, positive emotions, relationships, meaning, accomplishment, health and school engagement.

Similar to Geelong Grammar School's Comprehensive Model of Positive Education, PEP shows promising results as a framework that adopts a comprehensive approach to well-being and engagement by developing both implicit and explicit strategies to support the embedding of positive psychology within the school system. In a review of positive psychology interventions, Waters (2011) identified the adoption of a whole school approach as essential in order to embed positive education throughout the entire fabric of the school. A whole school approach moves beyond the use of specific programmes conducted within selected classrooms to the adoption of an approach that becomes the general way of life of the school. The results from this pilot study provide an indication that over the course of the year, PEP was gradually integrated into the school's everyday business with teachers becoming clearer about PEP's role in their classroom and school. Central to this was the provision of practical strategies and guidelines to support the roll out of PEP. Teachers repeatedly identified the importance of providing them with positive psychology-based activities (such as "Sun of the Week" and "Golden Button") that can be implemented with children on an ongoing basis. It is clear that observing well-being and engagement is a unique feature of PEP and that it is not only about gaining skills in the assessment of students. Focussing on well-being and engagement is also about a change in perspective towards pupils. Instead of looking at the weaknesses of the children and trying to address these weaknesses, this approach shifts the focus towards the resources and strengths of the children. The continuous focus on engagement appears to improve the academic achievement of the students as a result of the attention on a "deeper" way of learning (Laevers et al., 2013). Looqin as a system provides a large toolbox of possible interventions and activities to improve well-being and engagement for individual students and the class climate. In this research teachers highlighted the usefulness of Looqin as a practical instrument to observe and support student wellbeing and engagement. These results are in line with findings from Durlak and colleagues' (2011) meta-analysis of social and emotional skills-based interventions where the most effective interventions were shown to incorporate activity-based learning.

Similar to other whole school interventions developed and implemented in Europe and Australia, e.g. Up, Denmark (Nielsen et al., 2015); Together at School, Finland (Bjorklund et al., 2014); Kidsmatter (Graetz et al., 2008), Australia, Mindmatters (Wyn et al., 2000) Australia, the PEP whole school framework can be characterised as a "bottom up" approach. In an international review of social and emotional skills-based interventions, Weare and Nind (2011) established that this European "bottom up" approach promotes principles of local ownership, empowerment and adaptability and is in 
contrast to the USA "top down" manualised style. As was highlighted in the evaluation of Up, a whole school social and emotional skills intervention implemented in Denmark, Nielsen et al. (2015) the flexible European style emphasises user involvement that allows for local adaptation. PEP adopts similar European "bottom up" principles. The results from this pilot study revealed the importance of a flexible style that allows for local adaptation, a characteristic what was identified by teachers in this pilot study as important to its success.

\section{Limitations}

It is important when interpreting the results from this pilot study to keep several limitations in mind.

First, the observed changes in child, teacher and school outcomes cannot be exclusively attributed to the intervention because of the lack of a control condition. Unmeasured environmental characteristics such as socioeconomic position, home environment and ethnic background of the students, as well as normal child development may have impacted changes measured in this study. This study, however, was planned to serve as an investigation into the implementation of PEP prior to moving into a more comprehensive, large scale experimental study on programme efficacy.

Second, the results from the workshops are limited as a result of several teachers and parents not completing the workshop evaluation questionnaires. These unreturned/noncompleted questionnaires may have biased the results. Unfortunately, the study design did not allow any conclusion about those who did not want to provide feedback.

Third, a low percentage of parents (54 per cent) signed and returned the informed consent, which lead to a lot of unusable data for the impact evaluation.

Fourth, one could argue that conducting an internal evaluation is less objective than an external evaluation. In this pilot study, however, an internal evaluation was more convenient, efficient and less expensive. In the planned follow-up study the evaluation of the progress in well-being and engagement will be external.

Notwithstanding these potential limitations, the study also had some notable strengths. One of these strengths included the triangulation of data using multiple measures (quantitative and qualitative) and from multiple informants (children, teachers, principals and parents). A recommendation would be to strengthen this triangulation even more by also interviewing the students and parents in the next round of evaluation. 


\section{Implications for future practice and research}

The findings from this study underscore the need for practical strategies and activity-based resources to support the whole school implementation of PEP. The need for the connection between the theory of the workshop and the daily practices of the teachers was the key barrier mentioned in the interviews. It is important to start right away with providing teachers those practical strategies and activity-based resources. Observing well-being and engagement using the Looqin system and the use of its practical strategies and resources to support children's development was essential to the success of PEP in the two schools. However, a possible barrier for new schools in adopting PEP might be their change and adjustment to Looqin as the new student tracking system.

Results also revealed the importance of building on the work currently underway in schools and addressing their specific needs. Future implementation of PEP should seek to meet these requirements. More information is required on the integration of PEP within the schools system and the supports required to ensure its sustainability beyond the life of the research project.

Whilst the results from this pilot study of PEP are promising, there is a need for a full-scale evaluation using robust methods to determine the immediate and long-term impact of PEP on children, teachers and the school as a whole. Examining programme impact on social, emotional and behavioural outcomes is critical to determining the overall efficacy of a whole school positive education framework. To increase the robustness of the methodology the chance of false positive findings will be decreased by testing and reporting the subscale scores as primary outcomes. In addition, given the high prevalence and strong relationship of bullying to adverse well-being and mental health problems (Brown et al., 2011), future research should investigate the impact of PEP on bullying at a whole school level. Furthermore, it is worth investigating the use of Looqin to observe students' well-being and engagement and its impact on students' education outcomes, including academic achievement. To increase the response rate of the informed consent, and thereby increase the amount of usable data, it is recommended to use a passive informed consent instead of an active informed consent. An additional practical recommendation from the principals to increase the response rate is to hand out the informed consent and other questionnaires during the teacherparent meetings. Due to this handing out there was an increase in response rate for the SDQ and PSE on $\mathrm{T} 1$.

Finally, the quality of the implementation should be monitored in more detail in order to determine what works for whom and under what circumstances, and to examine the impact of implementation on programme outcomes. As part of this, it is important to gather information about environmental characteristics and other similar social and emotional skills-based initiatives or curricular 
interventions implemented in the school, how these operate within the PEP framework, and their combined impact on children's outcomes.

\section{Conclusion}

This study may be unique in its examination of the implementation of a whole school framework aimed at supporting well-being and creating a positive school climate in Dutch primary schools. The findings from this pilot study were encouraging and provide preliminary evidence regarding the positive impact of PEP on children's well-being and problem behaviour, teachers' awareness of children's strengths and overall school climate. Implementation findings highlight the importance of the adoption of a "bottom up" approach that allows for local adaptation and the need for practical, activity-based resources to support whole school implementation. More robust, detailed research on the implementation and impact of PEP will enhance our understanding on the role of whole-school positive psychology frameworks in supporting children's well-being and engagement. 


\section{References}

Barry, M., \& Jenkins, R. (2007). Implementing Mental Health Promotion. Oxford: Elsevier.

Björklund, K., Liski, A., Samposalo, H., Lindblom, J., Hella, J., Huhtinen, H., Ojala, T., Alasuvanto, P., Koskinen, H.L., Kiviruusu, O., Hemminki, E., Punamaki, R.L., Sund, R., Solantaus, T., \& Santalahti, P. (2014). Together at schoola school-based intervention program to promote socioemotional skills and mental health in children: study protocol for a cluster randomized controlled trial. BMC Public Health, 14(1), 1-11.

Bohlmeijer, E.T., Bolier, L., Westerhof, G.J., \& Walburg, J.A. (2013). Handboek Positieve Psychologie, theorie, onderzoek en toepassingen. Amsterdam: Uitgeverij Boom

Bolier, L., Walburg, J.A., \& Boerefijn, J. (2013). Positieve psychologie op school. In Bohlmeijer, E.T., Bolier, L., Westerhof, G.J., \& Walburg, J.A. (Eds), Handboek Positieve Psychologie (pp. 325-354). Amsterdam: Uitgeverij Boom.

Brown, E.C., Low, S., Smith, B.H., \& Haggerty, K.P. (2011). Outcomes from a school-randomized controlled trial of steps to respect: a bullying prevention program. School Psychology Review, 40(3), 423-443.

Clarke, A.M., \& Barry, M.M. (2015a). Implementing mental health promoting schools. In Simovska, V., \& McNamarra, P. (Eds), School for Health and Sustainability (pp. 313-338). Dordrecht: Springer.

Clarke, A.M., \& Barry, M.M. (2015b). Supporting a whole school approach to mental health promotion and wellbeing in post-primary schools in Ireland. In Kutcher, S., Wei, Y., \& Weist, M. (Eds), School Mental Health Global Opportunities and Challenges (pp. 112-124). Cambridge: Cambridge Press.

Cohen, J. (1988). Statistical Power Analysis for the Behavioral Sciences, 2nd ed. Hillsdale: Lawrence Erlbaum.
Dix, K.L., Slee, P.T., Lawson, M.J., \& Keeves, J.P. (2012). Implementation quality of whole-school mental health promotion and students' academic performance. Child and Adolescent Mental Health, 17(1), 45-51.

Durlak, J.A., Weissberg, R.P., Dymnici, A.B., Taylor, R.D., \& Schellinger, K.B. (2011). The impact of enhancing students' social and emotional learning: a meta-analysis of school-based universal interventions. Child Development, 82(1), 405-432.

Estrada, C.A., Isen, A.M., \& Young, M.J. (1994). Positive affect improves creative problem solving and influences reported source of practice satisfaction in physicians. Motivation and Emotion, 18(4), 285-299.

Fixsen, D.L., Naoom, S.F., Blase, K.A., Friedman, R.M., \& Wallace, F. (2005). Implementation Research: $A$ Synthesis of the Literature. Tampa: National Implementation Research Network, Louis de la Parte Florida Mental Health Institute, University of South Florida.

Fredrickson, B.L. (2001). The role of positive emotions in positive psychology: the broaden-and-build theory of positive emotions. American Psychologist, 56(3), 218226.

Fredrickson, B.L., \& Branigan, C. (2005). Positive emotions broaden thought-action repertoires: evidence for the broaden-and-build model. Cognition and Emotion, 19(3), 313-332.

Gilman, R., Huebner, E.S., \& Furlong, M.J. (2009). Handbook of Positive Psychology in Schools. New York: Routledge/Taylor \& Francis Group.

Goodman, R. (2001). Psychometric properties of the strengths and difficulties questionnaire. Journal of the American Academy of Child and Adolescent Psychiatry, 40(11), 1337-1345.

Graetz, B., Littlefield, L., Trinder, M., Dobia, B., Souter, M., Champion, C., \& Cummins, R. (2008). KidsMatter: a population health model to support student mental 
health and wellbeing in primary schools. International Journal of Mental Health Promotion, 10(4), 13-20.

Greenberg, M., Domitrovich, C., \& Bumbarger, B. (2001). The prevention of mental disorders in school-aged children: current state of the field. Prevention \& Treatment, 4(1), 1-52.

Isen, A.M., Rosenzweig, A.S., \& Young, M.J. (1991). The influence of positive affect on clinical problem solving. Medical Decision Making, 11(3), 221-227.

Keyes, C.L.M. (2002). The mental health continuum: from languishing to flourishing. Journal of Health and Social Research. 43(2), 207-222.

Keyes, C.L.M. (2005). Mental illness and/or mental health? Investigating axioms of the complete state model of health. Journal of Consulting and Clinical Psychology, 73(3), 539-548.

Koomen, H.M.Y., Verschueren, K., \& Pianta, R.C. (2007). Leerling Leerkracht Relatie Vragenlijst (LLRV). Houten: Bohn Stafleu van Loghum,

Kuhl, J. (2000). A functional-design approach to motivation and self-regulation: the dynamics of personality systems interactions. In Boekaerts, M., Pintrich, P.R., \& Zeidner, M. (Eds), Handbook of SelfRegulation(pp. 111-169). San Diego: Academic Press.

Laevers, F., \& Aerden, I. (n.d.). Looqin - KVS Een Digitaal Procesgericht Kindvolgsysteem Voor de Volledige Basisschool. Leuven: Centrum voor Ervaringsgericht Onderwijs.

Laevers, F., Heylen, L., \& Maes, J. (2013). Een Procesgerichte Aanpak Voor 6- tot 12-jarigen in Het Basisonderwijs. Leuven: Averbode.

Nielsen, K., \& Randall, R. (2013). Opening the black box: presenting a model for evaluating organizational-level interventions. European Journal of Work and Organizational Psychology, 22(5), 601-617.

Nielsen, L., Meilstrup, C., Nelausen, M.K., Koushede, V., \& Holstein, B.E. (2015). Promotion of social and emotional competence: experiences from a mental health intervention applying a whole school approach. Health Education, 115(3/4), 339-356.

Norrish, J.M., \& Vella-Brodrick, D.A. (2009). Positive psychology and adolescents: where are we now? Where to from here?. Australian Psychologist, 44(4), 270-278. Norrish, J.M., Williams, P., O'Connor, M., \& Robinson, J. (2013). An applied framework for positive education. International Journal of Wellbeing, 3(2), 147-161.

Ravens-Sieberer, U., \& Bullinger, M. (1998). Assessing health-related quality of life in chronically ill children with the German KINDL: first psychometric and content analytical results. Quality of Life Research, 7(5), 399-407.

Rowe, G., Hirsh, J.B., \& Anderson, A.K. (2007). Positive affect increases the breadth of attentional selection. Proceedings of the National Academy of Sciences, 104(1), 383-388.

Seligman, M.E. (2007). The Optimistic Child: A Proven Program to Safeguard Children Against Depression and Build Lifelong Resilience. Boston: Houghton Mifflin Harcourt.

Seligman, M.E. (2011). Flourish: A Visionary New Understanding of Happiness and Wellbeing. New York: Free Press.

Seligman, M.E.P., \& Csikszentmihalyi, M. (2000). Positive psychology: an introduction. American Psychologist, 55(1), 5-14

Seligman, M.E.P., Ernst, R.M., Gillham, J., Reivich, K., \& Linkins, M. (2009). Positive education: positive psychology and classroom interventions. Oxford Review of Education, 35(3), 293-311.

Sin, N.L., \& Lyubomirsky, S. (2009). Enhancing well-being and alleviating depressive symptoms with positive psychology interventions: a practice-friendly metaanalysis. Journal of Clinical Psychology, 65(5), 467-487. Vella-Brodrick, D.A., Rickard, N.S., \& Chin, T.-C. (2014). An Evaluation of Positive Education at Geelong Grammar 
School: A Snapshot of 2013. Melbourne: The University of Melbourne.

Waters, L. (2011). A review of school-based positive psychology interventions. The Australian Educational and Developmental Psychologist, 28(2), 75-90.

Weare, K., \& Markham, W. (2005). What do we know about promoting mental health through schools?

Promotion \& Education, 12(3/4), 118-122.

Weare, K., \& Nind, M. (2011). Mental health promotion and problem prevention in schools: what does the evidence say? Health Promotion International, 26(1), 2969.
Westerhof, G.J., \& Keyes, C.L.M. (2010). Mental illness and mental health: the two continua model across the lifespan. Journal of Adult Development, 17(2), 110-119.

World Health Organization (2003). Creating an

Environment for Emotional and Social Wellbeing: An Important Responsibility of a Health-promoting and Child-friendly School. Geneva: WHO Information Series on School Health.

Wyn, J., Cahill, H., Holdsworth, R., Rowling, L., \& Carson, S. (2000). MindMatters, a whole-school approach promoting mental health and wellbeing. Australian and New Zealand Journal of Psychiatry, 34(4), 594-601. 


\section{Chapter 4:}

\section{Positive Education in daily teaching, the promotion of wellbeing and engagement in a whole}

school approach: A clustered quasi-experimental trial

Goldberg, J.M., Sommers-Spijkerman, M.P.J., Clarke, A.M., Schreurs, K.M.G., \& Bohlmeijer, E.T. (2019). Positive education in daily teaching, the promotion of wellbeing and engagement in a whole school approach: A clustered quasi-experimental-trial. Manuscript under review. 


\section{Abstract}

There is growing interest in the application of positive psychology interventions in education, especially in applying such interventions through a whole school approach. In the current study, a Dutch whole school Positive Education Programme (PEP) was investigated. PEP is a bottom-up programme, aimed at shifting teacher's attention from solely focusing on learning outcomes towards a more comprehensive approach that takes the wellbeing and engagement of students during classes into account. To enable and stimulate the broadening of teacher's perspectives, schools implement activities at the whole school level based on the shared values of team members. In the current study, PEP was investigated through a clustered quasi-experimental trial. Four primary schools totalling 639 pupils were included of which two were allocated to PEP and two were placed in a control condition. At the beginning and end of the school year, student-report and teacherreport questionnaires were administered and observations were made so as to examine wellbeing, engagement, emotional problems, prosocial behaviour, student-teacher relationships, bullying and victimization. Implementation fidelity was assessed through a twelve-item checklist.

Multilevel analyses showed no significant differences between the intervention and control schools on any of the outcomes. However, the data did indicate a trend toward more engagement in the students in the intervention schools $(p=.09)$. Additionally, at post-measurement, the proportion of sufficiently engaged students was significantly higher in the intervention schools as compared to the control schools. Both experimental schools reported difficulties in the implementation. The nonsignificant results need to be interpreted in the context of these implementation difficulties, but also in the context of the applied bottom up approach and the short duration of the study. Although it seems too premature to draw conclusions regarding the effectiveness of such a whole school approach, the findings on engagement are promising and have the potential to engender a wide range of other beneficial outcomes. 


\section{Introduction}

\section{Wellbeing and engagement}

There is growing interest in applying positive psychology elements in education (World Government Summit, 2017). In 2000, Seligman and Csikszentmihaly (2000) presented positive psychology as the science of well-being and optimal functioning. Positive psychology in education, or positive education, is concerned with the development of pupils' strengths and well-being, thereby getting them to flourish and enabling them to achieve academic goals. Students are flourishing when they experience high levels of emotional, psychological and social wellbeing (Keyes, 2002). Positive education is addressed through the implementation of Positive Psychology Interventions (PPI's) aimed at cultivating positive feelings, positive behaviour or positive cognitions in school settings (Sin and Lyubomirsky, 2009; Norrish and Vella-Brodrick, 2009; Seligman et al., 2009). A systematic review of twelve international school-based PPI's, indicated that those interventions had significant positive effects on students' well-being, social relationships and academic performances (Waters, 2011). In addition to wellbeing, one vital focus in positive education is engagement. Engagement means that there is intense mental activity, that a pupil is functioning at the limits of its capabilities and with an energy flow that comes from intrinsic sources (Laevers, 1999). It is thought that when pupils experience a high level of wellbeing and engagement, their learning curve and learning outcomes will be optimal (Laevers, 1999). Previous research showed that pupils' levels of wellbeing and engagement can be linked to academic achievement (e.g. Pietarinen, Soini \& Pyhalto, 2014; Hughes and Kwok, 2007; Reyes et al., 2012), social emotional learning (Buhs, Ladd \& Herald, 2006; Hosan and Hoglund, 2017) and mental problems including anxiety and depressive symptoms (Fredrickson, 2001).

It has been discussed that wellbeing and engagement should not only be seen as outcome measures, but should be used as daily guidelines for teaching. Instead of adjusting the teachers approach based on the learning outcomes, the approach should be altered based on the indicators of the learning process: wellbeing and engagement (Laevers, 1999). This theory stems from the Centre for Experience Based Learning (CEGO) in Leuven. This requires teachers to adopt a change in perspective. They should not be merely focusing on learning outcomes (e.g. grades), but rather be actively looking for ways to engage students and to get students to flourish (based on their interests and strengths). A number of qualitative studies showed the potential of this process-oriented teaching approach by describing its positive influence on wellbeing and academic achievement 
(Laevers \& Heylen, 2013; Buyse, Snoeck, Bertrands, Declerq \& Laevers, 2009). In the current study, a Dutch positive education programme, focusing on the perspective change in line with the theory by CEGO, is investigated in a clustered controlled trial.

\section{Whole School Approach}

To date, the implementation of positive psychology programmes in schools has primarily taken place at the level of the classroom, with relatively short curriculum-based interventions (Waters, 2011). However, research on social and emotional learning interventions suggests that interventions are likely to be more successful when 1) integrated into the school culture and daily school practices, 2) engaging all staff, 3) reinforcing social skills outside the classroom, 4) supporting parental engagement and 5) supporting community engagement such as sport associations or local companies (Barry et al., 2017; Jones \& Bouffard, 2012; Weare \& Nind 2011; Ttofi \& Farrington, 2009; Adi et al., 2007; Wilson et al., 2003). Altogether, these characteristics point towards the potential of adopting a whole school approach for enhancing youth's wellbeing and engagement.

A whole school approach defines the entire school community as the unit of change and aims to integrate skill development into daily interactions and practices using collaborative efforts that include principals, teachers, other staff, parents and pupils (Jones \& Bouffard, 2012; Meyers et al., 2015). Based on the World Health Organisation (WHO) Health Promoting Schools Framework (1998), a whole school approach involves coordinated action between three components 1) curriculum, teaching and learning 2) school ethos and environment and 3) family and community partnerships. Effective curriculum teaching and learning involves teaching skills through the implementation of evidence-based programmes as well as modelling social-emotional competencies and providing continuous and consistent opportunities to practice these skills during everyday classroom situations (Oberle et al., 2016). At the school level, skills are reinforced in non-curriculum-based ways through policies, whole staff training, organisational structure, and daily activities in the school that are designed to promote a positive school climate which, in turn, helps youth to develop across academic, social, emotional and behavioural domains (Jones \& Bouffard, 2012; Meyers et al., 2015). Through involving not only school staff, but also parents and communities in a whole school approach, learning is not limited to the school setting, but also occurs in the home setting.

A recent meta-analysis (Goldberg et al., 2018) of 45 studies evaluating the impact of social and emotional learning interventions which adopted a whole school approach reported that these interventions have a significant positive impact on behavioural adjustment $(d=0.13)$, social emotional adjustment $(d=0.22)$ and internalizing symptoms $(d=0.11)$. The International Positive Education Network provides three international case studies of positive education applied via a 
whole school approach (World Government Summit, 2017): 1. Geelong Grammar School in Australia (Hoare \& Robinson, 2017), 2. St. Peter's College in Australia (White \& Waters, 2014) and 3. Universidad Tecmilenio in Mexico (Escamilla, 2017). These schools consider wellbeing to be equally important as academic achievement ensuring that all staff sees the improvement of wellbeing as their main responsibility (Hoare \& Robinson, 2017; White \& Waters, 2014). By implementing positive education as a whole school approach, a positive climate change has occurred at all three schools (World Government Summit, 2017). The findings from the case studies report positive results, however, these findings have yet to be confirmed by more robust evidence.

\section{Dutch Positive Education Programme}

At the core of this study, is the Dutch Positive Education Programme (in Dutch: Positief Educatief Programma), abbreviated as PEP. The key aim of PEP is to promote a shift in perspective among teaching staff, from a teaching approach solely based on learning outcome indicators towards a teaching approach informed by the learning process indicators wellbeing and engagement. To enable and foster this shift in perspective, schools participating in PEP implement activities at the whole school level based on the shared values of their team members.

PEP draws upon the principles of positive education and is derived from the Applied Model for Positive Education of Norrish et al. (2013). The Applied Model for Positive Education aims to increase flourishing, by living, teaching and embedding the principles of positive psychology (Norrish et al., 2013). During PEP, this is done by making the shared values of the team members a central theme. School teams identify their shared values and create (approximately five) life rules to give expression to these shared values. A school culture that reflects shared values is thought to positively affect learning outcomes (MacNeil, Prater \& Busch, 2009). In the 13 schools that currently adopted the PEP-approach in the Netherlands, a wide range of values are addressed through life rules (e.g. respect, safeness, kindness, humour). These life rules are expressed in the curriculum, in the physical school environment, in the interaction with parents and amongst team members. By implementing activities in the lessons (teach it) and school culture (embed it) that are closely associated with the values of the teachers (living it), the process indicators 'wellbeing' and 'engagement' are strengthened. If the process indicators appear to be insufficient, teachers change their approach. With high levels of wellbeing and engagement, behavioural problems are expected to be minimalised and social emotional development is expected to be optimised.

A process evaluation (Elfrink et al., 2017) was conducted, evaluating the implementation of PEP in two pilot primary schools in the Netherlands. Promising effects were identified across pupil and teacher outcomes including pupils' self-reported wellbeing and problem behaviour (e.g. bullying), 
teachers' awareness of pupils' strengths, and the overall school climate. In addition, teachers showed positive attitudes towards the philosophy of PEP and its key components. Teachers reported that they were more aware of the wellbeing and engagement of their pupils as a result of PEP. Also, they appreciated the fact that PEP's bottom-up approach starts from existing values of the team members. Goldberg, Prenger and Bohlmeijer (2018) demonstrated similar findings in a second process evaluation of an adapted version of PEP conducted in two schools in special needs education. In this evaluation, teachers reported feeling more confident to focus on the process of learning instead of focusing on learning outcomes. Although PEP as a Dutch whole school approach proved acceptable and feasible in these pilot studies, there is need for more robust research to determine the impact of PEP.

\section{Current study}

Despite emerging evidence for the effectiveness of whole school approaches in the social emotional learning domain (Goldberg et al., 2018), until to date little is known about whole school approaches that focus on the daily enhancement of wellbeing and engagement of pupils in primary schools. This study sought to contribute towards closing this knowledge gap through evaluating the effects of PEP in a quasi-experimental clustered trial in Dutch primary education. Wellbeing and engagement are considered the main working mechanisms in PEP and are measured as proximal outcomes in the current evaluation. As distal outcomes, the current study aimed to assess the impact of PEP on bullying behaviour among students, as well as students' emotional and behavioural problems.

\section{Methods}

Ethical approval was obtained from the Ethical Review Board of the University of Twente (document number: BCE17604). All participants were treated in accordance with ethical standards of the APA and were ensured anonymity, with no identification of individual responses.

\section{Study design}

This study employed a clustered quasi-experimental design with one intervention group and one control group. Both conditions consisted of two primary schools. Randomization was not possible, since two of the included schools were only willing to participate provided that they would be allocated to the control condition. The PEP-schools implemented the intervention from September 2017 to June 2018. The control schools were instructed to complete their school year as they would 
normally do, without implementing any positive psychology programmes in this time frame. Assessments took place before the start of PEP (i.e. baseline, September 2017) and at the end of the school year (i.e. post-measurement, June 2018).

\section{$\underline{\text { Sample size calculation }}$}

Prior to this study, a power analysis was conducted so as to determine the required sample size, aiming to be able to detect small significant effect sizes for the primary outcome wellbeing $(d=$ 0.20). The alpha was set to .05 , the power to .80 ( 1 - beta .20), and the correlation between preand-post measurement to .50 . This resulted in a required sample size of 591 participants (Borm, Fransen \& Lemmens, 2007).

\section{Procedure \& participants}

The four participating schools were recruited in the spring of 2017. The schools were part of a district-wide organization (Stichting Consent, Enschede) consisting of 32 primary schools. Of these 32 schools, five schools were already working with PEP and were, therefore, not eligible to participate in the present study. An information letter about the present study was spread across the 27 remaining schools, of which six schools communicated their interest in the programme. For each of these six schools, two meetings were organised to provide information about PEP and the study. Two out of the six schools appeared not eligible to participate because they were already implementing a whole school approach aimed at positive behavioural support. The remaining four schools were included in the trial.

In total, 639 pupils from four different primary schools in Enschede were enrolled in the present study of whom 401 pupils (two schools) were allocated to the control condition and 238 pupils (two schools) to the intervention condition. Informed consent was obtained from their parents or guardians prior to including the pupils in the study. Additionally, informed consent was sought from the school principals and teachers. Informed consent was given passively, meaning that parents/guardians, principals and teachers gave automatic consent unless they stated otherwise. They received an information leaflet with instructions on how to withdraw consent. The information letter also provided information on the study, including information about its purpose, the type of data that would be collected and how the data would be utilized. Five percent of the pupils $(N=32)$ were not included in the research as their parents or guardians did not provide consent. All teachers and principals provided consent. 
Data were collected from all school classes (i.e. grades $1-8$, ages $4-12$ ), with on average 21 pupils per class. The mean age of the participants was $7.71(S D=2.34)$, with $50 \%$ boys and $50 \%$ girls. All four schools were located in the same city. At baseline, the PEP-schools and control-schools did not significantly differ on any of the outcome measures, with $p$-values ranging from .08 (pro-social behaviour) to .78 (victimization).

\section{Intervention: Positive Education Programme (PEP)}

PEP is a whole school approach based on positive education. Key components of PEP are the daily enhancement of pupil's wellbeing and engagement and the shared values of the team members. The goal of PEP is to promote change in perspective among teaching staff, from a teaching approach based on learning outcome indicators towards a teaching approach informed by the learning process indicators wellbeing and engagement.

\section{Implementation activities}

At the start of the school year, both intervention schools selected $3-5$ teachers to form a project team to arrange all practicalities. The entire school staff received training in the form of two workshops. The first workshop took place in September 2017 and concerned the observation and promotion of children's wellbeing. In November 2017, the second workshop took place which focused on values and life rules. Additionally, both intervention schools were visited on a monthly basis by the researcher (first author) and a PEP-trainer, to participate in a PEP-talk. During these PEPtalks, the observing and enhancement of wellbeing and engagement as well as the activities around the values and life rules were discussed. The PEP-trainer provided guidance to both intervention schools during the entire school year, emphasizing the whole school approach of PEP. Schools were encouraged to implement activities to engage parents, to make PEP visible in the entire school and to update their policy based on their shared values. Except for the two workshops and the PEP-talks, the study was implemented using a bottom-up approach, without a strict manual. The implementation activities are listed in table 1.

Table 1: Implementation checklist intervention schools

\begin{tabular}{l}
\hline Implementation activities \\
\hline Establish a project team concerned with practicalities of PEP \\
Implement a workshop on the topic of wellbeing and engagement \\
Implement a workshop on the topic of values \\
Implement monthly PEP-talks with the entire team \\
All teachers conduct five engagement scans during the school year \\
Implement strategies to enhance wellbeing and engagement at the classroom level \\
Develop at least one life rule during the school year \\
\hline
\end{tabular}


Organize activities in the context of a life rule

Inform parents about PEP via a parent letter

Make PEP part of the yearly parent-conversations

Make PEP visible in the school and on the playground

Change or update the policy of the school

\section{Wellbeing and engagement as process indicators}

Within the PEP programme, the focus was on the learning process rather than on learning outcomes. Wellbeing and engagement are considered two major indicators of the learning process, providing a daily direction for teaching. During the implementation of PEP, teachers were encouraged to be constantly aware of the degree of engagement and wellbeing amongst their pupils. On five predetermined occasions during the school year, teachers gave observational scores based on the degree of engagement the pupils showed at that specific moment. These observations were not seen as outcome measures, but were solely intended to provide the teacher with information about the current level of engagement amongst their pupils. These methods followed the procedures as described by the CEGO (Leavers and Laurijssen, 2001; Appendix A). The engagement-score was given on a five-point scale, based on a two minute observation. Teachers observed all their pupils on these five occasions and discussed their observations with their colleagues. Teachers were provided with a student tracking system, which offered possible strategies and interventions on the individual level as well as at classroom level, with the overall aim to increase the wellbeing and engagement of the pupils. An example of such an implemented intervention was the placement of a suggestion box in the classroom in which pupils can post ideas for activities or lessons. Through observing their pupils on a regular basis, teachers were aware of the wellbeing and engagement of their pupils.

\section{Value clarification and implementation}

During the second workshop, schools identified their shared values and cooperatively created life rules to give expression to their shared values. The created life rules were applied in four different domains, leading to a whole school approach in line with the definition of the WHO (1998): 1) in the curriculum, 2) in the physical environment of the schools (e.g. hallways), 3) in the communication with the parents and 4) in the communication amongst the team members. These life rules were positively formulated, gave a direction for actions of everybody involved at school and specifically did not provide strict behavioural rules. Every four to six months, the schools focused on one of their life rules. Both intervention schools implemented two life rules in the context of the current study (see Table 2 for an overview). The life rule "no strength remains unknown", for example, was created based on the value 'personal growth' and stimulates pupils, teachers and parents to explore 
and make use of their strengths. Amongst others, lessons in finding your strengths took place, a talent market was organised for the entire school community (e.g. parents, guardians, neighbours, local companies) and talents of pupils, teachers and parents were displayed throughout the school (e.g. posters, drawings, banners).

Table 2: Shared values and formulated life rules of both intervention schools

\begin{tabular}{lll}
\hline School & Value & Life rule \\
\hline School A & Personal growth & No talent remains unknown \\
& Humour & Don't worry be happy \\
& Passion & \\
& Safety & You, I and We, everybody is welcome here \\
School B & Respect & School is a party and you are invited \\
& Fun & \\
& Talent enhancement & \\
& Safety & \\
& Authenticity & \\
\hline
\end{tabular}

\section{Measures}

\section{Proximal outcomes}

Wellbeing was assessed with the student self-reported KINDL-R questionnaire (Ravens-Sieberer and Bullinger, 1998). The KINDL-R was designed to measure six dimensions of youth's health related quality of life, including: physical well-being, emotional well-being, self-esteem, quality of relationships with family, quality of relationships with friends and everyday functioning in schools. Items were scored on a five-point Likert scale ranging from 1 (never) to 5 (always), with high scores reflecting greater levels of wellbeing. Pupils aged six years or younger completed the 12 -item Kiddy KINDL-R together with their teacher, whereas pupils aged seven years and above individually completed the 24-item Kid KINDL-R. Previous research indicates that the KINDL-R is a reliable and valid instrument (Ravens-Sieberer and Bullinger, 1998). In the current study, the reliability of the Kiddy KINDL-R total score as well as its subscales was insufficient (alphas ranging from .37 to .533) and therefore the Kiddy KINDL-R was excluded from the analyses. The internal consistency of the Kid KINDL-R was good with Cronbach's alphas $(\alpha)$ of .82 and .81 at baseline and post-measurement, respectively. For the subscales ( 4 items each), only the subscale Self-esteem was found reliable with alphas of .74 and .70 for pre and post, respectively. The remaining subscales showed insufficient reliability (alphas ranging from .55 to .62). Hence, only total scores and self-esteem scores were analysed. 
Engagement was measured through observations done by an independent researcher of the CEGO, using the Leuven Involvement Scale (LIS) developed by the respective organisation (Laevers, Peeters \& Vanwijsberghe, 1994). The CEGO researcher, who was blinded to the condition of each school (i.e. intervention or control), observed a random selection of approximately ten pupils of grades 1, 3, 5 and 7 per school (approximately 40 pupils per school). The selected pupils were observed twice per measurement (four times in total), whereby each student received a score between 1 and 5 points (Appendix A), with high scores reflecting greater levels of engagement. Previous research demonstrated high interrater reliability of the LIS with a kappa of .86 (Laevers et al., 1994). Laevers and colleagues (1994) considered scores of 3.5 and higher as adequate. Pupils who scored $\geq 3.5$ were therefore considered engaged, whereas pupils with a score $<3.5$ were labelled as nonengaged.

\section{Distal outcomes}

Pupils' social-emotional and behavioural functioning was examined through the 25 -item teacherreport Strengths and Difficulties Questionnaire (SDQ; Goodman, 2001). This questionnaire comprises five subscales with five items each, namely: emotional symptoms, conduct problems, hyperactivity, peer relationship problems and prosocial behaviour. Items deployed a three-point Likert scale with answers ranging from 1 (not true) to 3 (absolutely true). Higher scores reflected greater levels of difficulties, except for the subscale prosocial behaviour. SDQ scores were found to be valid in previous research, attesting to the feasibility of the SDQ as a screening instrument (Goodman, 2001). In the current study, Cronbach's $\alpha$ for the total scale was .42 at pre and .38 at post measurement, and, consequently, total scores were not used in the analyses. The subscales 'emotional problems' (Pre $\alpha=.74$, Post $\alpha=.74$ ) and 'prosocial behaviour' (Pre $\alpha=.81 \&$ Post $\alpha=.76)$, but not the remaining subscales, reached acceptable reliability and were included in the analyses.

The student-teacher relationship was examined with the 28-item teacher-report student-teacher relation questionnaire (in Dutch: Leerkracht-Leerling Relatie Vragenlijst, LLRV) of Koomen et al. (2007). The LLRV examines the student-teacher relationship in terms of conflict (11 items), closeness (11 items) and dependency (6 items). Items were rated on a five-point Likert scale with answers ranging from 1 (certainly not applicable) to 5 (certainly applicable). High scores on closeness reflected a better student-teacher relationship, whilst for conflict and dependence it was the other way around. Criterion validity was assessed to be good in earlier research (Koomen et al., 2007). In the current study, both the total scale and the subscales showed acceptable to good reliability with alpha's ranging from .73 to .88 . 
Among pupils in grades 4 to 8 , bullying and victimization were assessed with one question each. These questions were derived from the Olweus scale (Olweus, 1996). The first question asks how frequent the student has bullied others and the second question asks how frequent the student has been bullied by others. Both items were answered on a five-point Likert scale from 1 (never) to 5 (once per day or more), with higher scores reflecting greater levels of bullying or victimization.

\section{Implementation fidelity}

To measure the implementation fidelity of PEP, an implementation checklist was filled out by the researchers for both intervention schools. This checklist consists of twelve actions determined by the researchers (all authors) prior to the start of the intervention (see Table 1). These actions relate to among others the workshops, implementing life rules, connecting with parents and performing engagements scans.

\section{Analyses}

Attrition analyses were conducted to examine any baseline differences between pupils retained and pupils lost at post measurement. Independent samples $t$-tests were conducted to determine whether drop-outs significantly differed from non-drop-outs at baseline. Analyses were conducted according to the intention-to-treat (ITT) principle, using the Expectation Maximization (EM) algorithm (Dempster, Laird \& Rubin, 1977; El-Masri \& Fox-Wsylyshyn, 2005) to replace missing values on continuous variables at pre (4.5\%) and post (5.5\%) intervention.

Multilevel modeling procedures were performed in order to assess the impact of PEP on proximal and distal outcomes. The influence of clustering of the data was hereby considered, by assuming that the pupils were nested in grades and the grades were nested in schools. Clustered data violates the assumption of independent observations, hence if the clustering is ignored this may result in incorrect statistical inferences (Snijders \& Bosker, 2012). Schools and grades were therefore included as random effects, condition as fixed effect and condition as random slope (Field, Miles \& Field, 2012). To compare the proportion of pupils who conformed to the norm of engagement (i.e. LIS score $\geq 3.5$; Leavers et al., 1994) across conditions at post-measurement, a chi-squared test of independence was performed and odds ratios (ORs) were calculated.

Additionally, to gain insight in differences on all outcome measures between the two intervention schools, independent samples $t$-tests were conducted to compare pre-post change scores for both groups on each outcome. Multilevel procedures could not be performed for these additional analyses, because convergence was not reached. In interpreting the findings, we consider an alpha 
level of $p<.05$ as significant, yet effects with $p$-values up to .10 are indicated as trends (Hoglund \& Leadbeater, 2012). The multilevel analyses were conducted in R-studio, all other analyses were conducted in IBM SPSS statistics 25.

\section{Results}

\section{Drop-out}

For each measurement, the proportion of dropouts was determined. Due to practicalities, it was not possible to observe the level of engagement in two of the classes at post-intervention. This concerned one school class in grade 3 of the intervention condition and one school class in grade 1 of the control condition. As a consequence, a high percentage of drop-out was observed on that particular measurement (Table 3). The engagement scores of the drop-outs were significantly higher at baseline than the scores of the non-drop-outs. For none of the baseline measurements, a significant difference was found between drop-outs in the PEP condition and drop-outs in the control condition.

Table 3: Drop-outs per measurement

\begin{tabular}{lllll}
\hline Outcome (Measure) & $\begin{array}{l}\text { N consented to } \\
\text { start }\end{array}$ & $\begin{array}{l}\text { N filled out } \\
\text { Pre }\end{array}$ & $\begin{array}{l}\text { N filled out Pre } \\
\text { and Post }\end{array}$ & $\begin{array}{l}\text { N drop-out } \\
\text { (\%) }\end{array}$ \\
\hline Wellbeing \& Self Esteem & $399^{*}$ & 319 & 305 & $14(4 \%)$ \\
(Kid-Kindl-R) & & & & $41(23 \%)$ \\
Engagement (observation) & $173^{* *}$ & 173 & 132 & $29(5 \%)$ \\
Emotional problems \& Prosocial behaviour (SDQ) & 639 & 605 & 576 & $21(3 \%)$ \\
$\begin{array}{l}\text { Student-teacher Relationship, Conflict, Closeness \& } \\
\text { Dependence (LLRV) }\end{array}$ & 639 & 621 & 600 & $7(2 \%)$ \\
Bullying \& Victimization (Olweus) & $399 *$ & 282 & 275 & \\
\hline
\end{tabular}

* = Only completed by pupils in grades $4-8 ;{ }^{* *}=$ Samples of ten pupils from grades $1,3,5$ and 7 were scanned per school

\section{Intervention effects}

In Table 4, for each outcome, means and SDs are presented per condition and per assessment. The multilevel analysis indicated no significant difference between the intervention schools and the control schools on any of the outcomes (Table 5). Regarding engagement scores, no significant difference was found between the groups, but the data indicate a trend in favour of the PEP-schools $(\beta=-0.53 ; p=.09)$. The proportion of engaged pupils in the PEP group slightly (non-significantly) 
increased between baseline and post-measurement from $48 \%$ to $52 \%$, whilst the percentage of engaged pupils in the control group significantly decreased $\left(X^{2}=8.64, p<.01\right)$ over the same time interval with $41 \%$ engaged pupils at baseline and $18 \%$ engaged pupils at post-measurement. This difference between PEP-schools and control-schools was found to be significant $\left(X^{2}=8.48, p<.01\right)$. The odds ratio at post measurement was $4.97,(95 \% \mathrm{Cl}=2.25,10.98)$, meaning that pupils who followed PEP were nearly five times more like to be engaged by the end of the schoolyear compared to pupils who were in the control condition. The found odds ratio is comparable to a Cohens $d$ of 0.88 , indicating a large effect.

Table 4: Means and standard deviations for PEP-schools and control-schools

\begin{tabular}{|c|c|c|c|c|c|c|}
\hline \multirow{3}{*}{ Outcome } & \multicolumn{3}{|c|}{ PEP schools } & \multicolumn{3}{|c|}{ Control schools } \\
\hline & \multicolumn{2}{|r|}{ Pre } & \multirow{2}{*}{$\begin{array}{c}\text { Post } \\
M(S D)\end{array}$} & \multicolumn{2}{|r|}{ Pre } & \multirow{2}{*}{$\begin{array}{c}\text { Post } \\
M(S D)\end{array}$} \\
\hline & $N$ & $M(S D)$ & & $N$ & $M(S D)$ & \\
\hline Wellbeing & 143 & $3.93(0.51)$ & $4.05(0.46)$ & 162 & $3.86(0.47)$ & $3.90(0.42)$ \\
\hline Self-esteem & 143 & $3.95(0.84)$ & $4.08(0.70)$ & 162 & $3.88(0.74)$ & $3.92(0.70)$ \\
\hline Engagement & 65 & $3.21(0.62)$ & $3.32(0.69)$ & 68 & $3.10(0.73)$ & $2.68(0.86)$ \\
\hline Emotional problems & 207 & $0.31(0.41)$ & $0.27(0.39)$ & 369 & $0.27(0.34)$ & $0.25(0.35)$ \\
\hline Prosocial behaviour & 207 & $1.61(0.46)$ & $1.61(0.45)$ & 369 & $1.54(0.42)$ & $1.66(0.38)$ \\
\hline Student-teacher & 223 & $10.60(1.40)$ & $10.91(1.65)$ & 377 & $10.50(1.45)$ & $11.06(1.34)$ \\
\hline \multicolumn{7}{|l|}{ relationship } \\
\hline Conflict & 223 & $1.42(0.63)$ & $1.49(0.76)$ & 377 & $1.53(0.76)$ & $1.40(0.60)$ \\
\hline Closeness & 223 & $3.77(0.57)$ & $4.16(0.63)$ & 377 & $3.81(0.52)$ & $4.18(0.58)$ \\
\hline Dependence & 223 & $1.76(0.77)$ & $1.77(0.80)$ & 377 & $1.78(0.74)$ & $1.72(0.78)$ \\
\hline Bullying & 126 & $1.40(0.91)$ & $1.34(0.81)$ & 149 & $1.29(0.80)$ & $1.36(0.81)$ \\
\hline Victimisation & 126 & $1.79(1.26)$ & $1.89(1.35)$ & 149 & $1.84(1.30)$ & $1.96(1.33)$ \\
\hline
\end{tabular}

Note: $N$ = number of respondents; $M=$ mean score; $S D=$ standard deviation

When comparing both intervention schools with regard to teacher-student relationship scores, a significant difference was found in conflict scores $(t(221)=2.06, p=.04)$. School A remained stable in conflict $(M=-0.01 ; S D=0.05)$ whilst School $B$ increased significantly in conflict $(M=0.18 ; S D=0.07$; $t(95)=5.83, p=.02)$. Additionally, both School A $(M=0.29 ; S D=0.05 ; t(126)=8.26, p<.01)$ and school $\mathrm{B}(M=0.47 ; S D=0.06 ; t(95)=5.83, p<.01)$ improved significantly in change scores for closeness, though this improvement was significantly higher in School A compared to school B $(t(221)=-2.27, p=.02)$. For the remaining outcomes, no significant differences between the PEP schools were found. 
Table 5: Intervention effects per outcome

\begin{tabular}{|c|c|c|c|c|c|c|c|}
\hline Outcome & $N$ & AIC & BIC & LogLik & $\boldsymbol{\beta}$ & $S E$ & $p$-value \\
\hline Wellbeing & 305 & 2333.45 & 2366.99 & -1157.72 & -1.76 & 1.91 & .454 \\
\hline Self-esteem & 305 & 1644.24 & 1677.78 & -813.12 & -0.43 & 0.41 & .410 \\
\hline Engagement & 132 & 352.15 & 378.10 & -167.08 & -0.53 & 0.17 & .090 \\
\hline Emotional problems & 576 & 2253.10 & 2292.30 & -1117.55 & 0.11 & 0.24 & 688 \\
\hline Prosocial behaviour & 576 & 2452.54 & 2491.74 & -1217.27 & 0.55 & 0.29 & .199 \\
\hline Student-teacher relationship & 600 & 4673.42 & 4712.99 & -2327.71 & 2.73 & 2.56 & .398 \\
\hline Conflict & 600 & 3955.89 & 3995.46 & -1968.95 & -2.42 & 1.30 & .203 \\
\hline Closeness & 600 & 3857.90 & 3887.48 & -1914.95 & -0.31 & 1.11 & .807 \\
\hline Dependence & 600 & 3433.17 & 3472.74 & -1707.59 & -0.62 & 0.77 & .509 \\
\hline Bullying & 275 & 785.10 & 817.65 & -383.55 & 0.14 & 0.16 & .492 \\
\hline Victimization & 275 & 989.70 & 1022.25 & -485.85 & -0.02 & 0.33 & .955 \\
\hline
\end{tabular}

Note: $N$ = number of respondents; $A I C=$ Akaike Information Criterion; BIC = Bayesian Information Criterion;

LogLik = Log Likelihood; $\beta=$ slope; SE = Standard Error

Implementation of PEP (fidelity checklist)

To assess the implementation fidelity of PEP, a list of twelve implementation activities was checked for the two intervention schools (Table 1). Both intervention schools did not update their policy based on the shared values identified during PEP. Also, both schools did not complete all five engagement scans over the course of the year. School A completed four scans and School B completed three scans. Additionally, School A organized three more PEP-talks than School B (respectively ten and seven). Both schools reported significant changes in the school's management during the year. In school A, the principal was replaced at the beginning of the school year, whilst in school B the principal was replaced halfway through the school year. Additionally, school B received a negative review of the national school inspection with regard to the quality of their education. The teachers explained in the PEP-talks that this review led to a setback in their motivation for implementing PEP. These contextual difficulties led to school B not deploying any PEP-related activities in the two months before post-measurement.

\section{Discussion}

There is accumulating evidence regarding the impact of positive education on the wellbeing of youth (Waters, 2011). Fundamental in positive education is the focus on wellbeing and engagement. The key aim of the Dutch Positive Education Programme (PEP) is therefore to promote a shift in perspective among teaching staff, from a teaching approach solely based on learning outcome 
indicators towards a teaching approach informed by the learning process indicators wellbeing and engagement. To enable and foster this change in perspective, schools applying PEP, implement activities at the whole school level based on the shared values of their team members. To date, there is a lack of empirical evidence regarding the effectiveness of interventions focusing on increasing engagement and well-being of children during regular classes.

Results from this cluster quasi-experimental trial indicated no significant effects on the proximal outcomes (wellbeing and engagement) or on the distal outcomes (social-emotional behaviour, student-teacher relationship, bullying and victimization). Despite the lack of significant results, a positive trend was detected for pupil engagement. Also, the number of engaged pupils increased slightly in the intervention group and decreased largely in the control group. In the current study, the odds that pupils would be sufficiently engaged by the end of the school year was five times higher in the PEP schools compared to the control schools. The non-significant findings from this study are in contrast to most previous research which has shown the significant positive impact of whole school interventions on wellbeing, behavioural adjustment and social emotional adjustment (e.g. Goldberg et al., 2018; Barry et al., 2017). The findings are in line with a national evaluation of the whole school approach SEAL (Social and Emotional Aspects of Learning) that did not detect any significant impact outcomes in terms of social and emotional skills, mental health difficulties and behaviour (Humphrey et al., 2010). Like PEP, teachers in the SEAL intervention expressed that they experienced beneficial effects of the programme, but the data failed to show the impact (Hallam, 2009).

A first possible explanation for the non-significant results in the multi-level analyses, is the limited implementation fidelity. Findings in the current study revealed implementation difficulties for both intervention schools. According to Durlak et al. (2011), social emotional learning programmes with a higher quality of implementation produce higher effect sizes on skills, attitudes, positive social behaviours, conduct problems, emotional distress and academic performance. Other research indicated that whole school approaches tend to show difficulties in implementation fidelity because they require a substantial amount of planning, organization and support beyond the classroom (Wilson and Lipsey, 2007; Wilson et al., 2003). For both intervention schools in the current study, implementation difficulties arose because of changes at the principal level, leading to practical difficulties in the implementation of PEP. Results from the pilot study of PEP already demonstrated the importance of principal-support for teachers to feel the confidence to focus on the process of learning (Goldberg, Prenger \& Bohlmeijer, 2018). Additionally, the teachers identified changes in managerial staff as a hindering factor in the implementation of PEP (Elfrink et al., 2017). This aligns with research findings that adequate support from school principals is a crucial factor in intervention 
implementation in schools (Kam, Greenberg \& Walls, 2003). Besides changes at the principal level, one of the intervention schools received a negative review of the national inspection. This negative review had a demotivating effect on the teachers, which is reflected in significantly higher conflict scores and significantly lower closeness scores on the student-teacher-relationship scale relative to the other intervention school. Lastly, there were nationwide teacher-strikes during the implementation of PEP, leading to changes in the planning of the workshops and leading to agitation amongst team members and diminished focus on implementing PEP.

A second possible explanation for not finding any significant multi-level effects is the bottom up approach deployed in the current study. As argued by Weare and Nind (2011), programmes that are more prescriptive tend to show larger effects in the short term, whilst bottom up programmes lead to well-rooted and long-lasting changes of attitudes and policies (Weare and Nind, 2011).

Institutions need to think carefully about a balance between adaptability and prescription (Lendrum, Humphrey \& Wigelsworth, 2012), to avoid becoming vague and diluted. During PEP, schools use their own values as a starting point for the implementation. There is no strict manual or timeline that they have to follow. This requires school teams to take a lot of initiative to integrate the programme in their school culture. In an earlier pilot feasibility study, teachers reported that they need some time to get used to this ownership (Elfrink et al., 2017; Goldberg, Prenger \& Bohlmeijer, 2018). Teachers described that, at first, they were missing a manual or certain guidelines, but later on during the implementation process, PEP "got into their DNA". Teachers described that by staying close to their own values, they got to own the programme and they felt comfortable to continue with the programme for the upcoming years, also without the assistance of trainers. They also described that they noticed higher wellbeing in their pupils and less behavioural incidents (Elfrink et al., 2017; Goldberg, Prenger \& Bohlmeijer, 2018). The bottom-up approach requires teachers to not only change their perspective, but also change their actions. Therefore, the duration of the current study may have been too short to identify the true effects of such a whole school approach. The evaluation of SEAL (Wigelsworth, Humphrey \& Lendrum, 2012) found a similar result for their twoyear time frame, which was identified to be too short to fully analyze the impact of the programme.

Despite the potential disadvantages of the implementation challenges and the bottom-up approach, a positive trend was detected for pupil engagement. The odds that pupils would be classified as 'sufficiently engaged' by the end of the school year was five times higher in the PEP schools compared to the control schools. This trend for engagement has the potential to lead to a wide range of positive outcomes in the future. Previous research has shown that engagement is a predictor of academic achievement (e.g. Pietarinen, Soini \& Phyalto, 2014), wellbeing (e.g. Gase et al., 2017) and social emotional learning (e.g. Buhs, Ladd \& Herald, 2006). Theoretically, this could 
mean that there is a hierarchy in the working mechanisms of PEP. To achieve improvements in pupils' wellbeing may take a longer time investment than it does for engagement, and wellbeing may be influenced by the level of engagement. Practically, relative to most other countries, pupils in the Netherlands are found to perform well in many measures of wellbeing (OECD, 2019), making it more difficult to detect significant improvements on wellbeing.

\section{Limitations and recommendations}

In the current study, several limitations and recommendations arose concerning the deployed measurements. Firstly, multiple scales showed poor reliability and were therefore excluded from the analyses. In the case of measuring wellbeing, the exclusion of the Kiddy KINDL-R resulted in not being able to include pupils from grade one to three in the analyses. Secondly, the level of wellbeing was determined using a health-related quality of life questionnaire. This questionnaire did provide insight in certain aspects of wellbeing, but did not fully cover the construct of wellbeing as defined by Keyes (2002). Therefore, the wellbeing results should be interpreted with caution. It may be useful to get independent observation scores on wellbeing, similar to what is done for the outcome engagement. In general, the current study heavily relied on self-report questionnaires. Earlier research (Elfrink et al., 2017; Goldberg, Prenger \& Bohlmeijer, 2018) already showed the added value of qualitatively investigating the impact of whole school approaches. This added value is supported by the current finding that most baseline scores were already quite high or low, making it difficult to determine improvements in the quantitative analyses. Combining qualitative and quantitative results in future research could provide more information on potential differences between pre and post on the outcomes.

Another limitation of the current implementation is the sample. Although the sample size for the number of pupils included in the research is rather high (639 in total), only two schools were included per condition. The low number of intervention schools resulted in the research being too sensitive for implementation difficulties. Additional research should therefore aim to include a larger number of schools per condition. Ideally, this could be done by finding regional or national support for the implementation of the programme, as research finds this to be an important factor for successful, effective and sustainable whole school approaches (Mart et al., 2015; Barry et al., 2017).

To gain better insight in the effectiveness of a whole school approach to impact wellbeing and engagement, additional studies employing a longitudinal design are needed. It is currently unclear whether an increase of engagement in the short term leads to enhanced wellbeing, reduced behavioural problems and improved academic achievement in the long term. To conduct such an extensive long term research, it is advised to deploy a randomized controlled trial with a larger 
sample. Also, it is advised to make use of triangulation in the measures and to add qualitative outcomes as part of the evaluation. Finally, it is recommended to develop an implementation measure to keep track of the implementation quality, as an addition to implementation fidelity. Based on the research recommendations done by Greenberg and colleagues (Greenberg, Domitrovich, Graczyk \& Zins, 2005), it is advised for future research to routinely assess implementation quality, broaden evaluation efforts, evaluate implementation quality together with stakeholders and examine how variation in implementation affect the results.

\section{Conclusion}

This study did not yield evidence for the effectiveness of a whole school approach in primary schools aiming to increase well-being and engagement of pupils. Nonetheless, a positive trend was observed for engagement which may be interpreted as a preliminary indication of the shift in perspective the whole school approach aimed to achieve. Future research with longer follow-up periods may reveal whether implementing a bottom up whole school approach based on the shared values of all staff members leads to long term and long lasting effects on pupils wellbeing. Importantly, staff of the participating schools were so convinced of the impact of the programme, they decided to continue its implementation. 


\section{References}

Adi, Y., Killoran, A., Janmohamed, K. \& Stewart-Brown, S. (2007a). Systematic Review of The Effectiveness of Interventions to Promote Mental Wellbeing in Primary Schools: Universal Approaches Which Do not Focus on Violence or Bullying. London: National Institute for Health and Clinical Excellence.

Banerjee, R., Weare, K. \& Farr, W. (2014). Working with 'Social and Emotional Aspects of Learning' (SEAL): Associations with school ethos, pupils' social experiences, attendance, and attainment. British Education Research Journal, 4(40), 718-742.

Barry, M.M., Clarke, A.M., \& Dowling, K. (2017).

Promoting social and emotional wellbeing in schools. Health Education, 117(5), 434-451.

Bavarian, N., Lewis, K. M., DuBois, D. L., Acock, A., Vuchinich, S., Silverthorn, N., Snyder, F. J., Day, J. Ji, P., \& Flay, B. R. (2013). Using social-emotional and character development to improve academic outcomes: a matched-pair, cluster-randomized controlled trial in lowincome, urban schools. The Journal of School Health, 83(11), 10.1111/josh.12093.

http://doi.org/10.1111/josh.12093

Borm, G. F., Fransen, J., \& Lemmens, W. A. J. G. (2007). A simple sample size formula for analysis of covariance in randomized clinical trials. Journal of Clinical

Epidemiology, 60(12), 1234-8.

Bradshaw, C. P., Mitchell, M. M., \& Leaf, P. J. (2010).

Examining the Effects of Schoolwide Positive Behavioral Interventions and Supports on Student Outcomes: Results From a Randomized Controlled Effectiveness Trial in Elementary Schools. Journal of Positive Behavior Interventions, 12(3), 133-

148. https://doi.org/10.1177/1098300709334798

Buhs, E. S., Ladd, G. W., \& Herald, S. L. (2006). Peer exclusion and victimization: Processes that mediate the relation between peer group rejection and children's classroom engagement and achievement?. Journal of Educational Psychology, 98(1), 1.

Buyse, E., Snoeck, G., Bertrands, E., Declecq, B., \& Laevers, F. (2009). Fundamenteel diepteonderzoek naar krachtige GOK-leeromgevingen. Onderzoeksluik 'Betrokkenheid en Welbevinden'. Leuven: Steunpunt GOK / Expertisecentrum Ervaringsgericht Onderwijs

Datu, J. A. D., King, R. B., \& Valdez, J. P. M. (2017). The academic rewards of socially-oriented happiness: Interdependent happiness promotes academic engagement. Journal of school psychology, 61, 19-31.

Dempster, A. P., Laird, N. M., \& Rubin, D. B. (1977). Maximum likelihood from incomplete data via the EM algorithm. Journal of the Royal Statistical Society Series $B$ (Methodological), 39(1), 1-38.

Dix, K. L., Slee, P. T., Lawson, M. J. \& Keeves, J. P. (2012). Implementation quality of whole-school mental health promotion and students' academic performance. Child and Adolescent Mental Health, 17(1), 45-51.

Durlak, J. A., Weissberg, R. P., Dymnicki, A. B., Taylor, R. D. \& Schellinger, K. B. (2011). The Impact of Enhancing Students' Social and Emotional Learning: A MetaAnalysis of School-Based Universal Interventions. Child Development, 82, 405-432.

Eisen, M., Zellman, G. L., \& Murray, D. M. (2003). Evaluating the Lions-Quest "Skills for Adolescence" drug education program: Second-year behavior outcomes. Addictive Behaviors, 28(5), 883-897. http://doi.org/https://doi.org/10.1016/S03064603(01)00292-1

Elfrink, T. R., Goldberg, J. M., Schreurs, K. M. G., Bohlmeijer, E. T., \& Clarke, A. M. (2017). Positive educative programme: A whole school approach to supporting children's well-being and creating a positive school climate: a pilot study. Health Education, 117(2), 215-230. https://doi.org/10.1108/HE-09-2016-0039 
El-Masri, M. M., \& Fox-Wasylyshyn, S. M. (2005). Missing data: An introductory conceptual overview for the novice researcher. Canadian Journal of Nursing Research, 37(4), 156-171.

Escamilla, H. (2017). Universidad Tecmilenio, Mexico. In The State of Positive Education. Retrieved from https://www.

worldgovernmentsummit.org/api/publications/docume nt/ 8f647dc4-e97c-6578-b2f8-ff0000a7ddb6

Estrada, C. A., Isen, A. M. \& Young, M. J. (1994). Positive affect improves creative problem solving and influences reported source of practice satisfaction in physicians. Motivation and emotion, 18(4) 285-299.

Field, A. P., Miles, J., \& Field, Z. (2012). Discovering statistics using $R$. London: Sage.

Fonagy, P., Twemlow, S. W., Vernberg, E. M., Nelson, J. M., Dill, E. J., Little, T. D., \& Sargent, J. A. (2009). A cluster randomized controlled trial of child-focused psychiatric consultation and a school systems-focused intervention to reduce aggression. Journal of Child Psychology and Psychiatry, 50, 607-616. doi:10.1111/j.1469-7610.2008.02025.x Fredrickson, B.L. (2001). The role of positive emotions in positive psychology: The broaden-and-build theory of positive emotions. American Psychologist, 56(3), 218226.

Fredrickson, B.L. \& Branigan, C. (2005). Positive emotions broaden thought-action repertoires: Evidence for the broaden-and-build model. Cognition and Emotion, 19(3), 313-332.

Gase, L. N., Gomez, L. M., Kuo, T., Glenn, B. A., Inkelas, M., \& Ponce, N. A. (2017). Relationships among student, staff, and administrative measures of school climate and student health and academic outcomes. Journal of school health, 87(5), 319-328.

Goldberg, J.M., Sklad, M., Elfrink, T.R., Schreurs, K.M.G., Bohlmeijer, E.T., \& Clarke, A.M. (2018). Effectiveness of interventions adopting a whole school approach to enhancing social and emotional development: a metaanalysis. European Journal of Psychology of Education. https://doi.org/10.1007/s10212-018-0406-9 Goldberg, J.M., Prenger, M., \& Bohlmeijer, E.T. (2018). Positief Educatief Programma. De wereld van het jonge kind, 46(2), 10-13.

Goodman, R. (2001). Psychometric properties of the Strengths and Difficulties Questionnaire. Journal of the American Academy of Child and Adolescent Psychiatry, 40(11), 1337-1345

Greenberg, M. T., Domitrovich, C. E., Graczyk, P. A., \& Zins, J. E. (2005). The study of implementation in schoolbased preventive interventions: theory, research, and practice. Washington, DC: Center for Mental Health Services, Substance Abuse and Mental Health Administration, U.S. Department of Health and Human Services.

Hallam, S. (2009). An evaluation of the Social and Emotional Aspects of Learning (SEAL) programme: Promoting positive behaviour, effective learning and well-being in primary school children. Oxford Review of Education, 35(3), 313-330.

Hoare, E., Bott, D., \& Robinson, J. (2017). Learn it, Live it, Teach it, Embed it: Implementing a whole school approach to foster positive mental health and wellbeing through Positive Education. International Journal of Wellbeing, 7(3).

Hoglund, W. L. G., Hosan, N. E., \& Leadbeater, B. J. (2012). Using your WITS: A 6-year follow-up of a peer victimization prevention program. School Psychology Review, 41(2), 193-214.

Hosan, N. E., \& Hoglund, W. (2017). Do Teacher-Child Relationship and Friendship Quality Matter for Children's School Engagement and Academic Skills?. School Psychology Review, 46(2), 201-218.

Hughes, J., \& Kwok, O. M. (2007). Influence of studentteacher and parent-teacher relationships on lower achieving readers' engagement and achievement in the 
primary grades. Journal of Educational Psychology, 99(1), 39.

Humphrey, N., Lendrum, A., \& Wigelsworth, M. (2010). Social and emotional aspects of learning (SEAL) programme in secondary schools: National evaluation. London: Department for Education. Available from: https://www.education.gov.uk/publications/eOrderingD ownload/DFE-RR049.pdf

Isen, A. M., Rosenzweig, A. S., \& Young, M. J. (1991). The influence of positive affect on clinical problem solving. Medical Decision Making, 11(3), 221-227.

Jane-Llopis, E., Barry, M. M, Hosman, C., \& Patel, V. (2005). Mental health promotion works: a review. Promotion \& Education, (Supp/ 2), 9-25.

Jones, S.M. \& Bouffard, S.M. (2012), Social and emotional learning in schools: from programs to strategies: social policy report. Society for Research in Child Development, 26(4), 3-22.

Kam, C., Greenberg, M.T., \& Walls, C.T. (2003).

Examining the Role of Implementation Quality in SchoolBased Prevention Using the PATHS

Curriculum. Prevention Science, 4(1), 55-63.

Keyes, C.L.M. (2002). The mental health continuum: From languishing to flourishing in life. Journal of Health and Social Behavior, 43(2), 207-222.

Koomen, H.M.Y., Verschueren, K., \& Pianta, R.C. (2007). Leerling Leerkracht Relatie Vragenlijst (LLRV). Bohn Stafleu van Loghum, Houten, the Netherlands. Kuhl, J. (2000). A functional-design approach to motivation and self-regulation: the dynamics of personality systems interactions. In M. Boekaerts, P. R. Pintrich, and M. Zeidner (Eds.), Handbook of selfregulation (pp. 111-169). Academic Press, San Diego. Laevers F. (1999). The project Experiential Education. Well-being and involvement make the difference. Early Education, 27, 4
Laevers, F. \& Laurijssen, J. (2001). Welbevinden, betrokkenheid en tevredenheid van kleuters en leerlingen in het basisonderwijs. Een draaiboek voor systematische observatie en bevraging. Eindrapport OBPWO-project 98.07. Leuven: Onderzoekscentrum voor Kleuter- en Lager Onderwijs.

Laevers, F., \& Heylen, L. (2013) Een procesgerichte aanpak voor 6-tot 12 -jarigen in het basisonderwijs. Averbode: CEGO Publishers.

Laevers, F., Peeters, A. \& Vanwijnsberghe P. (1994). De Leuvense Betrokkenheidsschaal voor Leerlingen (LBS-L). Reeks: Onderzoek, opleiding, begeleiding, nr. 2. Leuven, Centrum voor Ervaringsgericht Onderwijs.

Lendrum, A., Humphrey, N. and Wigelsworth, M. (2013). Social and emotional aspects of learning (SEAL) for secondary schools: implementation difficulties and their implications for school based mental health promotion. Child Adolescent Mental Health, 18(3), 158-164.

MacNeil, A. J. \& Prater, D. L. \& Busch, S. (2009). The effects of school culture and climate on student achievement. International Journal of Leadership in Education, 12, 73-84. 10.1080/13603120701576241.

Mart, A. K., Weissberg, R. P., \& Kendziora, K. (2015). Systemic support for social and emotional learning in school districts. In J. A. Durlak, C. E. Domitrovich, R. P. Weissberg, \& T. P. Gullotta (Eds.), Handbook of social and emotional learning: research and practice (pp. 482499). New York: Guilford.

Meyers, D. C., Gil, L., Cross, R., Keister, S., Domitrovich, C. E., \& Weissberg, R. P. (2015). CASEL guide for schoolwide social and emotional learning. Chicago, IL: CASEL.

Norrish, J. M. \& Vella-Brodrick, D. A. (2009). 'Positive psychology and adolescents: Where are we now? Where to from here?. Australian Psychologist, 44(4), 270-278 Norrish, J.M., Williams, P., O'Connor, M. \& Robinson, J. (2013). An applied framework for positive Education. International Journal of Wellbeing, 3(2), 147-161. 
Oberle, E., Domitrovich, C. E., Meyers, D. C., \&

Weissberg, R. P. (2016). Establishing systemic social and emotional learning approaches in schools: A framework for schoolwide implementation. Cambridge Journal of Education, 46(3), 277-297.

$\operatorname{OECD}(2019$, July 6). Better life index: the Netherlands. Retrieved from:

http://www.oecdbetterlifeindex.org/countries/netherla nds/

Olweus, D. (1996). Bullying at School: Knowledge Base and an Effective Intervention Programa. Annals of the New York Academy of Sciences, 794, 265-276.

doi:10.1111/j.1749-6632.1996.tb32527.x

Pietarinen, J., Soini, T. \& Pyhältö, K. (2014). Students' emotional and cognitive engagement as the determinants of wellbeing and achievement in school. International Journal of Educational Research, 67, 40-51. Ravens-Sieberer, U. and Bullinger, M. (1998). Assessing health-related quality of life in chronically ill children with the German KINDL: first psychometric and content analytical results. Quality of Life Research, 7(5), 399-407.

Reyes, M. R., Brackett, M. A., Rivers, S. E., White, M., \& Salovey, P. (2012). Classroom emotional climate, student engagement, and academic achievement. Journal of educational psychology, 104(3), 700.

Rowe, G., Hirsh, J. B. \& Anderson, A. K. (2007). Positive affect increases the breadth of attentional selection. Proceedings of the National Academy of Sciences, 104(1), 383-388.

Seligman, M. E. (2007). The optimistic child: A proven program to safeguard children against depression and build lifelong resilience. Houghton Mifflin Harcourt, Boston.

Seligman, M.E.P. \& Csikszentmihalyi, M. (2000). Positive psychology: an introduction. American Psychologist, 55(1), 5-14.

Seligman, M.E.P., Ernst, R.M., Gillham, J., Reivich, K. \& Linkins, M. (2009). Positive education: positive psychology and classroom interventions. Oxford Review of Education, 35(3), 293-311.

Sin, N.L. \& Lyubomirsky, S. (2009). Enhancing well-being and alleviating depressive symptoms with positive psychology interventions: a practice-friendly metaanalysis. Journal of Clinical Psychology, 65(5) 467-487. Snijders, T., \& Bosker, R. (1999). Multilevel analysis: An introduction to basic and advanced multilevel modeling. London, Thousand Oaks, New Delhi: SAGE Publications Ltd.

Tennant, R., Goens, C., Barlow, J., Day, C. \& StewartBrown, S. (2007). A systematic review of reviews of interventions to promote mental health and prevent mental health problems in children and young people. Journal of Public Mental Health, 6(1), 25-32.

Ttofi, M. M., \& Farrington, D. P. (2011). Effectiveness of school-based programs to reduce bullying: A systematic and meta-analytic review. Journal of Experimental Criminology, 7(1), 27-56. doi:

10.1080/1754730X.2008.9715730

Waters, L. (2011). A review of school-based positive psychology interventions. The Australian Educational and Developmental Psychologist 28(2), 75-90.

Weare, K. \& Nind, M. (2011). Mental health promotion and problem prevention in schools: what does the evidence say?. Health promotion international, 26(1), 29-69.

Wells, J., Barlow, J., \& Stewart-Brown, S. (2003). A systematic review of universal approaches to mental health promotion in schools. Health Education, 103(4), $197-220$

White, M. A., \& Waters, L. E. (2014). A case study of 'The Good School:' Examples of the use of Peterson's strengths-based approach with students. The journal of positive psychology, 10(1), 69-76.

Wigelsworth, M., Humphrey, N., \& Lendrum, A. (2013). Evaluation of a School-wide Preventive Intervention for Adolescents: The Secondary Social and Emotional 
Aspects of Learning (SEAL) Programme. School Mental Health, 5(2), 96-109.

Wilson, S .J., Lipsey, M. W., \& Derzon, J. H. (2003). The effects of school-based intervention programs on aggressive behavior: A meta-analysis. Journal of Consulting and Clinical Psychology, 71(1), 136-149. doi: 10.1037/0022-006X.71.1.136

Wilson, S. J., \& Lipsey, M.W. (2007). School-based interventions for aggressive and disruptive behavior: update of a meta-analysis. American Journal of Preventive Medicine, 33(2), 130-143.

World Government Summit (2017). The state of positive education. Retrieved January 22th, 2018, from https://www.worldgovernmentsummit.org/api/publicati ons/document/8f647dc4-e97c-6578-b2f8-

ff0000a7ddb6?mc_cid=7ba0f17ca8\&mc_eid=713157905 6

World Health Organization (WHO). (1998). Health Promoting evaluation: recommendations for PolicyMakers, report of the WHO European Working Group on Health Promotion Evaluation. Copenhagen: WHO.

Wyn, J., Cahill, H., \& Holdsworth, R., (2000).

MindMatters, a whole-school approach promoting mental health and wellbeing. Australian \& New Zealand Journal of Psychiatry, 34, 594-601 


\section{Appendix A}

\section{Engagement - Score}

$\mathbf{1}=$ Rarely attains to actual activity; stares a lot, absent, apathetic; just brief moments of attention; hard to reach; when active the actions are stereotypical, simple and require minimal effort; mental activity is minimal; understands little.

$2=$ Mostly interrupted activity

3 = Mostly attains to activity with progress in the actions; is there with his mind, but misses the engagement signals: often distractible, limited attention span, not really absorbed or touched by the activity

$4=$ The pattern mostly consist of engagement

$\mathbf{5}$ = Concentrated and works continuously most of the time; hard to distract; alert; absorbed and fascinated; mentally active on a high level; appeals to his full potential; acts on the edge of his abilities; enjoys exploring

$?=$ Not enough information, very unclear image or not yet determined

\section{Well-being-Score}

1 = Doesn't feel good most of the time; lacks enjoyment; often tensed, misses inner peace; lots of signals of negative experiences; little confidence, low self-esteem; relationships with others are negatively loaded; mainly: not feeling happy

$\mathbf{2}=$ In the pattern mostly consists with discontentment 3 = A neutral or mixed pattern, signals of not feeling good; having fun is transitory and not intense $y$; relationships with the environment are not optimal, but also not alarming;: not happy nor unhappy 4 = The pattern mostly consists with well-being $\mathbf{5}=$ Feels optimal most of the time: enjoys at the highest level; appears to be full of vitality; is relaxed and experiences inner peace; is open for his environment and adjusts to it rapidly; is confident and acts in a resilient manner; is happy and content with himself $?=$ Not enough information, very unclear image or not yet determined 
$\underline{\text { Intermezzo }}$

The Dutch Positive Education Programme in practice: Real life examples of implementing a whole school approach in special needs education

Modeled after the original publication:

Goldberg, J.M., Prenger, M., \& Bohlmeijer, E.T. (2018). Positief Educatief Programma. De wereld van het jonge kind, 46(2), 10-13. 


\section{PEP at het Mozaïek in Almelo}

Starting in the academic year 2016/2017, PEP was implemented in special needs education. In the current intermezzo, Het Mozaïek in Almelo is put central. This school provides education for children aged 4 to 7, with behavioural and developmental problems. During the first year of PEP, Het Mozaïek, developed two life rules: 'you will find fun here' and 'shine in your own way'. The life rules represent the values 'fun' and 'talent enhancement'.

\section{PEP in the classroom}

Using the Leuven Engagement Scale, teacher Marlou scans the engagement of her students in all the different thematic corners of her classroom. She notices low engagement in the reading corner. Keeping the first life rule in mind (you will find fun here), she decides to rebuild the reading corner. She buys a bunk bed, to make the reading corner more attractive and to increase the engagement even more, children can decide to read with a flashlight under the blankets. A few weeks later, the engagement scores are much higher. The students find it relaxing and

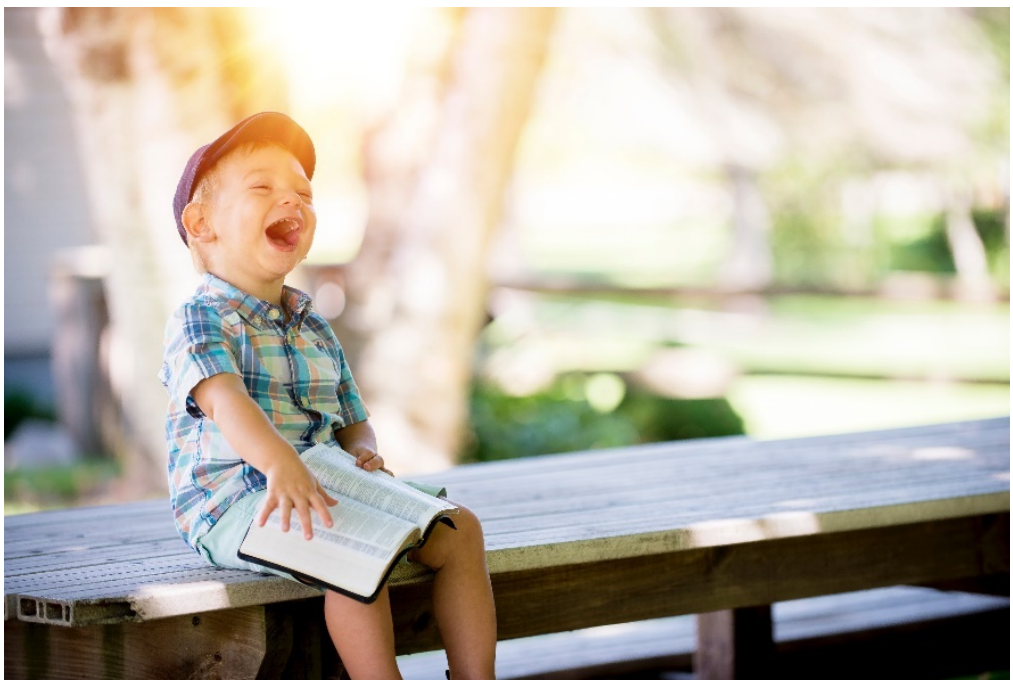
comfortable between all the cushions.

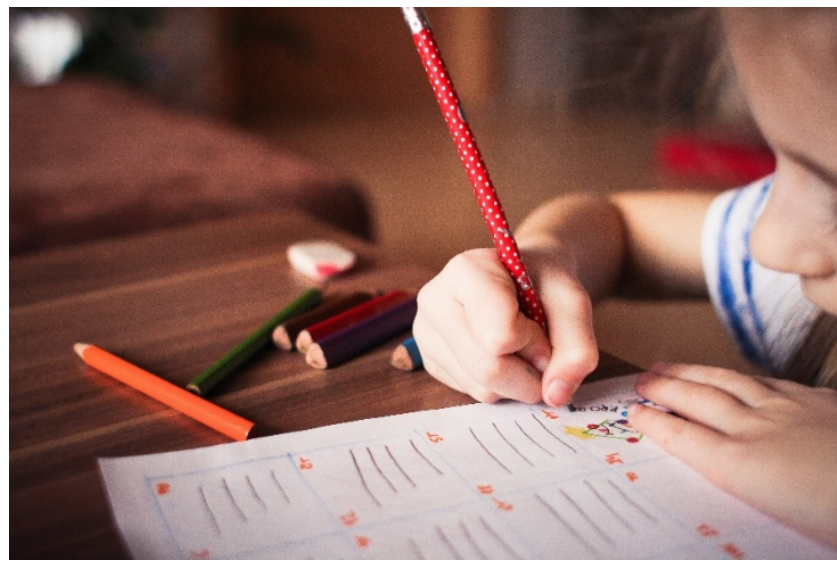

Teacher Esther got a new student in her group. This new student did not like any of the joint activities (worksheets). When all the children were working, he often crawled underneath his table. Esther decided to fit her approach to his needs and glued the worksheets to the bottom of his table. He did 
all the exercises on the worksheet flawless. After a while, he was ready to do his worksheets regularly like the other children.

\section{PEP in the school environment}

The team members scanned the engagement of the students at the schoolyard. They noticed that the little variety in activities resulted in low engagement. To increase the engagement, a barefoot path was laid out on which the students can experience new sensations. The team connects the path with different themes, like fairytales. Children can walk on

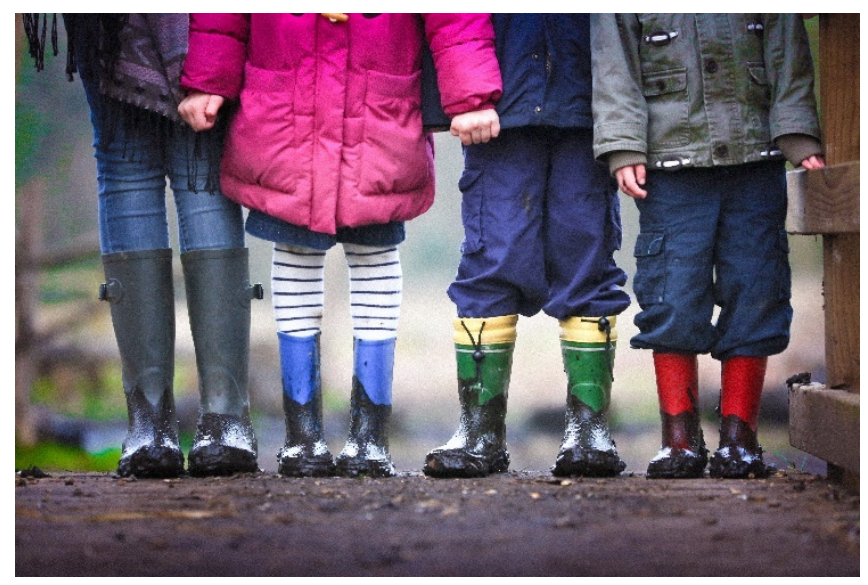
seven-league boots or collect Little Red Riding Hood's cookies. A rich learning environment, leads to the urge to explore and therefore to a high degree of engagement. The team notices that, when there is enough to do for the students in the schoolyard, there are little to no incidents.

\section{PEP in the team}

The whole school approach really manifests itself when you go to the restroom at Het Mozaïek. There is big poster at the wall with a picture of all the colleagues on it, on which you can write something nice for your them. Currently, there is a poster which entitles 'Do you see the talent of your colleague? Please write it down!'. This aligns with the value talent enhancement.

\section{PEP with parents}

Teacher Miranda was having a conversation with the mother of a student that recently started at Het Mozaiëk. The mother was quite nervous, but as soon as Miranda started to tell which kind of activities her son did at school and what he was good at, the mother began to cry. She told Miranda 
that for the first time in months, her child feels comfortable again. "He comes home whistling and he has completely flourished". Miranda adds that often you hear that parents have had negative experiences at schools. Parent conversations were never about what was actually going right. 


\section{Chapter 5:}

Wellbeing and Social Safeness Questionnaire (WSSQ): Initial psychometric assessment of a short digital screening instrument for primary school children

J. M. Goldberg, A. M. Clarke, P. M. ten Klooster, K. M. G. Schreurs \& E. T. Bohlmeijer. (2019).

Wellbeing and Social Safeness Questionnaire (WSSQ): Initial psychometric assessment of a short digital screening instrument for primary school children. Cogent Education, 6(1). 


\section{Abstract}

In the Netherlands, all schools are required to develop a wellbeing and social safeness policy. Despite this legislation, there is currently no adequate instrument available to measure the wellbeing and social safeness. Therefore, the present study investigates the psychometric properties of the Wellbeing and Social Safeness Questionnaire (WSSQ). The WSSQ is a Dutch online questionnaire and was filled in by 1468 students (grade 5-8, age 8-12) from 14 Dutch primary schools. Exploratory and confirmatory factory analysis showed an adequate fit for a two factor structure consisting of (1) School-Related Wellbeing and Social Safeness, and (2) Generic Wellbeing. Adequate reliability and construct validity were demonstrated for both factors. Conceptually, it was found that school-related social safeness and wellbeing are not empirically separate factors, however, generic wellbeing may deserve separate consideration. The initial psychometric properties of the WSSQ are promising. This online instrument could potentially be used as a screening tool for teachers to measure social safeness and wellbeing of students. 


\section{Introduction}

The impact of bullying has led to national anti-bullying legislation in e.g. The Netherlands, Canada, Australia, United States, Austria, United Kingdom, New Zealand. In the Netherlands, the national anti-bullying legislation obligates schools to monitor the social safeness of their students. Schools therefore need to have an efficient active safety policy in place, to do everything needed in securing a safe environment for their students. Monitoring the social safeness of the students provides information to implement this policy. A school is only able to act on their policy when they have insight in the objective and subjective social safeness of their students (Ministerie van Onderwijs, Cultuur en Wetenschap, 2016), resulting in a need for an effective measurement instrument.

Extensive research has been carried out in relation to the concept of social safeness in adults (Gilbert et al., 2009; Kelly, Zuroff, Leybmam \& Gilbert, 2012), but there is a dearth of research on children's social safeness. Gilbert et al., $(2009$, p. 136) define social safeness in adults as the "warm, calming affective experience of feeling cared about, reassured by and connected to other people". Kelly et al. (2012) state that social safeness is important for the health and wellbeing of an individual and is related to feelings of being accepted. Additional research by Gilbert et al. (2008), Gilbert (2010)) shows that social safeness correlates negatively with feelings of depression, anxiety, hostility and feelings of inferiority amongst adults. The World Government Summit in collaboration with the International Positive Education Network states that, to achieve socially valued outcomes, wellbeing is instrumental (World Government Summit, 2017).

When looking at the wellbeing of children more specifically, it is found that their wellbeing is influenced by external and internal child factors. External factors are for example: social economic status, quality of family relationships, quality of social network and a healthy and safe environment. Internal factors are for example: optimism, confidence, locus of control and social skills (Hicks, Newton, Haynes, \& Evans, 2011; Laevers, Heylen, \& Daniëls, 2014; Lippman, Moore, \& McIntosh, 2009; Michaelson, Mahony, \& Schifferes, 2012; Thompson \& Aked, 2009; UNICEF, 2007). Wellbeing is associated with better learning outcomes (Berger, Alcalay, Torretti, \& Milicic, 2011; Fredrickson, 2001; Martin \& Marsh, 2008 \&, 2009; Oswald, Proto, \& Sgroi, 2015; Pietarinen, Soini, Pyhältö, 2014; Rowe, Hirsch \& Anderson, 2007), greater creativity and holistic thinking (Fredrickson, 2001).

To the authors' knowledge, there is no research available on the relationship between wellbeing and social safeness in children. Previous research, however, indicates a relationship between social experiences (e.g. social support or bullying) and wellbeing in children. A meta-analysis comparing 
246 correlational studies found a small but positive association between social support and wellbeing of children and adolescents (Chu, Saucier, \& Hafner, 2010). Natvig, Albrektsen, and Qvarnstrøm (2003) found in their study with 887 adolescents that social support from teachers enhanced student happiness significantly and that the happiest pupils experienced significantly more support than students who reported to be unhappy. Tian, Zhao, and Huebner (2015) state in their research that social contextual factors (e.g. teacher support, classmate support) are crucial for adolescents' optimal subjective wellbeing in school. Additionally, research with over fifteen thousand children in public and private schools showed an association between bullying and poor psychosocial adjustment (Nansel et al., 2001). A more specific study with 1058 schoolchildren aged ten to twelve, showed that social bullying negatively correlated with indicators of subjective wellbeing (Navarro, Ruiz-Oliva, Larrañaga, \& Yubero, 2015).

To date, there is no instrument available in the Netherlands that can measure social safeness and wellbeing in schools. Existing questionnaires for children tend to focus on either psychological problems (e.g. SDQ (Goodman, 2001)) or Health Related Quality of Life (e.g. Kidscreen (RavensSieberer et al., 2007) or KINDL (Ravens-Sieberer \& Bullinger, 1998)). Although these instruments show good psychometric properties, they do not include all aspects that are particularly important for wellbeing and social safeness. The identification of low scoring individuals on these topics can stimulate teachers to implement interventions, aimed at increasing the wellbeing and social safeness of their children. This in turn, can lead to a wide range of beneficial outcomes (e.g. learning outcomes, creativity, psychological adjustment), as described earlier.

This paper therefore describes the first findings of the development and psychometric qualities of such an instrument, the Wellbeing and Social Safeness Questionnaire (WSSQ). This Dutch instrument intends to measure wellbeing and social safeness of primary school students aged 8-12. The current research describes the construction and preliminary validation of the WSSQ.

\section{Methods}

\section{Pilot study}

Before conducting the current research, 553 students filled in a draft version of the WSSQ on an IPad and 40 students were interviewed in focus groups (Berends \& Eenshuistra, 2016). Results from this pilot study indicated that the students were enthusiastic about the design of the tool and reported no difficulties in completing the questionnaire. The students had some suggestions to improve the 
wordings of several specific items. The results from this pilot study informed a revision of the questionnaire, taking into account the students' recommendations (Berends \& Eenshuistra, 2016).

\section{$\underline{\text { Participants }}$}

In April 2016, schools were recruited through convenience sampling. To ensure that the composition of the sample was similar to the composition of the Netherlands as a whole (Central Bureau of Statistics, CBS), the schools were recruited based on the social economic status, ethnicity and urbanity of their students. This information was gathered using CBS-data presented per zip code. The sample consisted of 1468 grade 5-8 students divided over 14 primary schools. The students were equally divided amongst grades (5-8) and age (8-12). 51.4\% of the participants was male.

\section{Procedure}

Prior to filling in the WSSQ, parents were informed about the goals of the research and about the possibility to object against using the data of their children. When parents did not object, passive informed was given for using the data. To ensure a uniform data collection, a researcher visited the schools and gave the students a verbal standardized introduction, explaining how to fill in the WSSQ and explaining the difficult terms (as described in Berends \& Eenshuistra, 2016). To avoid order effects, half of the students filled out the digital WSSQ first, followed by two theoretically related paper-and-pencil questionnaires, whereas the other half of the students filled out the measurements the other way around. To be able to match the data, while guaranteeing anonymity, students were given a unique student number.

As the WSSQ is a digital questionnaire (online application), the WWSQ-data were collected via an Ipad. There was no option for the students to fill in "don't know" or to skip a question, resulting in fully completed questionnaires with nomissing data. Both Likert scales and intensity items were used in the WSSQ. The range of answer categories was modified per item (e.g. very unhappy-very happy; totally disagree-totally agree). The layout of the WSSQ involves emoticons with matching colours, and is therefore both easy and fun to fill out for the students. The emoticons are provided in the appendix (Figure 1).

\section{$\underline{\text { Scale construction }}$}

The items for the WSSQ were developed based on concepts relevant to social safeness and wellbeing at the school level (Table 1). Subject matter experts were involved in the construction of these items. The formulation of the items of the WSSQ is deliberately concise and concrete, to make the questions understandable for young children. To conceptualize and measure wellbeing, Keyes (2005) describes three main components of wellbeing: emotional wellbeing, social wellbeing and 
psychological wellbeing. High levels on these factors indicate a state of flourishing. Laevers et al. (2014) state that flourishing in schools can be seen in signals of satisfaction, contentment and experiencing virtue. The child is feeling good in general and is content with his or her life (hedonic wellbeing), but also lives towards optimal personal development (eudemonic wellbeing). When applying Keyes' definition of wellbeing at a school level, Long, Huebner, Wedell, and Hills (2012) identified four factors critical to wellbeing in their study with 921 adolescents. These included positive emotions, negative emotions, fear-related negative emotions, and school satisfaction.

Based on the above described conceptualization of wellbeing, six items were formulated towards the concepts of hedonic wellbeing (emotional wellbeing), with four items reflecting different school situations in which the student can experience positive emotions, one item reflecting general satisfaction with life and one item reflecting vitality. Also, six items were formulated towards the concepts of eudemonic wellbeing (psychological and social wellbeing), with one question for each of the concepts: optimism, resilience, positive relations, selfappreciation, autonomy and meaning in life.

Additional to the social components embedded in hedonic and eudemonic wellbeing, eight items were formulated specifically aimed at measuring experienced bullying and subjective social safety evaluations. Including these items aligns with the policy of the Dutch government (Ministerie van Onderwijs, Cultuur en Wetenschap, 2016) and with the (fear related) negative emotions in the operationalization by Long et al. (2012). Of these eight items, four were generated based on actually experienced social behaviour, which is the amount of incidents in which a student was the victim (or felt a victim) as a result of actions of someone else. The incidents can consist of personally experienced bullying behavior or indirectly witnessed bullying of others. The remaining four items measure the degree in which a student experiences worries about victimization and included feeling safe in the classroom, getting along with classmates and feeling safe under supervision. 
Table 1: Scale construction

\begin{tabular}{|c|c|c|}
\hline Concept & Meaning & Items \\
\hline Positive feelings & $\begin{array}{l}\text { The child enjoys, is having fun, smiles, sings, } \\
\text { makes contact }\end{array}$ & $\begin{array}{l}\text { 1) How do you feel right now? } \\
\text { 2) How do you feel most of the time? } \\
\text { 3) How do you feel most of the time at } \\
\text { school? } \\
\text { 4) How do you feel when there is no adult } \\
\text { present during breaks? }\end{array}$ \\
\hline Satisfaction with life & $\begin{array}{l}\text { The child is flourishing within his or her } \\
\text { opportunities and his or her environment }\end{array}$ & 5) How content are you with your life? \\
\hline Vitality & $\begin{array}{l}\text { The child feels healthy, is energetic, feels } \\
\text { relaxed }\end{array}$ & 6) I feel healthy \\
\hline Optimism & $\begin{array}{l}\text { The child expects a positive outcome in most } \\
\text { situations. The child has an external locus of } \\
\text { control }\end{array}$ & $\begin{array}{l}\text { 7) If I have a problem at school, it usually } \\
\text { ends well }\end{array}$ \\
\hline Resilience & $\begin{array}{l}\text { The child regulates negative emotions in the } \\
\text { case of setbacks }\end{array}$ & $\begin{array}{l}\text { 8) If I have a bad experience at school, I } \\
\text { will be happy soon after }\end{array}$ \\
\hline Relationships with others & $\begin{array}{l}\text { The child is happy to engage in contact with } \\
\text { others, receives support from those contacts } \\
\text { and feels appreciated by others }\end{array}$ & 9) I have nice friends \\
\hline Self-appreciation & $\begin{array}{l}\text { The child feels self-worth and that his life is } \\
\text { important; is satisfied with his or her abilities }\end{array}$ & 10) I like myself \\
\hline Autonomy & $\begin{array}{l}\text { The child makes his or her own decisions } \\
\text { about his or her life, within his or her age } \\
\text { appropriate boundaries }\end{array}$ & 11) I can choose at school what I want to do \\
\hline Meaning in life & $\begin{array}{l}\text { The child values his or her life as important } \\
\text { and worthwhile }\end{array}$ & 12) It is good that I exist \\
\hline \multirow[t]{2}{*}{ Experienced bullying } & $\begin{array}{l}\text { The degree in which students personally have } \\
\text { experienced victimization }\end{array}$ & $\begin{array}{l}\text { 13) Classmates bully me (emotionally, } \\
\text { verbally or both) } \\
\text { 14) Classmates hit me or kick me } \\
\text { (physically) }\end{array}$ \\
\hline & $\begin{array}{l}\text { The degree in which students noticed } \\
\text { victimization at others }\end{array}$ & $\begin{array}{l}\text { 15) Classmates fight with each other } \\
\text { 16) In this class you get laughed at when } \\
\text { you ask a silly question }\end{array}$ \\
\hline \multirow[t]{2}{*}{$\begin{array}{l}\text { Subjective social safety } \\
\text { evaluations }\end{array}$} & $\begin{array}{l}\text { The degree in which students experience the } \\
\text { environment to be safe }\end{array}$ & $\begin{array}{l}\text { 17) I feel safe in this class (globally) } \\
\text { 18) I feel safe with this teacher (under } \\
\text { supervision) }\end{array}$ \\
\hline & $\begin{array}{l}\text { The degree in which students experience the } \\
\text { environment to be positive }\end{array}$ & $\begin{array}{l}\text { 19) I enjoy my class } \\
\text { 20) I get along with most of my classmates }\end{array}$ \\
\hline
\end{tabular}

\section{Measures}

In order to get an indication of the convergent and discriminant validity of the WSSQ, two paper and pen questionnaires that were considered to be theoretically related to the constructs "wellbeing" and "social safeness", were completed by the students: Kidscreen -27 (Ravens-Sieberer et al., 2007)) and Successful Schools questionnaire (Berend, 2015).

The Kidscreen-27 contains 27 items addressing the experience of health and wellbeing (quality of life) of the student. The instrument is specifically suitable for children older than 8 years. The Kidscreen addresses quality of life in the following areas: 1. Physical Well-Being (e.g. Have you felt fit and well?); 2. Psychological Well-Being (e.g. Has your life been enjoyable?); 3. Autonomy \& Parents (e.g. Have you had enough time for yourself?); 4. Peers \& Social Support (e.g. Have you spent time with your family?); and 5. School Environment (e.g. Have you been happy at school?). A 
psychometric evaluation of the Kidscreen- 27 showed sufficient construct validity, an interpretable factor structure that explained $56 \%$ of the variance, and acceptable reliability of the total scale and all subscales with Cronbach Alpha's above .70 (Ravens-Sieberer et al., 2007). In the current research, the total score showed good reliability (Cronbach's Alpha of .83), the individual subscales showed questionable to acceptable Cronbach's Alpha's ranging from .61 to .72, with subscale 4 "peers \& social support" as an exception showing a poor Cronbach's Alpha of .47. Therefore, subscale 4 wasn't analyzed independently. Answer categories of the Kidscreen-27 ranged from never (1) to always (5).

The Successful Schools questionnaire consists of 12 items addressing the degree to which the students experience unsafe situations at school (bullying, threatening, abusing, theft or victimization) and the degree to which they feel unsafe (Berends, 2015). Since no validated social safeness questionnaire was available to use in this study, this non-validated questionnaire was selected as on the base of its face-validity. In the current research, the reliability was found to be good (Cronbach's Alpha of .81). Sample questions from this instrument include: "Do other children bully you sometimes at school?" and "Do you feel unsafe in the classroom?". Answer categories ranged from never (1) to always (3).

\section{Results}

\section{Exploratory factor analysis}

The dataset was randomly divided in two separate samples of respectively 733 and 734 participants. To analyse the factor structure of the WSSQ, first an exploratory factor analysis with robust maximum likelihood estimation was conducted on the data of the first sample in the statistical programme Mplus 7.11 (Muthén \& Muthén, 1998-2010). The number of factors underlying the WSSQ items was determined using parallel analysis (Hayton, Allen, \& Scarpello, 2004), as the number of factors in the real data with eigenvalues greater than the average eigenvalue from random data.

The parallel analysis in the exploratory factor analysis on the first sample, indicated a two factor structure. Out of all the items, fifteen items loaded predominantly on the first factor (factor loadings ranging from .24 to .74) and five items loaded predominantly on the second factor (factor loadings ranging from .49 to .65$)$. Factor 1 consisted of all items related to school and factor 2 consisted of all general items (item 2, 5, 6, 10 and 12). The cumulative proportion explained variance of both factors 
was found to be $27.44 \%$. Since the factor loading of item $4(.24)$ was clearly lower than all other items and below the recommended .32 (Tabachnick \& Fidell, 2013), it was decided to leave this item out of the confirmatory analyses.

\section{Confirmatory factor analysis}

To cross-validate the factor structure, confirmatory factor analysis with robust maximum likelihood was conducted using the data of the second sample. The factor model derived from the exploratory analysis was tested with respect to fit to the data and compared with a strict unidimensional model in which all items loaded on a single dimension. The comparative fit index (CFI), the standardized root mean square residual (SRMR) and the root mean square error of approximation (RMSEA) were used to examine and compare the fit of the models. To be considered respectively an acceptable or good fit, CFI values should be $\geq .90$ or $\geq .95$, SRMR values should be $\leq .10$ or $\leq .08$, and RSMEA values should be $\leq .08$ or $\leq .06$ (Browne \& Cudeck, 1993; Hu \& Bentler, 1998). Additionally, the difference in fit between both models was statistically tested using the Mplus DIFFTEST procedure, which appropriately computes differences in chi-square values of nested models, with a $p$-value $\leq 0.05$ indicating a better fit for the least restrictive model.

The two factor structure showed a clearly better fit on CFI, RMSEA and SMRM (Table 2). The ChiSquare test for difference testing compared both the fits and also indicated a better fit for the two factor model $(X 2=103.18, p<.001)$. RMSEA and SRMR indicated adequate and good fit for the correlated two-fact model, but CFI was below the threshold for adequate fit.

Table 2: Fit indices confirmatory factor analysis with robust maximum likelihood

\begin{tabular}{llllllll}
\hline Model & $\mathrm{X}^{2}$ & $d f$ & CFI & RMSEA & SRMR & $\Delta X^{2}$ & $p$ \\
\hline One factor & 539.62 & 152 & 0.78 & 0.059 & 0.065 & & \\
Two factor & 426.91 & 151 & 0.84 & 0.050 & 0.057 & 103.18 & .000 \\
Two factor with error correlations & 319.56 & 146 & 0.90 & 0.041 & 0.047 & &
\end{tabular}

Note: CFI = comparative fit index, SRMR = standardized root mean square residual, RMSEA = root mean square error of approximation.

\section{Error correlations}

Initial models were based on the restrictive assumption that the error terms of the items were uncorrelated. However, findings of correlated error terms are common in psychological measures (Byrne, Baron, Larsson, \& Melin, 1995). The presence of correlated error terms may also indicate method effects, such as perceived redundancy or overlap in item content (Byrne, 2005). A model can be further improved by allowing such error terms to correlate, but only when this can be justified 
and interpreted substantively. When the best fitting model did not achieve acceptable fit, the constraints of the models were relaxed one at a time by allowing the error terms with the largest modification index within each factor to correlate, provided that this made substantive sense.

Based on overlap in item content, five error correlations were allowed (item 7 with 8, 8 with 9, 9 with 10, 18 with 19 and 5 with 13). The final two-correlated factor model demonstrated good fit according to both the RMSEA and SRMR and adequate fit according to the CFI. The final items of the WSSQ are provided in the appendix (Table 5), together with their corresponding factor loadings.

\section{Internal consistency and discriminant validity}

Reliability of the WSSQ was assessed by calculating Cronbach's Alpha and McDonald's Omega values. Alpha and Omega of .70 and above were considered to be acceptable for research purposes (Cicchetti, 1994). Additionally, Pearson intercorrelations between observed factors were determined. To be considered a related but sufficiently distinct factor, the factors are expected to be significantly but no more than moderately correlated (correlation coefficient lower than .70 as stated in Hinkle, Wiersma, and Jurs (2003).

The Cronbach's Alpha and McDonald Omega of the first subscale (resp. 0.83 and 0.76 ) and the second subscale (resp. .74 and .79) indicated an adequate reliability. There were no options to increase the reliability of the scales by deleting any of the items. A significant moderate Pearson correlation of .57 was found between both factors of the WSSQ, confirming that both subscales are related but sufficiently distinct to deserve separate status.

\section{Convergent and divergent validity}

Pearson correlations were calculated between (subscales of) the WSSQ and two theoretically related questionnaires (Table 3). Based on the scale construction, it was expected that subscales (partly) consisting of social behaviour items would correlate highly with the Successful Schools scale and that subscales (partly) consisting of wellbeing items would correlate highly with the Kidscreen-27 (convergent validity). It was also expected that subscales without social behaviour or wellbeing components would correlate low or moderate with respectively the Successful Schools scale or the Kidscreen-27 (divergent validity). To assess the significance of the difference between two correlation coefficients, the Fisher r-to-z transformations was used to calculate z-scores, followed by an asymptotic z-test (Steiger, 1980).

The first subscale of the WSSQ consisted of social behaviour items as well as wellbeing items and therefore was called "School-related Social Safeness and Wellbeing". Mean scores on this subscale 
correlated highly with the total scores of the Successful Schools Questionnaire as well as the Kidscreen-27. This subscale is formed by 14 items, tallied to possible total scores between 25 and 70 .

The second subscale of the WSSQ consisted solely of wellbeing items not focused on a specific school situation, and therefore was called "generic wellbeing". Mean scores on this subscale only correlated highly with the total score of the Kidscreen-27. This subscale is formed by 5 items, tallied to possible total scores between 5 and 25 .

The correlations of both the subscales with the Successful Schools Questionnaire differed significantly $(z=8.12, p<.001)$, indicating a significantly higher correlation between the Successful Schools Questionnaire and the School-related Social Safeness and Wellbeing subscale. The correlations of both the subscales with the total score of the Kidscreen-27 were not significantly different from each other.

Concerning the subscales of the Kidscreen-27, the scores on "Physical Wellbeing" were significantly higher correlated with the Generic Wellbeing subscale $(z=-1.71, p=.044)$, whereas the scores on "School Environment" $(z=3.78, p<.001)$ were significantly higher correlated with the Schoolrelated Social Safeness and Wellbeing subscale.

Table 3: Pearson's Correlation Coefficients between the WSSQ, Successful Schools total, Kidscreen-27 total and subscales of the Kidscreen-27

\begin{tabular}{|c|c|c|c|c|c|c|c|}
\hline & Successful & \multicolumn{6}{|c|}{ Kidscreen-27 } \\
\hline & Total & Total & Subscale & Subscale & Subscale & Subscale & Subscale \\
\hline & & & 1 & 2 & 3 & $4 * *$ & 5 \\
\hline School-related Social & $.63^{*}$ & $.65^{*}$ & $.44^{*}$ & .50 & .38 & - & $.58^{*}$ \\
\hline Safeness and Wellbeing & & & & & & & \\
\hline Generic Wellbeing & $.33^{*}$ & .62 & $.50^{*}$ & .46 & .39 & - & .45 \\
\hline
\end{tabular}

Note. Kidscreen-27 subscales are respectively: 1. Physical Wellbeing, 2. Psychological Wellbeing, 3. Autonomy and Parent Relation, 4. Social Support and Peers, 5. School Environment; * $p \leq 0.05$ (2-tailed); **subscale 4 was not analyzed independently based on its poor reliability

\section{$\underline{\text { Influences of age, grade and gender }}$}

T-tests with independent samples were conducted to test associations with age, grade and gender. Preliminary normative values were computed and decile scores were calculated.

In general, students scored high on both School-related Social Safeness and Wellbeing ( $M=4.15$, SD $=0.47)$ and Generic Wellbeing $(M=4.35, S D=0.48)$. No significant difference was found between gender, age or grade on either of the two subscales. Mean scores are presented in the appendix (Table 4), providing insight in the small differences in decile scores. 


\section{Discussion}

The present study is the first to investigate the psychometric properties of a Dutch wellbeing and social safeness instrument for school children. The need for such an instrument is evident, since developing a wellbeing and social safeness policy in schools is placed on national agendas (e.g. Ministerie van Onderwijs, Cultuur en Wetenschap, 2016; SCSEEC, 2013). The instrument developed and investigated in this research shows adequate reliability and validity to measure social safeness and wellbeing in grade $5-8$ students.

A two factor model was identified in the WSSQ, resulting in two subscales. The first subscale "School-related Social Safeness and Wellbeing" consists of fifteen school-related items about wellbeing and social behaviour at school. As would be expected, it correlated highly with both the theoretically related dimensions of wellbeing and social safeness, as measured with other instruments. The second subscale "Generic Wellbeing" consists of five general wellbeing items about wellbeing in non-school-related situations. Compared with the School-related Social Safeness and Wellbeing Subscale, the Generic Wellbeing subscale correlated significantly lower with the Successful Schools Questionnaire and the subscale "School Environment" from the Kidscreen-27. This pattern of correlations indicates both the convergent and discriminant construct validity of both subscales. This indication was strengthened by the moderate correlation between both the factors. Both the factors of the WSSQ also showed good reliability, with no relevant options to increase the reliability by removing any of the items.

Factor analysis did not show a clear distinction between school-related wellbeing and social safeness, which was expected a-priori. This aligns with the unclear definition of social safeness in children. The extent to which a child experiences wellbeing, is the result of a continuous interaction between external and internal factors, like "a healthy and safe environment" and "social skills" (Hicks et al., 2011; Laevers et al., 2014; Lippman et al., 2009; Michaelson et al., 2012; Thompson \& Aked, 2009; UNICEF, 2007). Therefore, social safeness may be an integral aspect of school-related wellbeing and not a separate construct. Long et al. (2012) found a similar result, showing that the absence of fear-elated negative emotions (feeling unsafe) is part of school-related subjective wellbeing. It can be argued that school-related wellbeing encompasses social safeness in schools. Social safeness for students can then be seen as a specific form of wellbeing applicable to the school environment. 


\section{Practical implications}

The majority of students scored very high on the WSSQ, which makes it easier to identify low scoring individuals, but harder to differentiate between high scoring individuals. This suggests that the WSSQ will be useful in identifying students at risk. The WSSQ can, therefore, be seen as a screening instrument, rather than an outcome instrument. Using this instrument, it is possible for the teacher to identify which student is experiencing problems and what aspect of wellbeing or social safeness the problem relates to. Since the different concepts in the WSSQ are addressed with one or two questions, more comprehensive measurements might be needed to further explore the needs of the individual student.

The fact that the WSSQ is an online questionnaire is beneficial for the screening purpose of the instrument. The online character of the instrument provides the teacher with the opportunity to get an easy and quick overview of low scoring students on School-related Social Safeness and Wellbeing or Generic Wellbeing. Based on these scores, teachers can choose to implement evidence-based strategies or interventions to support the development of students' wellbeing and social safeness. Teachers will also be able to choose whether they want to include the Generic Wellbeing scale in their measurements, or whether they are solely interested in the School-related factor.

\section{Strengths, limitations and recommendations}

The present study provides the first preliminary evaluation of a short measure of wellbeing and social safeness in children, using a large sample, similar to the composition of the Netherlands as a whole, based on criteria of the Central Bureau of Statistics. This results in robust norm scores.

Since not many studies have tried to assess wellbeing and social safeness in school children, there were no criterion measures and not many theoretically related questionnaires available to test the concurrent and construct validity of the WSSQ. The Successful Schools questionnaire was used as a theoretically related questionnaire for the concept of social safeness, but information about its psychometric properties was lacking. The Kidscreen-27, used as a theoretically related questionnaire for the concept of wellbeing, was validated extensively, but uses "health related quality of life" as their main concept, instead of "wellbeing". The true construct validity of the WSSQ requires further study, preferably by making use of the Multitrait-Multimethod approach (Campbell \& Fiske, 1959); for instance by examining associations with teacher-observed ratings.

It would be valuable to examine the added value of using the WSSQ as a screening instrument in a quantitative and qualitative manner. Further research should be conducted to determine (i) if screening the students via the instrument provides teachers with more accurate information about 
student overall wellbeing and social safeness and (ii) how this information can be utilized to enhance the classroom and school environment thereby supporting children's social, emotional and academic development. Additionally, it would be valuable to research whether this instrument is also suitable for younger (age 4-8) and older children (age 12-16).

Additionally, it would be valuable to investigate whether there any factors that influence the scores on the subscales. Interestingly, in the current research, there is hardly any variation found in subscale scores across age and gender. Previous research is inconclusive about the exact influence of gender and age on the wellbeing in children. For example, Løhre, Moksnes, and Lillefjell (2014), find no influence of gender on wellbeing, whilst Konu and Lintonen (2006) state that girls and younger students experience more wellbeing. Concerning social safeness in children, to date, there is little research done towards the influence of age and gender.

It can be noted that the WSSQ makes use of both Likert-type items and intensity items. Whilst it is not recommended practice in survey research to vary item type and directionality, the emoticon was consistent across all items. This procedure appeared to be well received by the students, sitting within groups. It is assumed that the emoticon can provide an easily understood way in which young students can report affect along a meaningful negative to positive dimension. The use of the current questionnaire without some form of the non-verbal emoticon is not recommended.

\section{Conclusion}

The results from this study indicate that the Wellbeing and Social Safeness Questionnaire is a promising screening instrument to measure the social safeness and wellbeing of students. The initial psychometric properties of the instrument are adequate and the factor structure provides more insight in the theoretical framework of social safeness and wellbeing. The WSSQ helps schools with putting their social safeness and wellbeing policies in practice and the digital environment gives teachers an immediate insight in the social safeness and wellbeing of their students. 


\section{References}

Assessment, 6(4), 284-290. doi:10.1037/1040-

3590.6.4.284

Berends, I. E. (2015). Ervaren sociale veiligheid meten in het primair onderwijs (in acht vragen). Duivendrecht: PI Research.

Berends, I. E., \& Eenshuistra, R. M. (2016). Eigenwijzr de handleiding. Duivendrecht: PI Research.

Berger, C., Alcalay, L., Torretti, A., \& Milicic, N. (2011). Socio-emotional well-being and academic achievement: Evidence from a multilevel approach. Psicologia: Reflexão e Crítica, 24(2), 344-351.

Browne, M. W., \& Cudeck, R. (1993). Alternative ways of assessing model fit. In K. A. Bollen \& J. S. Long (Eds.), Testing structural equation models (pp. 136-162). Newbury Park, CA: Sage.

Byrne, B. M. (2005). Factor analytic models: Viewing the structure of an assessment instrument from three perspectives. Journal of Personality Assessment, 85(1), 17-32. doi:10.1207/ s15327752jpa8501_02

Byrne, B. M., Baron, P., Larsson, B., \& Melin, L. (1995). The beck depression inventory: Testing and crossvalidating a second-order factorial structure for Swedish nonclinical adolescents. Behaviour Research and Therapy, 33(3), 345-356. doi:10.1016/ 00057967(94)E0050-S

Campbell, D. T., \& Fiske, D. W. (1959). Convergent and discriminant validation by the multitrait-multimethod matrix. Psychological Bulletin, 56(2), 81-105.

Chu, P. S., Saucier, D. A., \& Hafner, E. (2010). MetaAnalysis of the relationships between social support and well-being in children and adolescents. Journal of Social and Clinical Psychology, 29(6), 624-645.

doi:10.1521/jscp.2010.29.6.624

Cicchetti, D. V. (1994). Guidelines, criteria, and rules of thumb for evaluating normed and standardized assessment instruments in psychology. Psychological
Fredrickson, B. L. (2001). The role of positive emotions in positive psychology: The broaden- and-build theory of positive emotions. American Psychologist, 56(3), 218226.

Gilbert, P. (2010). The compassionate mind: A new approach to life's challenges. Oakland, CA: New Harbinger Publications.

Gilbert, P., McEwan, K., Mitra, R., Franks, L., Richter, A., \& Rockliff, H. (2008). Feeling safe and content: A specific affect regulation system? Relationship to depression, anxiety, stress, and self-criticism. Journal of Positive Psychology, 3(3), 182-191.

doi:10.1080/17439760801999461

Gilbert, P., McEwan, K., Mitra, R., Richter, A., Franks, L., Mills, A., ... Gale, C. (2009). An exploration of different types of positive affect in students and in patients with bipolar disorder. Clinical Neuropathology, 6(4), 135-143.

Goodman, R. (2001). Psychometric properties of the strengths and difficulties questionnaire. Journal of the American Academy of Child and Adolescent Psychiatry, 40(11), 1337-1345. doi:10.1097/00004583-20011100000015

Hayton, J. C., Allen, D. G., \& Scarpello, V. (2004). Factor retention decisions in exploratory factor analysis: $\mathrm{A}$ tutorial on parallel analysis. Organizational Research Methods, 7(2), 191-205.

doi:10.1177/1094428104263675

Hicks, S., Newton, J., Haynes, J., \& Evans, J. (2011). Measuring children's and young people's well-being. Cardiff: Office for National Statistics and BRASS.

Hinkle, D. E., Wiersma, W., \& Jurs, S. G. (2003). Applied statistics for the behavioral sciences. Boston, Mass: Houghton Mifflin. 
Hu, L. T., \& Bentler, P. M. (1998). Fit indices in covariance structure modeling: Sensitivity to underparameterized model misspecification. Psychological Methods, 3(4), 424-453.

doi:10.1037/1082-989X.3.4.424

Kelly, A. C., Zuroff, D. C., Leybman, M. J., \& Gilbert, P. (2012). Social safeness, received social support, and maladjustment: Testing a tripartite model of affect regulation. Cognitive Therapy and Research, 36(6), 815826. doi:10.1007/s10608-011-9432-5

Keyes, C. L. M. (2005). Mental illness and/or mental health? Investigating axioms of the complete state model of health. Journal of Consulting and Clinical Psychology, 73(3), 539-548. doi:10.1037/0022-

006X.73.3.539

Konu, A. I., \& Lintonen, T. P. (2006). School well-being in Grades 4-12. Health Education Research, 21(5), 633642. doi:10.1093/her/cyl032

Laevers, F., Heylen, L., \& Daniëls, D. (2014).

Ervaringsgericht werken met 6- tot 12-jarigen in het basisonderwijs. Leuven: Cego.

Lippman, L. H., Moore, K. A., \& McIntosh, H. (2009). Positive indicators of child well-being: A conceptual framework, measures and methodological issues. Applied Research in Quality of Life, 6(4), 425-449. doi:10.1007/s11482-011-9138-6

Løhre, A., Moksnes, U. K., \& Lillefjell, M. (2014). Gender differences in predictors of school wellbeing? Health Education Journal, 73(1), 90-100.

doi:10.1177/0017896912470822

Long, R. F., Huebner, E. S., Wedell, D. H., \& Hills, K. J. (2012). Measuring school-related subjective well-being in adolescents. American Journal of Orthopsychiatry, 82(1), 50-60. doi:10.1111/j.1939-0025.2011.01130.x Martin, A. J., \& Marsh, H. W. (2008). Academic buoyancy: Towards an understanding of students' everyday academic resilience. Journal of School Psychology, 46(1), 53-83. doi:10.1016/j.jsp.2007.01.002
Martin, A. J., \& Marsh, H. W. (2009). Academic resilience and academic buoyancy: Multidimensional and hierarchical conceptual framing of causes, correlates and cognate constructs. Oxford Review of Education, 35(3), 353-370. doi:10.1080/03054980902934639

Michaelson, J., Mahony, S., \& Schifferes, J. (2012). Measuring well-being. A guide to practicioners. London: New Economics Foundation.

Ministerie van Onderwijs, Cultuur en Wetenschap. (2016). Zorgplicht sociale veiligheid leerlingen op school. Retrieved from

https://www.rijksoverheid.nl/documenten/brochures/ 2016/07/18/zorgplicht- socialeveiligheid-

leerlingen-op-school

Muthén, L. K., \& Muthén, B. O. (1998-2010). Mplus user's guide (7th ed.). Los Angeles, CA: Muthén \& Muthén.

Nansel, T. R., Overpeck, M., Pilla, R. S., Ruan, W. J., Simons-Morton, B., \& Scheidt, P. (2001). Bullying behaviors among US youth: Prevalence and association with psychosocial adjustment. Journal of the American Medical Association, 285(16), 2094-2100.

doi:10.1001/jama.285.16.2094

Natvig, G. K., Albrektsen, G., \& Qvarnstrøm, U. (2003). Associations between psychosocial factors and happiness among school adolescents. International Journal of Nursing Practice, 9(3), 166-175. doi:10.1046/j.1440-172X.2003.00419.x Navarro, R., Ruiz-Oliva, R., Larrañaga, E., \& Yubero, S. (2015). The impact of cyberbullying and social bullying on optimism, global and school-Related happiness and life satisfaction among 10-12-year-old schoolchildren. Applied Research in Quality of Life, 10(1), 15-36. doi:10.1007/s11482-013-9292-0

Oswald, A. J., Proto, E., \& Sgroi, D. (2015). Happiness and productivity. Journal of Labor Economics, 33(4), 789822. doi:10.1086/681096 
Pietarinen, J., Soini, T., \& Pyhältö, K. (2014). Students' emotional and cognitive engagement as the determinants of well-being and achievement in school. International Journal of Educational Research, 67(1), 4051. doi:10.1016/j.ijer.2014.05.001

Ravens-Sieberer, U., Auquier, P., Erhart, M., Gosch, A., Rajmil, L., Bruil, J., ... Kilroe, J. (2007). The KIDSCREEN-27 quality of life measure for children and adolescents: Psychometric results from a cross-cultural survey in 13 European countries. Quality of Life Research, 16(8), 1347-1356. doi:10.1007/s11136-007-9240-2

Ravens-Sieberer, U., \& Bullinger, M. (1998). Assessing health-related quality of life in chronically ill children with the German KINDL: First psychometric and content analytical results. Quality of Life Research, 7(5), 399407.

Rowe, G., Hirsh, J. B., \& Anderson, A. K. (2007). Positive affect increases the breadth of attentional selection. Proceedings of the National Academy of Sciences, 104(1), 383-388. doi:10.1073/pnas.0605198104 Standing Council on School Education and Early Childhood. (2013). National safe schools framework. Retrieved from https://studentwellbeinghub.edu.au/ docs/default source/nationalsafeschoolsframeworkpdf. pdf?sfvrsn=0
Steiger, J. H. (1980). Tests for comparing elements of a correlation matrix. Psychological Bulletin, 87(2), 245251. doi:10.1037/0033-2909.87.2.245

Tabachnick, B. G., \& Fidell, L. S. (2013). Using multivariate statistics (6th ed.). Boston, MA: Pearson.

Thompson, S., \& Aked, J. (2009). A guide to measuring children's well-being. Backing the future: Practical guide 2. London: New Economics Foundation.

Tian, L., Zhao, J., \& Huebner, E. S. (2015). School-related social support and subjective well-being in school among adolescents: The role of self-system factors. Journal of Adolescence, 45(8), 138-148.

doi:10.1016/j.adolescence.2015.09.003

UNICEF. (2007). Child poverty in perspective: An overview of child well-being in rich countries. Florence: Author.

World Government Summit. (2017). The state of positive education. Retrieved January 22th, 2018, from https://www.worldgovernmentsummit.org/api/publicati ons/document/8f647dc4-e97c-6578-b2f8-

ff0000a7ddb6?mc_cid=7ba0f17ca8\&mc_eid=713157905 6 


\section{Appendix A}

Table 4: Raw and mean decile scores subscales WSSQ

\begin{tabular}{llllll}
\hline & \multicolumn{2}{l}{ School-related Social Safeness and wellbeing } & & \multicolumn{2}{l}{ Generic Wellbeing } \\
\cline { 2 - 3 } \cline { 5 - 6 } Decile & Raw total & Mean & & Raw total & Mean \\
\hline 1 & 50 & 3.6 & 19 & 3.8 \\
2 & 53 & 3.8 & & 20 & 4.0 \\
3 & 56 & 4.0 & 21 & 4.2 \\
4 & 58 & 4.1 & 22 & 4.4 \\
5 & 59 & 4.2 & 22 & 4.4 \\
6 & 60 & 4.3 & 23 & 4.6 \\
7 & 62 & 4.4 & 23 & 4.6 \\
8 & 64 & 4.6 & 24 & 4.8 \\
9 & 65 & 4.6 & 25 & 5.0 \\
\hline
\end{tabular}

\section{Appendix B}

Table 5: Item Content and Completely Standardized Factor Loadings in the Correlated Two Factor CFA Model of the WSSQ

\begin{tabular}{|c|c|c|}
\hline Items & $\begin{array}{l}\text { School-related Social } \\
\text { Safeness and } \\
\text { Wellbeing }\end{array}$ & $\begin{array}{l}\text { Generic } \\
\text { Wellbeing }\end{array}$ \\
\hline 1) How do you feel right now? & 0.469 & \\
\hline 2) How do you feel most of the time? & & 0.605 \\
\hline 3) How do you feel most of the time at school? & 0.552 & \\
\hline 4) How do you feel when there is no adult present during breaks?* & 0.234 & \\
\hline 5) How content are you with your life? & & 0.652 \\
\hline 6) I feel healthy & & 0.595 \\
\hline 7) If I have a problem at school, it usually ends well & 0.580 & \\
\hline 8) If I have a bad experience at school, I will be happy soon after & 0.513 & \\
\hline 9) I have nice friends & 0.470 & \\
\hline 10) I like myself & & 0.489 \\
\hline 11) I can choose at school what I want to do & 0.340 & \\
\hline 12) It is good that I exist & & 0.522 \\
\hline 13) Classmates bully me (emotionally, verbally or both) & 0.491 & \\
\hline 14) Classmates hit me or kick me (physically) & 0.389 & \\
\hline 15) Classmates fight with each other & 0.346 & \\
\hline 16) Classmates laugh, when you ask a silly question & 0.381 & \\
\hline 17) I feel safe in this class (globally) & 0.742 & \\
\hline 18) I feel safe with this teacher (under supervision) & 0.689 & \\
\hline 19) I enjoy my class & 0.582 & \\
\hline 20) I get along with most of my classmates & 0.544 & \\
\hline
\end{tabular}


Note. *Item 4 was removed from analyses based on its factor loading; CFA = confirmatory factor analysis; WSSQ = Wellbeing and Social Safeness Questionnaire; Answer categories for item 1-4 ranging from 'very unhappy’ to 'very happy', for item 5 ranging from 'not content at all' to 'very content', for item 6-12 ranging from 'totally disagree' to 'totally agree', for items 13-16 ranging from 'always' to ‘never' and for items 16-20 ranging from 'never' to 'always'.

\section{Appendix C}

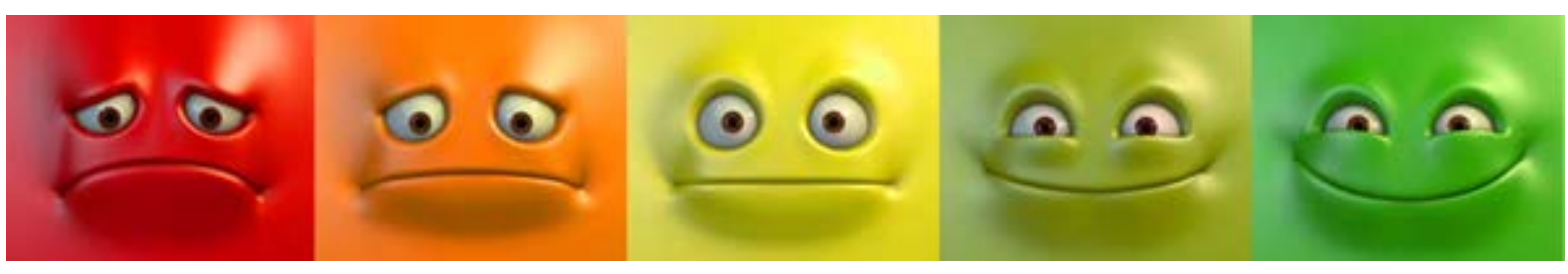

Figure 1: Emoticon answer categories, scored 1 to 5 per item 


\section{Chapter 6:}

\section{Exploring signs of wellbeing and behavioural intentions in youth's future expectations}

Goldberg, J.M., Muijsson, D.C., Clarke, A.M., Boniwell, I., Schreurs, K.M.G., Bohlmeijer, E.T. (2019). Exploring signs of wellbeing and behavioural intentions in youth's future expectations. Manuscript submitted for publication. 


\section{Abstract}

The ability to develop specific and realistic best possible selves predicts higher levels of wellbeing and more positive mental health outcomes. The current explorative study aims to gain insight into youth's writings about their best possible selves. Future perceptions of students $(11-14)$ were qualitatively analysed by identifying markers of wellbeing and behavioural intention. Data was collected from 255 Dutch students at the beginning and end of the academic year. During this year, a positive psychology intervention was taught.

The analyses indicated wellbeing-related statements in the domains 'Positive Emotions', 'Engagement', 'Positive Relationships', 'Meaning' and 'Accomplishment'. Additionally, statements were placed in 'Frustrations' 'Assets' and 'Factual Descriptions'. Significant increases were found for the percentage of wellbeing-related signals, behavioural intention signals and positive emotions. A significant decrease was found for the percentage of factual descriptions.

This study demonstrates that best-possible-self writings can be used to assess the five domains of wellbeing as well as behavioral intentions on these domains. Pupils tend to focus on positive relationships, accomplishments and positive emotions in their idealized futures. However, 'meaning', which is a vital dimension of wellbeing, is lacking in their best-possible-self writings. Therefore, implementing specific lessons on meaning in the context of positive education is recommended. 


\section{Introduction}

There is accumulating evidence regarding the positive impact of wellbeing on student learning (Adler, 2017; Berger et al., 2011; Miller, Connolly, \& Maguire, 2013; Pietarinen, Soini, \& Phältö, 2014). Seligman et al. (2009) describe three main effects of wellbeing that support the importance of focusing on wellbeing in schools: wellbeing predicts better learning and more creative thinking, wellbeing increases life satisfaction and wellbeing works as an antidote to depression. Between the ages 10 and 14, young people experience many changes in their school setting, social network and responsibilities, which may impact their wellbeing (Public Health England, 2014). Young students express concerns about choices they have to make in their schooling, their relationship with peers becomes more important and they also become more independent (Rice, Fredrickson, \& Seymour, 2011; Qualter et al., 2007). All of these factors are influencing the identity formation of the students and have the potential to undermine their wellbeing (Anderson et al., 2000; Galton, Morrisson, \& Pell, 2000).

Important decisions that influence the wellbeing of the students are made by imagining the self in various outcomes (Markus \& Nurius, 1986). Representations of the self in the future are called 'possible selves' and represent individual hopes, beliefs and expectations. Possible selves are constructed by people, based on their past self, their present self and their wishes for the future. By constructing possible selves, the current self and the identity of a person are influenced. Forming possible selves represents the "trying on of identity," and the construction of possible selves is a part of the identity formation for adolescents (Johnson, Blum \& Chang, 2014). In their research, Markus and Nurius (1986) argue that the construction of possible selves helps to make sense of past behaviour and provides patterns for new behaviour. The importance of constructing possible selves is underlined by the finding that it helps to evaluate current selves and serves as a motivation for people to behave in ways that will attain their Ideal Self and avoid their Feared Self (Strahan \& Wilson, 2006). To our knowledge, no research date, has been done, however, on analyzing possible selves of pupils by looking at markers of wellbeing.

As constructing possible selves is part of identity formation, it is found that constructing Best Possible Selves is associated with positive identity formation and is related to enhanced mood, an increase in subjective wellbeing and physical health benefits (King, 2001). Experimental research demonstrates, that the Best Possible Self intervention leads to: increased optimism (Meevissen, Peters, \& Alberts, 2011), increased life satisfaction (Peters, Meevissen, \& Hanssen, 2013), gains in self-esteem (Owens \& Patterson, 2013) and raising and maintaining positive mood (Sheldon \& 
Lyubomirsky, 2006). Additional research shows that having strategies to attain best possible selves predicts better in-class behaviour, fewer depressive symptoms and better exam performance and college preparation (Bi \& Oyserman, 2015; Oyserman, Destin, \& Novin, 2015). Van Gelder, Hershfield and Nordgren (2013) also found that students who wrote a letter to their ideal future self were less inclined to make delinquent choices than students who did not write such a letter.

When constructing Best Possible Selves, two forms of thinking can be identified: expectations and fantasies. Positive future expectations can be described as judging a desired future as likely, whilst positive fantasies can be described as positively experienced mental images of future desired events (Oettingen \& Mayer, 2002; Wyman et al., 1993). Positive future expectations are associated with prosocial behaviour and indicators of mental health, whilst the reverse was true for fantasies (Oettingen \& Mayer, 2002; Wyman et al., 1993). When comparing a Best Possible Self intervention with a neutral writing intervention, Peters et al. (2010) found that the Best Possible Self intervention increased the amount of positive future expectations. Furthermore, research finds that positive future expectations can be linked to psychosocial outcomes, resilience and less risky behaviours amongst adolescents (Sipsma et al., 2012). In addition, positive future expectations can facilitate optimal development and contribute to healthier outcomes in youth (Stoddard \& Pierce, 2015). This research highlights the important link between having positive future expectations and wellbeing in youth.

\section{Current research}

The current explorative study aims to gain insight into youth's writings about their best possible selves. Most of the research on best possible selves has been conducted with adults and there is a scarcity of research studying best possible selves in young students. As the previous research shows, the ability to develop specific and realistic best possible selves has been shown to relate to wellbeing and predicts better mental health outcomes. But it remains unclear what the actual content of youth's best possible selves is and whether writing about a positive future means implies that the students are writing about their wellbeing as well. To address this question, we used the PERMA model of wellbeing to investigate whether indicators of wellbeing can be identified in the writings of youth about their best possible selves. The PERMA-model of wellbeing is a widely used conceptualization of wellbeing (Seligman, 2011) that consists of five domains: 'Positive Emotions' refers to living a pleasant life (e.g. happiness), 'Engagement' refers to active involvement in life domains (e.g. work), 'Positive Relationships' refers to being socially integrated, 'Meaning' refers to serving something that is bigger than the self and 'Accomplishment' refers to having a sense of achievement. 
Secondly, when a person imagines a positive future, meaningful goals and plans are formed. Setting goals gives meaning and structure to someone's life (Boudreaux \& Ozer, 2013) and improves adolescent health and adolescent development (Johnson, Blum \& Chang, 2014). This goal setting automatically occurs when imagining possible selves (Markus \& Nurius, 1986). Markus and Nurius (1986) discuss that people's possible selves are personal representations of their goals. This indicates that people's Best Possible Selves represent their most meaningful goals. Pursuing such meaningful goals, in turn, is associated with healthy psychological functioning, subjective wellbeing (Diener et al., 1999) and is highly protective against psychopathology (Seligman et al., 2013). Anderson (1983) found, that the more frequently people imagine themselves conducting behaviour towards these meaningful goals, the more intention change is developed. However, it remains unclear whether youth actually write about their goals when writing about their best possible selves. Therefore, possible indicators of behavioural intentions was investigated in the writings of youth about their best possible selves.

Thirdly, the potential to increase the wellbeing of youth by having positive future expectations aligns with the focus of the science of positive psychology on wellbeing (Marques, Pais-Ribeiro, \& Lopez, 2011). Positive psychology is suitable to the educational setting in understanding and developing the mental health and wellbeing of youth and the school culture as a whole (Goldberg et al., 2018; Green, Oades, \& Robinson, 2011; Marques, Pais-Ribeiro, \& Lopez, 2011). Positive psychology is applied in the school setting through School-Based Positive Psychology Interventions (SB-PPIs). SBPPIs are found to be effective in increasing the wellbeing, relationships and academic performance of students (Waters, 2011). Therefore during one academic year, we investigated whether changes occurred in the content of youth's writings about their best possible selves when the student were taught a positive psychology intervention. We expected a significant increase of indicators of wellbeing at the end of the academic year in comparison to the beginning of the year (i.e., from preto post- measurement).

\section{Methods}

\section{Study design and participants}

An explorative, pre-post study design was deployed with two measurements. Participants were Dutch students in the sixth, seventh and eighth grade of primary school and in the first and second grade of secondary school. Data was collected from 255 students ( $52.2 \%$ boys), with a mean age of 
$12(M=12.26, S D=1.18$, range $10-15)$. A total of 179 students $(70.2 \%)$ attended primary school, with the remaining 76 students in secondary school.

\section{Procedure}

Ethical approval for this study was obtained from The Ethics Committee of the University of Twente (Behavioural, Management, and Social Sciences). Schools were recruited in September 2016 by offering a free-of-charge two-day training session for teachers on the British School-based Positive Psychology Intervention 'Personal Well-being Lessons' (Boniwell \& Ryan, 2012). This intervention has been successfully implemented in secondary schools in London, with the results indicating that the intervention has a significant buffering effect throughout the first year of middle school in protecting students against declines in: satisfaction with self, satisfaction with friends, positive affect, and an increase in negative affect (Boniwell, Osin \& Martinez, 2016). Translated into Dutch (Boniwell \& Ryan, 2016), the intervention was offered to schools in the Netherlands. Individual teachers associated with the recruited schools could register for this training. After the training, these teachers received an information letter about the research, consent forms and a writing exercise for each student in their class. Parents were asked to return the passive consent form if they had an objection to their child participating in the research. Students completed the writing exercise in October 2016 (T0) and in June 2017 (T1). Between the two measurements, teachers taught the wellbeing-related lessons, resulting in a year-long focus on wellbeing.

\section{Working with Positive Psychology}

Personal Well-being Lessons is a positive psychology programme aimed at 10-15 year old students (Boniwell \& Ryan, 2012). The programme consists of 34 lessons designed to enhance student wellbeing, which each lessons divided into six modules: positive self, positive body, positive emotions, positive mind-set, positive direction and positive relationships. Each lesson includes a detailed lesson plan, handouts for the students and corresponding PowerPoint presentations. In this study, teachers had flexibility in the number of sessions that they could implement and the order in which they implemented the lessons, allowing the programme to address the particular needs of the class. Teachers were given a recommended roadmap (the order and number of lessons) that they could use if they wished. Teachers were required to commence and complete the programme with lesson five, the Best Possible Self exercise, which served as pre- and post-measurement. For this study a Dutch translation (Aan de slag met Positieve Psychologie) of the Personal Well-being lessons was used. 


\section{$\underline{\text { Measure }}$}

Participants filled out the Best Possible Self exercise (in Dutch), which is suitable for youth, students and adults (Loveday, Lovell \& Jones, 2018). In the current study, the Best Possible Self exercise was used as a measure to identify indicators of student wellbeing. Students completed the Best Possible Self exercise at the beginning and end of the academic year. Before filling out the exercise, students were asked to read the following instruction: 'Imagine yourself in the future (about a year from now). Imagine that you are doing all kinds of things that you can only dream about now. Take a few minutes to really think about how you are in a year from now and what your life looks like then. Think about how things are for you at school and at home. Also, think about how your family and friends are doing. When you have thought carefully about it, please describe your thoughts in the space below.'

\section{$\underline{\text { Analyses }}$}

The results from the Best Possible Self exercise were analysed qualitatively through thematic analysis (Braun \& Clark, 2006) using the Atlas.ti software. The content of the Best Possible Selves was analysed top down into eight main codes. The first five codes were based on the wellbeing domains of Seligman (2011). Each code consisted of two sub-codes, differentiating between statements that indicated an action towards the pursuit of life goals (e.g., Behavioural Intention) and statements that did not indicate such an action. The code 'Positive Emotions' encompassed statements that described life going well and students experiencing joy or satisfaction. This also included statements concerning positive health. The second code 'Engagement' encompassed statements in which students expressed a specific interest in an activity, sport or hobby. The third code 'Positive Relationships' included statements that described students' positive experiences when in contact with other people. The fourth code 'Meaning' entailed statements that described something larger than the self, like faith or religion. The final wellbeing code 'Accomplishment' included statements about making progress in a certain life domain, such as school or sports.

Statements that could not be placed into one of the five wellbeing codes were coded into three additional domains. Firstly, the code 'Frustrations' encompassed statements that indicated uncertainty, stress or problems. Secondly, the code 'Assets' included statements about the belongings the participants had or wanted to have. Thirdly, 'Factual Descriptions' entailed all the facts that the participants wrote about their future. There were no behavioural intention codes associated with these three additional codes. 
Coded statements could consist of parts of sentences, full sentences or multiple sentences.

Statements were only coded once, with no overlap in codes, resulting in a mutually exclusive code scheme. All statements in the Best Possible Selves were coded; no text was left uncoded. Two of the researchers (J.G. \& D.M.) read multiple writings to obtain a general overview of the writings, after which they jointly set up the coding scheme. Once establishing the agreed-upon coding scheme, they independently coded five Best Possible Selves. Sufficient interrater reliability was immediately reached for these five writings with a Cohens Kappa of .85. The similarities and differences between the coding of both researchers was discussed to achieve an even better consensus. Within the reported results, the variety within the code is displayed.

To gain insights into the changes in the student writings between T0 and T1, the percentage of the total number of statements was calculated for each of the eight subcodes. Also, the cumulative percentage of wellbeing-related statements and behavioural intention statements was calculated. Lastly, percentages were calculated for the number of behavioural intention statements in the five wellbeing-related domains. Wilcoxon signed rank tests were deployed to test for significant differences. All analyses maintained a significance level of $p=.05$, whilst findings up to a $p$-score of .10 were seen as a trend. Finally, a standardized difference between two means 'Cohens $d$ ' was calculated. Effect sizes of 0.20 were considered small, 0.50 moderate and 0.80 high (Lipsey \& Wilson, 1993).

\section{Results}

Indicators of wellbeing

A total of 1,315 codes at T0 and 1,161 codes at T1 were extracted from the Best Possible Self exercises of the 255 students, averaging 5 codes per writing. Most statements were placed under the codes 'Positive Relationships' $(M=437)$ and 'Accomplishment' $(M=364)$. The code 'Meaning' was only used four times per measurement. On average, there were 233 statements per measurement that could not be classified as one of the five wellbeing domains of Seligman (2011) and were consequently categorised into one of the three additional codes. The number of statements per code can be found in Table 1.

Positive Emotions: These statements described hedonic feelings, such as happiness, pleasure, warmth, life satisfaction, joy and comfort: "I hope that I will be happy" - Participant 9. Participants also referred to things going well in the future and that they were healthy, or that health was 
important: "The most important thing is that I stay healthy" - Participant 3. Lastly, participants described the desire that certain aspects of their life would stay the same: "I hope that I will still live in the same house" - Participant 4.

Engagement: Students described a psychological connection with an activity. Participants described something they liked or their interest in something. Mainly, participants described that they had hobbies and/or that they continued playing sports or other activities: "I will have the same hobbies, like basketball, swimming and playing chess" - Participant 100. Lastly, participants described their desire to spend more time doing a particular hobby or activity: "I would like to spend more time riding my horse"- Participant 116.

Positive Relationships: These statements described old or new relationships with friends, family members, classmates and teachers: "My friends are doing fine, we play a lot and we do a lot of activities together!" - Participant 46 . Also, participants wrote about their feelings with regard to their being socially integrated, loved, valued or supported by others: "My parents will still be proud of me"- Participant 211. Additionally, participants expressed satisfaction with their relationships and their desire to keep in contact with current friends as they were on the brink of a transfer to secondary school: "I hope that I still see my friends from primary school" - Participant 20.

Meaning: These statements described participants' desires to serve some idea or vision larger than the self: "I want to invent something that is good for the environment" - Participant 62. Additionally, they also described that they were hoping for something to happen that is larger than the self: "I want our city to be the most environmental-friendly city in the Netherlands" - Participant 138.

Accomplishment: Participants wrote 'Accomplishment' statements around study and sport: "I hope that I will get a lot of good grades next year at school" - Participant 34 . The statements also described students' goals. These goals were mostly concerned with sport, school and future professions, especially because their current study results could influence their admission into a secondary school: "I would like to go to a good school next year, because I want to go to university later" - Participant 12.

Frustrations: These statements included students' frustrations around having a lot of homework, being busy and experiencing difficulties with homework: "I won't have time for games, because I have such a lot of homework to do" - Participant 19. The students also described problems in their relationships, such as irritations, quarrels, being bullied or missing someone: "I won't see all my friends anymore, because they will go to a different school" - Participant 26. Lastly, students 
described 'Frustrations' as a consequence of a particular circumstance: "I don't like that I have to carry a very heavy backpack often" - Participant 17.

Assets: These statements described belongings that the participants wanted to have. These assets were materialistic, like having more money, a new home, a car, a computer or a new telephone: "I will have a new phone, which is really cool" - Participant 17. Besides materialistic assets, the participants also fantasised about less realistic assets: "I will be rich and I will build a time machine" Participant 24.

Factual descriptions: Besides wishes and future expectations, students also wrote about facts. These descriptions were mostly about other people or themselves: "In one year I will be 12 years old" Participant 28. Additionally, the descriptions also included daily routines, the description of their residence or a description of society: "New movies will have aired, like Pirates of the Caribbean" Participant 31.

Indicators of behavioural intention

A total of 140 behavioural codes at T0 and 177 behavioural codes at T1 were extracted from the Best Possible Self exercises, averaging 0.6 behavioural codes per respondent. Statements categorised as 'Behavioural' showed an action or an intention to act in the realization of an aspect of wellbeing. Most statements were placed under the codes 'Positive Relationships' ( $N=71$ and $N=92)$ and 'Accomplishment' ( $N=48$ and $N=58$ ). The code 'Meaning' was used infrequently ( $N=2$ and $N=3$ ). The percentage of Behavioural Intention statements per code can be found in Table 1.

Positive Emotions: Participants wrote about their intention to do something pleasant: "I will do lots of nice things in my spare time" - Participant 66. Participants also wrote about something pleasant they had done which resulted in positive emotions: "I have chosen a nice secondary school" Participant 110. Additionally, participants described how they experienced positive emotions as a result of a particular behaviour: "I will choose to do my schoolwork in the morning, and I will really like that" - Participant 95.

Engagement: Participants described the intention to conduct activities that will lead to engagement. This mostly concerned hobbies: "I will be processing wood and building bird houses from it" Participant 23. Other participants wrote about their intention to pick up a neglected hobby or their intention to increase the frequency of their activities: "I will pick up playing tennis" - Participant 86. Positive Relationships: The intention to keep in contact with their peers and with their family was a central topic: "I will make sure that I keep in contact with my friends when we all go to secondary school" - Participant 102. Besides maintaining current relationships, the participants also expressed 
clear intentions to make new friends, especially when transferring from primary to secondary school: "I will make lots of new trustworthy friends at my new school!" - Participant 140.

Meaning: Students wrote about their intention to do something for the good of others or society. Some statements referred to supporting a charity: "I will have donated my hair to charity" Participant 132. Other statements were linked to faith or religion: "I will start wearing a headscarf as soon as I go to college" - Participant 45.

Accomplishment: Students wrote about their intention to work towards achieving their goals: "I want to became a heart surgeon. I want to achieve this goal by paying attention in class and by being serious about school" - Participant 48. Additionally, students wrote about their intention to try their best in sport and school: "I will try the best I can to get good grades" - Participant 126.

\section{Changes in writings}

At both T0 and T1, students showed most indicators of the themes Positive Relationships, Accomplishment and Positive Emotions (Table 1). When the statements between T0 and T1were compared, the T1 results showed a significant decrease in the total number of statements $(Z=-4.10$; $p<.001)$, a significant increase in the percentage of wellbeing-related statements $(Z=4.47 ; p<.001)$ and a significant increase in the percentage of behavioural intention statements $(Z=3.62 ; p<.001)$. When looking at the individual codes, a significant increase in the number of statements concerning positive emotions was found $(Z=2.21 ; p=.027)$ as well as a significant decrease in the number of factual descriptions in the writings $(Z=-3.40 ; p<.001)$. All found effect sizes were classified as small or small to medium. There were no significant differences between boys and girls or between primary and secondary school students.

Table 1: Percentages of total amount of statements

\begin{tabular}{llllll}
\hline & $\mathrm{T} 0$ & $\mathrm{~T} 1$ & $Z$ & $p$ & $d$ \\
\hline Wellbeing statements & $77 \%$ & $86 \%$ & 4.47 & $<.001^{*}$ & 0.41 \\
Behavioural statements & $11 \%$ & $15 \%$ & 3.62 & $<.001^{*}$ & 0.19 \\
Positive emotions & $11 \%$ & $14 \%$ & 2.21 & $.027^{*}$ & 0.18 \\
Engagement & $3 \%$ & $4 \%$ & 1.40 & .163 & 0.11 \\
Positive relationships & $34 \%$ & $37 \%$ & 1.06 & .298 & 0.09 \\
Meaning** & $0 \%$ & $0 \%$ & - & - & - \\
Accomplishments & $28 \%$ & $30 \%$ & 0.97 & .335 & 0.08 \\
Frustrations & $9 \%$ & $7 \%$ & -1.95 & .051 & -0.14 \\
Assets & $6 \%$ & $3 \%$ & -1.61 & .108 & -0.20 \\
Factual descriptions & $9 \%$ & $5 \%$ & -3.40 & $.001^{*}$ & -0.25 \\
\hline
\end{tabular}

Notes: * = Significant at the .05 level; ** = Four statements per measurement, no difference between T0 and T1. 
Statements indicating behavioural intention could be identified for every wellbeing-related code (Table 2). Also, the percentage of behavioural intention statements increased for every code. These increases, however, were found to be insignificant, as all found effect sizes were classified as small. Again, there were also no significant differences between boys and girls and primary and secondary school. 
Table 2: Percentages of behavioural intention statements per wellbeing-related code

\begin{tabular}{lccccc}
\hline & $\mathrm{T} 0$ & $\mathrm{~T} 1$ & $Z$ & $p$ & $d$ \\
\hline Positive Emotions & $3 \%$ & $6 \%$ & 0.38 & .705 & 0.16 \\
Engagement & $25 \%$ & $31 \%$ & 1.41 & .157 & 0.13 \\
Positive Relationships & $17 \%$ & $20 \%$ & 1.29 & .198 & 0.09 \\
Meaning* & $50 \%$ & $67 \%$ & - & - & - \\
Accomplishment & $12 \%$ & $13 \%$ & 0.45 & .655 & 0.04 \\
\hline Note: * = Numbers too small (T0 = 2 \& T1 = 3) to perform analyses.
\end{tabular}

\section{Discussion}

This research is one of the first studies to analyse Best Possible Self writings of 10-15 year old youth. The main aim of the study was to analyse the future perceptions of youth from a wellbeing and behavioural intention perspective. It is important for youth to pursue meaningful actions towards their wellbeing, as this is found to be associated with healthy psychological functioning (Diener et al., 1999; Seligman et al., 2013). This beneficial effect is of the utmost importance since ten to twenty percent of youth experience mental health problems or mental disorders (WHO, 2013). However, it is currently unknown whether youth actually visualize wellbeing or actions related to wellbeing when they think about their future. Additionally, it remains uncertain how those visualizations can be strengthened. A second aim was, therefore, to assess whether the students' writings change during a year in which they receive lessons related to positive psychology.

At the beginning and the end of the school year, 255 students completed the Best Possible Self exercise. A high interrater reliability of the used coding scheme was reached immediately, indicating the feasibility of analyzing the writings from a wellbeing and behavioural intention perspective. Participants mostly wrote about positive relationships and accomplishment. Over the year we found a significant increase in the percentage of wellbeing-related codes and the percentage of behavioural intention codes. Also, when looking at the individual codes, a significant increase in the percentage of 'Positive Emotions' and a decrease in the percentage of 'Factual Descriptions' was found, as well as a trend towards the decrease of 'Frustrations'. The effect sizes of all found effects were small.

Students wrote about all five pre-determined wellbeing domains (Seligman, 2011), and for all of these domains, behavioural intentions were identified. The fact that students demonstrated their intentions to conduct their behaviour towards the achievement of wellbeing also has the potential 
to actually lead to increased wellbeing (Diener et al., 1999) as well as to protect against psychopathology (Seligman et al., 2013) and to improve their health in general (Johnson, , Blum \& Chang, 2014). According to the theory of planned behaviour (Azjen, 1991), having behavioural intentions has a major influence on whether an individual actually carries out a behaviour. In the current student writings, this could indicate that participants who write more about behavioural intentions related to one of the domains of wellbeing will deploy more actions towards increasing their wellbeing in those domains. This possibility that might prove valuable as topic for future research.

Students not only wrote about wellbeing-related themes, but also about three additional themes: frustrations, assets and factual descriptions. Interestingly, these additional themes may reflect other domains to which a possible self can belong: the Ideal Self, the Actual Self, the Ought Self and the Feared Self (Markus \& Nurius, 1986; Higgins, 1987; Carver, Lawrence, \& Scheier, 1999). The Ideal Self is the self-perception of the attributes a person would prefer to have in the future while the Actual Self represents the self-perception of a person's attributes in the future. The Ought Self is the selfperception of the attributes a person should have in the future, such as responsibilities, and the Feared Self is the self-perception of the attributes a person fears having in the future. All four types of possible selves provide patterns for new behaviour and represent hopes, beliefs and (negative) expectations for the future (Markus \& Nurius, 1986). Therefore, in the future when analyzing the writings of students from a wellbeing and behavioural intention perspective, all four types of possible selves could be included to gain more insight into students' future perceptions.

Analysing the best possible selves of the pupils also has the potential to provide practitioners with information to implement lessons that further strengthen the visualisation of meaningful actions of their students. In the current study, lessons in positive psychology were implemented, as positive psychology interventions show beneficial results on, for example, wellbeing (Waters, 2011) and academic achievement (Adler, 2017). Although the results do show an increase in the percentage of wellbeing-signs and behavioural intentions, most writings remained short and factual. This is reflected in the low effect sizes found in this research. Connecting the content of the writings with lessons, interventions or teaching strategies could potentially empower the future perceptions of youth, thereby positively influencing their optimal development (Stoddard \& Pierce, 2015) and strengthening the lessons' effect.

The need to empower the students' writings aligns with the striking finding that we identified only a few signs of meaning and, similarly, only a few behavioural intention codes related to meaning. Meaning and the pursuit of goals, however, are very important topics in future projections. Pursuing 
goals for autonomous motives positively relates to self-actualisation (Miquelon \& Vallerand, 2006). By having a clear sense of meaning, the intrinsic motivation of students to attain goals and the intrinsic motivation for them to formulate new goals is strengthened (Carver \& Baird, 1998; Sheldon et al., 2004). The positive psychology programme which teachers in this study used (Boniwell \& Ryan, 2016) offers several lessons around 'positive direction' which can be used for this purpose. For example, teachers can choose to implement the lesson which encourages students to think about important goals and aspects of their lives. Conducting this lesson can potentially increase the signs of meaning and behavioural intentions in the future perceptions of the students.

Research suggests that the more frequently one imagines oneself in a behavioral script, the more intention to change is produced (Anderson, 1983). It would, therefore, be a valuable suggestion for teachers to frequently practice imagining the future with their students. The writing exercise can also be expanded by making use of existing techniques from adult writing exercises. Students could be instructed to start each sentence with 'In the future I will...', to encourage them to write about realistic and attainable goals and to make sure they focus on the positive discrepancy between their current self and their desired self (Meevissen, Peters, \& Alberts, 2011). An example of such a technique could be the writing about a specific domain, such as a personal domain, a relational domain or a professional domain. Students could write why they want to change this domain in the future, what their wishes are for that domain and how they imagine themselves in five years when they have fulfilled these wishes (Bohlmeijer \& Hulsbergen, 2018).

\section{Limitations}

With regard to any limitations of this research, firstly, the content of the students' writings might be influenced by the prompts in the instructions of the Best Possible Self exercise. This instruction explicitly asks participants to 'think about how things are for you at school and at home' as well as to 'think about your family and friends'. This text has the potential to steer the participant in the direction of writing about accomplishments and relationships, which were the two most frequently used codes. Another explanation for the frequency of the codes 'accomplishment' and 'relationships' can be the students' current situation. Students were on the brink of a transfer to a new school or had recently transferred, so building new relationships and having to maintain old relationships were naturally topics that more readily concerned them. Additionally, the school to which they will eventually transfer and/or the direction they will follow depends on their academic achievement, making achievement an immediate topic as well (Rice, Fredrickson, \& Seymour, 2011; Qualter et al., 2007). 
The current research makes use of an explorative design, without a control group. The changes in wellbeing and behavioural intention can, therefore, not be related to the Positive Psychology intervention. There might be other factors influencing the construction of the writings, like writing in the beginning of the school year versus the end of the school year or the season in which the measurement took place. Also the fact that the students wrote about their best possible selves twice might have led to the found effect. The Best Possible Self exercise on its own is already associated with a wide range of beneficial outcomes (e.g. King, 2001; Meevissen, Peters, \& Alberts, 2011; Owens \& Patterson, 2013; Peters, Meevissen \& Hanssen, 2013; Sheldon \& Lyubomirsky, 2006). Additionally, a potential limitation to assessing the impact of this School-Based Positive Psychology Intervention is the lack of knowledge about its programme fidelity. A greater focus on implementation research is required to assess an intervention's true effects (Durlak, 2015). It is unknown how many lessons were implemented per school/class, but it can be expected that the amount of wellbeing lessons does influence the participants' ideal selves. It would, therefore, be valuable to assess whether the amount of lessons moderates the impact of the intervention. However, one of the important characteristics of the intervention is that teachers can decide for themselves how many lessons their class needs. All teachers received a two-day training in which they received this specific instruction. The training in itself might be enough to create a year-long focus on wellbeing.

\section{Conclusion}

This study demonstrates that best-possible-self writings can be used to assess dimensions of wellbeing as well as behavioral intentions on these dimensions among 10-15 years old students. In addition, best-possible-self writings can be used to assess the impact of positive psychology interventions. Children ranging in age from 11-14 years old tend to focus on positive relationships, accomplishments and positive emotions in their idealized futures. In contrast, meaning, which is a vital dimension of wellbeing, is lacking in their best-possible-self writings. Consequently, implementing specific lessons on meaning in the context of positive education is recommended. 


\section{References}

Adler A. (2017). Well-Being and Academic Achievement: Towards a New Evidence-Based Educational Paradigm. In: White M., Slemp G., Murray A. (eds), Future Directions in Well-Being. Cham: Springer.

Anderson, C. A. (1983). Imagination and expectation: The effect of imagining behavioral scripts on personal influences. Journal of Personality and Social Psychology, 45(2), 293-305.

Anderson, L.W., Jacobs, J., Schramm, S., \& Splittgerber, F. (2000). School transitions: beginning of the end or a new beginning? International Journal of Education, 33(4), 325-339.

Azjen, I. (1991). The theory of planned behavior. Organizational Behavior and Human Decision Processes, $50(2), 179-211$.

Berger, C., Alcalay, L., Torretti, A., \& Milicic, N. (2011). Socio-emotional well-being and academic achievement: Evidence from a multilevel approach. Psicologia: Reflexão e Crítica, 24(2), 344-351.

Bi, C., \& Oyserman, D. (2015). Left behind or moving forward? Effects of possible selves and strategies to attain them among rural Chinese children. Journal of adolescence, 44, 245-58.

Bohlmeijer, E.T., \& Hulsbergen, M. (2018). Cursus goed leven met een bipolaire stoornis: handleiding voor cursisten. Unpublished manuscript.

Boudreaux, M. J., \& Ozer, D. J. (2013). Goal conflict, goal striving, and psychological wellbeing. Motivation and Emotion, 37(3), 433-443.

Boniwell, I., Osin, E. N., \& Martinez, C. (2016). Teaching happiness at school: Non-randomised controlled mixedmethods feasibility study on the effectiveness of Personal Well-Being Lessons. The Journal of Positive Psychology, 11(1), 85-98.
Boniwell, I., \& Ryan, L. (2012). Personal well-being lessons for secondary school students: Positive psychology in action for 11 to 14 year olds. Oxford: McGraw-Hill.

Boniwell, I., \& Ryan, L. (2016). Aan de slag met Positieve Psychologie. Amsterdam, Netherlands: Uitgeverij SWP. Braun, V., \& Clark, V. (2006). Using thematic analysis in psychology. Qualitative Research in Psychology, 3(2), 77101. doi: 10.1191/1478088706qp063oa

Carver, C. S., \& Baird, E. (1998). The American dream revisited: Is it what you want or why you want it that matters? Psychological Science, 9(4), 289-292.

Carver, C. S., Lawrence, J. W., \& Scheier, M. F. (1999). Self-discrepancies and affect: Incorporating the role of feared selves. Personality and Social Psychology Bulletin, 25(7), 783-792.

Diener, E., Suh, E. M., Lucas, R. E., \& Smith, H. L. (1999). Subjective well-being: Three decades of progress. Psychological Bulletin, 125(2), 276-302.

Durlak, J. A. (2015). What everyone should know about implementation. In J. A. Durlak, C. E. Domitrovich, R. P. Weissberg, \& T. P. Gullotta (Eds.), Handbook of social and emotional learning: research and practice (pp.482499). New York: Guilford.

Galton, M., Morrison, I., \& Pell. (2000). Transfer and transition in English schools: reviewing the evidence. International Journal of Education, 33(4), 341-363. van Gelder, J.-L., Hershfield, H. E., \& Nordgren, L. F. (2013). Vividness of the Future Self Predicts Delinquency. Psychological Science, 24(6), 974-980. Goldberg, J. M., Sklad, M., Elfrink, T. R., Schreurs, K. M. G., Bohlmeijer, E. T., \& Clarke, A. M.

(2018). Effectiveness of interventions adopting a whole school approach to enhancing social and emotional development: a meta-analysis. European Journal of Psychology of Education, 33, 1-28. 
Green, S., Oades, L., \& Robinson, P. (2011). Positive education: Creating flourishing students, staff and schools. InPsych, 33(2). Retrieved from https://www.psychology. org.au/publications/inpsych/2011/april/green/ Higgins, E. T. (1987). Self-discrepancy: A theory relating self and affect. Psychological Review, 94(3), 319-340. Johnson, S. R., Blum, R. W., \& Cheng, T. L. (2014). Future orientation: a construct with implications for adolescent health and wellbeing. International journal of adolescent medicine and health, 26(4), 459-68.

King, L. A. (2001). The Health Benefits of Writing about Life Goals. Personality and Social Psychology Bulletin, 27(7), 798-807.

Lipsey, M. W., \& Wilson, D. B. (1993). The efficacy of psychological, educational, and behavioral treatment: Confirmation from meta-analysis. American Psychologist, 48(12), 1181-1209.

Loveday, P.M., Lovell, G.P., \& Jones, C.M. (2018). The best possible selves intervention: A review of the literature to evaluate efficacy and guide further research. Journal of Happiness Studies, 19(2), 607-628.

Markus, H., \& Nurius, P. (1986). Possible selves.

American Psychologist, 41(9), 954-969.

Marques, S.C., Pais-Ribeiro, J.L., \& Lopez, S.J. (2011). The role of positive psychology constructs in predicting mental health and academic achievement in children and adolescents: A two-year longitudinal study. Journal of Happiness Studies, 12(6), 1049-1062.

Meevissen, Y.M.C., Peters, M.L., \& Alberts, H.J.E.M. (2011). Become more optimistic by imagining a best possible self: Effects of a two week intervention. Journal of Behavior Therapy and Experimental Psychiatry, 42(3), 371-378.

Miller, S., Connolly, P., \& Maguire, L. K. (2013).

Wellbeing, academic buoyancy and educational achievement in primary school students. International Journal of Educational Research, 62(1), 239-248.
Miquelon, P., \& Vallerand, R.J. (2006). Goal Motives, Well-Being, and Physical Health: Happiness and SelfRealization as Psychological Resources Under Challenge. Motivation and Emotion, 30(4), 259-272.

Oettingen, G., \& Mayer, D. (2002). The motivating Function of Thinking About the Future: Expectations Versus Fantasies. Journal of Personality and Social Psychology, 83(5), 1198-1212.

Owens, R.L., \& Patterson, M.M. (2013). Positive psychological interventions for children: A comparison of gratitude and best possible selves approaches. The Journal of Genetic Psychology, 174(4), 403-428.

Oyserman, D., Destin, M., \& Novin, S. (2015). The context-sensitive future self: Possible selves motivate in context, not otherwise. Self and Identity, 14(2), 173188.

Peters, M.L., Meevissen, Y.M.C., \& Hanssen, M.M. (2013). Specificity of the best possible self intervention for increasing optimism: Comparison with a gratitude intervention. Terapia Psicológica, 31(1), 93-100.

Pietarinen, J., Soini, T., \& Pyhältö, K. (2014). Students' emotional and cognitive engagement as the determinants of wellbeing and achievement in school. International Journal of Educational Research, 67(1), 4051.

Public Health England. (2014). Early Adolescence: applying All Our Heath. Retrieved from https://www.gov.uk/government/publications/earlyadolescence-applying-all-our-health/early-adolescenceapplying-all-our-health

Qualter, P., Whiteley, H.E., Hutchinson, J.M., \& Pope, D.J. (2007). Supporting the development of emotional intelligence competencies to ease the transition from primary to high school. Educational Psychology in Practice, 23(1), 79-95. 
Rice, F., Frederickson, N., \& Seymour, J. (2011).

Assessing pupil concerns about transition to secondary

school. British Journal of Educational Psychology, 81(2),

244-263.

Seligman, M.E.P. (2011). Flourish: A visionary new understanding of happiness and well-being. Retrieved from

https://books.google.nl/books/about/Flourish.html?id= ng7RJW-udoQC\&redir_esc=y

Seligman, M.E.P., Ernst, R.M., Gillham, J., Reivich, K., \& Linkins, M. (2009). Positive education: positive psychology and classroom interventions. Oxford Review of Education, 35(3), 293-311.

Seligman, M.E.P., Railton, P., Baumeister, R.F., \& Sripada, C. (2013). Navigating Into the Future or Driven by the Past. Perspectives on Psychological Science, 8(2), $119-141$

Sheldon, K. M., Ryan, R. M., Deci, E. L., \& Kasser, T. (2004). The independent effects of goal contents and motives in well-being: It's both what you pursue and why you pursue it. Personality and Social Psychology Bulletin, 30(4), 475-486.

Sheldon, K.M., \& Lyubomirksy, S. (2006). How to increase and sustain positive emotion: The effects of expressing gratitude and visualizing best possible selves. The Journal of Positive Psychology, 1(2), 73-82.

Sipsma, H.L., Ickovics, J.R., Lin, H., \& Kershaw, T.S. (2012). Future expectations among adolescents: A latent class analysis. American Journal of Community Psychology, 50(1-2), 169-182.

Stoddard, S.A., \& Pierce, J. (2015). Promoting Positive Future Expectations during Adolescence: The Role of Assets. American Journal of Community

Psychology, 56(0), 332-341.

Strahan, E.J., \& Wilson, A.E. (2006). Temporal comparisons and motivation: The relation between past, present, and possible future selves. In C. Dunkel \& J. Kerpelman (Eds.). Possible selves: Theory, research, and application. (pp. 1-15). Hauppauge, NY: Nova Science Publishers.

Waters, L. (2011). A review of school-based positive psychology interventions. The Australian Educational and Developmental Psychologist, 28(2), 75-90.

Wyman, P. A., Cowen, E. L., Work, W. C., \& Kerley, J. H. (1993). The role of children's future expectations in selfesteem functioning and adjustment to life stress: A prospective study of urban at-risk children. Development and Psychopathology, 5(4), 649-661. 
Chapter 7:

General discussion 


\section{Introduction}

There is growing interest in implementing positive psychology in education, i.e. positive education (Bolier, Walburg \& Boerefijn, 2013). The core assumption is that learning, personal development and wellbeing go hand in hand. Learning social-emotional skills has already a long tradition in primary education (e.g. Hoffman, 2009). Recent comprehensive meta-analyses confirmed that children perform better academically in the short term (Durlak, Weissberg, Dymnicki, Taylor \& Schellinger, 2011) and the long term (Mahoney, Durlak \& Weissberg, 2018) in schools that address social and emotional skills. Positive education builds on this work but goes beyond it. It puts wellbeing and engagement centre stage. Positive education aims for high levels of wellbeing or flourishing and engagement of pupils. Focusing on positive emotions, use of strengths and positive relationships is seen as instrumental in improving wellbeing in schools (Seligman, Ernst, Gillham, Reivich \& Linkins, 2009).

High levels of wellbeing and engagement are expected to create a context for optimal learning (Laevers, Heylen \& Maes, 2013). However, scientific research on implementation of positive education is still relatively scarce. The studies in this thesis aim to contribute to our knowledge on positive education. One exploration is on the benefits of positive education as a whole-school approach. Though various potentially effective wellbeing interventions have been developed for primary schools, schools are burdened with requests to implement interventions on various topics. A whole school positive education approach does not primarily aim to add new curricula but aims to change all facets of school functioning and to transform these into a strength-based and appreciative way of working. Within this context it makes sense to focus on engagement of pupils on a daily basis as part of continuous teaching and learning processes. This should result in a positive school climate that promotes the optimal functioning and development of children. But is this whole school approach potentially effective and is it feasible? In this dissertation, we conducted a metaanalysis on whole school approaches, as well as a pilot study and a quasi-experimental study on a Dutch whole school positive education programme. Monitoring the wellbeing and social safeness of pupils, and intervening when necessary, is an important component of positive education. In the Netherlands, the national anti-bullying legislation obligates schools to monitor this on a yearly basis (Ministry of Education, Culture and Science, 2016). We conducted a study on the reliability and validity of a new online instrument that gives teachers an insight into the level of wellbeing and social safety within the classroom. Furthermore, we explored the potential of a written positive psychology exercise to yield qualitative insight into the wellbeing of children. This study sought to examine the extent to which components of wellbeing can be found in the writings of children 
between 11-14 years old, imagining their best possible selves? And how could this be informative to teachers in addressing positive education in the classroom?

The results of the studies described in this dissertation will be discussed in relation to four overarching themes:

- Whole school approach to positive education

- Focus on engagement

- Monitoring of wellbeing and social safeness

- Best-possible-self writings as indicators of wellbeing

\section{Whole school approach to positive education}

In chapter two we described a meta-analysis on the effects of whole school social-emotional learning interventions. Social and emotional skills such as understanding and managing emotions, navigating social conflicts effectively, and making responsible decisions have been shown to influence numerous measures of social outcomes, including improved health, life satisfaction, subjective wellbeing, and reduced odds of engagement in anti-social behaviours (Goodman et al., 2015). Fifty studies were included in our meta-analysis. Small but significant effects of whole school approaches were found on behavioural adjustment, social-emotional adjustment and internalising symptoms. Few studies reported impact on academic achievement $(N=8)$. No significant effect was found for this outcome. Higher effect sizes could be identified for studies with low quality, studies that included a community component and studies that were developed and evaluated in the USA. The results from this meta-analysis highlight the potential of whole school intervention in supporting children's behavioural and social-emotional outcomes, however, the complex nature of whole school interventions require further effort in assisting schools to select an evidence-based intervention that fits their needs, implement it with quality and address the challenges posed by the need to adapt programmes once implemented.

To further explore the benefits of positive education as a whole-school approach, a Dutch whole school approach to positive education (PEP) was evaluated in two studies. A feasibility study, described in chapter three, demonstrated that teachers perceived PEP to be a valuable addition to their schools and to have had a positive impact on the wellbeing of pupils. The teachers valued the bottom up nature of the programme and believed that PEP led to a clearer vision for their school. Initial quantitative results indicated small positive effects of the programme on wellbeing, student- 
teacher relationship, problem behaviour, school climate and bullying. Contextual factors like workpressure and changes in staff were reported to have hindered the implementation of the programme. In a quasi-experimental follow-up study, described in chapter four, two schools implemented PEP and the effects of the program were compared to two no-intervention control schools. No significant effects were found on outcomes such as wellbeing, student-teacher relationship and emotional problems. However, there were some positive trends including higher levels of engagement among children in the intervention schools at the end of the school year in comparison to the children in the control school. Two factors could explain the absence of significant effects in the trial: implementation issues and level of prescription.

\section{$\underline{\text { Implementation }}$}

Researchers have found that comprehensive school-wide interventions frequently encounter problems with implementation (Durlak \& Dupre, 2008; Wilson \& Lipsey, 2007; Wilson et al. 2003). These interventions are complex and require substantial planning and support. Whole school interventions require connecting and extending learning through the school ethos and environment and they require partnerships with families and communities (Wilson and Lipsey, 2007; Wilson et al., 2003). Data from 500 quantitative studies on health promoting interventions show that mean effect sizes are two to three times higher when programmes are carefully implemented (Durlak \& DuPre, 2008). The complex character of whole school approaches makes such interventions vulnerable to implementation difficulties. Durlak and DuPre (2008) identified 23 relevant factors influencing the implementation process of interventions. These factors include community characteristics, practitioner characteristics, programme characteristics, organisational characteristics and specific staffing considerations. Regarding the implementation fidelity of PEP, both schools failed to update their school policy based on the shared values identified during PEP. Also, both schools failed to complete all five pre-scheduled engagement scans (respectively three and four scans) and one of the schools only conducted seven out of ten PEP-talks. These are important issues in terms of quality of implementation and are therefore likely to have had an impact on programme outcomes. Two main factors hindered the implementation of PEP: leadership (organisational characteristics) and politics and policy (community characteristics).

Firstly, the changes at principal level negatively influenced the implementation of PEP across both schools (Chapter 4). One of the principals was replaced at the beginning of the school year and the other principal was replaced during the school year. Besides practical difficulties, the change in principals led to teachers experiencing a lack of support. Results from the pilot study of PEP (Chapter 3) demonstrated the importance of principal-support for teachers. Teachers identified changes in 
managerial staff as a hindering factor in the implementation of PEP. This aligns with research findings that adequate support from school principals is a crucial factor in supporting high quality implementation (Kam, Greenberg \& Walls, 2003). The evaluation of the Social and Emotional Aspects of Learning programme (SEAL) in the United Kingdom reported that the commitment of the senior management team was crucial component for programme effectiveness (Hallam, 2009). Secondly, regarding policy and politics, Dutch teachers are currently dissatisfied with the government, based on their working hours and salary. During the implementation of PEP, this led to nationwide strikes. Asking teachers to commit to this new programme in this turbulent context was difficult. Furthermore, during the implementation of PEP, one of the implementation schools received a negative review from the national school inspection. This led to a setback in teachers' motivation to implement PEP. However, implementing PEP could actually challenge teachers to think critically about their educational methods. PEP can therefore serve as a framework for handling negative inspection reviews. For this to work, it is important that the national school inspection recognises and values the core elements of PEP. This way we can prevent schools from being discouraged by a negative review, while they are in the middle of reorganising their way of teaching. In the current implementation of PEP, we aimed to achieve high quality implementation by conducting monthly PEP-talks, during which the implementation of the core elements of PEP was discussed extensively. However, it can be concluded that this is not enough for high quality implementation. A more thorough and structured approach is needed. Reviews of implementation literature emphasise that implementation is a multistage process operating at multiple levels, going beyond implementation fidelity and dosage. To ensure high quality implementation, schools need to be supported in the preparation for taking on a whole school intervention in terms of e.g. policy, planning, leadership and management, organisation support, evaluation, pupil participation and partnerships (Rowling and Samdall, 2011; Barry, Kuosmanen \& Clarke, 2017; Durlak and DuPre, 2008; Greenhalgh et al., 2004; Fixsen et al., 2005). Researchers and practitioners need tools that help them with the implementation process. The Collaborative for Academic Social Emotional Learning's (CASEL) School Theory of Action (School ToA) resource is an example of a framework which provides specific tools and resources for setting up and sustaining a whole school approach to social and emotional learning (Oberle et al., 2016). Factors known to promote sustainability and impact are addressed, including the following: ongoing professional development, ongoing assessment and evaluation, infrastructure and school-wide integration, family-school-community partnerships, and ongoing communication. In addition to the need for implementation tools, national support for wellbeing interventions in schools is required. Without national support, it will difficult for schools to prioritise interventions like PEP and to ensure high quality implementation. 


\section{Level of prescription}

The complex nature of whole school approaches makes it difficult to implement such interventions to its full extent and to its full effectiveness. One solution for this is to make whole school approaches more prescriptive. Weare and Nind (2011) in their review of social and emotional skillsbased interventions contend that, compared with European and Australian interventions, US interventions are more prescriptive in their training, programme manual, and requirements for programme fidelity. They argue that some non-US interventions fail to show impact as a result of their more flexible, bottom-up approach to skill development which can make it difficult for teachers to know what to implement and how it should be implemented. However, teachers implementing PEP appreciated the bottom up approach and suggested that this leads to more ownership of the programme (Chapter 3).

Discussing and formulating the vision and key values of the school is one core component of PEP. According to the teachers, this process promoted ownership of the programme and motivated them to continue with the programme beyond the research study without the assistance of trainers. Bottom up programmes tend to lead to well-rooted and long-lasting changes of attitudes and policies (Weare and Nind, 2011). A bottom up approach which is centred around the school's values helps schools to gain a better overview of how the activities relate to the school's principles and schools are better able to assess on which values more effort is needed. This can be a comforting realisation for teachers. Teachers often don't see the benefits of "yet another intervention", which takes up a lot of time, but they do see the advantages of an approach which helps them focus on what is actually important. When implementing a whole school approach, schools need to think carefully about this balance between adaptability and prescription (Lendrum, Humphrey \& Wigelsworth, 2012). This goes hand in hand with the factors influencing the quality of implementation, as described in the previous section. When the whole school approach is in line with current politics and policy, and when there is a supporting principal involved, it appears to be of added value to apply a bottom up approach. When the quality of implementation is not ensured, a bottom up approach like PEP is not likely to be successful.

\section{Focus on engagement}

In the Dutch Positive Education Programme, engagement is the most proximal outcome. Teachers receive a full day training in observing the engagement of their pupils. The engagement of the pupils 
is a standard topic in the monthly PEP-talks. Teachers are encouraged to scan the engagement of all their pupils (at least) five times per year, and teachers are encouraged to take actions to enhance the engagement level of individual pupils or the whole group if necessary. The observations of pupils in real life (changing) settings is crucial to being able to increase their engagement on a daily basis (Laevers, 2005). Engagement refers to the intensity of an activity, to concentration, to being focused, to exploring and losing track of time (Laevers, Heylen \& Maes, 2013). In this description engagement is seen as emotional or psychological engagement and not as behavioural engagement (e.g. attendance or homework completion). Experiencing engagement is an indicator of deep-levellearning. It is theorised that the combination of being intensely mentally active, being intrinsically motivated, and moving towards the limit of your capabilities leads to long-lasting development (Laevers, 2000, 2005 \& 2015). Csikszentmihayli (1979) refers to this as the state of flow.

Engagement is at the heart of PEP. However, focusing on engagement should not mean that teachers "forget" about learning goals. It is important to keep the learning goals in sight, so that the engagement of pupils can be used to help them develop across these learning domains. In the quasiexperimental study described in chapter four, a positive trend for the enhancement of engagement was identified. A significant higher number of pupils in the intervention schools showed sufficient levels of engagement at post measurement in comparison to the control schools. The odds ratios showed that pupils in the PEP schools were five times more likely to be engaged at post measurement compared with pupils in the control schools. This increase in engagement is the result of the year-long focus on engagement. Teachers are trained in observing engagement and during the monthly PEP-talks they discuss these observations with each other. During these PEP-talks they also discuss interventions or activities that they implemented to increase the engagement of their pupils. Recent research carried out by CEGO found similar results to the current study (Chapter 4). CEGO reported that a focus on wellbeing and engagement daily over the course of one school year led to increased engagement, whilst wellbeing remained stable (Laevers, 2015; Laevers, Stas, \& van Cleynenbreugel, 2018). However, besides the research in the current dissertation and the research carried out by the CEGO, there is a dearth of research examining the effect of engagement on pupil outcomes. Therefore, it is worth looking at literature on the concept of intrinsic motivation. Research shows that a learner who has a higher degree of intrinsic motivation will achieve more (Gottfried, 1985; Gottfried, 1990; Lepper, Corpus \& Iyengar, 2005; Lin, McKeachie \& Kim, 2003; Unrau \& Schlackman, 2006; Logan, Medford \& Hughes, 2011). This is confirmed by two metaanalyses, stating that interventions grounded in motivation theory are generally effective in increasing student achievement (Lazowski \& Hulleman, 2016; Orhan-Özen, 2018). 
Being intrinsically motivated is a requirement for being engaged (Laevers, 2000, 2005 \& 2015). Being intrinsically motivated refers to an individual having intrinsic desires which are already present in the individual or which are reflected in the individual while acquiring new information and learning (Lin, 2012). The main sources of intrinsic motivation are the interest, curiosity and needs of the individual. Actions which are performed through intrinsic motivation and which originate from these sources are inherently rewarding for the individual, thus no additional motive or punishment is needed (Şen 2006). Self-determination theory states that intrinsic motivation can be achieved by obtaining three basic needs: competency, relatedness \& autonomy (Ryan \& Deci, 2000). The three basic needs also form the foundation of the interventions developed by CEGO to enhance engagement. For example, by letting pupils teach about their favourite subjects.

As stated above, engagement and intrinsic motivation are key processes that enable learning. Some researchers even argue that it is more important than standardised metrics such as test scores (Eccles et al., 1983; Hidi \& Harackiewicz, 2000; Nicholls, 1979; Ryan \& Brown, 2005). Educational researchers and practitioners regard intrinsic motivation as one of the most important factors in student achievement and in ensuring continuous achievement (Alkış 2015; Aluçdibi and Ekici 2012; Guay et al. 2010; Pintrich 2003). The use of observation-based monitoring of engagement as part of PEP was highly valued by teachers and further research on its impact on social-emotional and academic outcomes is warranted.

\section{Monitoring of wellbeing and social safeness}

When conducting the studies presented in this dissertation, we continuously ran into the difficulty of measuring pupil wellbeing. To our knowledge, there was no valid and reliable Dutch instrument available. Existing questionnaires for children tend to focus on either psychological problems (e.g. SDQ (Goodman, 2001)) or Health Related Quality of Life (e.g. Kidscreen (Ravens- Sieberer et al., 2007) or KINDL (Ravens-Sieberer \& Bullinger, 1998)) and not specifically on wellbeing. The Dutch government, however, requires schools to keep track of pupil's wellbeing, as well as pupil's social safeness (Ministry of Education, Culture and Science, 2016). One of the goals of this dissertation was to develop a valid and reliable wellbeing and social safeness questionnaire (WSSQ, Chapter 5).

The WSSQ explicitly aims to measure the entire concept of wellbeing. Therefore, the conceptualisation of Keyes (2005) was used in the development of this questionnaire. Keyes (2005) describes three main components of wellbeing: emotional wellbeing, social wellbeing and 
psychological wellbeing. High levels on these factors indicate a state of flourishing. Emotional wellbeing is linked to hedonic wellbeing. It demonstrates that the child is feeling good in general, is functioning well and is satisfied with his or her life. Psychological and social wellbeing are linked to eudemonic wellbeing. Psychological wellbeing demonstrates positive individual functioning in terms of self-realisation, whilst social wellbeing demonstrates positive societal functioning in terms of being of social value (Keyes, 2005). Social safeness was found to be an integral aspect of schoolrelated wellbeing and therefore these two constructs cannot be seen as empirically different. The extent to which a child experiences wellbeing is the result of a continuous interaction between external and internal factors, like 'a healthy and safe environment' and 'social skills' (Hicks et al., 2011; Laevers et al., 2014; Lippman et al., 2009; Michaelson et al., 2012; Thompson \& Aked, 2009; UNICEF, 2007). Therefore, social safeness should be seen an integral aspect of school-related wellbeing and not as a separate construct.

When researching the Wellbeing and Social Safeness Questionnaire (WSSQ) a two-factor model was identified: 'school related social safeness and wellbeing', and 'generic wellbeing'. The found psychometric properties were promising. Using the WSSQ as a digital screening instrument to identify pupils at risk of low wellbeing is a useful practical implication. The found factor structure of the WSSQ has implications for school policies. Governments require schools in the Netherlands to have safeness policies or anti-bullying policies in place (SCSEEC, 2013). Since social safeness has been found to be an aspect of school-related wellbeing, implementing a whole school programme focused on wellbeing can serve in fulfilling a school's role in supporting children's social safety. Data on the pilot study of PEP (Chapter 3) and special needs implementation of PEP (see Intermezzo) suggest that implementing a whole school approach to wellbeing reduces bullying and victimisation. However, this result was not confirmed in the quasi-experimental evaluation of PEP (Chapter 4) in which no improvement in bullying or victimisation was identified. The WSSQ can help schools with putting their social safeness and wellbeing policies in practice. By letting their pupils fill in the WSSQ regularly, schools can take action to enhance the wellbeing when necessary.

In general, positive psychology in education research could benefit from having adequate measuring instruments in place. In this dissertation no significant effect on wellbeing was found in the quasiexperimental study (Chapter 4). Potentially this has to do with the way wellbeing was measured. A health-related quality of life questionnaire was used. This measure focuses on physical wellbeing, emotional wellbeing, self-esteem, family, friends and everyday functioning, instead of encompassing the three wellbeing domains described by Keyes (2005). Deploying such a health-related quality of life questionnaire does not provide an adequate representation of the pupil's level of wellbeing. The WSSQ could be a good alternative to the health-related quality of life questionnaire in future 
studies. Additionally, the WSSQ is designed as a screening instrument. This fits well with assessing wellbeing as one of the process indicators of learning. During PEP, teachers are encouraged to screen their pupils using the screening method developed by CEGO. In this method engagement as well as wellbeing of pupils are scored on separate scales. The wellbeing score is based on six weeks of observations. This is quite an intensive procedure. Using the digital WSSQ as an addition to the already deployed observations would allow teachers to gain an insight into the wellbeing of their pupils on a more frequent basis. This would support teachers in further understanding pupils process of learning, making it possible to successfully adjust their approach.

\section{Best-possible-self writings as indicators of wellbeing}

A final study sought to gain further insight into children's wellbeing. For this study, pupils were asked to write about their best possible selves at the beginning and the end of the school year, while their teachers implemented several wellbeing related lessons (Chapter 6$)$. The aims of this study were to investigate if it was possible to (i) identify wellbeing indicators in pupils writings about their future, (ii) identify signs of behavioural intention and (iii) identify whether changes occurred in children's writings over the course of the school year. The Best Possible Self exercise is a frequently used positive psychology intervention. Constructing best possible selves is associated with positive identity formation and is related to enhanced mood, an increase in subjective wellbeing and physical health benefits (King, 2001). Furthermore, research finds that positive future expectations can be linked to psychosocial outcomes, resilience and less risky behaviours amongst adolescents (Sipsma et al., 2012). In addition, positive future expectations can facilitate optimal development and contribute to healthier outcomes in youth (Stoddard \& Pierce, 2015).

To date, the majority of research carried out on best possible selves has been conducted with adults. There is a scarcity of research studying best possible selves in pupils. Furthermore, it is unclear what the actual content of pupils' best possible selves is and whether domains of wellbeing can be identified in pupils' writing about a positive future. The Best Possible Self writings of the pupils that participated in our research (Chapter 6) contained statements about all five wellbeing domains, as described by Seligman (2011): positive emotions, engagement, positive relationships, meaning and accomplishment. For all these wellbeing domains, behavioural intentions were identified. The fact that pupils demonstrated their intentions to conduct their behaviour towards the achievement of wellbeing also has the potential to actually lead to increased wellbeing (Diener et al., 1999) as well 
as to protect against psychopathology (Seligman et al., 2013) and to improve their health in general (Johnson, Blum \& Chang, 2014). Pupils not only wrote about wellbeing-related themes, but also about three additional themes: frustrations, assets and factual descriptions. At the end of the school year (at post measurement), a significant higher percentage of the writings referred to concepts of wellbeing and a significant higher percentage of the writings showed behavioural intention. However, the results of this study should be interpreted with much caution since there was no comparison group. There was also no information about the number of implemented positive psychology lessons in each school, and only small effect sizes were found. Overall, we conclude that best-possible self writings have the potential to be used to measure changes in wellbeing among pupils in the context of positive education. An advantage in comparison to questionnaires is that the writings add to the knowledge of researchers and teachers on how the indicators of wellbeing are manifested in the pupils' lives.

Although the results of our study show an increase in the percentage of wellbeing signs and behavioural intentions, most writings remained short and factual. Connecting the content of the writings with lessons, interventions or teaching strategies could potentially empower the future perceptions of youth, thereby positively influencing their optimal development (Stoddard \& Pierce, 2015). This could be done by incorporating the Best Possible Self exercise in a whole school approach like PEP. Based on the contents of the pupil's writings, teachers can deploy specific tailored activities that will increase the wellbeing and engagement of the pupils. In particular, activities to increase a sense of meaning amongst pupils would be beneficial. In our study, we identified only a few signs of meaning and, similarly, only a few behavioural intention codes related to meaning. Meaning and the pursuit of goals, however, are important topics in future projections and wellbeing. Pursuing goals for autonomous motives positively relates to self-actualisation (Miquelon \& Vallerand, 2006). By having a clear sense of meaning, the intrinsic motivation of pupils to attain goals and the intrinsic motivation for them to formulate new goals is strengthened (Carver \& Baird, 1998; Sheldon et al., 2004). Research suggests that the more frequently one imagines oneself in a behavioural script, the more intention to change is produced (Anderson, 1983). It is, therefore, suggested that teachers practice imagining the future with their pupils and use the contents of the writings as a qualitative insight into the wellbeing of their pupils. 


\section{Strengths and limitations}

A strength of this dissertations lies in the novelty of the research with its focus on the integration of positive education in primary schools in the Netherlands. A further strength is the applicability of the findings. The meta-analysis conducted as part of this dissertation was the first meta-analysis to examine the impact of interventions adopting a whole school approach to social and emotional learning across studies. As a result of the meta-analysis, we gained a better understanding of the effective components of whole school approaches. This knowledge was integrated in the Dutch Positive Education Programme, which we piloted in regular primary schools as well as special needs primary schools. As a result of the pilot studies, adaptations were made to the programme before conducting the quasi-experimental study. A unique component of the PEP pilot study and quasiexperimental trial was the evaluation of the programme at a whole school level. We were able to collect data from pupils and teachers in every grade. To date, the majority of research carried out on whole school interventions only report data of specific age groups or grades, whilst the PEP-study included the entire school in all analyses. Furthermore, the WSSQ-study and the BPS-study contribute to the field of positive education in primary schools. The WSSQ is the first Dutch valid and reliable instrument to measure emotional, psychological and social wellbeing and social safeness in youth and the BPS-study is one of the first studies that gains insight into the wellbeing-related content of young people's future perceptions. The WSSQ-study and the BPS-study were performed in a real-life setting and provide results that can be applied directly to the school system.

Every study included in this dissertation had its own limitations that were discussed in the various chapters of this dissertation. We identified three major, overarching themes. The first limitation across the various studies, is implementation fidelity. In the quasi-experimental PEP-study, organisational and community factors hindered the implementation quality and thereby potentially influenced the effectiveness of the programme. Higher implementation quality relates to higher effect sizes (Durlak and DuPre, 2008). Although the sample size for the number of pupils included in the PEP-study was quite high, only two schools were included per condition. The low number of intervention schools resulted in the research being too sensitive for implementation difficulties. In the BPS-study, the absence of data on the implementation of the wellbeing lessons made it impossible to analyse the outcomes in the context of the implementation. As discussed before, implementation should be studied in more detail, especially in the context of a whole school approach. A further limitation of the research was the selected measurement tools for the evaluation of PEP . Firstly, several instruments demonstrated poor reliability, resulting in them being 
removed from the analysis. Secondly, wellbeing was measured using a health-related quality of life scale, instead of a scale specifically aimed at wellbeing. Thirdly, baseline scores of wellbeing were already quite high, making it difficult to determine improvements. Fourthly, there were no qualitative measures selected. Combining qualitative and quantitative results could have provided more information on programme impact. Another limitation of the presented in this dissertation is the absence of long term follow up data. It is insufficient to just study impact over the course of one school year, particularly in the context of whole school interventions like PEP when the programme really needs to be embedded in the entire school culture and this can take time. Also, in the metaanalysis, we were unable to study the long-term impact of whole school interventions because of the absence of these data across the studies.

\section{Directions for theory, research and practice}

\section{Future research towards PEP}

Firstly, we recommend an implementation timeframe of three to five years, during and after which the effects of PEP should be assessed. The current research solely investigated the implementation and impact of PEP after one year of implementation. Implementing PEP, however, is about structurally changing the school climate and the culture of the entire school so that there is a sharper focus on wellbeing and engagement throughout every aspect of the school. Schools will need time to develop all their shared values into life rules and to implement activities accordingly. It is currently unclear whether a non-significant increase of engagement, which was detected in the evaluation of PEP could result in enhanced wellbeing, reduced behavioural problems and improved academic achievement in the long term. The evaluation of SEAL in the UK (Wigelsworth, Humphrey \& Lendrum, 2012) reported a similar issue with their two-year evaluation timeframe, which was regarded as too short to fully analyse the impact of the programme.

Secondly, we advise for this long-term research to routinely and thoroughly assess implementation quality. Implementation research provides information on the connections between intervention activities, influencing factors in the local context, and the intended intermediate and long-term outcomes (Dooris and Barry, 2013). Based on the relevant literature described earlier in this discussion, components that should be evaluated are adaption and acceptability of the programme, hindering and facilitating factors influencing the implementation of the programme, planning, leadership and management and organisation support (Rowling and Samdall, 2011; Barry, 
Kuosmanen \& Clarke, 2017; Durlak and DuPre, 2008; Greenhalgh et al., 2004; Fixsen et al., 2005; Clarke, Moreale, Field, Hussein \& Barry, 2015).

Third, we recommend future research on PEP to focus more on case studies of single schools instead of randomised controlled trials or quasi-experimental trials. In reality, a true control school does not exist. There are a variety of factors influencing the outcomes, such as location, social economic status, group size, number of teachers, school type and religious diversity. Contrary to a labexperiment, it is almost impossible to control for all differences. Therefore, there will always be an uncertainty about the true effects of PEP. Additionally, with PEP being a bottom up approach, the process of implementation will be different for each school, as well as the achievable results. It is therefore more relevant for schools to look at their own improvements, than comparing themselves with other schools. Such case studies helps to understand the context in which a programme is implemented and therefore could help schools identify how they improved during the implementation of PEP as well as identify on which aspects more attention is needed.

Fourth, schools that started with PEP, all expressed the wish to continue implementing PEP after the first year of implementation, even in the absence of significant outcomes. This could mean that, during this first year of implementation, PEP positively influenced other outcomes that we did not measure (e.g. school climate, teacher wellbeing). Adding qualitative measures to the research would provide us with more information about teachers' perceived the impact of PEP. We hypothesise that the willingness to continue with PEP after the first year of implementation, is a result from using the shared values of the team as a starting point for implementation on all levels of the school. Long term research should investigate whether this indeed leads to the desired effects.

Fifth, researching PEP in different educational settings should be a central topic in future research. The focus on wellbeing and education as indicators of the process of learning, together with the shared values as a starting point for implementation can be applied to all school types and ages. The found values and implementing activities based on those values will differ per school or school type, but the key principles of PEP will stay the same. We hypothesise that PEP can be effective for all school types (e.g. regular education, special needs education, primary school, secondary school, higher education), if the quality of implementation is guaranteed. We recommend further exploration of the implementation of PEP in special needs education. Pupils in special needs education often cannot fulfil the needs and expectations of regular primary schools leading to problematic behaviour and learning disadvantages. We argue that it is important to focus on these pupils' individual strengths, qualities and interests, instead of their shortcomings. There is currently a lack of wellbeing interventions applicable to special needs education. The experiences of teachers 
working with PEP in special needs education, as shared in the intermezzo of this dissertation, give reason to suspect positive effects on wellbeing, engagement and problem behaviour. A long term quantitative and qualitative evaluation is needed to gain insight in these effects.

\section{Future development of PEP}

To improve PEP, we recommend adding the WSSQ to the programme. Using the WSSQ will be an easy way for teachers to gain immediate insight into the wellbeing of pupils in addition to deploying six-week-long observations. For example, it would be beneficial to align filling in the WSSQ with the five engagement observations which are carried out annually by the teachers. Additionally, by adding the WSSQ to the programme, more emphasis would be placed on the social safety of pupils, which aligns with the regulations of the Dutch national government. In the quasi-experimental study of PEP (Chapter 4), there was no indication of improvement in bullying or victimisation. Use of the WSSQ would help schools to gain a better insight in these aspects, which could further result in schools being able to react more adequately to bullying and victimisation.

Furthermore, it would be a valuable addition to the programme to develop a toolbox of activities that teachers can use to enhance the wellbeing and engagement of their pupils and to deploy activities around their shared values. A starting point for this can be the existing student tracking system Looqin (Laevers \& Aerden, n.d.). This toolbox would help to bridge the gap between the schools' wishes for a more prescriptive programme and PEP's bottom up approach. The Best Possible Self exercise could be one of the interventions added to this toolbox. Teachers can analyse the writings of their pupils using the wellbeing domains described in chapter six of this dissertation. Other interventions added to the toolbox should be designed to help teachers deploy activities in the context of the shared values, to help visualise the shared values in the entire school, or to involve parents in value-related activities.

\section{Measuring wellbeing}

Measuring pupil wellbeing should be a central topic in future research. One of the possibilities presented in this dissertation is using the WSSQ as a screening instrument. Further research should be conducted to determine the concurrent validity of the WSSQ in comparison with the wellbeing screening method of the CEGO. The WSSQ provides information on the pupils' perspective of their wellbeing at that specific moment whilst the screening method of the CEGO provides a long-term teachers perspective of pupils' wellbeing. Additionally, it would be valuable to research whether the WSSQ is also suitable for younger (age 4-8) and older children (age 12-16). In addition to investigating the WSSQ, it would be interesting to research the use of the BPS writings as an 
outcome measurement of wellbeing. This work could include investigating whether it is possible to identify changes in writings because of positive psychology interventions and whether the BPS exercise would be a good alternative to the frequently used self-report measures. A quasiexperimental trial is suggested, with the BPS exercise at pre and post measurement, and with experimental schools implementing an evidence-based positive psychology intervention. We recommend that the pupils also fill in the WSSQ at pre and post to assess whether there is a correlation between the wellbeing signals displayed in the writings and the scores on the questionnaire.

Beyond measuring pupil wellbeing, it would be of added value to investigate the wellbeing of the teachers. Recently the CEGO reported that pupil wellbeing and engagement are strongly related to teacher wellbeing and engagement (Laevers, Stas, \& van Cleynenbreugel, 2018). The results of the evaluation questionnaires and the semi-structured interviews in the pilot studies of PEP identified a similar relationship. Teachers reported that by focusing on the wellbeing and engagement of their pupils, they were working more closely with their personal values, resulting in more relaxed and positive feelings. To further research this association, we advise use of the Mental Health Continuum Short Form (Lamers, Westerhof, Bohlmeijer, ten Klooster, \& Keyes, 2011) to measure the wellbeing of the teachers and to correlate these data with the wellbeing of the pupils. Additionally, it would be interesting to investigate whether the wellbeing of the teachers is increased by the implementation of a school-based positive psychology intervention like PEP. We hypothesise that by using the values of the teachers as a starting point for implementation, teachers will experience more job satisfaction, experience less work pressure and feel more closely related to the school. We expect that this in turn will lead to a higher degree of teacher wellbeing.

\section{Positive education policy}

To successfully integrate positive psychology in education, it should be embedded in (inter)national and regional policies. Having an anti-bulling policy and measuring social safeness is already on the national agendas. Incorporating a focus on the wellbeing and engagement of pupils alongside a focus on academic achievement is an important next step. Rising rates of depression and mental health problems among adolescents over the past two decades as well as stress and burnout among teachers underline the need for this next step (World Government Summit, 2017; EU, 2015). The WHO $(2013,2014,2015)$ emphasise the need for creating conditions that will protect and promote pupils' wellbeing (WHO, 2013; WHO, 2014; WHO, 2015). The challenge is to mainstream costeffective and sustainable practices which promote wellbeing. This can be achieved by investing in evidence-based approaches with explicit intervention strategies (Clarke, Morreale, Field, Hussein \& 
Barry, 2015). Research shows that implementing social emotional school-based interventions are cost-saving in terms of the impact on crime and health outcomes (McCabe, 2007; Knapp et al., 2011). More specifically concerning the Netherlands, it would be valuable to work closely together with the national school inspection. It is important to avoid schools experiencing a conflict of interest between the goals of the inspection and the more process-oriented view of positive education.

\section{Conclusion}

Positive psychology needs to be woven into the DNA of the wider school in order to have sustainable effects. Positive education should be the integration of positive psychology in the whole school rather than solely implementing it in the curriculum. However, given the findings of the current dissertation it should not be taken for granted that integrating positive psychology in every layer of the school leads to the desired effects at least in the short term. Currently the Dutch Positive Education Programme only displayed short term effects on the enhancement of engagement, however, this does not prevent schools from continuing to implement PEP. It is remarkable that after one year of implementation, all schools decided to continue with the programme. Teachers described feeling intrinsically motivated to continue practicing the positive education principles. PEP can therefore be seen as a promising programme. A larger and more long-term project is needed to fully understand the impact of positive education as a whole school approach. 


\section{References}

Adi, Y., Killoran, A., Janmohamed, K., \& Stewart-Brown, S. (2007a). Systematic review of the effectiveness of interventions to promote mental wellbeing in primary schools: universal approaches which do not focus on violence or bullying. London: National Institute for Health and Clinical Excellence.

Adi, Y., Killoran, A., Janmohamed, K., \& Stewart-Brown, S. (2007b). Systematic review of the effectiveness of interventions to promote mental wellbeing in primary schools: universal approaches with focus on prevention of violence or bullying. London: National Institute for Health and Clinical Excellence.

Alkış, N. (2015). The influence of personality traits, motivation and persuasion principles on academic performance (Unpublished Doctoral Dissertation). Middle East Technical University, Ankara.

Aluçdibi, F., \& Ekici, G. (2012). The effect of biology teachers' classroom management profiles on the biology course motivation level of the high school students. Hacettepe University Journal of Education, 43, 25-36. Anderson, C. A. (1983). Imagination and expectation: The effect of imagining behavioural scripts on personal influences. Journal of Personality and Social Psychology, 45(2), 293-305Bolier, L., Walburg, J.A., \& Boerefijn, J. (2013). Positieve psychologie op school. In Bohlmeijer, E.T., Bolier, L., Westerhof, G.J., \& Walburg, J.A. (Eds), Handboek Positieve Psychologie (pp. 325-354). Amsterdam: Uitgeverij Boom.

Barry, M.M., Kuosmanen, T. and Clarke A.M. (2017). Implementing Effective Interventions for Promoting Adolescents' Mental Health and Wellbeing and Preventing Mental Health and Behavioural Problems: A Review of the Evidence in the WHO European Region. A report produced by the World Health Organization Collaborating Centre for Health Promotion Research, National University of Ireland Galway.
Carver, C. S., \& Baird, E. (1998). The American dream revisited: Is it what you want or why you want it that matters? Psychological Science, 9(4), 289-292.

Clarke, A.M., Morreale, S., Field, C.A., Hussein, Y., \& Barry, M.M. (2015). What works in enhancing social and emotional skills development during childhood and adolescence? A review of the evidence on the effectiveness of school-based and out-of-school programmes in the UK. A report produced by the World Health Organization Collaborating Centre for Health Promotion Research, National University of Ireland Galway.

Diener, E., Suh, E. M., Lucas, R. E., \& Smith, H. L. (1999). Subjective well-being: Three decades of progress. Psychological Bulletin, 125(2), 276-302.

Dooris, M., \& Barry, M.M. (2013). Overview of implementation in health promoting settings. In Samdal O. \& Rowling L. (Eds.), The Implementation of Health Promoting Schools: Exploring the Theories of What, Why and How (pp. 14-33). Oxfordshire: Routledge.

Durlak, J. A., \& DuPre, E. P. (2008). Implementation matters: a review of research on the influence of implementation on program outcomes and the factors affecting implementation. American Journal of Community Psychology, 41(3-4), 327-350.

Durlak, J. A., Weissberg, R. P., Dymnicki, A. B., Taylor, R. D., \& Schellinger, K. B. (2011). The impact of enhancing students' social and emotional learning: a meta-analysis of school-based universal interventions. Child Development, 82(1), 405-432.

Eccles, J. S., Adler, T. F., Futterman, R., Goff, S. B., Kaczala, C. M., Meece, J. L., \& Midgley, C. (1983). Expectancies, values, and academic behaviors. In J. T. Spence (Ed.), Achievement and achievement motivation (pp. 74-146). San Francisco, CA: W. H. Freeman. 
European Union. (2015). EU Youth Report 2015.

Luxembourg: Publications Office of the European Union.

Fixsen, D.L., Naoom, S.F., Blasé, K.A., Friedman, M.R. \&

Wallace, F. (2005). Implementation Research: A

Synthesis of the Literature. The National Implementation Research Network, University of South Florida, Louis de la Parte Florida Mental Health Institute, Tampa, FL.

Furlong, M. J., Pavelski, R., \& Saxton, J. (2002). The

prevention of school violence. In S. Brock, P. Lazarus \& S.

Jimerson (Eds.), Best practices in school crisis

management (pp. 131 - 150). Washington, DC: National Association of School Psychologists.

Furrer, C., \& Skinner, E. (2003). Sense of relatedness as a factor in children's academic engagement and performance. Journal of Education Psychology, 95, 148162.

Goodman, R. (2001). Psychometric properties of the strengths and difficulties questionnaire. Journal of the American Academy of Child and Adolescent Psychiatry, 40(11), 1337-1345. doi:10.1097/00004583-20011100000015

Goodman, A., Joshi, H., Nasim, B., \& Tyler, C. (2015).

Social and emotional skills in childhood and their longterm effects on adult life. London: Institute of Education.

Gottfried, A. E. (1985). Academic intrinsic motivation in elementary and junior high school students. Journal of Educational Psychology, 77, 631-645.

Gottfried, A. E. (1990). Academic intrinsic motivation in young elementary school children. Journal of Educational Psychology, 82, 525-538.

Greenberg, M. T., Domitrovich, C. E., Graczyk, P. A., \& Zins, J. E. (2005). The study of implementation in schoolbased preventive interventions: theory, research, and practice. Washington, DC: Center for Mental Health Services, Substance Abuse and Mental Health Administration, U.S. Department of Health and Human Services.
Griffins, A-J., Sharkey, J. D., \& Furlong, M. J. (2009).

Student engagement and Positive School Adaptation. In R.Gilman, E. S. Huebner, \& M. J. Furlong (Eds.), Handbook of positive psychology in schools (pp. 65-76). New York, NY US: Routledge/Taylor \& Francis Group. Greenhalgh, T., Glenn, R., Macfarlane, F., Bate, P. \& Kyriakidou, O. (2004). Diffusion of innovations in service organizations: systematic literature review and recommendations for future research. Milbank Quarterly, 82(4), 581-629.

Guay, F., Ratelle, C. F., Roy, A., \& Litalien, D. (2010). Academic self-concept, autonomous academic motivation, and academic achievement: Mediating and additive effects. Learning and Individual Differences, 20(6), 644-653.

Gutman, L. M., \& Midgley, C. (2000). The role of protective factors in supporting academic achievement of poor African American students during the middle school transition. Journal of Youth and Adolescence, 29, 223-248.

Hallam, S. (2009). An evaluation of the Social and Emotional Aspects of Learning (SEAL) programme: Promoting positive behaviour, effective learning and well-being in primary school children. Oxford Review of Education, 35(3), 313-330.

Hicks, S., Newton, J., Haynes, J., \& Evans, J. (2011). Measuring children's and young people's well-being. Cardiff: Office for National Statistics and BRASS.

Hidi, S., \& Harackiewicz, J. M. (2000). Motivating the academically unmotivated: A critical issue for the 21st century. Review of Educational Research, 70, 151-179.

Hoffman, D. (2009). Reflecting on Social Emotional Learning: A Critical Perspective on Trends in the United States. Review of Educational Research, 79(2), 533-556 Jane-Llopis, E., Barry, M. M, Hosman, C., \& Patel, V. (2005). Mental health promotion works: a review. Promotion \& Education, (Suppl 2), 9-25. 
Johnson, S. R., Blum, R. W., \& Cheng, T. L. (2014). Future orientation: a construct with implications for adolescent health and wellbeing. International journal of adolescent medicine and health, 26(4), 459-68.

Kam, C., Greenberg, M.T., \& Walls, C.T. (2003).

Examining the Role of Implementation Quality in School-

Based Prevention Using the PATHS

Curriculum. Prevention Science, 4(1), 55-63.

Keyes, C. L. M. (2005). Mental illness and/or mental health? Investigating axioms of the complete state model of health. Journal of Consulting and Clinical Psychology, 73(3), 539-548. doi:10.1037/0022006X.73.3.539

King, L. A. (2001). The Health Benefits of Writing about Life Goals. Personality and Social Psychology Bulletin, 27(7), 798-807.

Knapp, M., McDaid, D. \& Parsonage, M. (Eds.) (2011). Mental Health Promotion and Mental IIIness Prevention: The Economic Case. London: Department of Health. Laevers, F. (2000). Forward to Basics! Deep-levellearning and the Experiential Approach. Early Years, 20(2), 20-29.

Laevers, F. (2005). The curriculum as means to raise the quality of early childhood education. Implications for policy. European Early Childhood Education Research Journal, 13(1), 17-29.

Laevers, F. (2015). Making care and education more effective through wellbeing and involvement. An introduction to Experiental Education. Leuven: Center for Experiental Education.

Laevers, F., \& Aerden, I. (n.d.). Looqin - KVS Een Digitaal Procesgericht Kindvolgsysteem Voor de Volledige Basisschool. Leuven: Centrum voor Ervaringsgericht Onderwijs.

Laevers, F., \& Declerq, B. (2018). How well-being and involvement fit into the commitment to children's rights. European Journal of Education, 53(3), 325-335.
Laevers, F., Heylen, L., \& Daniëls, D. (2014).

Ervaringsgericht werken met 6- tot 12-jarigen in het basisonderwijs. Leuven: Cego.

Laevers, F., Heylen, L., \& Maes, J. (2013). Een

Procesgerichte Aanpak Voor 6- tot 12-jarigen in Het Basisonderwijs. Leuven: Averbode.

Laevers, F. Stas, T., Van Cleynenbreugel, C. (2018). Elk kind goed in zijn vel. Implementatie en effectonderzoek van een interventiepakket voor de preventie van emotionele problemen en zelfdoding. Rapportage van het flankerend onderzoek. Leuven: ExpertiseCentrum ErvaringsGericht Onderwijs, KU Leuven.

Lamers, S.M.A., Westerhof, G.J., Bohlmeijer, E.T., ten Klooster, P.M., \& Keyes, C.L.M. (2011). Evaluating the psychometric properties of the Mental Health Continuum-Short Form (MHCSF). Journal of Clinical Psychology, 67(1), 99-110.

Lazowski, R., \& Hulleman, C. (2016). Motivation Interventions in Education: A Meta-Analytic Review. Review of Educational Research, 86(2), 602-640.

Lendrum, A., Humphrey, N. and Wigelsworth, M. (2013). Social and emotional aspects of learning (SEAL) for secondary schools: implementation difficulties and their implications for school based mental health promotion. Child Adolescent Mental Health, 18(3), 158-164.

Lepper, M. R., Corpus, J. H., \& lyengar, S. S. (2005). Intrinsic and extrinsic motivational orientations in the classroom: Age differences and academic correlates. Journal of Educational Psychology, 97(2), 184-196.

Lin, L. C. (2012). Measuring adult learners' foreign language anxiety, motivational factors, and achievement expectations: A comparative study between Chinese as a second-language students and English as a second language students (Unpublished Doctoral Dissertation). Cleveland State University.

Lin, Y. G., McKeachie, W. J., \& Kim, Y. C. (2003). College student intrinsic and/or extrinsic motivation and 
learning. Learning and individual differences, 13(3), 251258.

Lippman, L. H., Moore, K. A., \& McIntosh, H. (2009). Positive indicators of child well-being: A conceptual framework, measures and methodological issues. Applied Research in Quality of Life, 6(4), 425-449. doi:10.1007/s11482-011-9138-6

Logan, S., Medford, E., \& Hughes, N. (2011). The importance of intrinsic motivation for high and low ability readers' reading comprehension performance. Learning and Individual Differences, 21(1), 124-128.

McCabe, C.A. (2007). Estimating the Cost Effectiveness of a Universal Mental Health Promotion Intervention in Primary Schools: a Preliminary Analysis. Report to the NICE Public Health Interventions Programme. Retrieved fromhttps://www.nice.org.uk/guidance/ph12/evidence/ socialand-emotional-wellbeing-of-children-economicmodelling-combined-report2.

Mahoney, J. L., Durlak, J. A., \& Weissberg, R. P. (2018). An update on social and emotional learning outcome research. Phi Delta Kappan, 100(4), 18-23.

Michaelson, J., Mahony, S., \& Schifferes, J. (2012).

Measuring well-being. A guide to practicioners. London: New Economics Foundation

Ministerie van Onderwijs, Cultuur en Wetenschap. (2016). Zorgplicht sociale veiligheid leerlingen op school. Retrieved from

https://www.rijksoverheid.nl/documenten/brochures/ 2016/07/18/zorgplicht-socialeveiligheid-leerlingen-opschool

Miquelon, P., \& Vallerand, R.J. (2006). Goal Motives, Well-Being, and Physical Health: Happiness and SelfRealization as Psychological Resources Under Challenge. Motivation and Emotion, 30(4), 259-272.

Nicholls, J. G. (1979). Quality and equality in intellectual development: The role of motivation in education.

American Psychologist, 34, 1071-1084.
Oberle, E., Domitrovich, C. E., Meyers, D. C., \& Weissberg, R. P. (2016). Establishing systemic social and emotional learning approaches in schools: a framework for schoolwide implementation. Cambridge Journal of Education, 46(3), 277-297.

Orhan-Özen, S. (2017). The effect of Motivation on Student Achievement. In E. Karadag (Ed.), The Factors Effecting Student Achievement (pp. 35-56). Cham, Switzerland: Springer Nature.

Pintrich, P. R. (2003). A motivational science perspective on the role of student motivation in learning and teaching contexts. Journal of Educational Psychology, 95, 667-686.

Ravens-Sieberer, U., Auquier, P., Erhart, M., Gosch, A., Rajmil, L., Bruil, J., Power, M., Duer, W., Cloetta, B., Czemy, L., Mazur, J., Czimbalmos, A., Tountas, Y., Hagguist, C., \& Kilroe, J. (2007). The KIDSCREEN-27 quality of life measure for children and adolescents: Psychometric results from a cross-cultural survey in 13 European countries. Quality of Life Research, 16(8), 1347-1356. doi:10.1007/s11136-007-9240-2

Ravens-Sieberer, U., \& Bullinger, M. (1998). Assessing health-related quality of life in chronically ill children with the German KINDL: First psychometric and content analytical results. Quality of Life Research, 7(5), 399407.

Rowling, L., \& Samdal, O. (2011). Filling the black box of implementation for health-promoting schools. Health Education, 111, 347-66.

Ryan, R. M., \& Brown, K. W. (2005). Legislating competence: High-stakes testing policies and their relations with psychological theories and research. In A. J. Elliot \& C. S. Dweck (Eds.), Handbook of competence and motivation (pp. 354-372). New York, NY: Guilford Press.

Ryan, R. M., \& Deci, E. L. (2000). Self-determination theory and the facilitation of intrinsic motivation, social development, and well-being. American Psychologist, $55,68-78$. 
Seligman, M.E.P. (2011). Flourish: A visionary new understanding of happiness and well-being. Retrieved from

https://books.google.nl/books/about/Flourish.html?id= ng7RJW-udoQC\&redir_esc=y

Seligman, M.E.P., Ernst, R.M., Gillham, J., Reivich, K. \& Linkins, M. (2009). Positive education: positive psychology and classroom interventions. Oxford Review of Education, 35(3), 293-311.

Seligman, M.E.P., Railton, P., Baumeister, R.F., \& Sripada, C. (2013). Navigating Into the Future or Driven by the Past. Perspectives on Psychological Science, 8(2), 119-141.

Şen, M. (2006). Effects of English lessons, based on multiple intelligence theory, on students' motivation, self-efficacy, self-esteem and multiple intelligences (Unpublished Master dissertation). Ankara University, Ankara.

Shankland, R. \& Rosset, E. (2017). Review of Brief School-Based Positive Psychological Interventions: a Taster for Teachers and Educators. Educational Psychology Review, 29(20), 3630392.

Sheldon, K. M., Ryan, R. M., Deci, E. L., \& Kasser, T. (2004). The independent effects of goal contents and motives in well-being: It's both what you pursue and why you pursue it. Personality and Social Psychology Bulletin, 30(4), 475-486.

Standing Council on School Education and Early Childhood. (2013). National safe schools framework. Retrieved from https://studentwellbeinghub.edu.au/ docs/default source/nationalsafeschoolsframeworkpdf. pdf?sfvrsn=0

Sipsma, H.L., Ickovics, J.R., Lin, H., \& Kershaw, T.S.

(2012). Future expectations among adolescents: A latent class analysis. American Journal of Community Psychology, 50(1-2), 169-182.

Stoddard, S.A., \& Pierce, J. (2015). Promoting Positive Future Expectations during Adolescence: The Role of
Assets. American Journal of Community

Psychology, 56(0), 332-341.

Tennant, R., Goens, C., Barlow, J., Day, C., \& StewartBrown, S. (2007). A systematic review of reviews of interventions to promote mental health and prevent mental health problems in children and young people. Journal of Public Mental Health, 6(1), 25-32.

Thompson, S., \& Aked, J. (2009). A guide to measuring children's well-being. Backing the future: Practical guide 2. London: New Economics Foundation.

UNICEF. (2007). Child poverty in perspective: An overview of child well-being in rich countries. Florence: Author.

Unrau, N., \& Schlackman, J. (2006). Motivation and its relationship with reading achievement in an urban middle school. Journal of Educational Research, 100(2), 81-101.

Waters, L. (2011). A review of school-based positive psychology interventions. The Australian Educational and Developmental Psychologist 28(2), 75-90.

Weare, K., \& Nind, M. (2011). Mental health promotion and problem prevention in schools: what does the evidence say? Health Promotion International, 26(1), 29-69.

Wells, J., Barlow, J., \& Stewart-Brown, S. (2003). A systematic review of universal approaches to mental health promotion in schools. Health Education, 103(4), $197-220$

Wigelsworth, M., Humphrey, N., \& Lendrum, A. (2013). Evaluation of a School-wide Preventive Intervention for Adolescents: The Secondary Social and Emotional Aspects of Learning (SEAL) Programme. School Mental Health, 5(2), 96-109.

Wilson, S. J., \& Lipsey, M.W. (2007). School-based interventions for aggressive and disruptive behavior: update of a meta-analysis. American Journal of Preventive Medicine, 33, 130-143. 
Wilson, S. J., Lipsey, M. W., \& Derzon, J. H. (2003). The effects of school-based intervention programs on aggressive behavior: a meta-analysis. Journal of Consulting and Clinical Psychology, 71(1), 136-149. https://doi.org/10.1037/0022-006X.71.1.136

World Health Organization. (2013). Health 2020: A European Policy Framework Supporting Action Across Government and Society for Health and Well-being. Copenhagen: World Health Organization Regional Office for Europe.
World Health Organization. (2014). Investing in Children: Child and Adolescent Health Strategy for Europe 20152020. Copenhagen: World Health Organization Regional Office for Europe.

World Health Organization. (2015). The European Mental Health Action Plan 2013-2020. Copenhagen: World Health Organization Regional Office for Europe. 
Appendices 


\section{Summary}

High levels of wellbeing and engagement are expected to create a context for optimal learning. When experiencing a high level of wellbeing, pupils feel at ease, feel emotionally safe and feel the freedom to be themselves. Engagement refers to the intensity of an activity, to concentration, to being focused, to exploring and to lose track of time. The principles of wellbeing and engagement align with positive psychology in education, or positive education. To date, positive education interventions are primarily implemented at the classroom level. However, programmes integrated across the entire school context could be more promising in attaining a sustainable effect on wellbeing and engagement. The overall aim of this dissertation is to advance research on the integration of positive education using a whole school approach in primary schools in the Netherlands. Central is the proposition that positive education should not just be implemented as 'yet another specific positive psychology intervention in the classroom' but rather as a whole school approach creating a foundation for the vision of the school. Whole school approaches that operate across school curriculum, throughout the school ethos and environment and in the partnerships with parents are expected to increase wellbeing and engagement, skill development and social-emotional learning.

Chapter two presented the results of a meta-analysis on the effects of whole school social-emotional learning interventions aimed at improving pupil wellbeing. Fifty studies were included in this metaanalysis. The results indicated a positive effect of whole school approaches on social emotional adjustment $(d=0.220)$, behavioural adjustment $(d=0.134)$ and reducing internalizing symptoms $(d=$ 0.109). No significant effect was found on school performance. Only a few studies reported on academic achievement as an outcome. Higher effect sizes could be identified for studies with low quality, studies that included a community component and studies that were US-based. This was a core aim of the evaluation of PEP. This meta-analysis adds to the growing body of research suggesting that for optimal impact, social and emotional skill development needs to be embedded within a whole school, multi-modal approach. To gain more insight in the effective components of whole school approaches aimed at increasing wellbeing, more research on the implementation of such interventions is required. This was a core aim of the evaluation of PEP.

Chapter three presented the results of the process evaluation of the Dutch Positive Education Programme (PEP). PEP is a whole school approach to positive education and was piloted in two primary schools in the Netherlands. Key components of PEP are the daily enhancement of pupil's wellbeing and engagement and the shared values of the team members. As part of the PEP programme, schools participated in two workshops and they received monthly training during PEP- 
talks. The programme is bottom-up, schools decide for themselves how to apply the principles of PEP to their educational programme. Results from the pilot study indicated that the teachers perceived PEP to be a valuable addition to their schools and that PEP had a positive impact on the students' wellbeing. Additionally, the teachers valued the bottom up character of the programme and they believed that PEP led to a clearer vision for their school. Initial quantitative results confirmed the positive feelings of the teachers. The results indicated positive effects of the programme on wellbeing, student-teacher relationship, problem behaviour, school climate and bullying. Contextual factors including work-pressure and changes in staff were reported to have hindered the implementation of the programme.

Chapter four presented the results of the quasi experimental evaluation of PEP which sought to examine the impact of the programme on children's wellbeing, engagement, social-emotional skills, student-teacher relationship and bullying. The evaluation was conducted with two intervention schools and two control schools, with comparable characteristics and all part of the same districtwide organization. In this research, a trend was found for the enhancement of engagement. A higher number of pupils showed sufficient levels of engagement at post measurement. The odds ratio's showed that pupils in a PEP school were five times as likely to be engaged at post measurement. On the other outcome measurements, there were no significant effects to be found. Similar to results from the pilot study of PEP, the implementation of PEP was hindered by organizational and community characteristics, including leadership and politics. During the implementation of PEP, both intervention schools had to deal with changes on the principal level and one of the intervention schools received a negative review by the national school inspection. These factors potentially hindered the quality of implementation, and consequently limited the effectiveness of the intervention. The complex character of a whole school approach makes it complicated to implement the programme, especially when there are limited guidelines for implementation. Implementation quality and the level of prescription appear to influence the results on the short term.

Chapter five presented the results of a study evaluating the Wellbeing and Social Safeness Questionnaire (WSSQ). The Dutch government requires schools to keep track of the wellbeing and social safeness of their pupils. However, there is a lack of valid and reliable instruments measuring this wellbeing and social safeness. In this study, the WSSQ was developed and tested. The WSSQ consists of 20 questions aimed at hedonic and eudemonic wellbeing, experienced bullying and subjective social safety evaluations. In the analyses, a two-factor model was identified, being 'school related social safeness and wellbeing', and 'generic wellbeing'. Social safeness might be an integral aspect of school-related wellbeing and therefore these two constructs cannot be seen as empirically 
different. The found psychometric properties are promising and using the WSSQ as a digital screening instrument to identify students at risk of low wellbeing is a useful application.

Chapter six presented the results of the Best Possible Self writings of the pupils. To gain further insight into children's wellbeing, pupils wrote about themselves one year in the future in the context of a positive psychology intervention. This intervention consisted of a variety of 34 wellbeing lessons. Writings were collected at the beginning and end of the intervention. Qualitative analyses of these writings identified positive emotions, engagement, positive relationships, meaning and accomplishment (as wellbeing factors), as well as factual descriptions, assets and frustrations. Students showed behavioural intentions for each wellbeing element, indicating that they imagine themselves conducting wellbeing related behaviour. Between pre and post intervention a significant higher percentage of the writings was aimed at wellbeing and a significant higher percentage of the writings showed behavioural intention. These increases in the future expectations can be linked to beneficial psychosocial outcomes, resilience and less risky behaviours. The results of this study should be interpreted with caution since there was no control group and only small effect sizes were found. However, the content of the writings can provide teachers with valuable information to build on to in their lessons.

In sum, four main lessons can be drawn from this dissertation. (1) Whole school approaches are promising, but short-term effects are not always to be expected. Implementation quality and the level of prescription appear to influence the results on the short term. However, the bottom-up approach does lead to increased ownership amongst the teams. (2) Having the observation-based monitoring of engagement at the heart of the whole school approach has been highly valued by teachers and has the potential to lead to a wide range of beneficial outcomes on the long term. With teachers having access to a database of engagement increasing interventions, the daily observations of engagement can be used as the starting point of education. A short-term effect on engagement is to be expected. (3) A valid and reliable instrument like the WSSQ is needed to gain a better insight in the school related wellbeing of pupils. To date, wellbeing instruments do not measure all aspects of wellbeing, making it difficult for researchers and teachers to adequately keep track of pupil wellbeing. The WSSQ has the potential, after further validation, to fulfil this need. (4) Analysing the future perceptions of pupils can add to teachers' insight in the wellbeing of their pupils. Pupils not only write about the different components of wellbeing, they also formulate intentions for behaviour, related to their wellbeing. Teachers can respond to these writings by implementing lessons to further increase the wellbeing of their pupils. 


\section{Samenvatting}

Een hoge mate van welbevinden en betrokkenheid creëert een context waarin leerlingen optimaal tot leren komen. Wanneer leerlingen een hoge mate van welbevinden ervaren, voelen ze zich prettig, veilig en vrij om zichzelf te zijn. Betrokkenheid refereert naar de intensiteit van een activiteit, concentratie, gefocust zijn, ontdekkend leren en tijdvergeten bezig zijn. Deze principes sluiten aan bij de positieve psychologie stroming in het onderwijs, ofwel positieve educatie. Vooralsnog zijn positieve educatieve interventies hoofdzakelijk uitsluitend gericht op het curriculum, terwijl juist programma's die geïntegreerd zijn in de gehele schoolcontext als zeer effectief worden beschouwd. Het overkoepelende doel van deze dissertatie is daarom om bij te dragen aan de 'evidence-based' integratie van positieve educatie in Nederlandse basisscholen. Centraal bij dit doel is de aanname dat positieve educatie niet gezien moet worden als "weer een nieuw positieve psychologie programma voor in de klas", maar juist als heleschoolbenadering die als voedingsbodem functioneert voor het beleid van de school. Heleschoolbenaderingen waarin het curriculum, het gedachtengoed en de relaties met ouders geïntegreerd zijn, leidt naar verwachting tot een hogere mate van welbevinden en betrokkenheid, betere prestaties en sociaal-emotioneel leren.

Hoofdstuk twee presenteerde de resultaten van een meta-analyse over de effecten van hele-school interventies gericht op sociaal-emotioneel leren die als doel hadden om het welbevinden van leerlingen te verhogen. Vijftig studies werden geïncludeerd in deze meta-analyse. De resultaten lieten een positief effect zien van heleschoolbenaderingen op sociaal emotionele vaardigheden $(d=$ $0.220)$, probleemgedrag $(d=0.134)$ en op geïnternaliseerde symptomen $(d=0.109)$. Er zijn geen significante effecten gevonden van heleschoolbenaderingen op academische vaardigheden. Slechts enkele studies rapporteerden over deze academische vaardigheden als uitkomst. Sterkere effecten zijn gevonden voor studies met een lage kwaliteitsscore, studies die gebruik maakten van een 'community component' en studies die in de Verenigde Staten plaatsvonden. Om nog meer inzicht te krijgen in effectieve componenten van heleschoolbenaderingen die het welbevinden van leerlingen kunnen stimuleren is er meer onderzoek nodig gericht op de implementatie van zulke interventies. In de evaluatie van PEP stond implementatie daarom centraal.

Hoofdstuk drie presenteerde de resultaten van de procesevaluatie van het Nederlandse Positief Educatief Programma (PEP). PEP is een positief educatieve heleschoolbenadering en werd uitgevoerd bij twee pilotscholen in Nederland. De belangrijkste onderdelen van PEP zijn het dagelijks verhogen van het welbevinden en de betrokkenheid van leerlingen en de gedeelde waarden van de teamleden. Tijdens PEP volgen scholen twee studiedagen en worden ze maandelijks gecoachte tijdens PEP-talks. Het programma is 'bottom-up', waarbij scholen zelf de concrete uitvoering van het 
programma bepalen. Resultaten van de pilot studie lieten zien dat leerkrachten PEP een goede toevoeging vonden aan het beleid van hun school en dat de leerkrachten ervoeren dat PEP een positieve impact had op het welbevinden van de leerlingen. Daarnaast vonden de leerkrachten het 'bottom-up' karakter van het programma waardevol en hadden ze de indruk dat PEP heeft geleid tot een duidelijkere visie van hun school. Initiële kwantitatieve analyses ondersteunden deze positieve ervaringen van de leerkrachten. De resultaten lieten zien dat het welbevinden van de leerlingen, leerling-leerkracht-relatie, probleemgedrag, schoolklimaat en pestgedrag positief zijn beïnvloed. Contextuele factoren zoals werkdruk en veranderingen binnen het team werden gezien als hinderend voor de implementatie van het programma.

Hoofdstuk vier presenteerde de resultaten van het quasi-experimentele onderzoek naar PEP. Dit onderzoek is uitgevoerd met twee interventiescholen en twee controlescholen. In dit onderzoek werd er een trend gevonden voor het verhogen van betrokkenheid. Een hoger aantal leerlingen werd geïdentificeerd als 'betrokken' tijdens de nameting. De 'odds-ratio's' lieten zien dat het vijf keer zo waarschijnlijk was dat een leerling betrokken was bij de nameting, wanneer deze leerling onderdeel uitmaakte van een PEP-school. Op de andere uitkomsten werden geen significante effecten gevonden. Beide interventiescholen hadden gedurende de implementatie van PEP te maken met wisselingen in de directie en één van de twee scholen ontving tijdens de implementatie een negatief rapport van de nationale school inspectie. Deze hinderende factoren hebben de kwaliteit van implementatie mogelijk dusdanig beïnvloed, dat er geen effecten werden gevonden. Het complexe karakter van een heleschoolbenadering maakt het ingewikkeld om het op een kwalitatief goede manier te implementeren, zeker wanneer er weinig richtlijnen voor de implementatie zijn. De kwaliteit van de implementatie en het bottom up karakter van het programma lijken de resultaten op korte termijn te beïnvloeden.

Hoofdstuk vijf presenteerde de resultaten van de 'Wellbeing and Social Safeness Questionnaire' (WSSQ). De Nederlandse overheid vraagt scholen om het welbevinden de sociale veiligheid van hun leerlingen in kaart te brengen, maar valide en betrouwbare instrumenten ontbraken. In deze studie werd de WSSQ ontwikkeld en onderzocht. De WSSQ bestaat uit 20 vragen gericht op hedonisch en eudaimonisch welbevinden, ervaren pesterijen en subjectieve sociale veiligheid observaties. In de analyses werd een twee-factor-model geïdentificeerd, namelijk 'school-gerelateerde sociale veiligheid en wellbevinden' en 'algemeen welbevinden'. In deze studie bleek dat sociale veiligheid gezien dient te worden als een onderdeel van school-gerelateerd welbevinden en niet als losse factor. Welbevinden en sociale veiligheid kunnen dus niet beschouwd worden als twee verschillende constructen. De gevonden psychometrische kwaliteiten van de WSSQ zijn veelbelovend en er werd 
vastgesteld dat de WSSQ geschikt is om te implementeren als digitaal screeningsinstrument om leerlingen te identificeren die een lage mate van welbevinden ervaren.

Hoofdstuk zes presenteerde de resultaten van de 'Best Possible Self' schrijfopdrachten. Leerlingen schreven hierin over hun beste zelf een jaar in de toekomst in de context van een positieve psychologie interventie. De interventie bestond uit 34 verschillende lessen in welbevinden. De schrijfopdrachten werden verzameld aan het begin en aan het eind van de interventie. Uit de kwalitatieve analyses van deze schrijfopdrachten bleek dat de leerlingen schreven over positieve emoties, betrokkenheid, positieve relaties, zingeving en prestaties (als factoren van welbevinden), maar ook over feitelijke situaties, bezittingen en frustraties. De leerlingen lieten gedragsintenties zien voor alle factoren van welbevinden. Tussen de voor- en de nameting werden verschillen gevonden in de inhoud van de schrijfopdrachten. Een significant hoger percentage van de schrijfopdrachten was gericht op de welbevinden factoren en een significant hoger percentage was gericht op gedragsintenties. De resultaten van dit onderzoek dienen met voorzichtigheid geïnterpreteerd te worden, omdat er geen controlegroep aanwezig was en omdat er slechts kleine effecten gevonden werden. Echter, het lijkt veelbelovend om op basis van de schrijfopdrachten van de leerlingen, lessen vorm te geven die de verschillende factoren van welbevinden verder belichten.

Op basis van alle onderzoeken in deze dissertatie, zijn er vier belangrijke lessen te leren. (1) Heleschoolbenaderingen zijn veelbelovend, maar korte termijn effecten kunnen niet altijd verwacht worden. De kwaliteit van de implementatie en de mate waarin het programma 'bottom-up' wordt geïmplementeerd, beïnvloeden de resultaten op korte termijn. De 'bottom-up' aanpak leidt echter ook tot meer eigenaarschap bij de teams. (2) De observaties van betrokkenheid als basis van een heleschoolbenadering worden als zeer waardevol ervaren door leerkrachten en hebben de potentie om tot een grote variëteit aan positieve uitkomsten te leiden op de lange termijn. Leerkrachten die toegang hebben tot een database met betrokkenheid-verhogende-interventies kunnen de dagelijkse observaties van betrokkenheid gebruiken als uitgangspunt voor de lessen. Een korte termijn effect op betrokkenheid mag dan verwacht worden. (3) Een valide en betrouwbaar instrument, zoals de WSSQ, is nodig om beter inzicht te krijgen in het school-gerelateerde welbevinden van leerlingen. Tot op heden meten veel instrumenten niet alle aspecten van welbevinden en zijn onderzoekers en leerkrachten niet goed in staat om een adequaat beeld te krijgen van het welbevinden van hun leerlingen. De WSSQ kan, na verdere validatie, hier een bijdrage aan leveren. (4) Het analyseren van toekomstpercepties van leerlingen kan bijdragen aan het inzicht van de leerkrachten over het welbevinden van leerlingen. Leerlingen schrijven niet alleen over de diverse factoren van welbevinden, maar formuleren ook intenties tot gedrag, gerelateerd aan hun welbevinden. De leerkrachten kunnen hier in de klas op inspelen om het welbevinden verder te verhogen. 


\section{Acknowledgements / Dankwoord}

Met veel plezier heb ik voor dit onderdeel van mijn proefschrift teruggedacht aan wie er allemaal betrokken zijn geweest bij mijn promotie-traject. Ik wil alle deelnemers aan de onderzoeken, coauteurs, familieleden, vrienden en collega's, heel hartelijk bedanken voor het fijne proces. Ik heb me altijd enorm gesteund gevoeld door iedereen. In het bijzonder zijn er een paar mensen die ik nog eens extra wil bedanken.

Allereerst wil ik mijn "promotieteam" bedanken: Ernst Bohlmeijer, Karlein Schreurs en Aleisha Clarke. Ernst, ik heb heel veel van jou geleerd de afgelopen jaren en ik ben heel dankbaar dat jij mijn promotor wilde zijn in dit traject. Ik heb ook erg genoten van onze fietstochtjes naar de verschillende scholen, waarbij je me (dankzij mijn krakkemikkige fiets) soms letterlijk een duwtje in de goede richting hebt moeten geven. Karlein, jij was al tijdens de bachelorthese één van mijn begeleiders. Tijdens die these zei je zoiets als "is onderzoek doen niet iets voor jou?" en die gedachte kon ik maar moeilijk loslaten. Ik ben heel blij dat je me op dit spoor hebt gezet en ik heb je grondige feedback altijd heel erg gewaardeerd tijdens het promotieproces. Tot slot Aleisha, ook voor jou typ ik maar gewoon in het Nederlands. Ik heb het heel fijn gevonden om zoveel met jou samen te werken. In eerste instantie in de Cubicus, maar later veelal via de telefoon. Jouw kennis en kunde over sociaal emotioneel leren, positieve educatie en heleschoolbenaderingen was cruciaal voor de artikelen. Heel erg bedankt voor alle samenwerking!

Daarnaast wil ik de commissieleden bedanken die de tijd en de moeite hebben genomen om plaats te nemen in de promotiecommissie: dr. Tessa Eysink, Prof. dr. Nele Jacobs, Prof. dr. Susan McKenney, Prof. dr. Ferre Laevers en Prof. dr. Gerben Westerhof.

Naast al het onderzoek naar de theoretische kanten en de effectiviteit van PEP, ben ik de afgelopen jaren voornamelijk ook heel veel op pad geweest om op scholen bezig te zijn met positieve educatie. Tot mijn grote plezier heb ik deze uitvoer van PEP altijd samen met Marjolein Prenger kunnen doen. Marjolein, ik wil je heel erg bedanken voor de energie-gevende samenwerking in alles wat met PEP (maar ook met stages) te maken heeft. Ik kijk er heel erg naar uit om onze samenwerking door te zetten en PEP nog verder op de kaart te zetten.

Ik heb de vakgroep Psychologie, Gezondheid en Technologie altijd als een hele fijne werkomgeving ervaren. Ik heb heel veel gehad aan alle samenwerkingen, overleggen en praatjes bij de koffieautomaat. In het bijzonder: Teuntje Elfrink bedankt voor de samenwerking bij de procesevaluatie, Peter ten Klooster voor het vragenlijstartikel, Dauw Muijsson en Ilona Boniwell voor 
het BPS-artikel, Marcin Sklad voor de meta-analyse en Marion Sommers-Spijkerman voor het PEPartikel. Marieke Smellink - Kleisman en Daniëlle Boeken - Tanke, veel dank voor alle organisatorische hulp en voor alle gezellige praatjes. Marieke, ik denk nog regelmatig met heel veel plezier terug aan het organiseren van het positieve educatie congres, samen met jou en Marjolein. Ik heb genoten in het busje er naar toe en ik heb veel bewondering voor hoe jij alles onder controle had. Veel dank daarvoor!

Ook heb ik de mazzel gehad dat ik tijdens mijn promotietraject samen op kon trekken en kantoren mocht delen met Jannis, Noortje, Marion, Mareike, Marjolein en Teuntje. Ik heb genoten van het balletjes gooien, fika-momentjes, Luther kijken, de zelfgebakken koekjes en de boer zoekt vrouw nabespreeksessies. Ik wil jullie heel erg bedanken voor deze leuke Cubicus-tijd. Een specifiek woord van dank is hierbij voor jou, Teuntje. Ik heb met ontzettend veel plezier samen met jou de start van PEP beleefd. We hebben ontzettend veel lol gehad in de Cubicus en zullen dat in de toekomst, bij de nodige etentjes, ongetwijfeld voortzetten.

Ik voelde niet alleen de nodige support binnen de Cubicus, maar ook daarbuiten. Nick, Jetse, MarieLouise, Irma, Niels, Benjamin, Melle, Annemarie, Anouk, maar ook alle andere vrienden, kennissen en teamgenoten die regelmatig even "incheckten" om de stand van zaken te horen, heel erg bedankt! Ik voelde de steun en ik heb er veel aan gehad. In het bijzonder wil ik jou hierbij nog even noemen Nick. Jij bent tijdens mijn promotieproces niet alleen van waarde geweest omdat ik via jou als leerkracht alle PEP-ideeën kon toetsen, maar vooral ook voor momenten van ontspanning in de vorm van alle spelletjes, verhalen en noaberschap.

De afgelopen drukke jaren heb ik me ook altijd erg welkom gevoeld in Boekelo. Daarvoor wil ik Fred, Anja, Maud, Ella, Tommie en Sven erg bedanken.

Bijna aan het eind van dit dankwoord kan ik niet anders dan vast te stellen dat de wortels voor dit proefschrift in Roden liggen. Matthijs en Anna, als ik tijdens workshops of trainingen wel eens een voorbeeld moet geven van mijn eigen hoge betrokkenheid als kind dan denk ik altijd terug aan de skeelerrecords en het bijbehorende schriftje. Bovenal wil ik mijn ouders, Maarten en Liesbeth, bedanken voor het aanwakkeren van mijn nieuwsgierigheid, het overbrengen van de liefde voor lezen en de steun tijdens alle periodes van mijn studie en promotie. Ik vind het een hele mooie gedachte dat dit boekje straks een plek krijgt in jullie volle boekenkast.

Helemaal tot slot wil ik jou bedanken, Nena, voor de onvoorwaardelijke steun de afgelopen jaren. Ik vind het heel bijzonder dat wij elkaar zomaar zijn tegengekomen en ik kan me geen leven meer 
voorstellen zonder je. Als kind vond ik het altijd al fijn om thuis te komen, maar nu is het dat wat ik het liefste doe. 


\section{Curriculum vitae}

Jochem Goldberg was born in Roden, the Netherlands. In 2009, he graduated from high school at the Lindenborg in Leek. After high school, Jochem moved to Enschede, where he completed his bachelor in Psychology in 2013, completed his master in Positive Psychology and Technology in 2014 and started with his PhDresearch in 2016. Besides his PhD-research, Jochem worked for the department of Psychology, Health and Technology as a teacher and

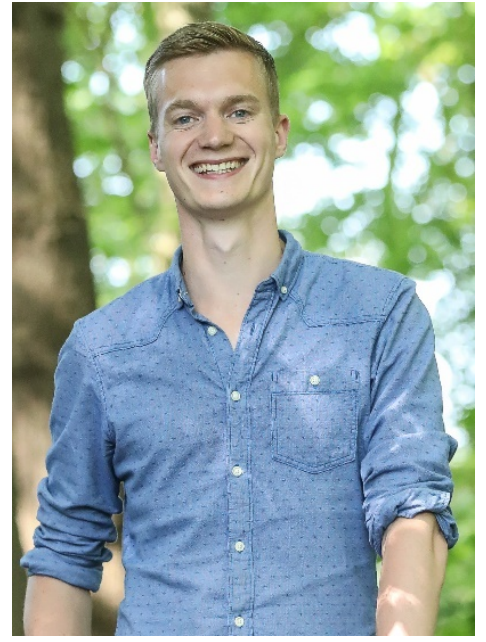
supervisor in various courses and modules. In 2019 he was appointed as an internship coordinator for clinical internships in the Positive Psychology and Technology master. At the same time, Jochem started working as a behavioural scientist at Stichting Actolei, a local health care institution providing 24 hour care to mentally disabled adults.

\section{List of publications}

Elfrink, T. R., Goldberg, J. M., Schreurs, K. M. G., Bohlmeijer, E. T., \& Clarke, A. M. (2017). Positive educative programme: A whole school approach to supporting children's well-being and creating a positive school climate: a pilot study. Health Education, 117(2), 215-230. https://doi.org/10.1108/HE-09-2016-0039 Goldberg, J.M., Clarke, A.M., ten Klooster, P.M., Schreurs, K.M.G. \& Bohlmeijer, E.T. (2019). Wellbeing and Social Safeness Questionnaire (WSSQ): Initial psychometric assessment of a short digital screening instrument for primary school children. Cogent Education, 6(1).

Goldberg, J.M., Muijsson, D.C., Clarke, A.M., Boniwell, I., Schreurs, K.M.G., Bohlmeijer, E.T. (2019). Exploring signs of wellbeing and behavioural intentions in youth's future expectations. Manuscript submitted for publication.
Goldberg, J.M., Prenger, M., \& Bohlmeijer, E.T. (2018). Positief Educatief Programma. De wereld van het jonge kind, 46(2), 10-13.

Goldberg, J.M., Prenger, M., Clarke, A.M., Elfrink, T.R., Schreurs, K.M.G., \& Bohlmeijer, E.T. (2017). Positieve psychologie als heleschoolbenadering op basisscholen: het Positief Educatief Programma. Tijdschrift Positieve Psychologie, 2(1), 43-47.

Goldberg, J.M., Sklad, M., Elfrink, T.R., Schreurs, K.M.G., Bohlmeijer, E.T., \& Clarke, A.M. (2018). Effectiveness of interventions adopting a whole school approach to enhancing social and emotional development: a metaanalysis. European Journal of Psychology of Education. https://doi.org/10.1007/s10212-018-0406-9 Goldberg, J.M., Sommers-Spijkerman, M.P.J., Clarke, A.M., Schreurs, K.M.G., \& Bohlmeijer, E.T. (2019). Positive education in daily teaching, the promotion of wellbeing and engagement in a whole school approach: A clustered quasi-experimental-trial. Manuscript under review. 
